\title{
Gravity Measurements at Sea by Use of the T.S.S.G. Part 2. Results of the Measurements
}

\author{
By \\ Jiro SEGAWA \\ Ocean Research Institute, University of Tokyo
}

\begin{abstract}
Among numerous cruises on which gravity was measured by use of the T.S.S.G. the cruises of the Umitaka-maru of the Tokyo University of Fisheries made in July and August 1966 and from November 1967 to February 1968, the cruises of the Hakuho-maru of the Ocean Research Institute, University of Tokyo made in August 1967, in July and August 1968 and from April to June 1969, and the cruise of the Meiyo of the Hydrographic Office, Maritime Safety Agency of Japan are selected to illustrate actual situations of gravity measurements during each of the cruises. Gravity measurements by use of the Vening Meinesz gravity meter made in 1934 and 1935 by Matsuyama $e t$ al. are also taken up and compared with the measurements by use of the T.S.S.G.

Gravity values obtained by these measurements have been compiled into gravity tables, and maps or profiles of certain tectonically intimate areas have been drawn. The areas selected from tectonical viewpoint are; Japan trench and its vicinity, Suiko sea-mount at the emperor ridge, Brisbane Hill at the coral sea, Shatzky rise (north-west Pacific rise), Bismark plateau, Mariana trench and Solomon trench.
\end{abstract}

\section{$\S 1$. Description of Cruises on which Gravity Measurements were made}

Accuracy of gravity measurements at sea depends much on the ships where gravity meters are settled, and conditions of measurement such as calibration points or sailing methods are likely to be determined by ship's situations. Therefore it is important to have correct knowledges about the ship for enhancing accuracies of measurements. In this section descriptions of the measurement in each cruise are given with particular reference to the following items;

1) characteristics of dynamic gravity meters in use

2) effects of various vibrations on the ship

3) effect of temperature

4) ship's motions and 2nd order corrections

5) verticality of the gravity meter axis

6) Calibrations

7) Eötvös corrections

for seven cruises on which the T.S.S.G.'s were used. Though measurements were not by the T.S.S.G. the measurements made in 1934 and 1935 by use of the Vening Meinesz gravity meter in the Japan trench and its vicinities by MatsuYama et al. (1934) are also described in this section because they are not only of historical importance but also still as reliable as the present day measurements.

1-1 Gravity measurements by use of a Vening Meinesz Gravity meter in 1934 and 1935

Details of these measurements have already been obscured. Here Kumagal (1953) is referred concerning the measurements carried out in October 1934 and 1935 by M. Matsuyama, N. Kumagai and M. Hurutani on board submarines. The measured areas are across the Japan trench in 1934 and across the Izu Ogasawara trench in 1935.

The first test on board a submarine RO-57 was made at the Sagami Bay and actual measurements across the Japan trench followed it, starting from Yokosuka on October 17th and returning there on November 1st. 27 measurements were performed during this cruise with 25 divings, in two cases of which measurements were made twice each, but it does not mean that they were made at the same place (the measured positions of both 1934 and 1935 are indicated in Fig. 1.). 


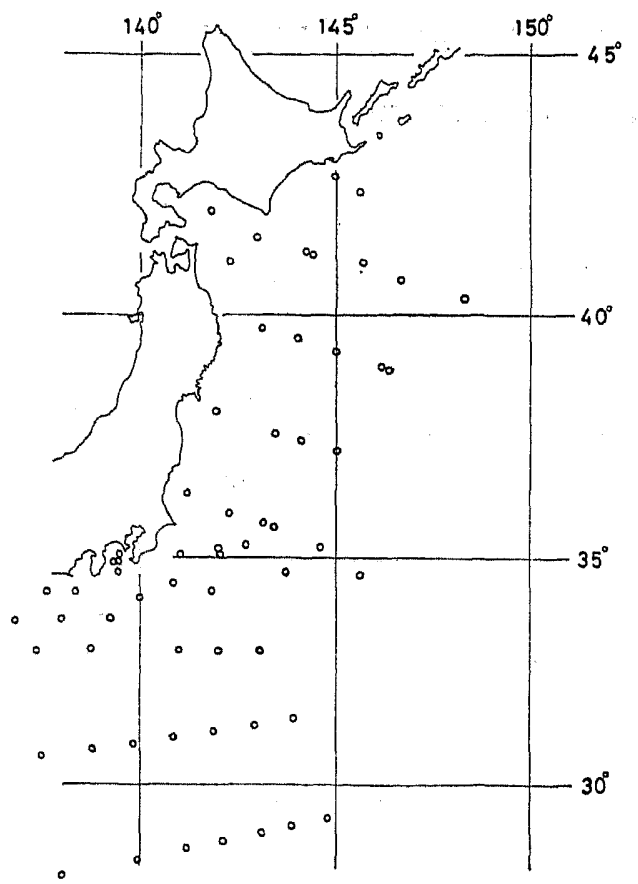

Fig. 1. Positions of measurements of gravity by use of the Vening Meinesz gravity meter, 1934 and 1935.

As a gravity base station the second class gravity station of the Potsdam system located at $35^{\circ} 01.6 \mathrm{~N}$ and $135^{\circ} 47.2 \mathrm{E}$ at the department of geology and mineralogy, Kyoto University was used, where the gravity value is 979.721 \pm 0.0018 gal.

The instrument used had been purchased by the Japan Geodetic Commission in July 1932 from the N.V. Nederlandsche Seintoestellen Fabriek, Hilversum, Holland, and adjusted and calibrated by KUMAGAI at the department of geology and mineralogy, Kyoto University.

Positions of the measured places were determined by both the astronomical observations and the ship's log. The water depths were obtained from the charts published by the then Hydrographic Office of the Japanese Navy.

The period of the Vening Meinesz Pendulum is slightly over $1 / 2 \mathrm{sec}$. Its temperature coefficient is about $-10^{-5} /{ }^{\circ} \mathrm{C}$ which corresponds to $+20 \mathrm{mgal} /{ }^{\circ} \mathrm{C}$. As the pressure of the air

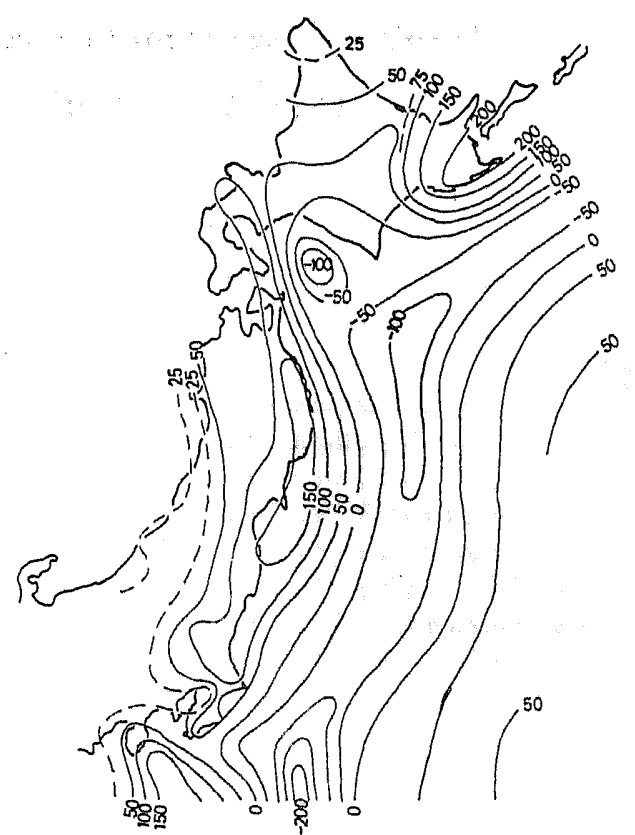

Fig. 2. Free air anomaly contour over the Japan trench drawn by Kumagai. Contour interval is 50 mgal.

also influences the pendulum corrections for the pressure are applied to the measured period according to $-5 \times 10^{-6} \mathrm{D}$, where $D$ is a relative density of air expressed by

$$
D=\frac{b-0.375 e}{760(1+0.003665 t)}
$$

where $t$ is temperature $\left({ }^{\circ} \mathrm{C}\right), e$ vapour pressure in $\mathrm{mmHg}$ and $b$ barometric height in $\mathrm{mmHg}$.

There are found no discussions of the ship's motion or the Eötvös effect in KUMAGAI's paper. Though it is unable for us to tell something about the submarine measurements because no informations are available of the capacity of the then submarines, more or less than $10 \mathrm{mgal}$ effect due to the current such as Kuroshio is suspected to have existed. Other things that seem to have had influences on accuracies of the measurement include the daily variation of chronometers, to which Kumagai referred by stating that he took all corrections into account that were possible to make at that time.

The standard formula of gravity used to 
calculate gravity anomalies is the Helmert's formula given in 1901. This is by about 15 mgal smaller than the International formula given in 1936. This difference is taken into account when the gravity values are compared with those measured by the T.S.S. G. Free air anomaly coutour drawn by KUMAGAI is quoted in Fig. 2.

\section{1-2 Gravity measurements in 1966 by use of} the T.S.S.G. on board the Umitaka-maru

From July to August in 1966 gravity measurements were made in the north part of the sea around Japan (Japan trench, continental shelves south of Hokkaido, north part of the Japan sea, Musashi bank and continental shelves off Sanriku and Kanto -districts) on board the Umitaka-maru of Tokyo University of Fisheries (TOMODA and SEGAWA 1966).

The T.S.S.G. was first equipped on the Umitaka-maru in October 1963 and since then used for the world wide measurements in case of the Indian ocean expedition from 1963 to 1964, the southern sea expedition from 1964 to 1965, the Hawaii and Mexico expedition from 1965 to 1966, measurements near and around Japan in 1966, the southern

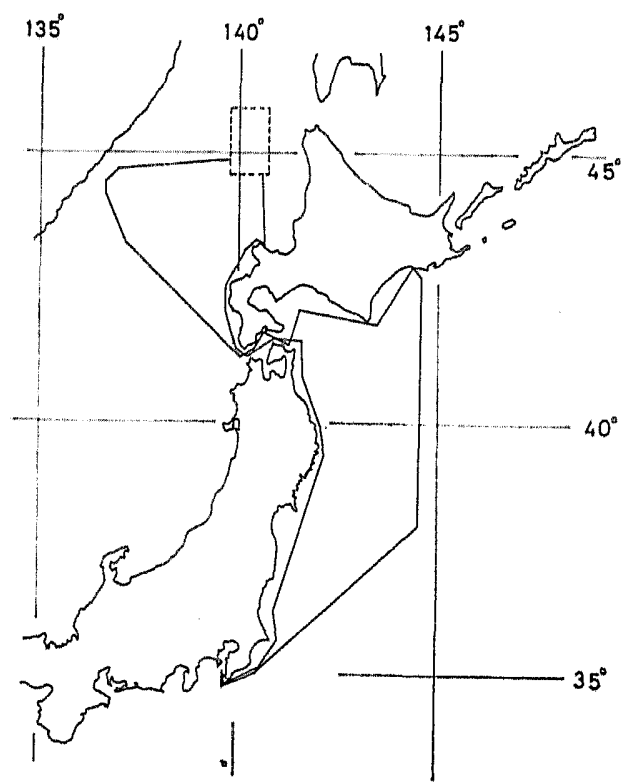

Fig. 3. Ship's track of the Umitaka-maru in July and August 1966. sea expedition from 1966 to 1967, measurements near and around Japan in 1967 and the Coral and Tasman sea expedition from 1967 to 1968. The situations of the ship have therefore been well familiarized (TOMODA 1967, SEgAWA 1967 and TOMODA, OzAWA and SEgAWA 1968).

Tracks of the Umitaka-maru in case of the measurement in 1966 are shown in Fig. 3. Method of measurement was of the punching tape system (refer Part 1). The measurement was started at Tateyama at $14^{\mathrm{h}} 30^{\mathrm{m}}$ on July 18 th. The ship proceeded northward up to Kushiro and then visited Hakodate, Otaru by way of Rebun Is. and Musashi bank in the north Japan sea. She returned to Tateyama on August 19th.

The dynamic gravity meter used in this cruise is the so called " $\mathrm{Z}-0$ ", which was constructed in 1963 and used for the measurements in case of the Indian ocean expedition from 1963 to 1964 and the southern sea expedition from 1964 to 1965 . Just after it

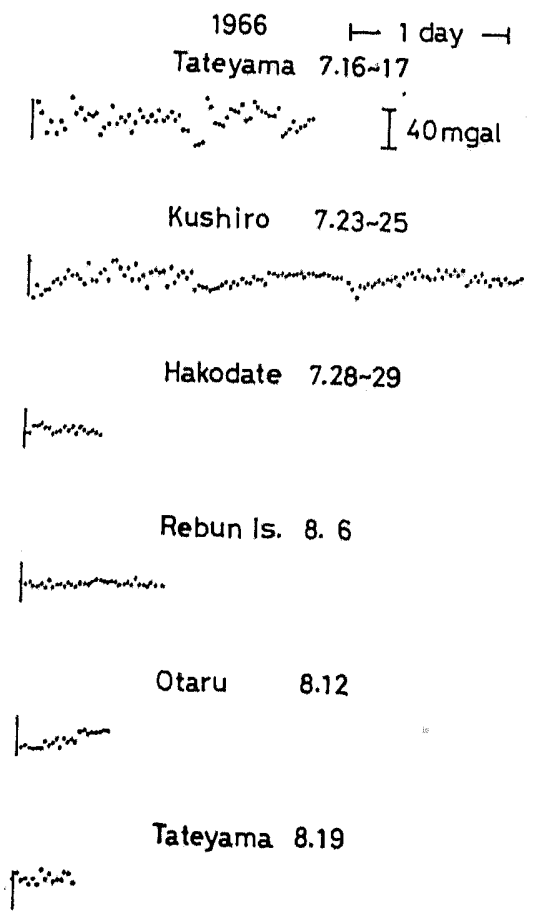

Fig. 4. Results of measurement when the ship was anchoring at the harbours in July and August 1966. 
was constructed it showed a positive drift but became steady in about a day with less than $1 \mathrm{mgal} /$ day drift. Its natural frequency is $1750 \mathrm{~Hz}$ at $42^{\circ} \mathrm{C}$ and its " $\mathrm{Q}$ " value was 100,000 at the time of construction but now it has been lowered to about 30,000 . The fall of " $Q$ " value is not necessarily connected to the drift rate of the meter. The results of measurements when the ship was at anchor are shown in Fig. 4. Variations of the apparent gravity seen in the figure can be looked upon as a clue to know conditions of the meter.

What were most troublesome in the measurements of this cruise are vibrations caused by gyro spin motors and those caused by ship's engines. Vibrations of several hundred $\mathrm{Hz}$ occur at the gyrotable due to the rotation of a spin motor, producing accelerations of normally 100-200 gal r.m.s. amplitude. However vibrations up to 500 gal sometimes occur due to unbalancing of the rotor. Such noises can not be reduced to as small as it may not cause decreases of gravity due to the 2nd order effect. Measurements at Tateyama seen in Fig. 4 seem particularly affected by such vibrations giving rise to fluctuations of the values of $\pm 20 \mathrm{mgal}$. In other measurements such fluctuations are reduced to \pm 5 mgal. Variations found in the meaşurements at Kushiro appear to be a diurnal variation, but it is not assured. Long period variations in other measurements may be caused either by variations of vibration strength or by deflections of the vertical gyroscope. In such a respect the measurements in this cruise may involve errors as large as $\pm 20 \mathrm{mgal}$.

Vibrations of the ship's floor caused by engines and screws are especially strong on the Umitaka-maru, and it is likely that they increase year by year with superannuation of the ship. Resonances of vibration seem to occur when the engine is in full rotation $(190 \mathrm{r} / \mathrm{m})$. The frequency of vibration is from 3 to $20 \mathrm{~Hz}$ and can not be eliminated by usual shock absorbers. The amount of the effect of vibrations can be estimated by measuring the differences of apparent gravities which take place when the engine is started or stopped while the ship is proceeding in the direction of the least Eötvös effect. The 2nd order effect due to ship's floor vibrations is remarkable when the ship is in full speed and it has been estimated to be approximately $-35 \mathrm{mgal}$ decrease. Therefore. corrections of $+35 \mathrm{mgal}$ have been applied to all the data measured under such conditions.

In Figs. 5 and 6 results of temperature coefficient measurement are shown with respect. to the dynamic gravity meter " $Z-0$ ". In Fig. 5 it is seen that the meter " $Z-0$ " is more sensitive to the speed of temperature change than temperature itself. The temperature co-efficient measured by the differences of apparent gravity at stationary states is obtained from Fig. 6. It is a positive value of $+10 \mathrm{mgal} /{ }^{\circ} \mathrm{C}$. Signs of the co-efficients are not always positive but some gravity meters have negative co-efficients, as will be indicated later.

The dynamic gravity meter is enclosed in an oven whose temperature is regulated within variation of $\pm 0.01^{\circ} \mathrm{C}$ in short term accuracy,

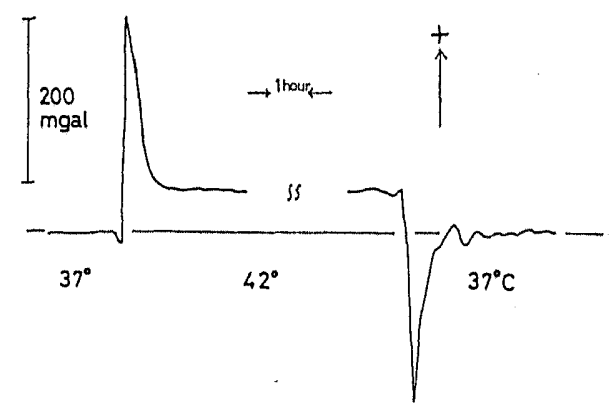

Fig. 5. Temperature response of the dynamic: gravity meter $Z-0$.

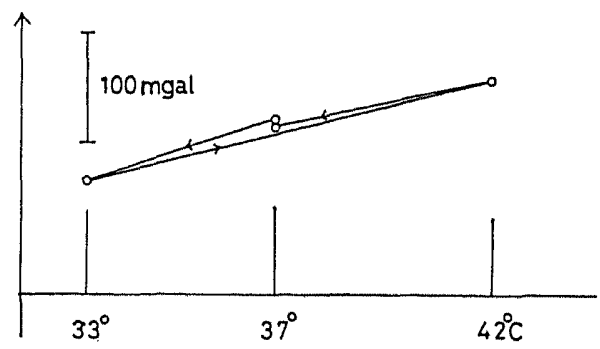

Fig. 6. Determination of the temperature co-... efficient of the dynamic gravity meter Z-0. 
but in the presence of long term temperature variations the meter is subjected to temperature variation of about one twentieth of the ambient temperature variation. Conspicuous variation of room temperatnre was observed between Tateyama and Kushiro of the order of $15^{\circ} \mathrm{C}$, for which corrections have been made according to the temperature co-efficient.

Verticality of the gravity meter was checked sufficiently in the harbours and it is assured that it maintained an accuracy of better than $\pm 4^{\prime}$. Accuracy in the cruising state however was not checked. It is reasonably suspected that some amount of deflection may have occured, as is discussed in Part 1.

Sea conditions were favourable in the most part of the measurements in which the amounts of the 2nd order corrections are comparatively small, as is shown in Fig. 7, with the exception of the measurement be-
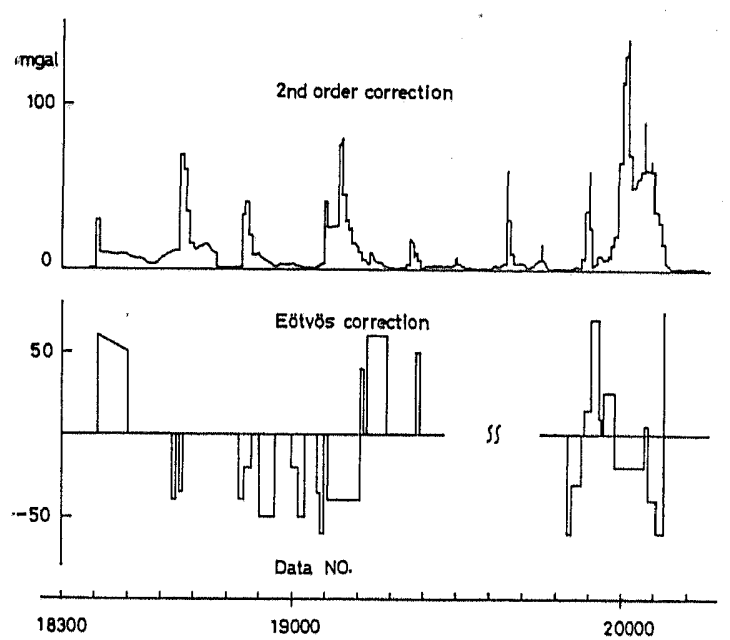

Fig. 7. Variations of the 2nd order correction and the Eötvös correction in the measurement of the Umitaka-maru in July and August 1966. tween Otaru and Tateyama. The 2nd order corrections have been applied uniformly according to the formula $\Delta g=0.20 \tilde{\alpha}^{2}$ in mgal, where $\tilde{\alpha}^{2}$ is an averaged dispersion of vertical accelerations in $(\mathrm{gal})^{2}$.

Eötvös corrections have been calculated from the formula $\Delta E=(44.94 \cos \varphi) \Delta L$ in mgal, where $\varphi$ is latitude and $\Delta L$ is longitude difference in $10 \mathrm{~min}$ (the unit in'), on the basis of positions determined by astronomical observations or by Loran fixings. However data of ship's positions can never be directly applied to the Eötvös corrections but. it is necessary to smoothe them before the applications, with reference to informations such as rotation of engines, water currents or wind velocity. The Eötvös corrections are also indicated in Fig. 7 in relation to the number attached to gravity values.

Calibrations of the dynamic gravity meter were made at the harbour which the Umitakamaru visited. Gravities of the stations, though they were not directly measured by a land gravity meter but deduced from values of the surrounding area by use of a land gravity map, are compared with the gravities measured by the T.S.S.G. The results of comparison are tabulated in Table 1.

The gravities $g_{m}$ 's are those which are determined according to an idealized equation of the dynamic gravity meter mentioned in Part 1, with a single gravity constant calibrated at the preceding base station. So the differences $\left(g_{m}-g_{t}\right)$ 's may well be supposed to be caused by the "elastic tension". From the differences between Tateyama and Kushiro and between Otaru and Tateyama the elastic tension can be calculated for " $\mathrm{Z}-0$ ", according to the formula mentioned in Part 1. In Fig. 8 are plotted the differences $g_{m}-$

Table 1

\begin{tabular}{l|l|l|l|r}
\hline \multicolumn{1}{c|}{ Date } & \multicolumn{1}{|c|}{ Base } & $g_{s}$ & $g_{m}$ & $g_{m}-g_{\theta}$ \\
\hline July 16-18 & Tateyama & $979.795 \mathrm{gal}$ & $979.795 \mathrm{gal}$ & $0 \mathrm{mgal}$ \\
July 22-25 & Kushiro & 980.620 & 980.662 & +42 \\
July 28-Aug. 1 & Hakodate & 980.420 & 980.410 & -10 \\
Aug. 12-15 & Otaru & 980.520 & 980.535 & +15 \\
Aug. 19 & Tateyama & 979.795 & 979.775 & -20 \\
\hline
\end{tabular}




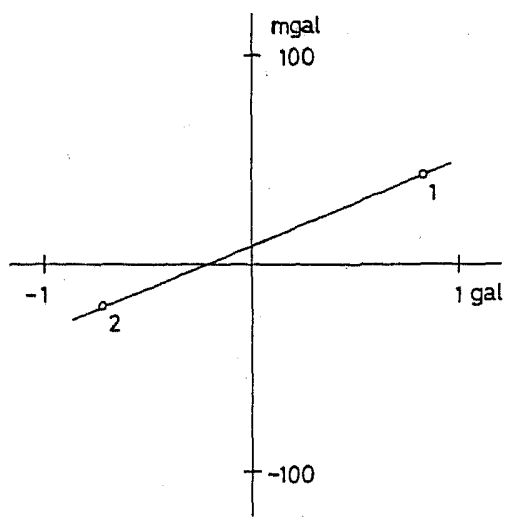

Fig. 8. $g_{m}-g_{e}$ in relation to $\Delta g_{e}$.

Table 2

\begin{tabular}{l|l}
\hline Dynamic gravity meter & $\mathrm{Z}-0$ made in 1963 \\
averaged frequency & $1750 \mathrm{~Hz}$ at $42^{\circ} \mathrm{C}$ \\
temperature co-efficient & $+10 \mathrm{mgal} /{ }^{\circ} \mathrm{C}$ \\
Q-value & $100,000-30,000$ \\
elastic tension & +39 gals \\
\hline
\end{tabular}

$g_{e}$ in relation to $\Delta g_{e}$. A slope of the most fitted line to be drawn in the figure will give an approximate value of the elastic tension though it is likely to be subjected to errors owing to the unknown factors of measurement. It is found that the elastic tension $A$ for the dynamic gravity meter " $Z-0$ " is +39 gal. With this elastic tension corrections are made to all the gravity values obtained at the cruising state according to the way described in Part 1.

It is interesting to note that the positive elastic tension is accompanied with a positive temperature co-efficient, to which we will refer in case of other cruises as well.

In Table 2 characteristics of the dynamic gravity meter " $\mathrm{Z}-0$ " are summed.

\section{1-3 Gravity measurements between 1967 and} 1968 by use of the T.S.S.G. on board the Umitaka-maru

From November 1st 1967 to February 23rd 1968 gravity measurements were made in the Pacific ocean, Coral sea and Tasman sea on board the Umitaka-maru by use of the T.S.S.G. The ship started from Takeshiba pier in the bay of Tokyo and visited

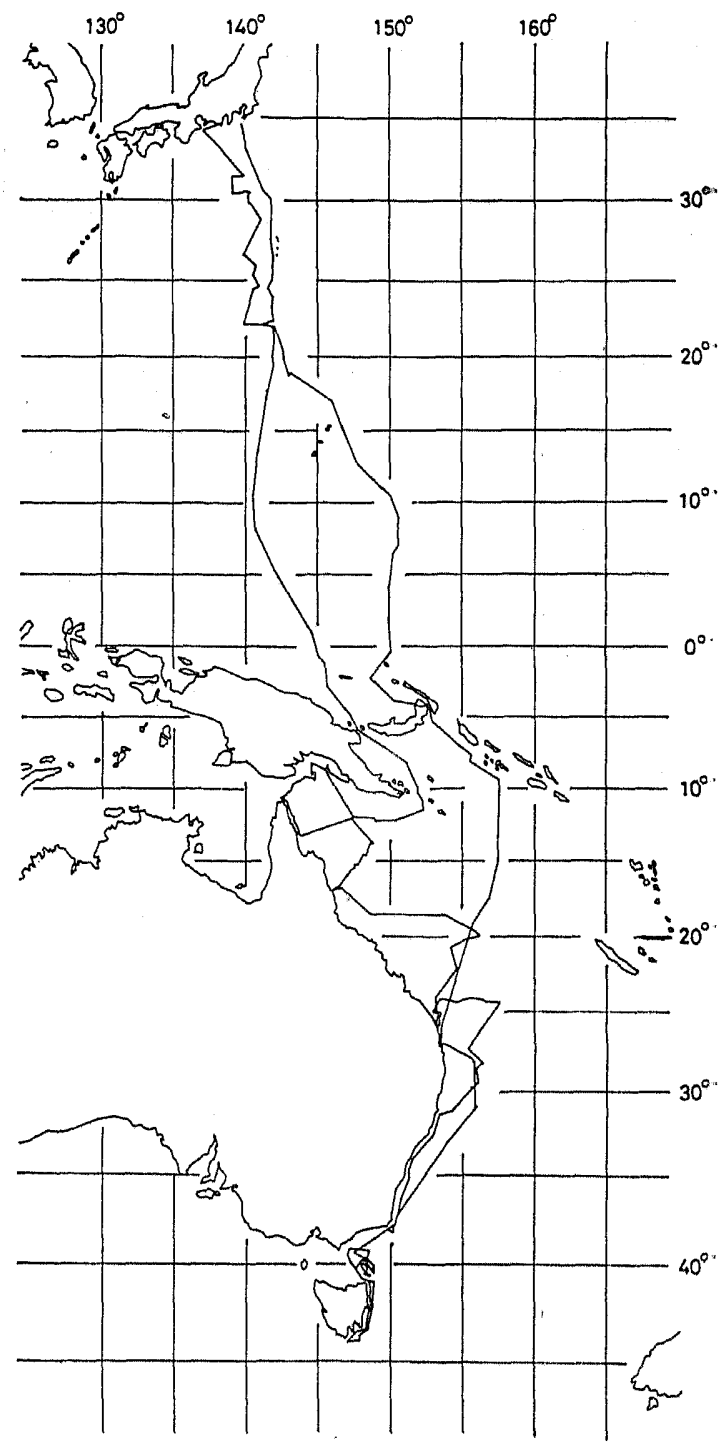

Fig. 9. Ship's track of the Umitaka-maru from Nov. 1967 to Feb. 1968.

Port Moresby, Thursday island, Cairns, Sydney, Hobart and Brisbane. The ship's track is shown in Fig. 9. In addition to these visits which had been scheduled there were two unscheduled places where the ship anchored, Hervey Bay of Australia and Yaizu Harbour of Japan. Gravity measurements were made by use of the T.S.S.G.-D.P.U. (ref. Part 1).

The dynamic gravity meter used on this cruise is " $Z$-2", which was constructed in 1963 together with the meter ' Z-0”'. Q-value 


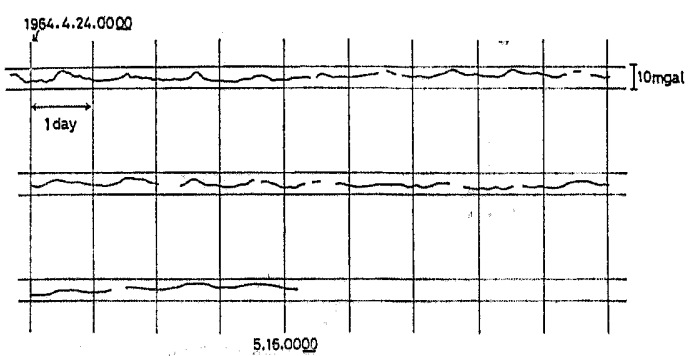

Fig. 10. Drift measurement of the dynamic gravity meter Z-2 between April 24 th and May 16 th, 1964.

was 50,000 at the time of construction. Drift rate just after the construction showed a positive value and became steady in about a day with a drift rate of less than $1 \mathrm{mgal} /$ day. There is a comparatively long term observation of drift with the meter " $\mathrm{Z}-2$ " ' which was carried out about 6 months after the construction (Fig. 10). From the figure it is found that no long term drift is recognized but short term fluctuations of $\pm 3 \mathrm{mgal}$. After that Q-value was lowered gradually and showed a value of 10,000 at the time of departure from Tokyo in the present expedition. Natural frequency of the meter ' $\mathrm{Z}-2$ " ' is 1910 $\mathrm{Hz}$ at $46.5^{\circ} \mathrm{C}$.

On November 12th when the ship was cruising in the sea near Caroline islands an accident occurred: A thermister attached to the dynamic gravity meter to control the oven temperature was broken and the temperature in it rised as high as it melted the hermetic seal of the meter. After this trouble Q-value was extremely lowered owing to the air leaked into from the molten seal. This accident once made us think it was impossible to continue the measurements. But fortunately we could make the dynamic gravity meter vibrate again after repairs and resumed the measurement, when the natural frequency of the meter was $1907 \mathrm{~Hz}$ at $46.5^{\circ} \mathrm{C}$ and the $\mathrm{Q}$-value was 2000 .

Drift measurements at harbours are shown in Fig. 11. Fluctuations of the measured values found in the measurements at Hobart, Brisbane and Yaizu are probably caused by the deflection of the measuring axis of the meter. The use of an overheated gravity meter of low Q-value showed a useful instruction that such matters did not become fatal defects. Temperature co-efficient of " $Z$ - 2 " which was once overheated was measured when the ship stayed at Hobart (Fig. 12). According to the measurement the coefficient of the overheated meter is found to be $-70 \mathrm{mgal} /{ }^{\circ} \mathrm{C}$ (Fig. 13). For the sake of comparison drift measurements and the measurement of temperature co-efficient carried

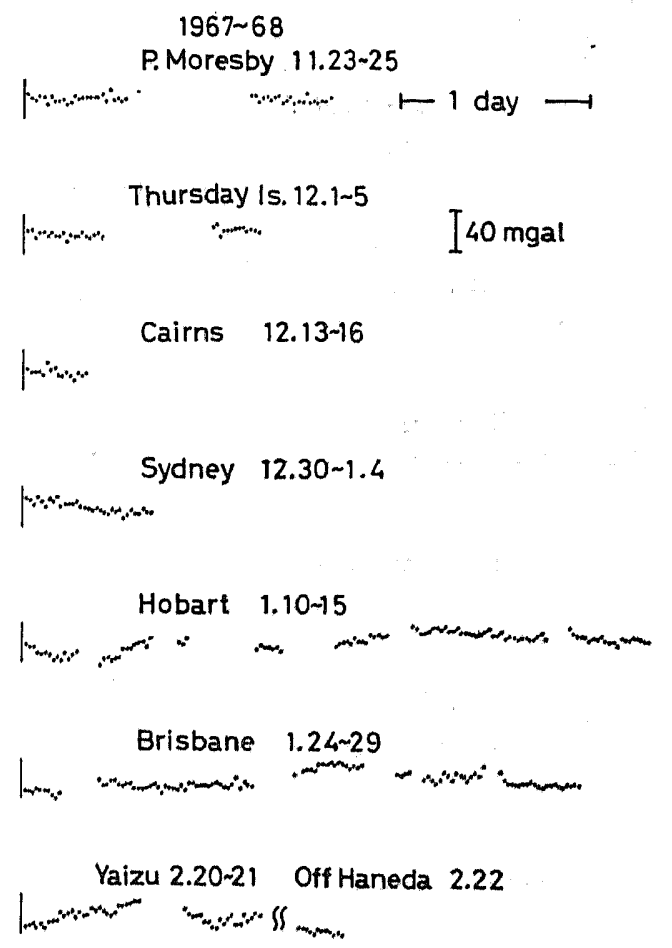

Fig. 11. Results of measurement when the ship was anchoring at the harbours from Nov. 1967 to Feb. 1968.

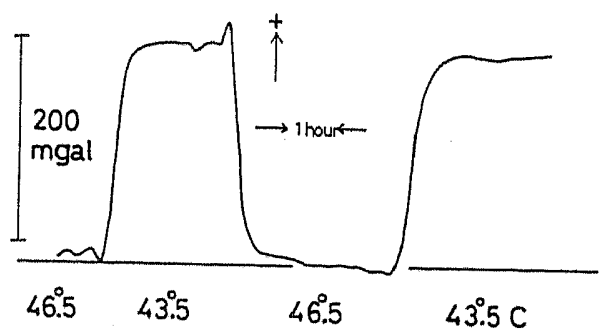

Fig. 12. Temperature response of the once overheated dynamic gravity meter Z-2. 


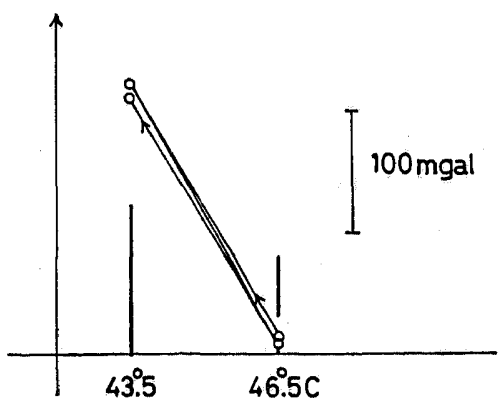

Fig. 13. Determination of the temperature coefficient of the once overheated dynamic gravity meter Z-2.

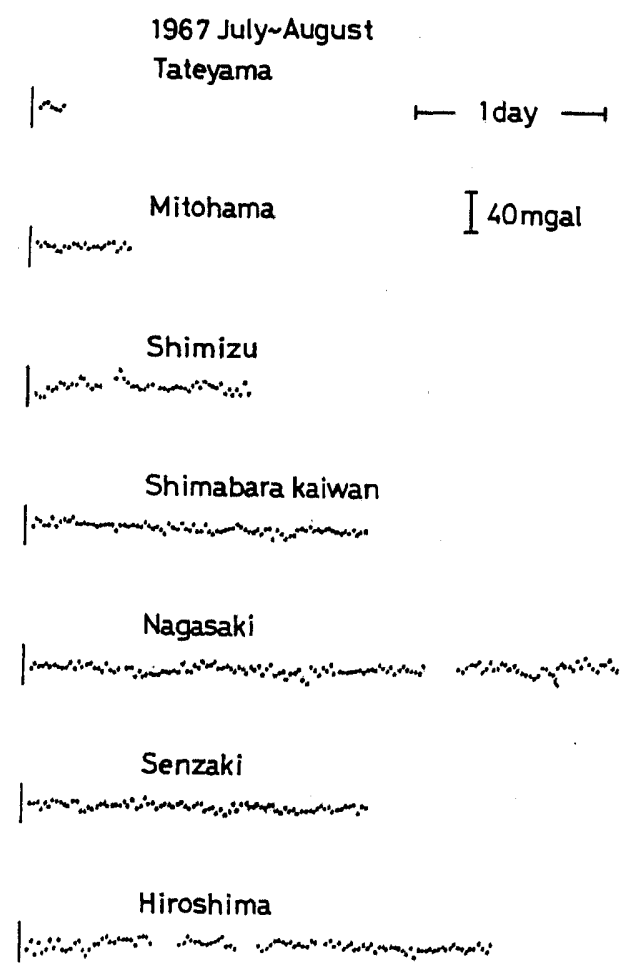

Fig. 14. Results of measurement when the ship was anchoring at the harbours from July to August 1967.

out on the cruise of the Umitaka-maru around south part of Japan in July and August 1967 (ref. Part 1) are indicated in Figs. 14 and 15. On this cruise the meter " $Z$-2" was used also. From the figures it seems there is no distinction between the two cases if slight differences are neglected coming from the reasons other than those of the dynamic

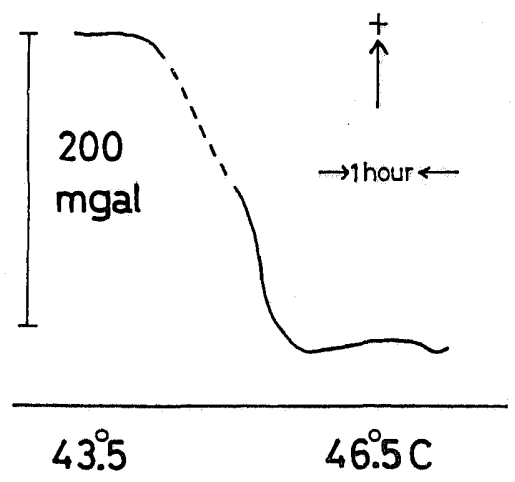

Fig. 15. Temperature response of the dynamic gravity meter $\mathrm{Z}-2$ in its normal state.

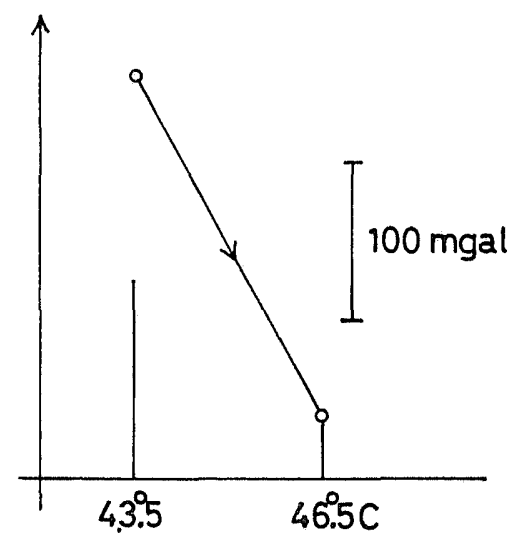

Fig. 16. Determination of the temperature coefficient of the dynamic gravity meter Z-2 in its normal state.

gravity meter, showing that the temperature co-efficient of " $Z-2$ " at normal state was also about $-70 \mathrm{mgal} /{ }^{\circ} \mathrm{C}$ (Fig. 16).

In the measurement of this cruise we suffered from short period vibrations of the floor as was the case in the measurement made in 1966 and 1967. Vibrations from the rotor of the vertical gyroscope could be reduced by adjusting the speed of rotation. Long term air temperature variations throughout the cruise were observed to be $25^{\circ} \mathrm{C}$, but its effect could be made as small as possible by adjusting ventilations and by making calibrations at every visiting port.

The 2nd order corrections were made according to a simplified method, which is described in Part 1 with respect to the 

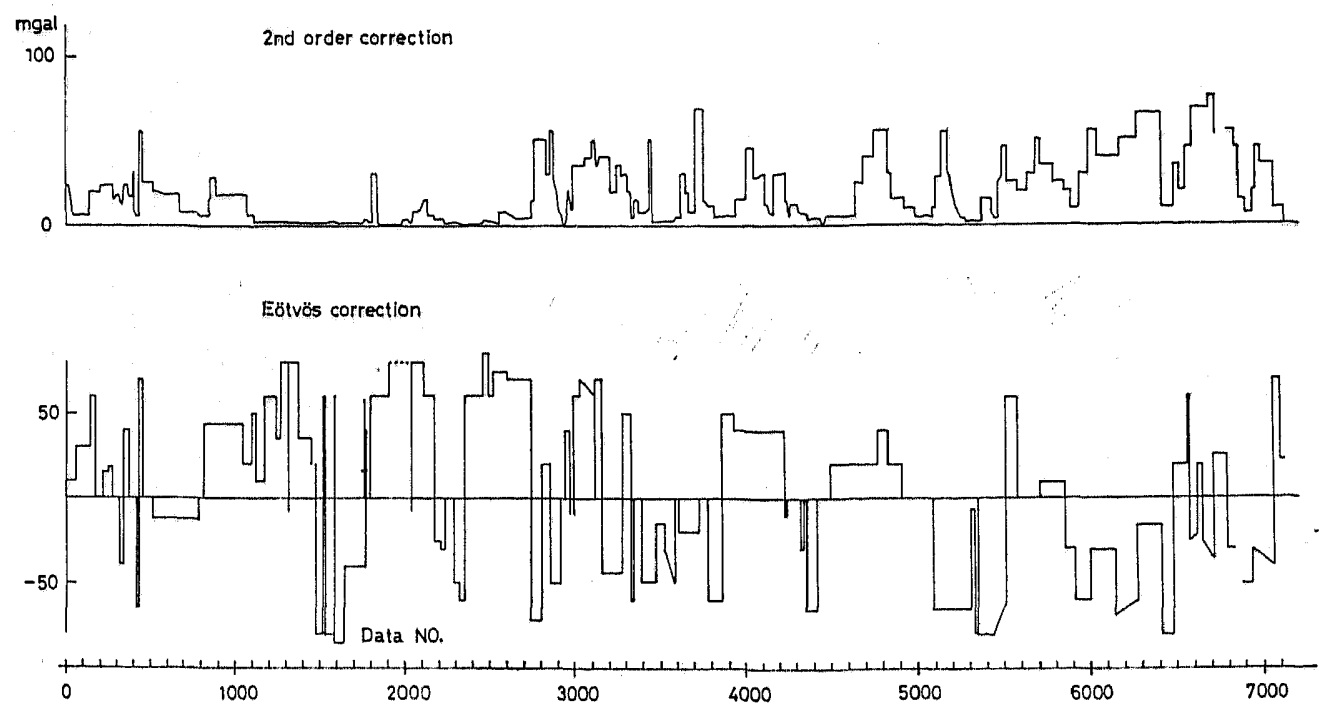

Fig. 17. Variations of the 2nd order corrections and the Eötvös corrections in the measurement of the Umitaka-maru from Nov. 1967 to Feb. 1968.

Table 3

\begin{tabular}{l|l|c|c|c}
\hline \multicolumn{1}{c|}{ Date } & \multicolumn{1}{c|}{ Base } & $g_{e}$ & $g_{m}$ & $g_{m}-g_{e}$ \\
\hline Nov. 1 & Takeshiba Tokyo & $979.790 \mathrm{gal}$ & $979.790 \mathrm{gal}$ & 0 mgal \\
Nov. 23-25 & Port Moresby & 978.245 & - & - \\
Dec. 2-5 & Thursday island & 978.261 & 978.261 & 0 \\
Dec. 13-16 & Cairns & 978.513 & 978.504 & -9 \\
Dec. 30-Jan. 4 & Sydney & 979.690 & 979.708 & +18 ? \\
Jan. 10-15 & Hobart & 980.443 & 980.405 & -40 \\
Jan. 24-29 & Brisbane & 979.179 & 979.224 & +45 \\
Feb. 20-21 & Yaizu & 979.773 & 979.752 & -21 \\
\hline
\end{tabular}

T.S.S.G.-D.P.U. As the 2nd order correction co-efficient we took $0.021 \mathrm{mgal} /(\mathrm{gal})^{2}$. In Fig. 17 the results of 2 nd order corrections are indicated in relation to the number attached to gravity values.

Eötvös corrections were made in the same way as is described in section 1-2. The results are indicated also in Fig. 17 in relation to the number attached to gravity values.

Calibrations of the gravity meter were made at every port except for Port Moresby, where gravity values of the piers were measured by use of a La Coste-Romberg land gravity meter. In Table 3 date, base stations, gravity values of the stations $g_{t}$ measured by the land gravity meter, gravity values $g_{m}$ measured by the T.S.S.G. and the differences

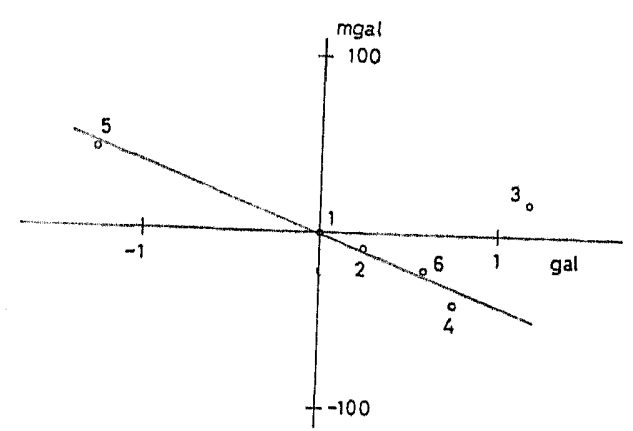

Fig. 18. $g_{m}-g_{\theta}$ in relation to $\Delta g_{B}$.

$g_{m}-g_{6}$ are listed. The elastic tension $A$ of the meter " $Z-2$ " can be calculated from the the relation $\left(g_{m}-g_{a}\right)$ to the variations of $g_{e}$, as is shown in Fig. 18. Distributions of 
Table 4

\begin{tabular}{l|l}
\hline $\begin{array}{l}\text { Dynamic gravity meter } \\
\text { averaged frequency }\end{array}$ & 1910 (or 1907$) \mathrm{Hz}$ at $46.5^{\circ} \mathrm{C}$ \\
temperature co-efficient & $-70 \mathrm{mgal} /{ }^{\circ} \mathrm{C}$ \\
Q-value & $50000-10000-2000$ \\
elastic tension & -39 gals \\
\hline
\end{tabular}

$\left(g_{m}-g_{\theta}\right)$ in the figure can be represented by a line passing the origin, except for a point measured at Sydney. The reason why the value at Sydney is exceptional is that there was a trouble in the gyro erection devices just before arriving at Sydney when the gyrotable was too much deflected to recover the initial state. From a slope of the line drawn in the figure we can get the elastic tension of ' $\mathrm{Z}-2$ '" as $-39 \mathrm{gal}$, which is opposite in sign compared with that of the meter " $Z-0$ ". As is noted in section 1-2 a negative elastic tension seems to be related to a negative temperature co-efficient. With the elastic tension thus obtained corrections are made also to all the gravity values measured at the cruising state according to the way described in Part 1. In Table 4 characteristics

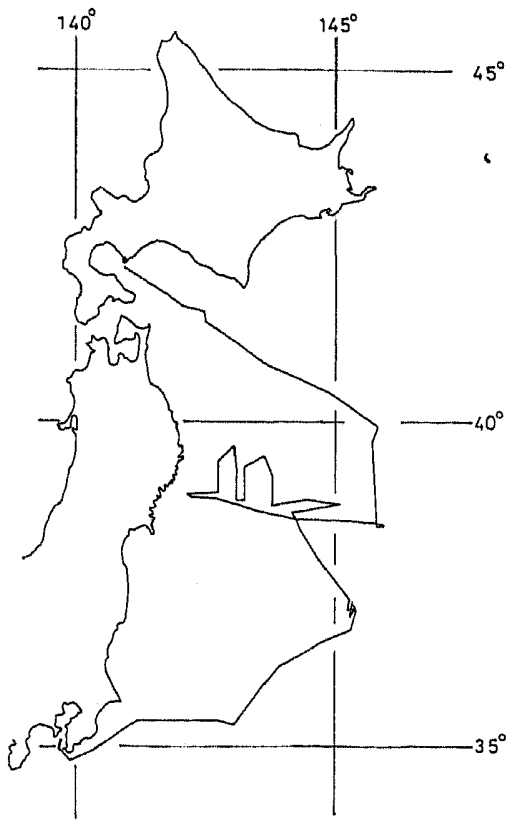

Fig. 19. Ship's track of the Hakuho-maru, cruise $\mathrm{KH}-67-2$ in August 1967. of the gravity meter " $\mathrm{Z}-2$ " are summed.

1-4 Gravity measurements in August 1967 by use of the T.S.S.G. on board the Hakuho-maru, cruise KH-67-2

From August 9th to 18th a newly built research vessel the Hakuho-maru of the Ocean Research Institute, University of Tokyo was first used for the measurement of gravity. On this cruise named KH-67-2 gravity was measured from Muroran, Hokkaido to Tokyo with triple crossings of the Japan trench. The system of the measurement was of the paper tape punching method (ref. Part 1). Dynamic gravity meter " $Z$ - 0 "' was used. Details of this measurement will be reported by Tomoda et al (Tomoda and Koizumi, 1968 personal communication). Ship's tracks are shown in Fig. 19.

\section{1-5 Gravity measurements in July and August} 1968 by use of the T.S.S.G. on board the Hakuho-maru, cruise KH-68-3

From July 19 th to August 16 th 1968 gravity measurements were made in the north Pacific ocean including the Japan trench, Emperor sea mounts and Shatsky rise on board the Hakuho-maru (TOMODA et al., 1968, Preliminary Report of the Hakuho-maru, Cruise $\mathrm{KH}-68-3)$. By this time the Hakuhomaru has been equipped with a high speed electronic computer with sufficient memory circuits (Facom 270-20).

Though in this case on-line real time processings of gravity data were not started the computer served well to process the punched tapes on practically real time basis, preceding the true on-line processings performed on the cruise KH-68-4 (ref. Part 1). Ship's track is

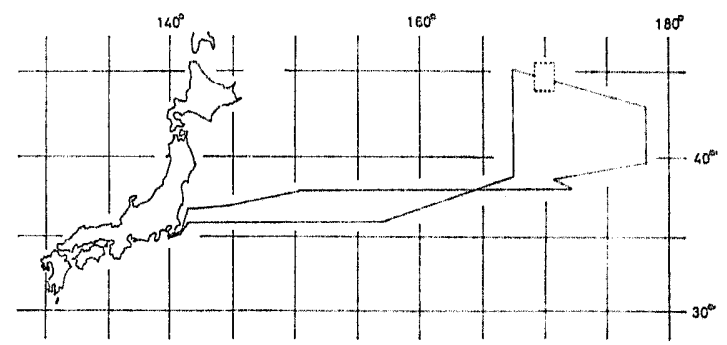

Fig. 20. Ship's track of the Hakuho-maru, cruise KH-68-3 in July and August 1968. 
shown in Fig. 20.

The dynamic gravity meter used on this cruise is named "No-68-7-14", which was constructed in 1968. Its Q-value is 30,000 , and its natural frequency is $1582 \mathrm{~Hz}$ at $40^{\circ} \mathrm{C}$. Measurements were started from Tateyama, where an abnormal positive drift of the meter was observed and prevented us to make calibrations, which we had to wait to do until we returned to Tokyo. The results of measurements at the harbours, Tateyama, the entrance of Tokyo Bay (off Haneda) and the Harumi pier of the Ocean Research Institute are shown in Fig. 21.

\section{8}

\section{Tateyama 7.19}

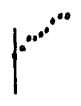

\section{I $40 \mathrm{mgal}$}

\section{Off Haneda \& Harumi 8.15}
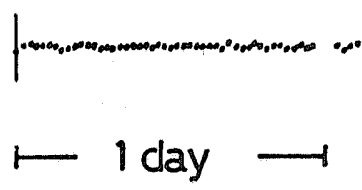

Fig. 21. Results of measurement when the ship was anchoring at the harbours in July and August 1968.

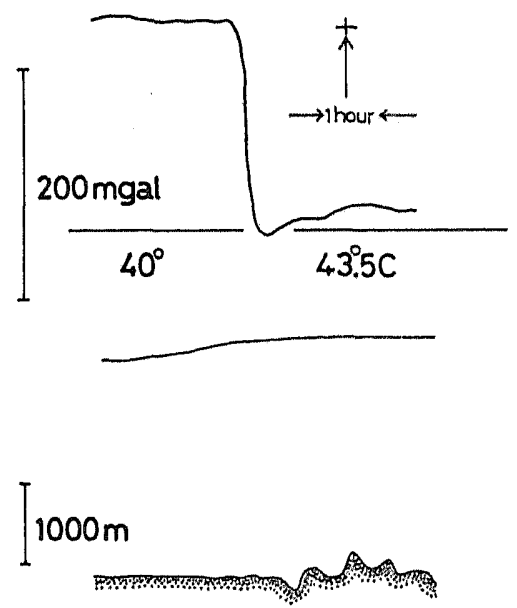

Fig. 22. Temperature response of the dynamic gravity meter NO-68-7-14.
After leaving Tateyama temperature in the gravity meter room was gradually elevated, and it became hard to keep the present oven temperature which had been set $40^{\circ} \mathrm{C}$. So we were obliged to alter the preset point to be $43.5^{\circ} \mathrm{C}$ at $16^{\mathrm{h}} 00^{\mathrm{m}}$ on July $21 \mathrm{st}$, when the ship was cruising. Fig. 22 shows variations of apparent gravity which occurred in this case. From this figure it is found that the variation of apparent gravity is -170 mgal due to temperature variation of $+3.5^{\circ} \mathrm{C}$, if the effects of latitude, water depth and coriolis forces are taken into account. Temperature co-efficient of $-49 \mathrm{mgai} /{ }^{\circ} \mathrm{C}$ is obtained from this measurement with the meter No-68-7-14.

The gravity meter room of the Hakuhomaru is air-conditioned but it is controlled by a ship's central air conditioner with a single control system. Therefore it is impossible to control each room according to each condition. The temperature variation of the gravity meter room was $25^{\circ} \mathrm{C} \pm 5^{\circ} \mathrm{C}$. If a variation of $\pm 0.25^{\circ} \mathrm{C}$ is supposed in the temperature of the oven corrections of \pm 13 mgal must be made to the measured values.

Distributions of the 2nd order corrections are shown in Fig. 23, which are as a whole not so large with a maximum value of 40 mgal. The 2nd order correction co-efficient is taken as $0.021 \mathrm{mgal} /(\mathrm{gal})^{2}$.

Eötvös corrections are made according to the same method in section 1-2. In Fig. 23 distributions of Eötvös corrections are also shown in relation to the number attached to the gravity values.

In the measurement at Tateyama the first value indicated in Fig. 21 agrees with the true gravity of the station 979.795 gal, but it increases with time by about 30 mgal. With the same gravity constant first determined at Tateyama, however, the value observed at Harumi when we returned there is 979.780 gal which is only 7 mgals smaller than the true value. From these facts it is found that the positive drift observed at Tateyama changed to a negative drift and almost recovered the initial state, though details of the variation are unable to be clarified. 

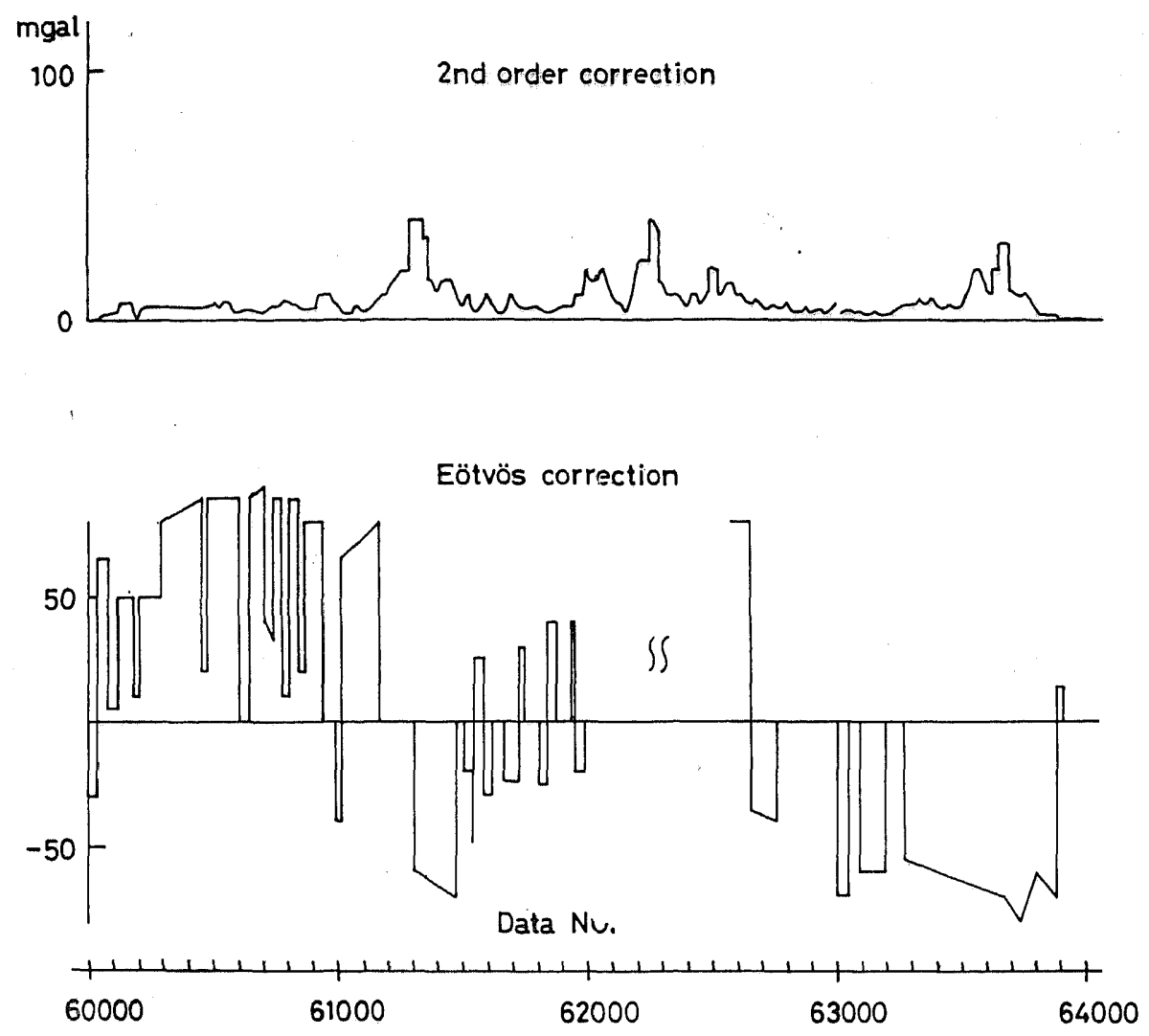

Fig. 23. Variations of the 2nd order corrections and the Eötvös corrections in the measurement of the Hakuho-maru, cruise $\mathrm{KH}-68-3$ in July and August 1968.

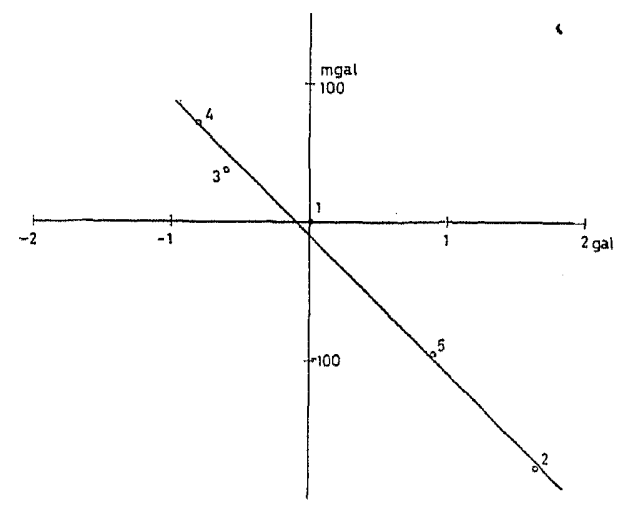

Fig. 24. $g_{m}-g_{e}$ in relation to $\Delta g_{e}$.

The dynamic gravity meter No-68-7-14 has a large elastic tension of $-98 \mathrm{gal}$ which had not been determined until another cruise of the Hakuho-maru KH-68-4, southern-cross expedition carried out from November 1968
Table 5

\begin{tabular}{l|c|c|c}
\hline \multicolumn{1}{c|}{ Base } & $\begin{array}{c}g_{e} \\
\text { gal }\end{array}$ & $\begin{array}{c}g_{m} \\
\text { gal }\end{array}$ & $\begin{array}{c}g_{m}-g_{e} \\
\text { mgal }\end{array}$ \\
\hline Apia & 978.645 & 978.645 & 0 \\
Wellington & 980.302 & 980.125 & -177 \\
Sydney & 979.705 & 979.742 & +37 \\
Noumea & 978.902 & 978.973 & +71 \\
Tokyo & 979.800 & 979.705 & -95 \\
\hline
\end{tabular}

to March 1969 (ref. Preliminary Report of the Hakuho-maru, Cruise KH-68-4 edited by Horibe).

In the cruise $\mathrm{KH}-68-4$ the ship visited Apia, Wellington, Sydney, Noumea and Tokyo, where the gravities $g_{m}$ measured by the $\mathrm{T}$. S.S.G. were compared with those $g_{e}$ measured by a La Coste-Romberg gravity meter. The results are shown in Table 5 and in Fig. 24, 
from which the elastic tension can be calculated as is indicated in Part 1.

Vibrations of the floor caused by engines are extremely small on the Hakuho-maru. The measurement of floor vibration just after the construction of the ship showed that they were less than $5 \mathrm{gal}$ in acceleration at the gravity meter room. It is easy to eliminate such amount of vibration by means of a usual shock absorber. Vibrations of ship's body are, however, caused remarkably by water hammers in the Hakuho-maru, of the frequency of $2-3 \mathrm{~Hz}$, which it is difficult to reduce completely. The effect of such vibrations has not been estimated yet.

Vibrations of the gyrotable were negligibly small. In Table 6 characteristics of the dynamic gravity meter No-68-7-14 are summed.

Table 6

\begin{tabular}{l|l}
\hline Dynamic gravity meter & No-68-7-14 made in 1968 \\
averaged frequency & $1582 \mathrm{~Hz}$ at $40^{\circ} \mathrm{C}$ \\
temperature co-efficient & $-49 \mathrm{mgal} /{ }^{\circ} \mathrm{C}$ \\
Q-value & 30,000 \\
elastic tension & -98 gals \\
\hline
\end{tabular}

\section{1-6 Gravity measurements from April to June} 1969 by use of the T.S.S.G. on board the Hakuho-maru, cruise KH-69-2

Details of this measurement are described by the author in the other publication (Preliminary Report of the Hakuho-maru, Cruise KH-69-2, edited by NASU and TOMODA, in press). So only brief descriptions will be given here.

The cruise KH-69-2 was planned to investigate the Japan trench and the Japan Sea and carried out from April 26 th to June 14th. Ship's track is shown in Fig. 25. Gravity measurements carried out on this cruise are characterized by the on-line real time processings of two T.S.S.G. gravity meters operated at the same time. The gravity meters were settled at the same floor close to each other and operated quite independently. One of the dynamic gravity meters used was No-68-7-14 which had beed in use since 1968 and the other was No-67-11-9 which had been

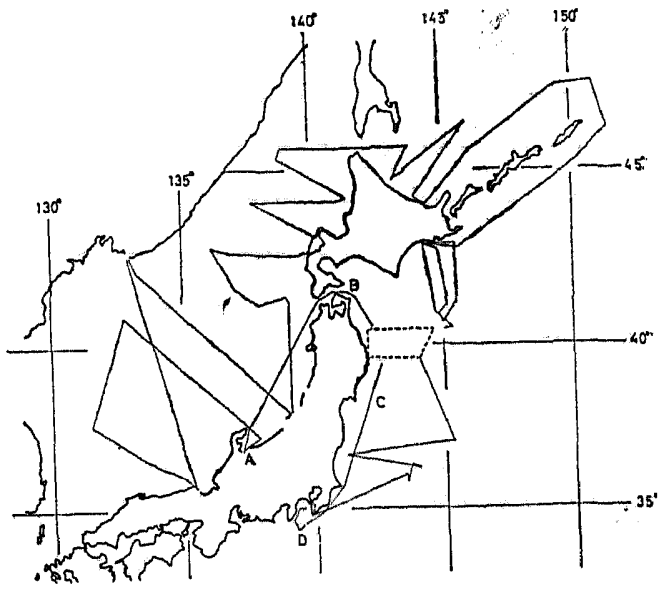

Fig. 25. Ship's track of the Hakuho-maru, cruiseKH-69-2 from April to June 1969.

constructed in 1967 but kept unused. The characteristics of the latter gravity meter are listed in Table 7.

Table 7

\begin{tabular}{l|l}
\hline Dynamic gravity meter & No.67-11-9 made in 1967 \\
averaged frequency & $1476 \mathrm{~Hz}$ at $38^{\circ} \mathrm{C}$ \\
temperature co-efficient & $-25 \mathrm{mgal} /{ }^{\circ} \mathrm{C}$ \\
Q-value & 4,500 \\
elastic tension & $-70.6 \mathrm{gal}$ \\
\hline
\end{tabular}

Gravity data obtained in this cruise are now being arranged and will be published in near future (therefore these data are not included in this paper), but for comparison between the two simultaneous measurements the gravity value outputs from the computer, though they are not corrected for the Eötvös effect, are directly compared. An example of the comparison measurements is shown in Fig. 26, where gravities along the track from Toyama to Tokyo by way of Tsugaru strait (the track indicated by $A, B, C$ and $D$ in Fig. 25) are plotted. These values were obtained in a period of about a week.

Agreement between the two measurements is considered to be satisfactory for the present instruments when averaged differences have been estimated to be less than 3 mgal. 


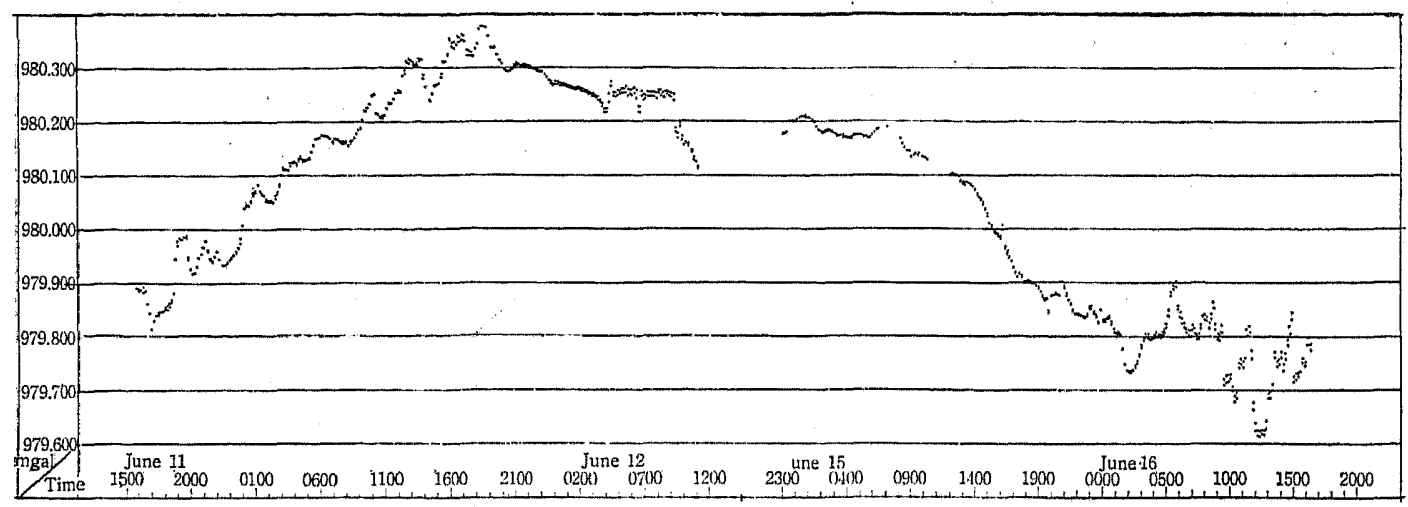

Fig. 26. Comparison of the results obtained by two sets of the T.S.S.G. gravity meters installed at the same place.

1-7 Gravity measurements in June 1968 by use of the T.S.S.G. on board the Meiyo These measurements were carried out by the Hydrographic Office, Maritime Safety Agency of Japan (Data report of Hydrographic observations, series of astronomy and geodesy, No. 4, September 1969). The ship RV Meiyo started from Shiogama on June 2nd and went

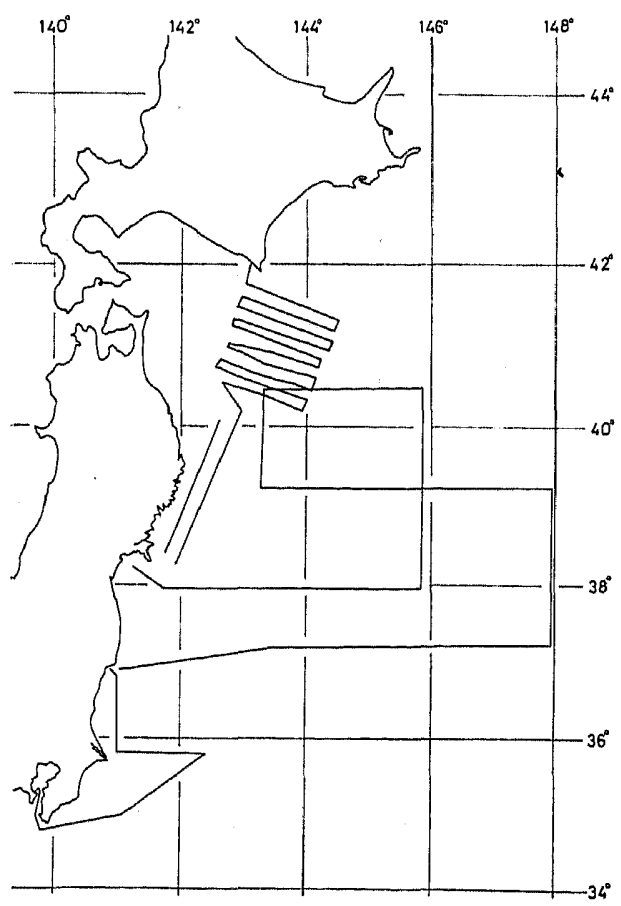

Fig. 27. Ship's track of the Meiyo in June 1968. northward to Horoizumi near the Erimo peninsula, where she anchored and made calibrations. After surveying continental shelves and slopes south of Erimo she returned to Shiogama on June 8th. On June 12th the Meiyo left Shiogama again and surveyed the Japan trench by crossing it four times until June 25th when she returned to Onahama. The ship left Onahama on June 27 th and went to Kurihama on June 29th. Ship's tracks are shown in Fig. 27.

The dynamic gravity meter used for this measurement is Hydrographic Office type No. 1 which was made in 1965 . Ambient temperature between Shiogama and Horoizumi showed a maximum variation of $20^{\circ} \mathrm{C}$. Quantities of the 2nd order corrections are less than $30 \mathrm{mgal}$ in the measurements south of the Erimo peninsula, less than $150 \mathrm{mgal}$ in the measurements crossing the Japan trench eastwards, less than $10 \mathrm{mgal}$ in the measurements crossing the Japan trench westwards and less than $70 \mathrm{mgal}$ in the measurements of north-to-south direction.

As is described in Part 1 the T.S.S. G. of the Hydrographic Office is of the paper tape punching system and corrections for the 2nd order effect are made by the interpolation method (ToKUHIRO, 1967).

\section{§2. Results}

Gravity values are tabulated in this section. The values are those which have been ob- 
tained for the most part by the T.S.S.G. with the exception of those measured by MATSUYAMA et al. by use of the Vening Meinesz gravity meter over the Japan trench.

Tables are classified into several divisions from tectonical point of view as;

1. The Japan trench and its vicinity.

2. The Mariana trench.

3. The Solomon trench.

4. The Brisbane hill.

5. The Suiko seamount.

6. The Shatsky rise.

7. The Bismark plateau.

In tables are listed from the left column to the right data numbers, date of measurement, positions, standard gravities according to the International formula, measured gravities, water depths, simple Bouguer corrections, calculated Bouguer corrections, free air anomalies, simple Bouguer anomalies and calculated Bouguer anomalies.' Corrections for the Eötvös effect, the 2nd order effect and the elastic tension are not displayed. Simple Bouguer corrections are calculated by assuming that water depth of a thousand meters uniformly corresponds to a correction of 69 mgal. As to the calculated Bouguer corrections refer to appendices.

\section{Gravity Table 1}

The Japan trench and its vicinity Note

This table includes those values which were obtained by a submarine observation by use of the Vening Meinesz gravity meter in 1934 (sec. 1-1), observation by the Umitaka-maru by use of the T.S.S.G. in 1966 (sec. 1-2), and observations by the Hakuho-maru in 1967 (sec. 1-4) and 1968 (sec. 1-5). Gravity values measured by the Meiyo in 1968 (sec. 1-7) are also included in making the contour maps (Data report of Hydrographic observations, Series of Astronomy and Geodesy, No. 4, September, 1969). In Fig. 28 measuring tracks of this area are shown, where tracks of the Meiyo are also included. In Figs. 29, 30, 31 and 32 mean topography, mean free air anomaly, mean Bouguer anomalies and mean Bouguer corrections over a mesh of $10^{\prime} \times 10^{\prime}$

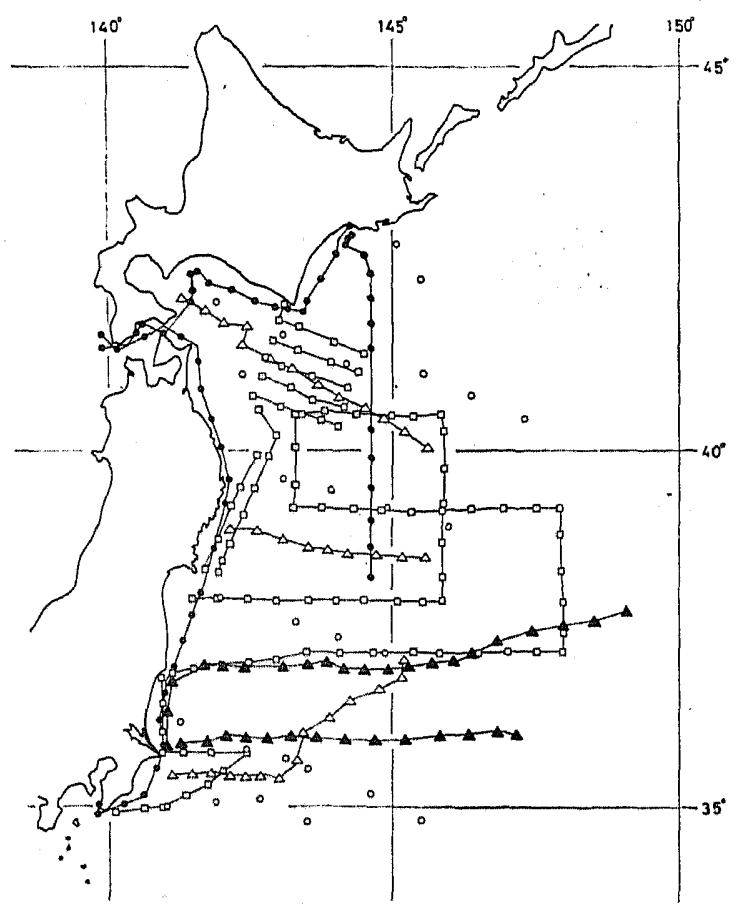

Fig. 28. Measuring tracks in and near the Japan trench before 1968 .

are displayed respectively, where land gravity values measured by the Geographical survey institute of Japan (1955, 1957 and 1964) are partially taken into account. Bouguer corrections in Fig. 32 applied to obtain mean Bouguer anomalies are not the simple Bouguer corrections but those which have been calculated from the mean topography by use of the Talwani's method in three dimensions (TALWANI and EWING, 1960) on the basis of the bathymetric chart No. 6301 published by the Hydrographic office of Japan. Details of this calculations are described in Appendices 1 and 2-1. Contour maps are also drawn with respect to both the free air anomalies and the Bouguer anomalies as are shown in Figs. 33 and 34 on the basis of the values displayed in the previous figures. The contour interval is 25 mgals.

\section{Interpretation}

Two regions of negative Bouguer anomaly located at both sides of the Hidaka-Erimo line are conspicuous. The Hidaka mountain area 


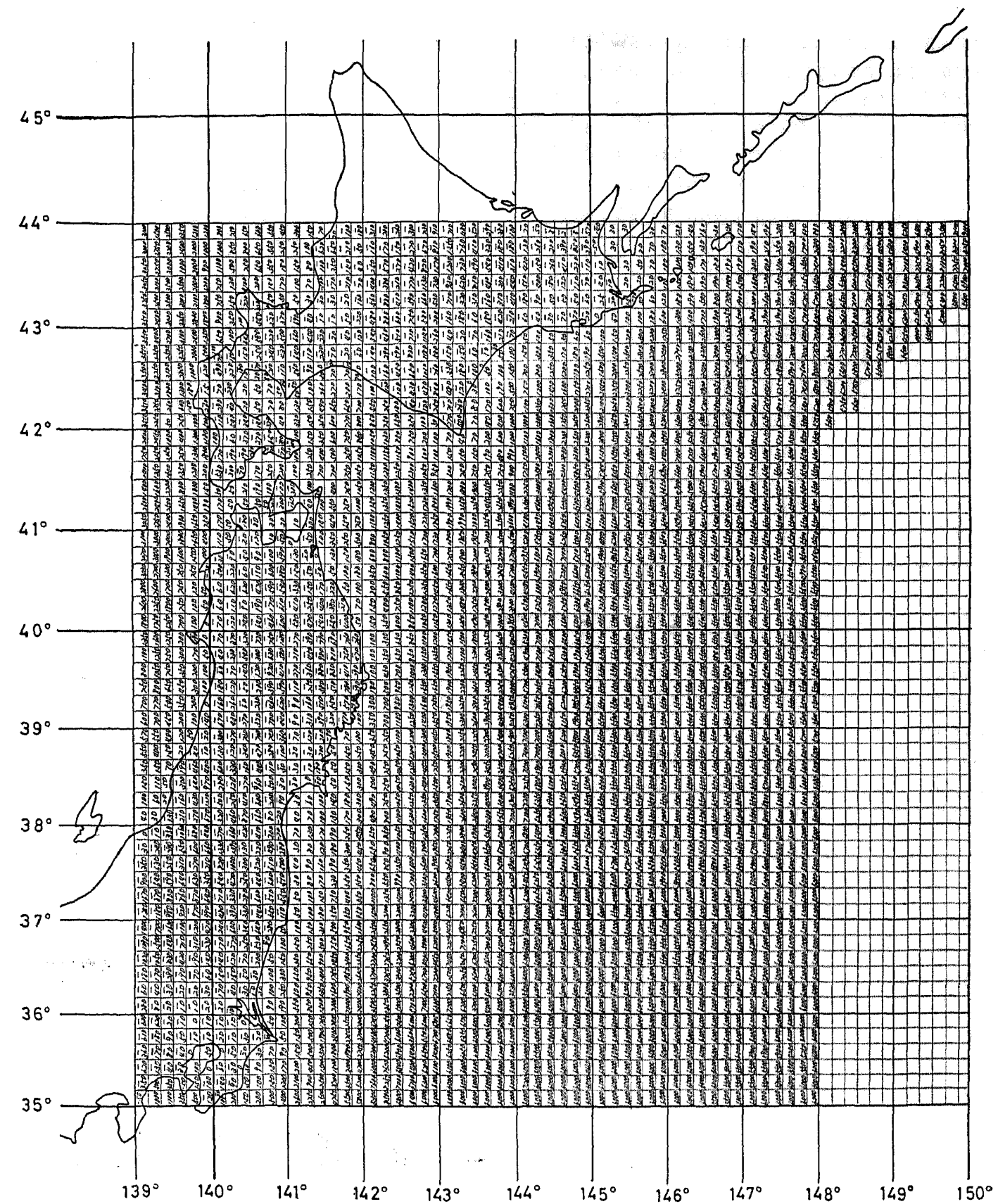

Fig. 29. Mean water depth over meshes $10^{\prime} \times 10^{\prime}$ in and near the Japan trench. Unit in meter. On land the values indicate mean elevation.

is trending from north to south at the These regions are comparatively shallow. Hokkaido district, passing by the Erimo pen- According to a geological map (Tectonic insula. Bouguer anomalies of both the regions map of Japan, 2, geologic provinces, compiled show negative values lower than -100 mgal. by Hiroshi IsomI, 1965, the Geological Survey 


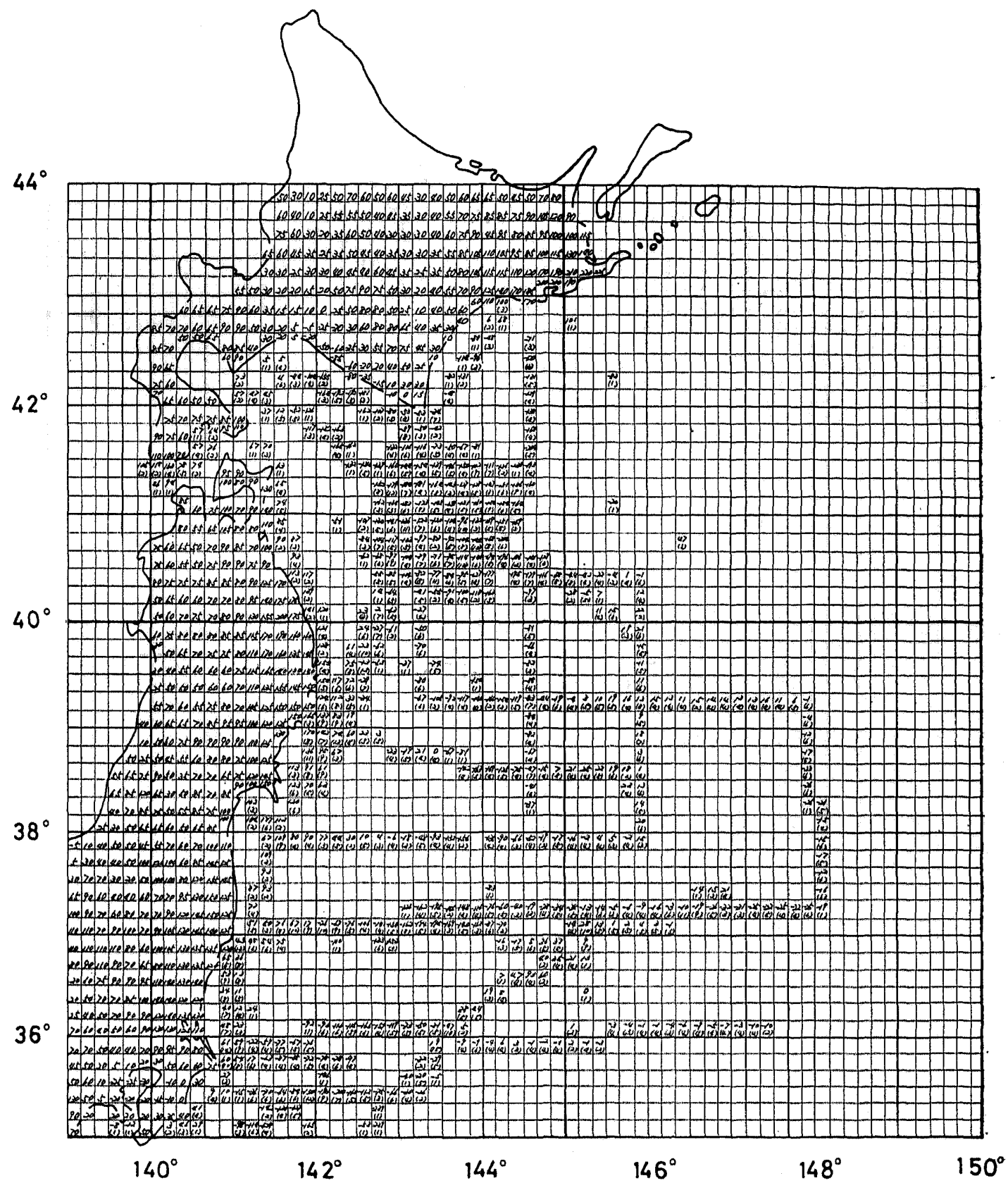

Fig. 30. Mean free air anomaly in mgal over meshes of $10^{\prime} \times 10^{\prime}$ in and near the Japan trench.

The values indicated in parenthesis are numbers of measured points in a mesh.

Institute of Japan, published in 1968) positive free air and Bouguer anomalies over the Hidaka mountains correspond to the area where the named Hidaka metamorphic rocks are distributed. The negative Bouguer anomaly region west of the Erimo peninsula exists at the extension of a tertiary zone trending parallel to the west side of the Hidaka mountains, the negative region east of the Erimo peninsula existing at the extension of a quarternary zone trending parallel to the east side of the same mountains. At 


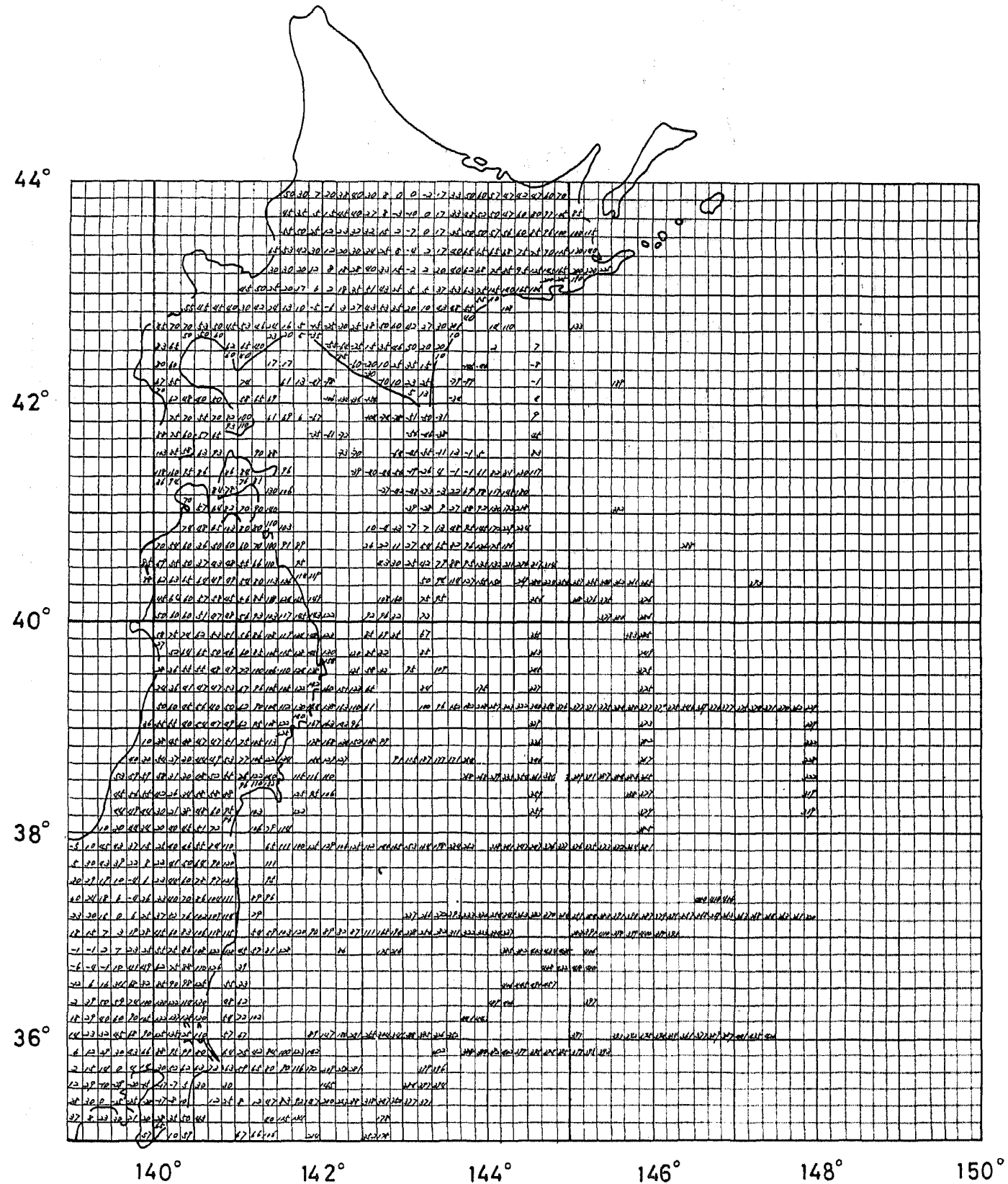

Fig. 31. Mean Bouguer anomaly in mgal over meshes of $10^{\prime} \times 10^{\prime}$ in and near the Japan trench.

the south margin of the negative region earthquakes occur frequently, which are named 'Tokachi-oki earthquake' (earthquakes at sea off the Tokachi district).

A region of positive free air anomaly higher than $100 \mathrm{mgal}$ is found over the Kitakami mountains at the Honshu and extended over the sea region off the Sanriku coast. The maximum Bouguer anomalies exist trending north to south off the Sanriku coast between Kamaishi and Ōfunato, where the zone of Variscan geosynclinal deposit and Cretaceous 


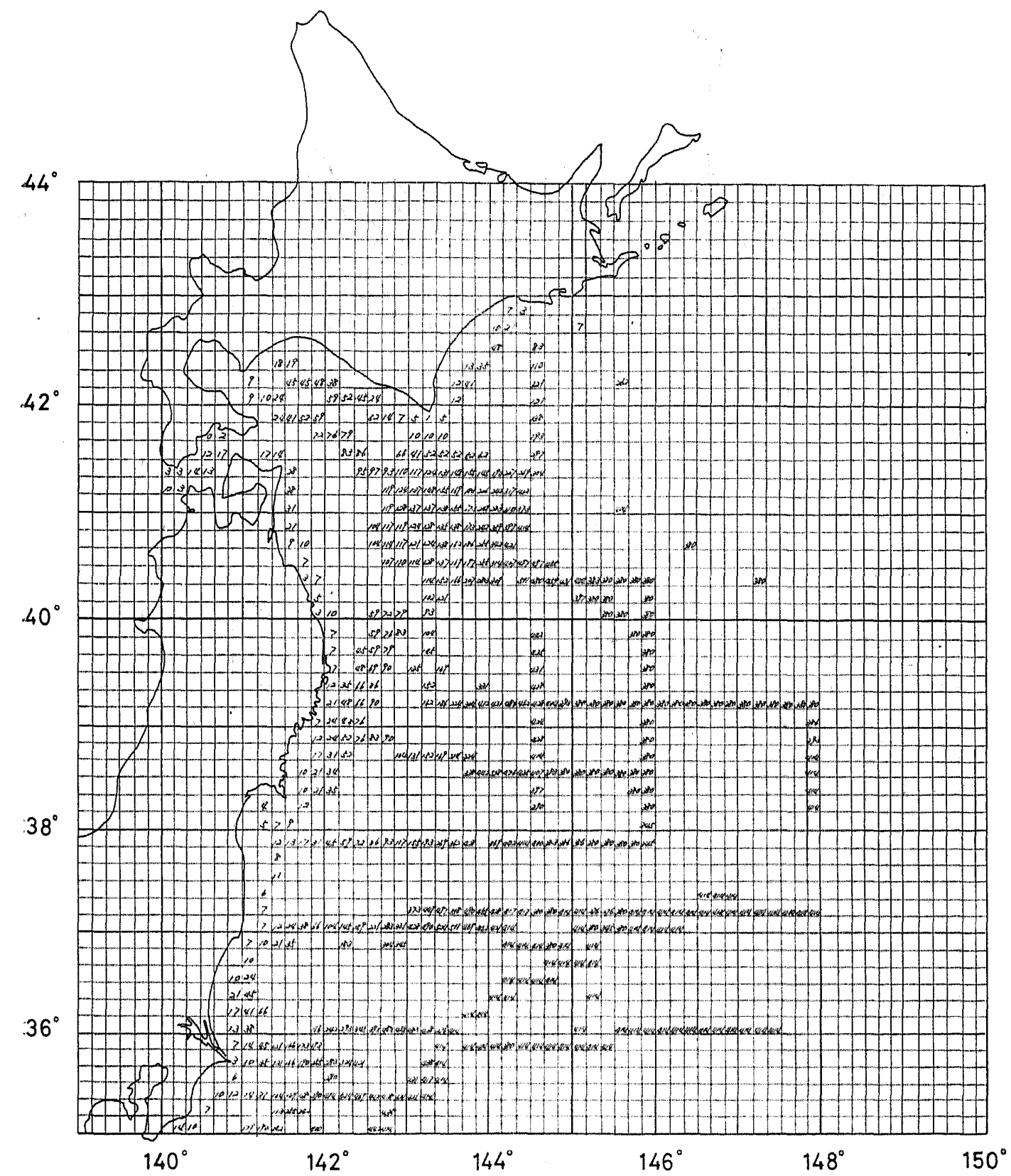

Fig. 32. Mean Bouguer correction in mgal over meshes of $10^{\prime} \times 10^{\prime}$ in and near the Japan trench.

granites are found.

Free air gravity anomalies over the Japan trench show minimum values of about -200 mgals at the north and south part. The values at the middle part of the trench are a little higher than the former. This is partly because of sedimentation which has made the sediment at the middle part of the trench particularly thicker than at the both ends and made the bottom shallower. This fact will be verified by the Bouguer anomaly distributions which show no particu- 


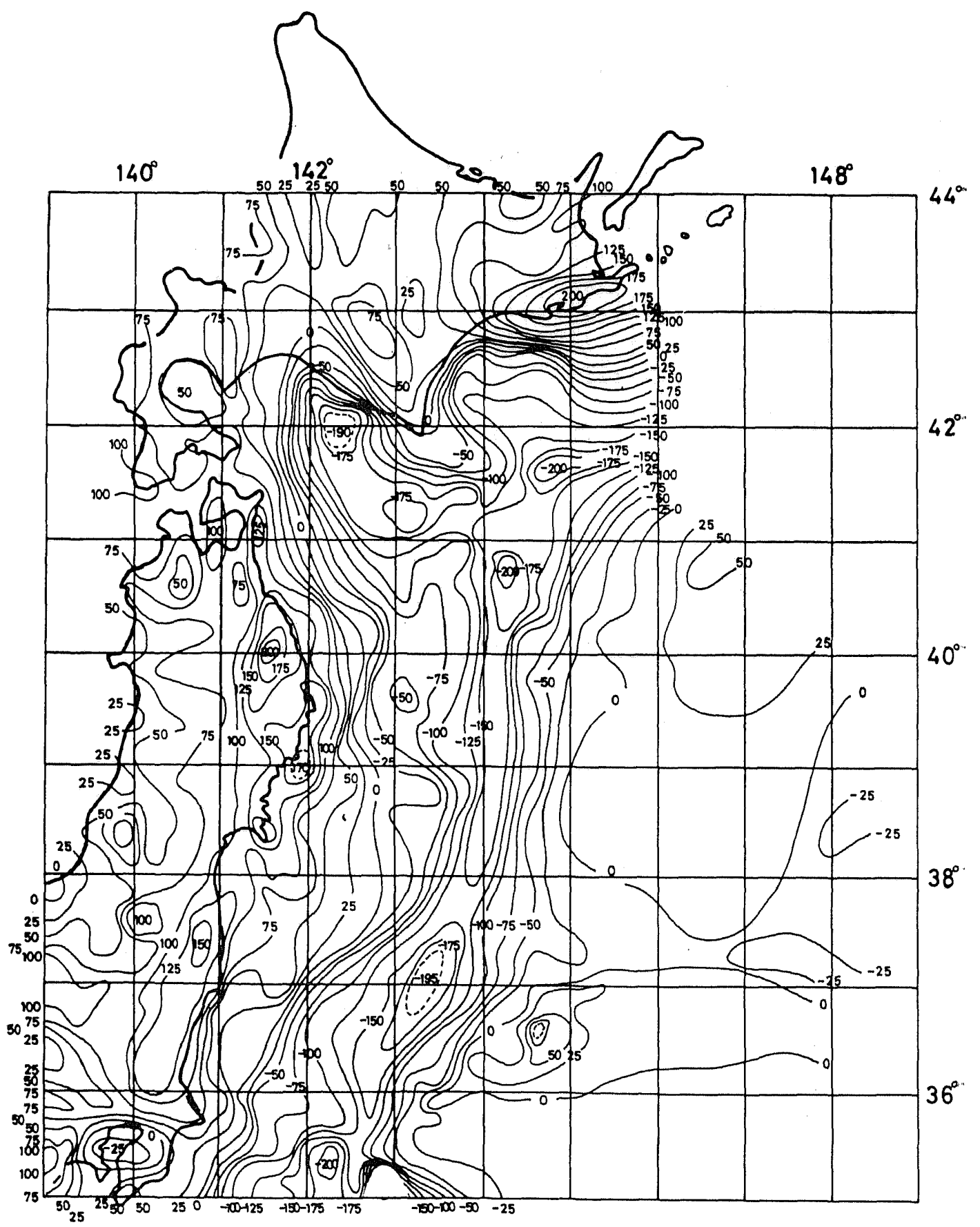

Fig. 33. Contour map of free air anomaly over the Japan trench and its vicinity. Contour interval. is $25 \mathrm{mgal}$. 
Gravity Measurements at Sea by Use of the T.S.S.G. Part 2.

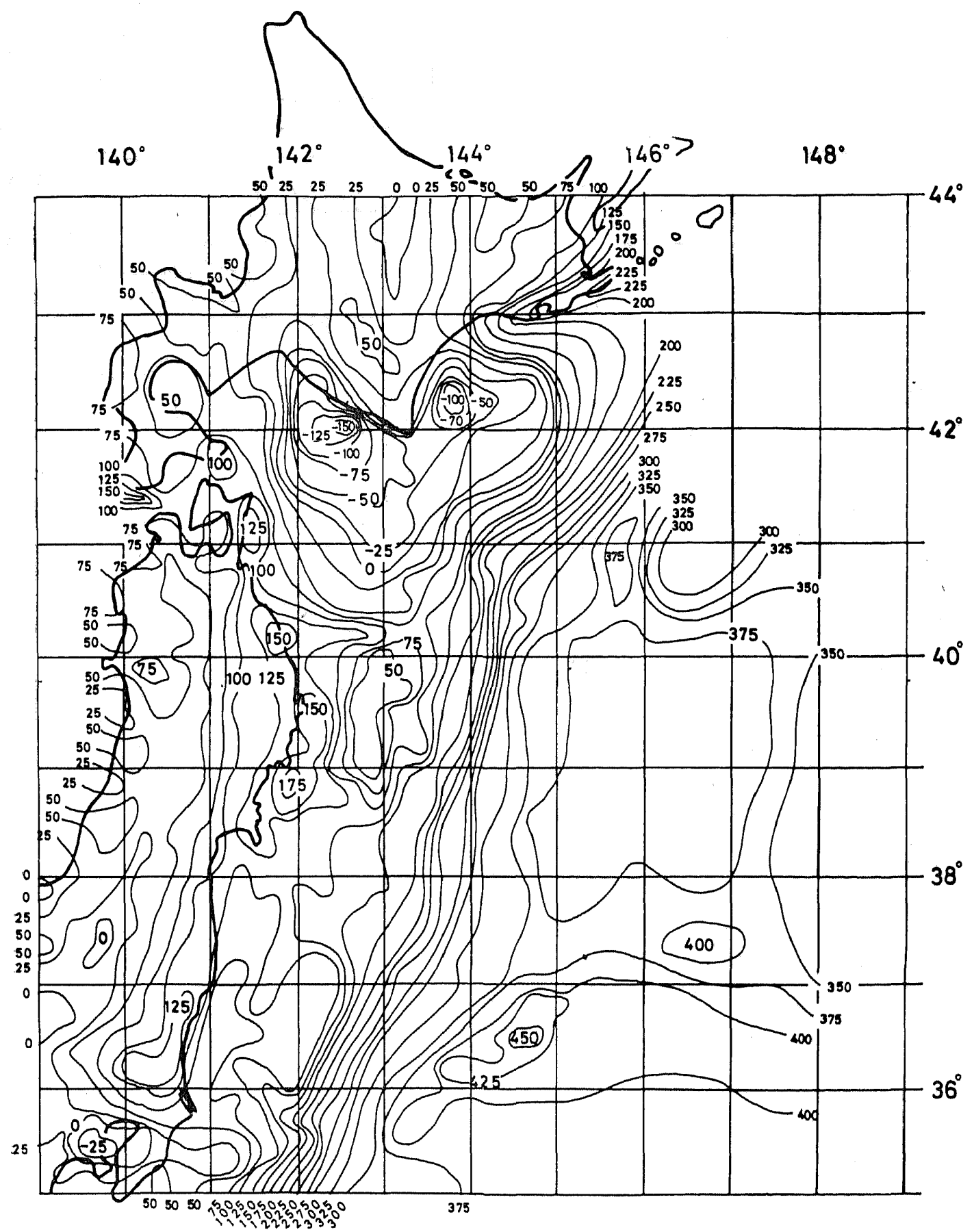

Fig. 34. Contour map of Bouguer anomaly over the Japan trench and its vicinity. Contour interval is $25 \mathrm{mgal}$. 


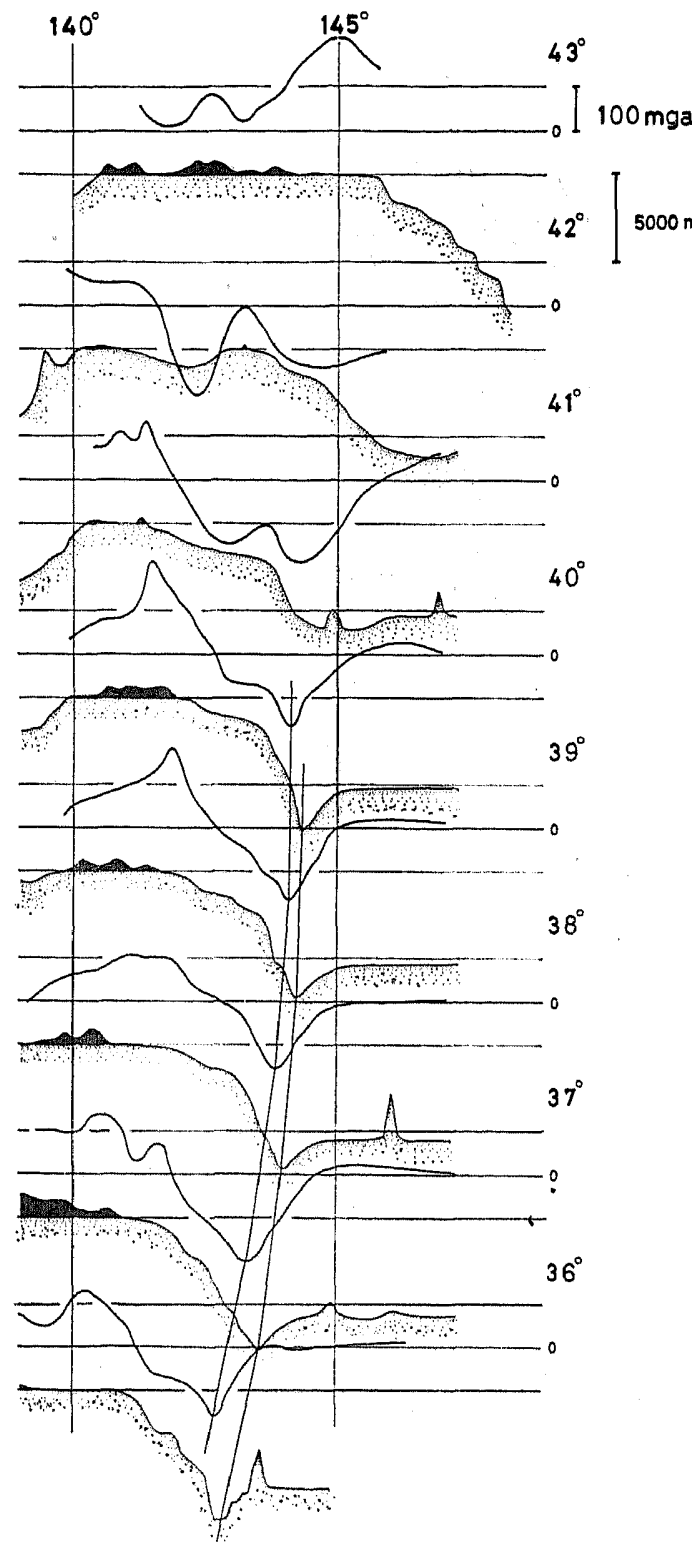

Fig. 35. Profiles of free air anomaly across the Japan trench.

lar distinction between the middle part and the north and south parts. In Figs. 35 and 36 profiles of free air and Bouguer anomalies across the Japan trench are indicated along the parallels from $36^{\circ} \mathrm{N}$ to $43^{\circ} \mathrm{N}$ at the interval of one degree, together with profiles of the bottom topography. A line connecting points of minimum free air anomalies does not agree
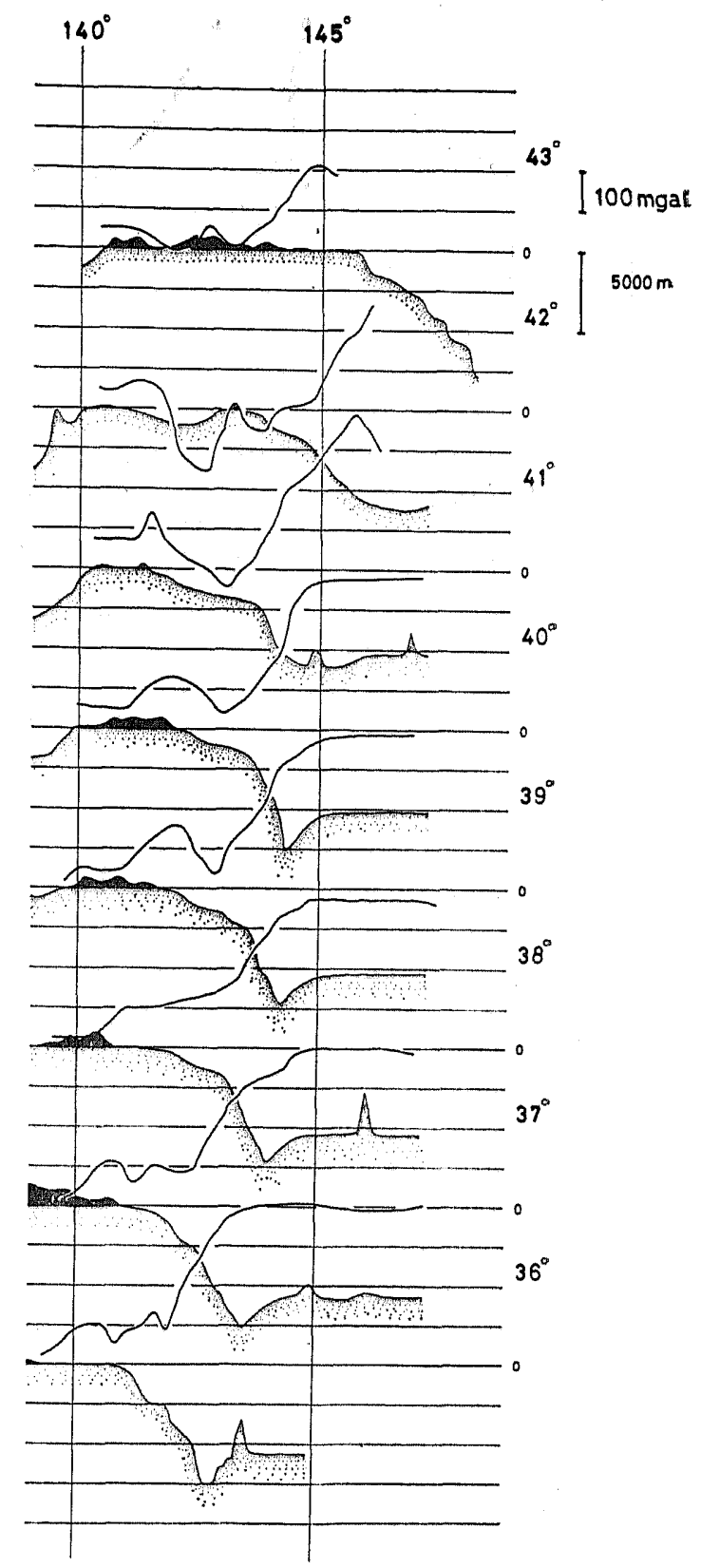

Fig. 36. Profiles of Bouguer anomaly across the Japan trench.

with the trench axis, but lies by $5-10$ miles apart from the axis towards the land. The phenomenon will be simply explained by the lateral effect of an isostatically expected root of the continental mass which is supposed to 
show sudden thickening below the continental slope of the Honshu. According to a calculation of the depth of Mohorovicic surface from a profile of Bouguer gravity anomaly across the trench off the Sanriku coast (the data obtained in the cruise $\mathrm{KH}-67-2$ of the Hakuhomaru) it is found that the M-surface is suddenly deepened at the continental slope (more or less $30 \mathrm{~km}$ ) (SEGAWA, 1969). It is not always true, however, that the minimum line of free air anomaly is apart from the trench axis. In case of the Mariana trench the minimum line agrees exactly with the trench axis (refer Gravity Table 2).

Gravity Table 2

Note The Mariana trench

This table consists of values obtained in 1968

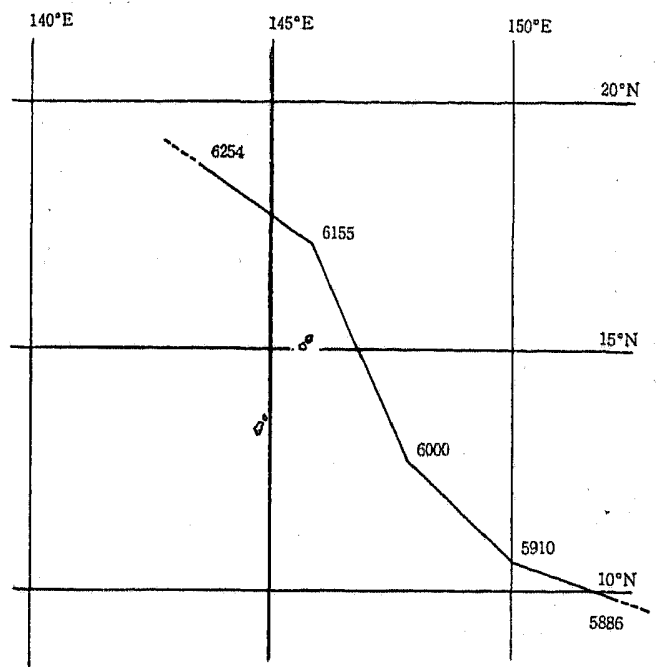

Fig. 37. Measuring track across the Mariana trench in 1968.

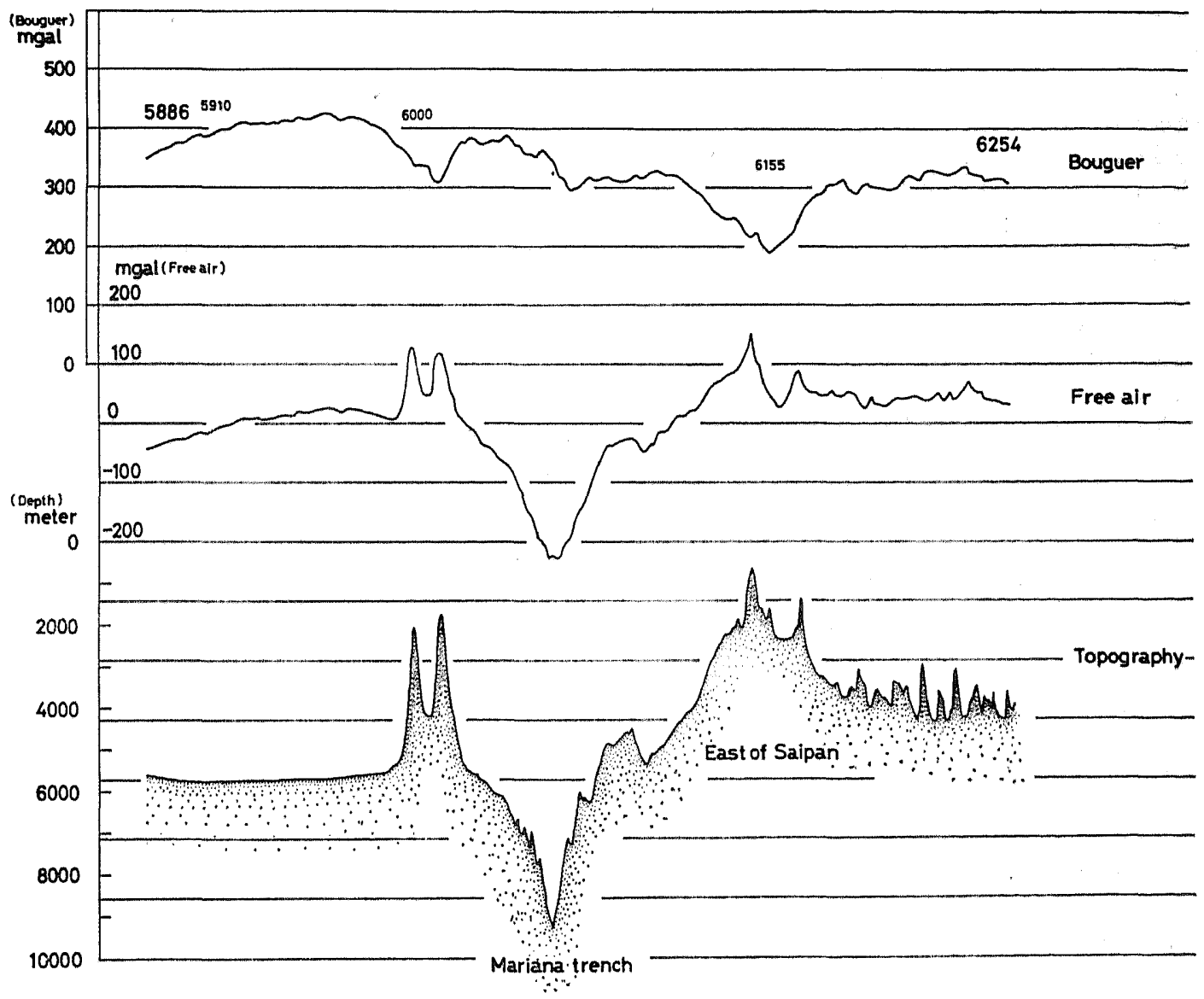

Fig. 38, Profiles of topography, free air anomaly and calculated Bouguer anomaly across the Mariana trench. 
by the observations on board the Umitakamaru (sec. 1-3). In Fig. 37 the measuring track is shown. Calculated Bouguer anomalies in which the effect of topography is taken into account with the assumption of 2 dimensional case are also given in addition to simple Bouguer anomalies (see Appendix 3). Profiles of free air and Bouguer gravity anomalies and the topography are shown in Fig. 38. Numbers indicated in Fig. 37 along the ship's track and in Fig. 38 along the profile are those attached to gravity values found in the table, and can be used as indices.

\section{Interpretation}

This is a measurement across the Mariana trench from south to north. The deepest point which the ship traversed was $9600 \mathrm{~m}$, which is called the Nero deep. Free air anomaly at the deepest point is $-230 \mathrm{mgal}$. Different from the case of the Japan trench the point of minimum free air anomaly agrees with the trench axis in the case of the Mariana trench. At the northern slope of this trench (at the side of the Mariana islands) the depth of Mohorovicic surface is estimated to be $15 \mathrm{~km}$. It is much shallower compared with the case of the Japan trench (SEGAWA, 1969). The deepest Mohorovicic surface lies below Guam and Saipan islands and shows the depth of about $25 \mathrm{~km}$. As a general tendency the Mohorovicic surface seems to be deepened gradually from south to north across the trench, unless minute undulation is taken into account.

\section{Gravity Table 3}

The Solomon trench.

\section{Note}

This table consists of values obtained in 1968 by the observations on board the Umitaka-maru (sec. 1-3). In Fig. 39 the measuring track is shown. Calculated Bouguer anomalies in which the effect of topography is taken into account with the assumption of 2 dimensional case are also given in addition to simple Bouguer anomalies (see Appendix 3). Profiles of free air and Bouguer gravity anomalies and the topography are shown in Fig. 40. Numbers indicated in Fig. 39 along

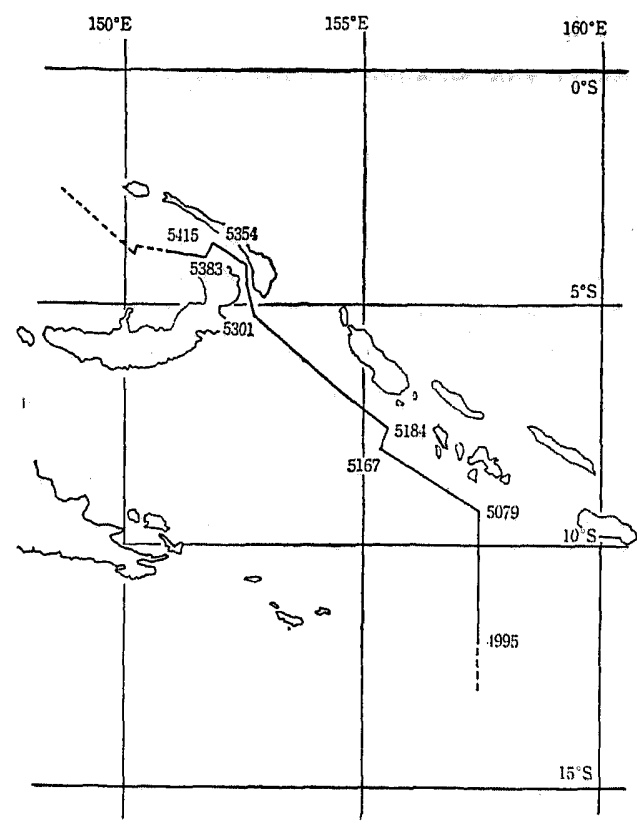

Fig. 39. Measuring track across the Solomon trench in 1968.

the ship's track and in Fig. 40 along the profile are those attached to gravity values found in the table, and can be used as indices.

\section{Interpretation}

This is a measurement running northwestwards along the Solomon islands, crossing the Solomon trench obliquely and entering the Bismark archipelago sea by way of the St. George strait. Minimum free air anomaly is found above a point of maximum depth showing a value of $-280 \mathrm{mgal}$. According to the paper (SEGAWA, 1969) Mohorovicic depth near the St. George strait between the New Britain island and the New Ireland island is estimated to be $30 \mathrm{~km}$.

\section{Gravity Table 4}

The Brisbane Hill

\section{Note}

This table consists of values obtained in 1967 and 1968 by the observations on board the Umitaka-maru (sec. 1-3). The Brisbane hill is a bank lying off the east coast of Australia in the Coral sea. Measuring tracks with contours of topography. are shown in 


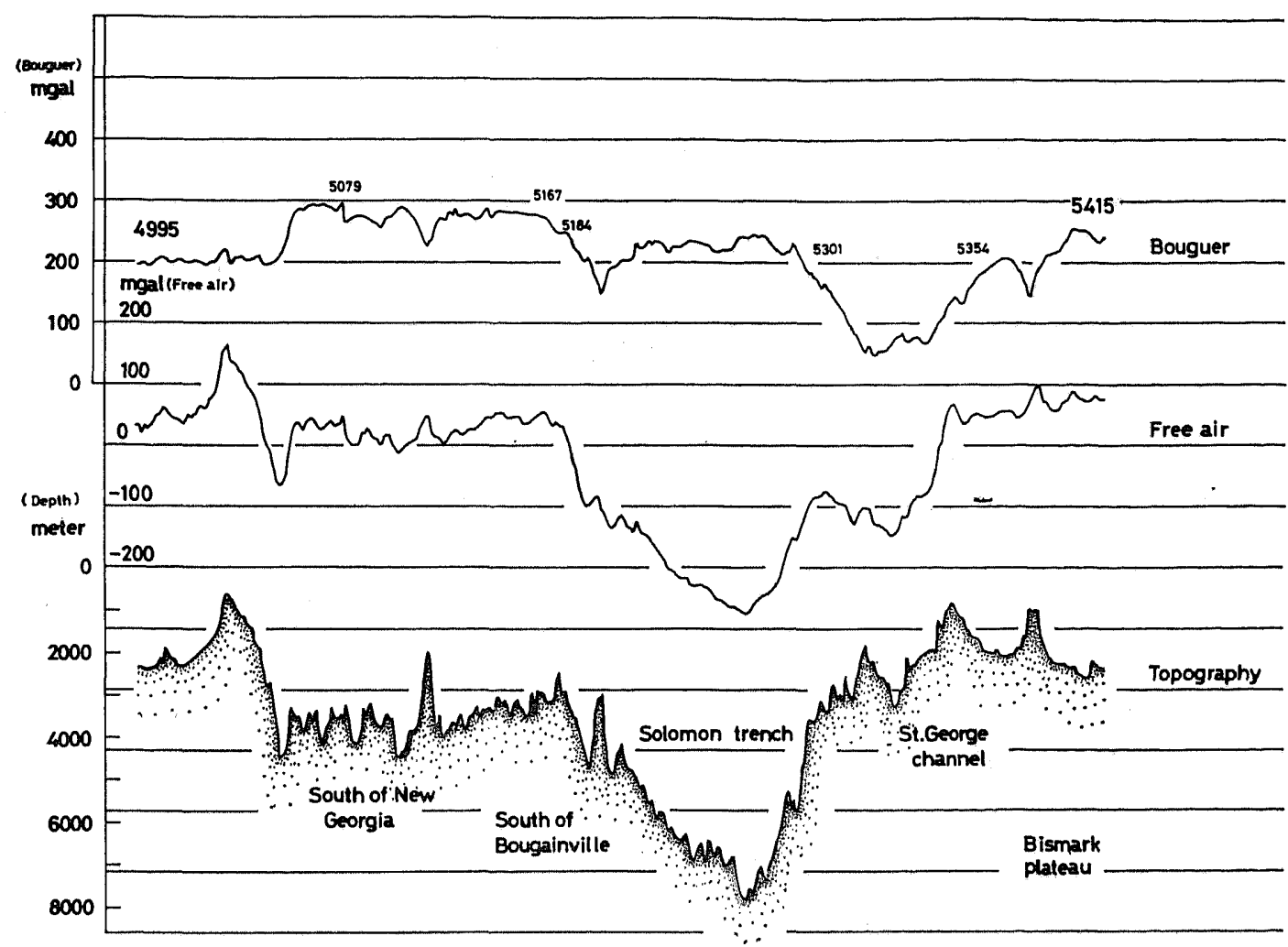

Fig. 40. Profiles of topography, free air anomaly and calculated Bouguer anomaly across the Solomon trench.

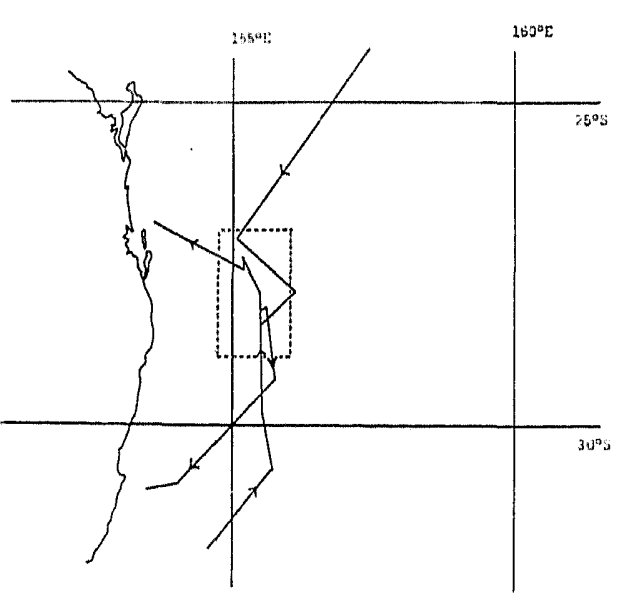

Fig. 41. Ship's track near the Brisbane Hill in 1968.

Figs. 41 and 42. The tracks $A-A^{\prime}, B-B^{\prime}$, $C-C^{\prime}$ and $D-D^{\prime}$ correspond to the profiles $A-A^{\prime}, B-B^{\prime}, C-C^{\prime}$ and $D-D^{\prime}$ drawn in
Figs. 43 and 44. Calculated Bouguer anomalies are given in addition to simple Bouguer anomalies in the table (see Appendix 3). Profiles of free air and Bouguer gravity anomalies and the topography are shown in Fig. 43.

\section{Interpretation}

The Brisbane hill is a bank lying east of Brisbane at the east of Australia. Free air anomalies observed near the top of the bank show the values of $200-250$ mgal. Bouguer anomalies obtained by taking the topograpy of the mountains into account, assuming the density difference between rock and water to be $1.64 \mathrm{gr} / \mathrm{cm}^{3}$ (Fig. 43), show relatively lower values above the top of the moutains. This situation may of course be changed with the density differences which is adopted in the calculation. In Fig. 44 comparisons are made between observed free air anomalies and calculated free air anomalies. Calculated 


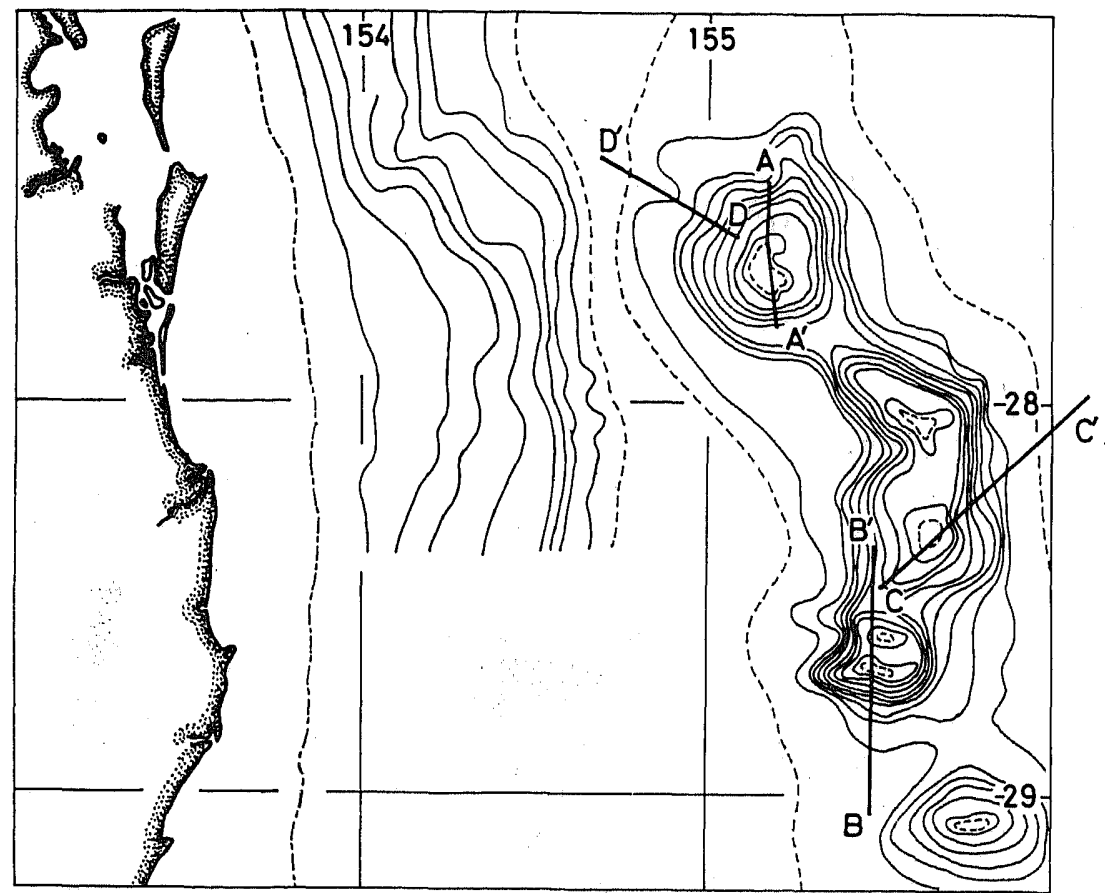

Fig. 42. Measuring tracks with contours of topography at the Brisbane Hill. Interval of solid contour line is $500 \mathrm{~m}$. Interval between solid and dotted contour line is $250 \mathrm{~m}$. The deepest contour shows $4750 \mathrm{~m}$.

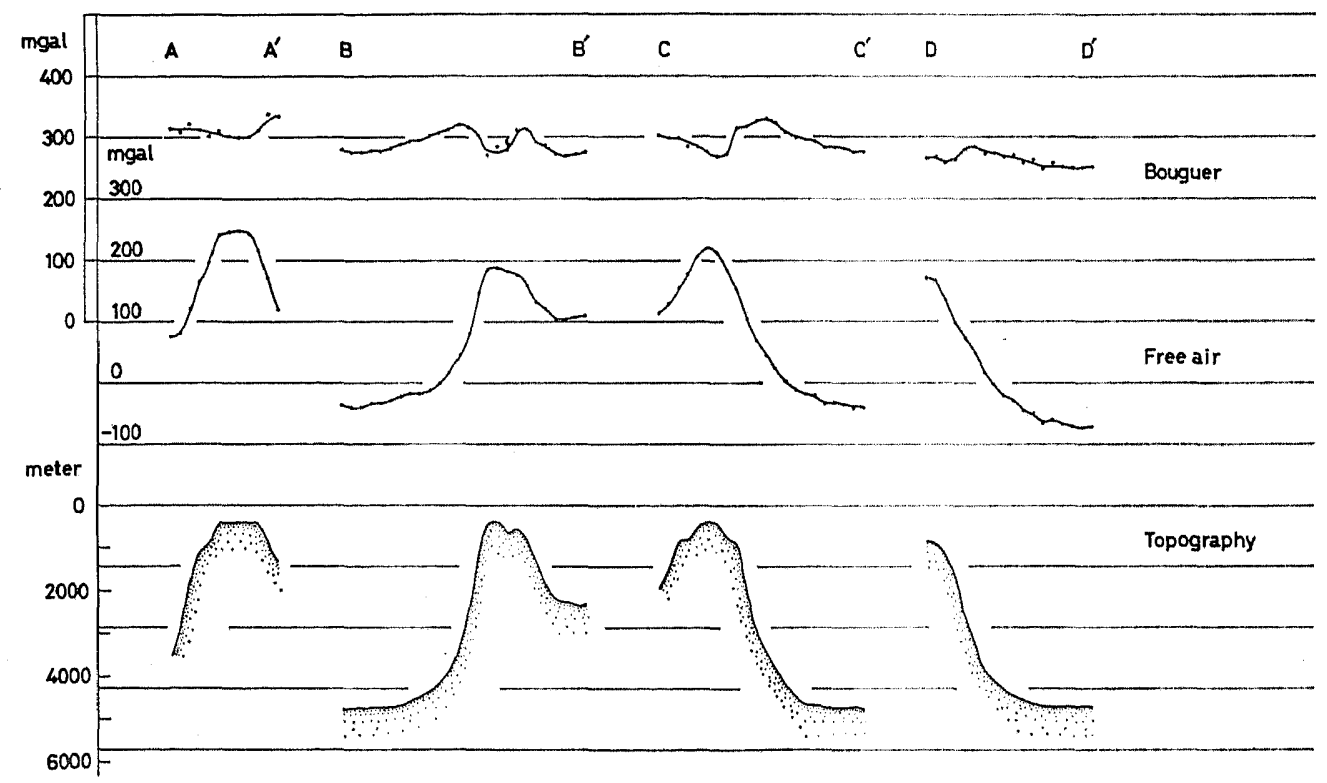

Fig. 43. Profiles of topography, free air anomaly and calculated Bouguer anomaly along the tracks $A-A^{\prime}, B-B^{\prime}, C-C^{\prime}$ and $D-D^{\prime}$ indicated in Fig. 42. 

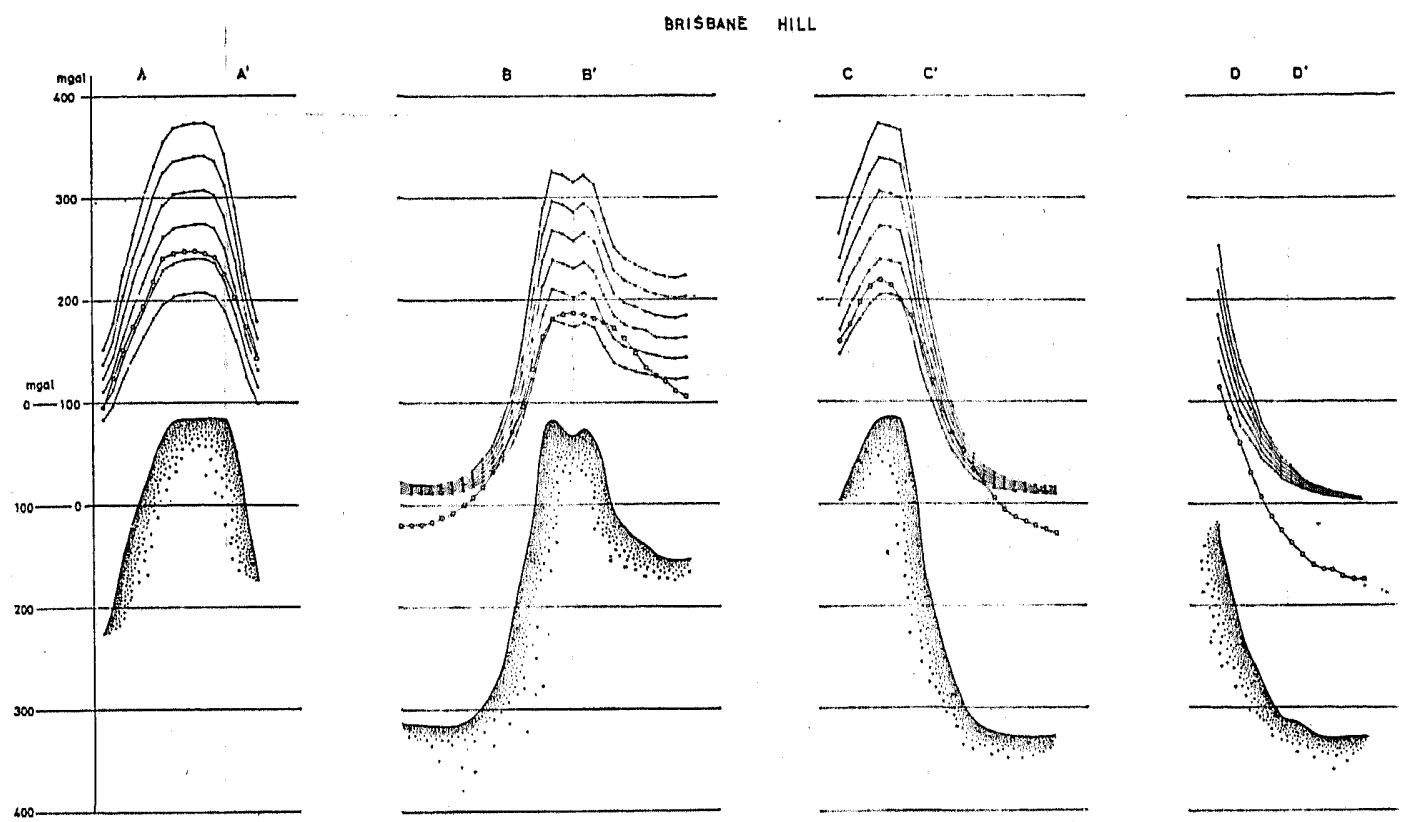

Fig. 44. Comparison of observed free air anomalies with calculated free air anomalies at the Brisbane Hill. $\mathrm{O} \bigcirc \mathrm{O}$ observed. calculated.

free air anomalies are obtained by assuming that the standard depth of the ocean bottom is $4750 \mathrm{~m}$ and that the bank is completely nonisostatic. Density of rocks composing the bank is changed from $2.27 \mathrm{gr} / \mathrm{cm}^{3}$ to $3.27 \mathrm{gr} / \mathrm{cm}^{3}$ with the interval of $0.2 \mathrm{gr} / \mathrm{cm}^{3}$. From these calculations an averaged density, which seems to be most fitted to the observations, is estimated to be $2.27-2.47 \mathrm{gr} / \mathrm{cm}^{3}$. This is too small to be the density of the bank. It may be wrong to try to fit forcibly the calculated free air anomalies of an non-isostatic seamount to the observed one. The differences between the calculated and the observed free air anomalies appear rather systematic; the observed free air anomalies are lower than the calculated one above the top of the bank and show negative values locally at the foot of the bank. This may well be thought to be a character of a mountain which is more or less isostatically constructed.

\section{Gravity Table 5}

\section{The Suiko seamount}

Note

This table consists of values obtained in
1968 by the observations on board the Hakuhomaru (cruise KH-68-3) (sec. 1-5). The Suiko seamount is located in the Emperor ridge in the north Pacific ocean. In Fig. 45 measuring tracks are shown. In Figs. 46, 47 and 48 mean topography, mean free air gravity anomalies and mean calculated Bouguer anomalies (see Appendix 2-3) over a mesh of $2^{\prime} \times 2^{\prime}$ are displayed. Contour maps of topography in Fig. 49 and of free air gravity anomaly in Fig. 50 are drawn according to Figs. 46 and 47 respectively.

\section{Interpretation}

In Fig. 51 profiles of topography, observed free air anomalies, calculated free air anomalies (obtained by assuming that the standard water depth is $6400 \mathrm{~m}$, that the mountain is non-isostatic and that the density of rocks composing the mountain is $2.27,2.67$ or 3.07 $\mathrm{gr} / \mathrm{cm}^{3}$ respectively) and calculated Bouguer anomalies are indicated along parallels of $43^{\circ} 50^{\prime} \mathrm{N}, 44^{\circ} \mathrm{N}, 44^{\circ} 10^{\prime} \mathrm{N}, 44^{\circ} 20^{\prime} \mathrm{N}, 44^{\circ} 24^{\prime} \mathrm{N}$, $44^{\circ} 30^{\prime} \mathrm{N}, 44^{\circ} 34^{\prime}, 44^{\circ} 40^{\prime} \mathrm{N}, 44^{\circ} 50^{\prime} \mathrm{N}$ and $45^{\circ} \mathrm{N}$. The shallowest point of the seamount lies along the parallel of $44^{\circ} 34^{\prime} \mathrm{N}$. It is soon found that the observed free air anomalies are quite 


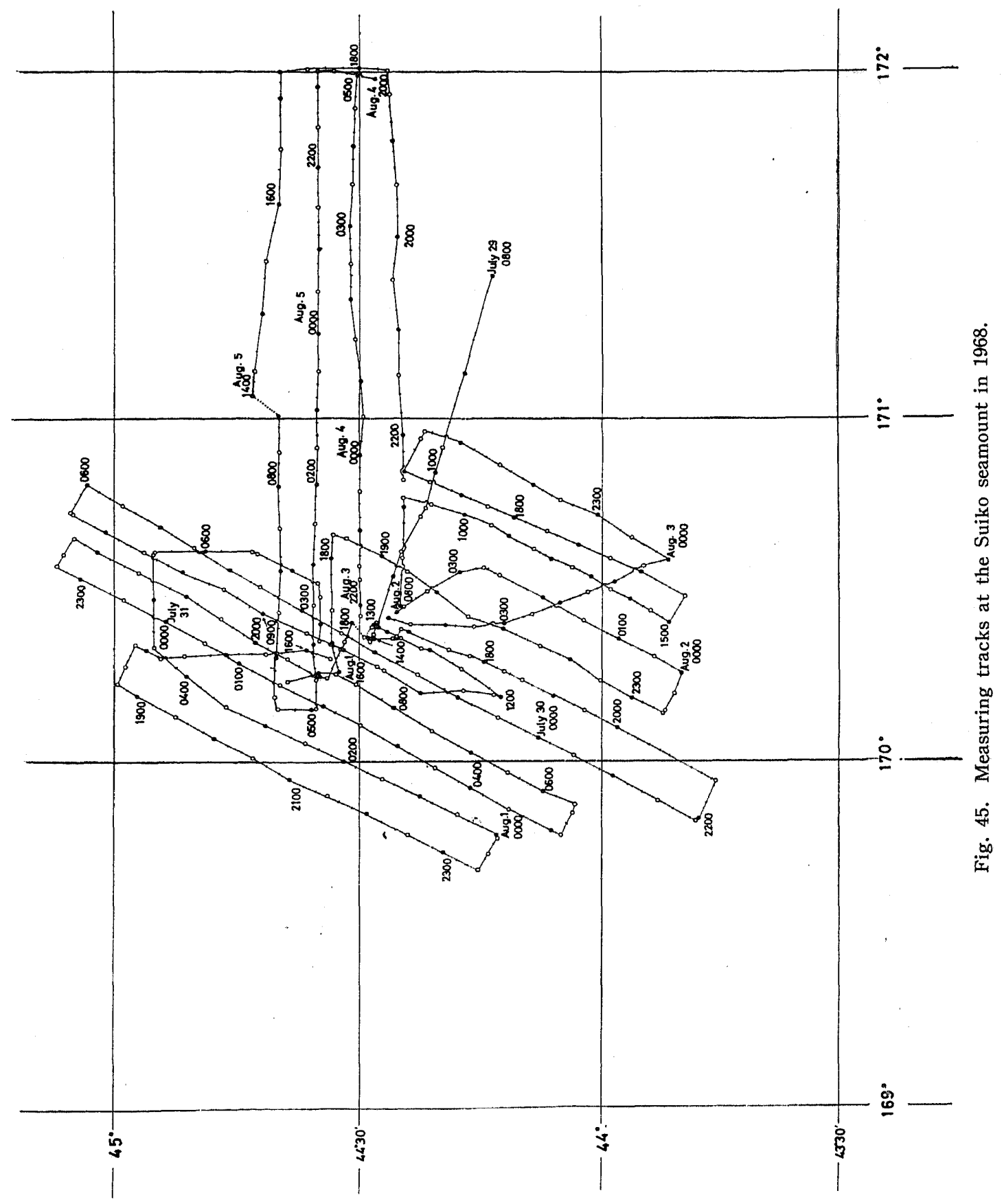




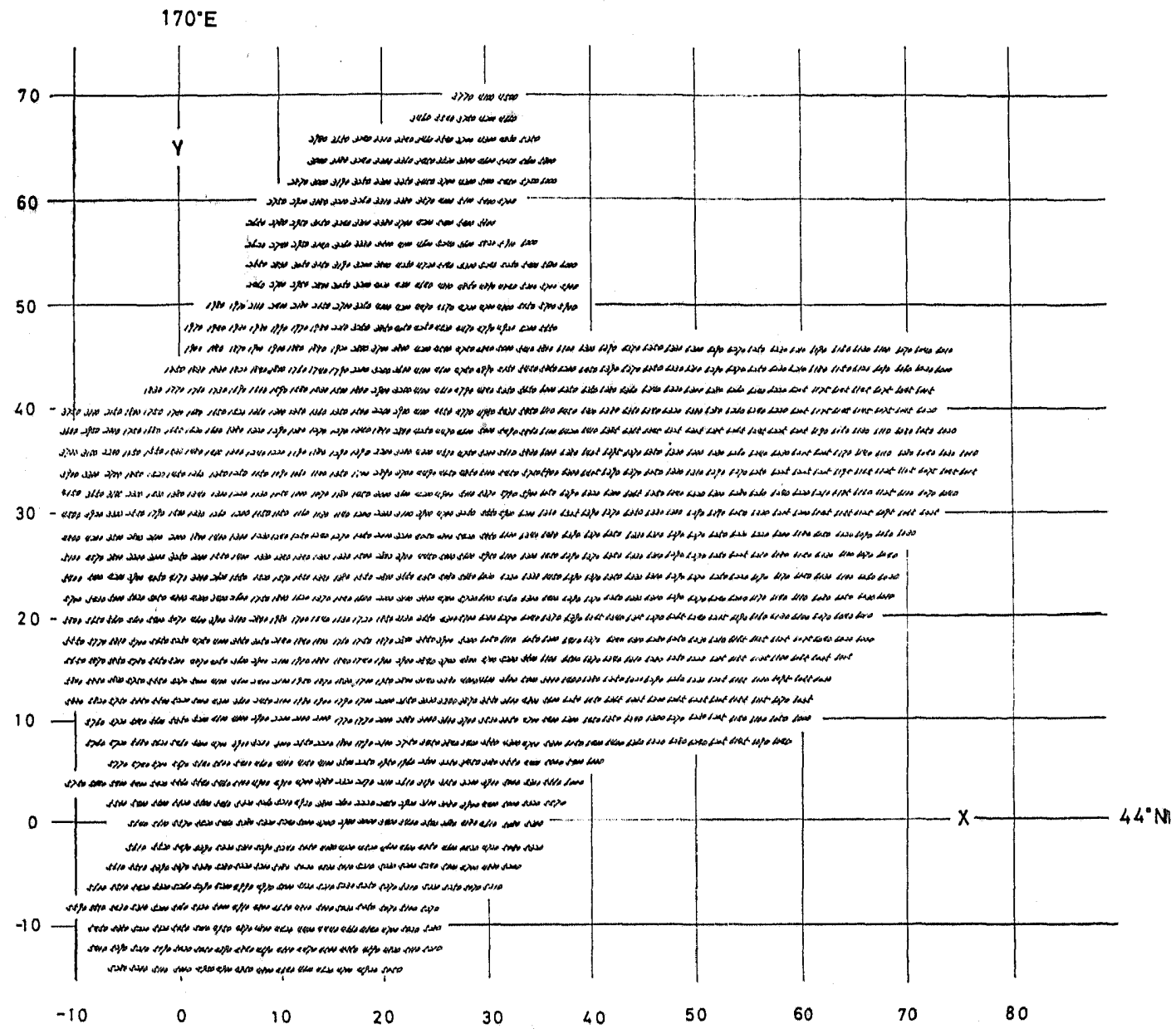

Fig. 46. Mean water depth in meter over meshes of $2^{\prime} \times 2^{\prime}$ at the Suiko seamount.

different from the calculated one. Topography of the Suiko seamount is unsymmetric between east and west. The depth at the foot of the east side is particularly large, showing a depth of $6400 \mathrm{~m}$, whereas it is $5800 \mathrm{~m}$ at the west side. Free air anomalies at the foot of the mountain show negative values; $-80 \mathrm{mgal}$ at the east and $-60 \mathrm{mgal}$ at the west. Free air anomalies near the top of the mountain show a largest value of $340 \mathrm{mgal}$. The negative free air anomalies observed at the foot of the mountain can not be explained unless an isostatic mass beneath the mountain is supposed to exist. The Bouguer gravity anomalies calculated by assuming the density difference to be 1.64 $\mathrm{gr} / \mathrm{cm}^{3}$ show relatively higher values above the top of the mountain. In this respect the Suiko seamount is different from the Brisbane hill.

Gravity Table 6 The Shatsky rise

Note

This table consists of values obtained in 1968 by the observations on board the Hakuhomaru (cruise KH-68-3) (sec. 1-5). The Shatsky rise is located in the northwest Pacific ocean trending from north to south. In Fig. 52 measuring tracks are shown. In Fig. 53 profiles of free air anomalies and calculated Bouguer anomalies with profiles of topography 


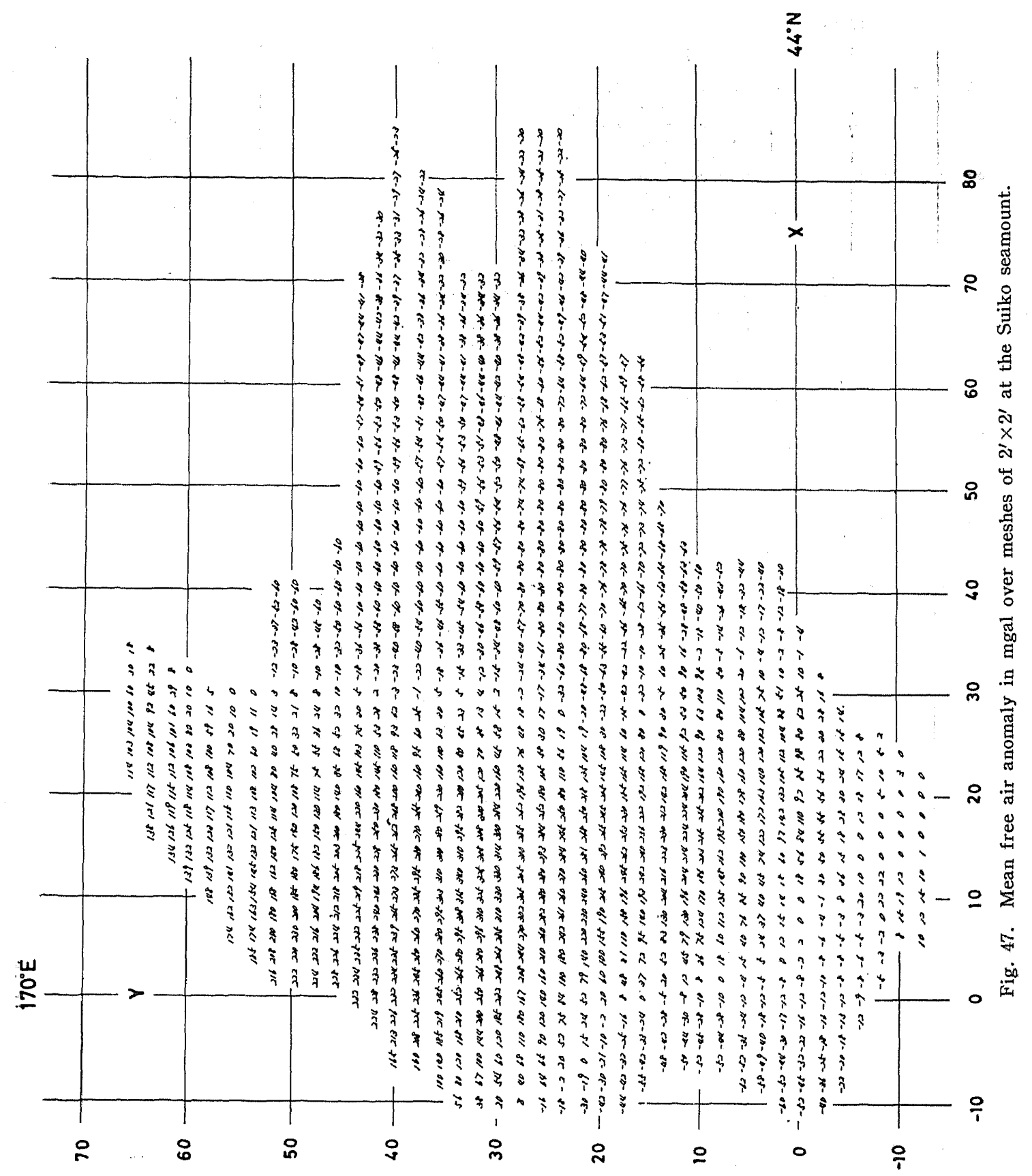




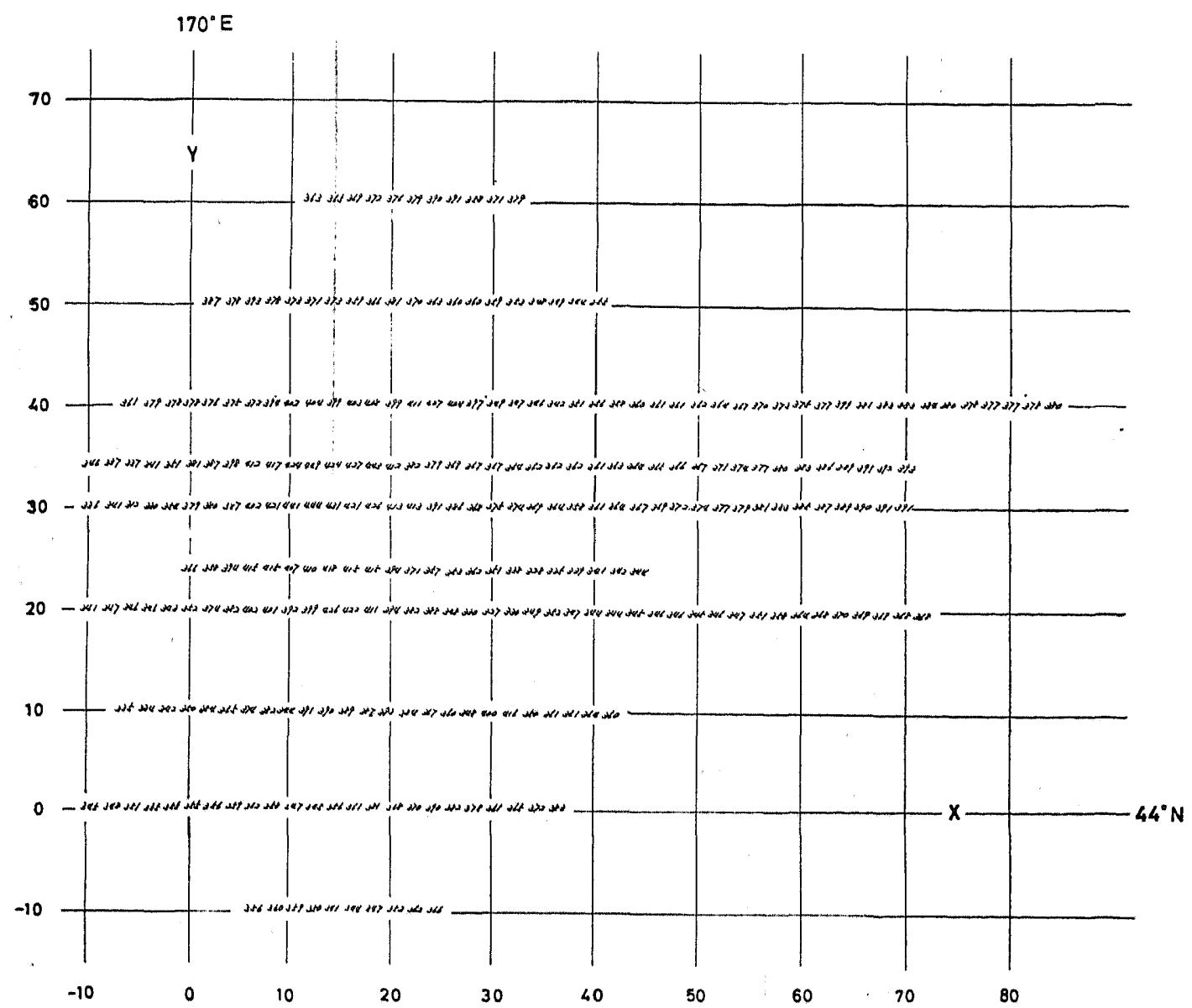

Fig. 48. Mean calculated Bouguer anomaly in mgal over meshes of $2^{\prime} \times 2^{\prime}$ at the Suiko seamount.

are shown (see Appendix 3). At both ends of the profiles the time of measurement is indicated as indices.

\section{Interpretation}

In Fig. 53 topography, free air anomalies and calculated Bouguer anomalies are shown along two tracks, one of which crosses the rise from west to east and the other from east to west. In these measurements it is remarkable that the free air anomalies do not so much increase above the rise. This is probably because of a compensating mass existing beneath the rise. At the foot of the rise relative decrease of free air anomaly by about $10-20 \mathrm{mgal}$ is found as in the case of other seamount, and the region continues in the wide range. Though the height of the rise is not so large its width is four times as large as that of the Brisbane hill or the Suiko seamount. Decrease of Gravity caused by the distance between the rise and the observation points, therefore, is expected to be small.

\section{Gravity Table 7}

\section{The Bismark plateau}

\section{Note}

This table consists of values obtained in 1967 and 1968 by the observations on board the Umitaka-maru (sec. 1-3). The Bismark plateau is a temporary name, which means the area surrounded by the Bismark archipelagoes, making an uplifted region bounded by the Vitiaz trench to the north and by the Solomon trench to the south. In Fig. 54 measuring 


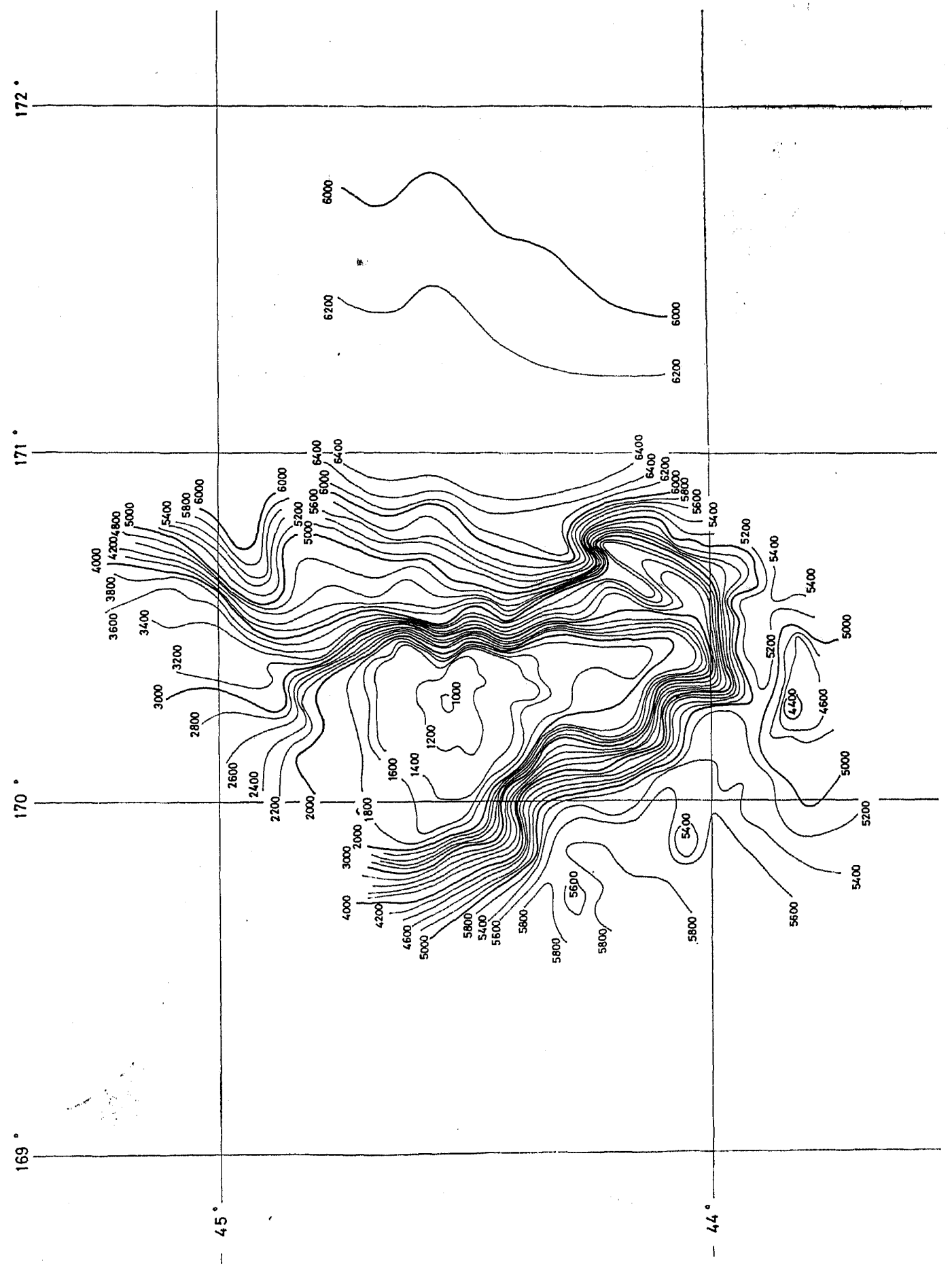


Gravity Measurements at Sea by Use of the T.S.S.G. Part 2.

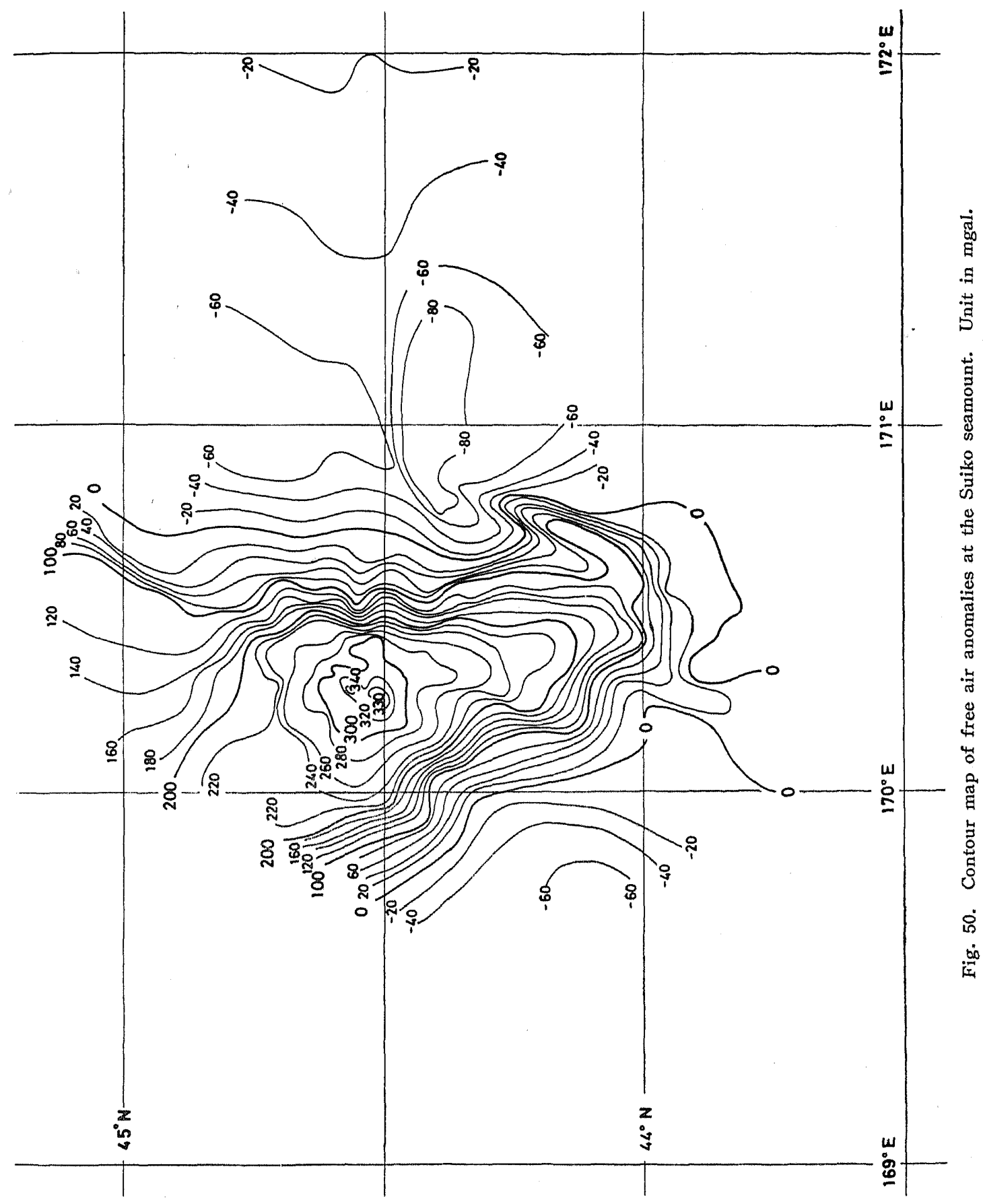



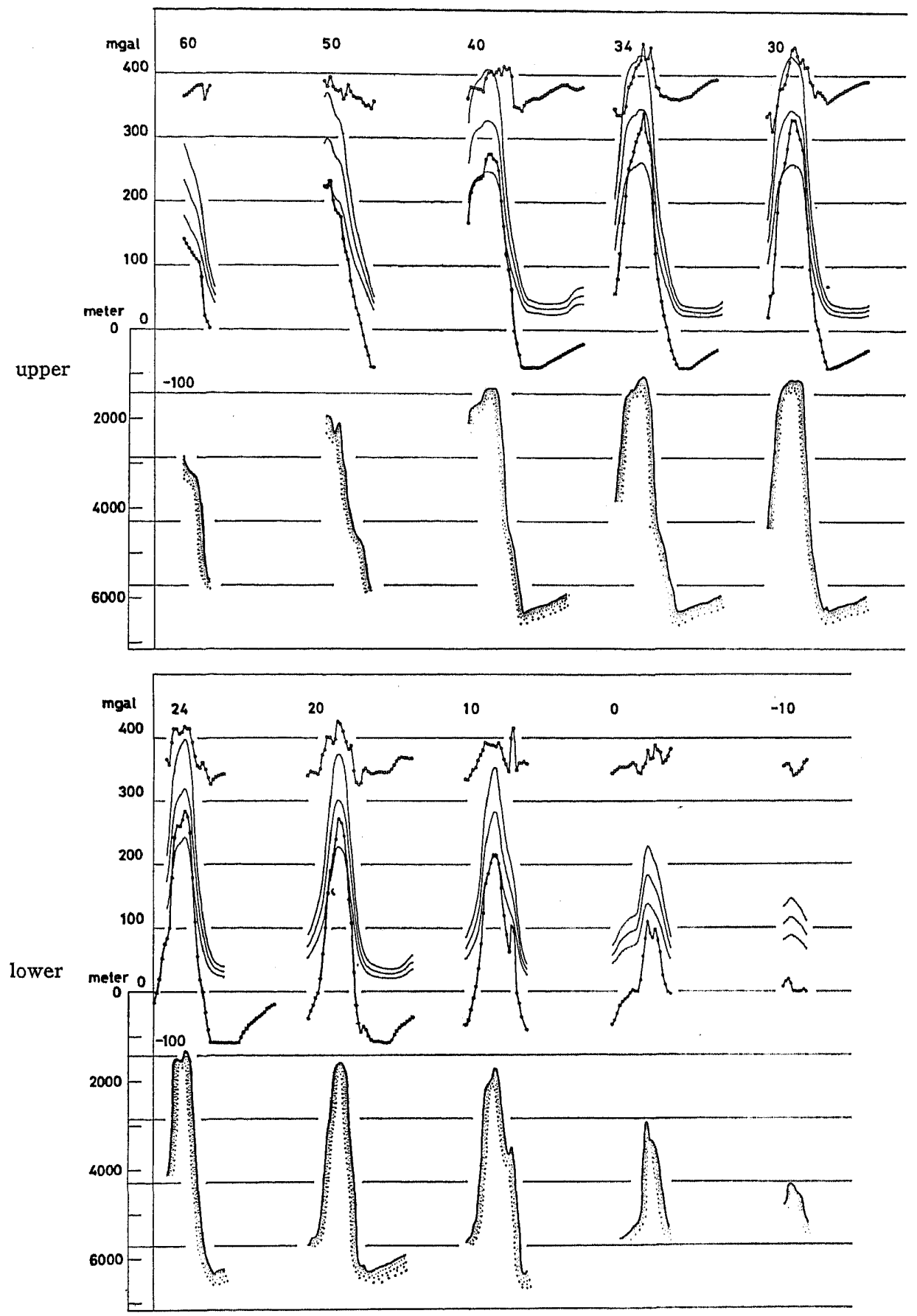

Fig. 51. Profiles of topography, observed free air anomalies, calculated free air anomalies and calculated Bouguer anomalies across the Suiko seamount.

- oberved free air anomaly. — calculated free air anomaly. 0 - calculated Bouguer anomaly.

From left to right; (upper) $45^{\circ} \mathrm{N}, 44^{\circ} 50^{\prime} \mathrm{N}, 44^{\circ} 40^{\prime} \mathrm{N}, 44^{\circ} 34^{\prime} \mathrm{N}, 44^{\circ} 30^{\prime}$ (lower) $44^{\circ} 24^{\prime} \mathrm{N}, 44^{\circ} 20^{\prime}, 44^{\circ} 10^{\prime} \mathrm{N}, 44^{\circ} \mathrm{N}, 43^{\circ} 50^{\prime} \mathrm{N}$ 
Gravity Measurements at Sea by Use of the T.S.S.G. Part 2.

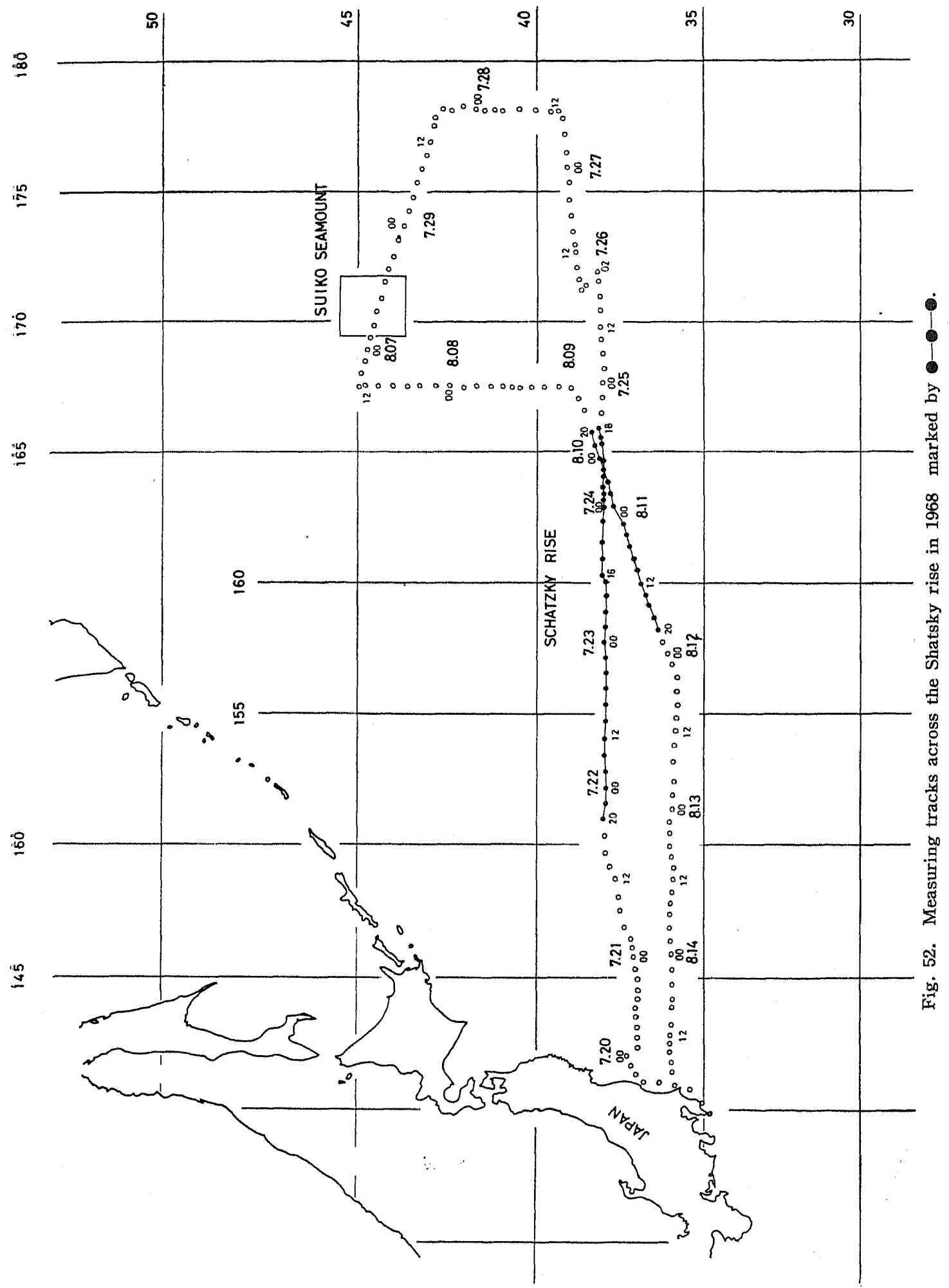


(a)

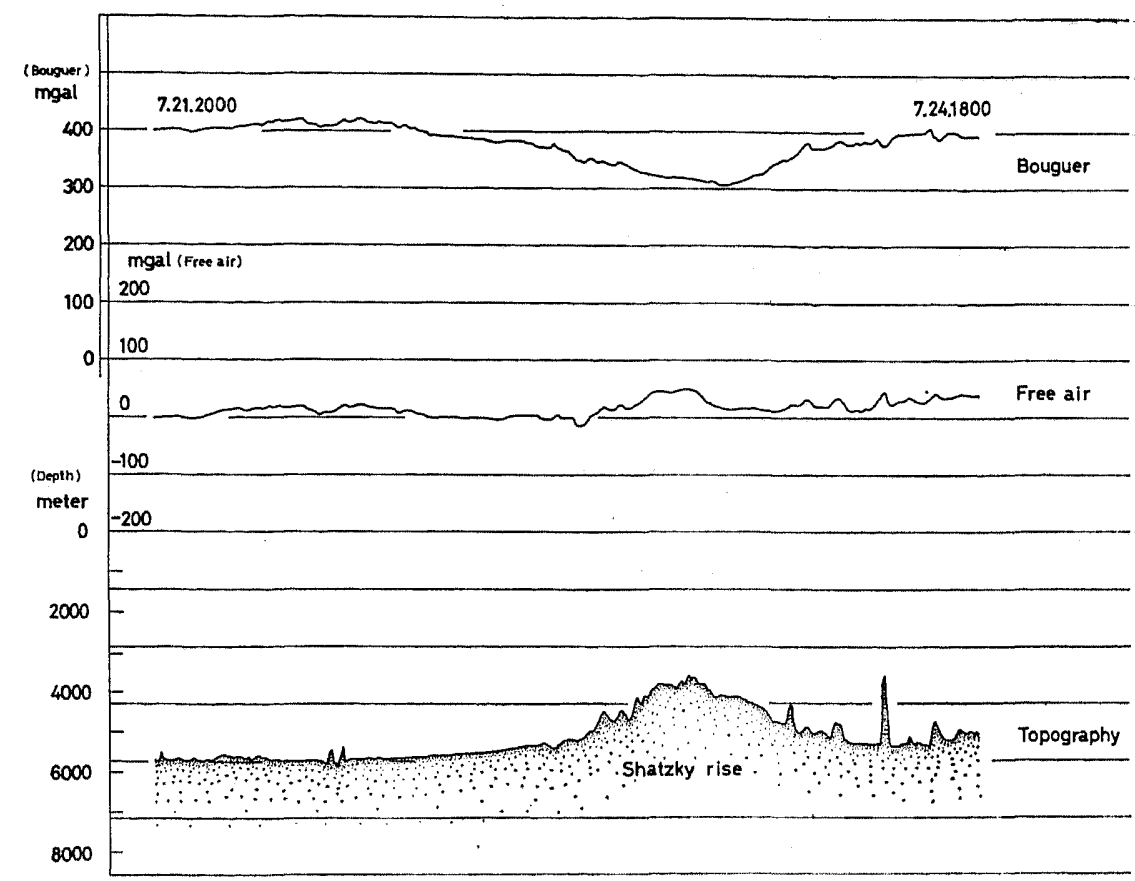

(b)

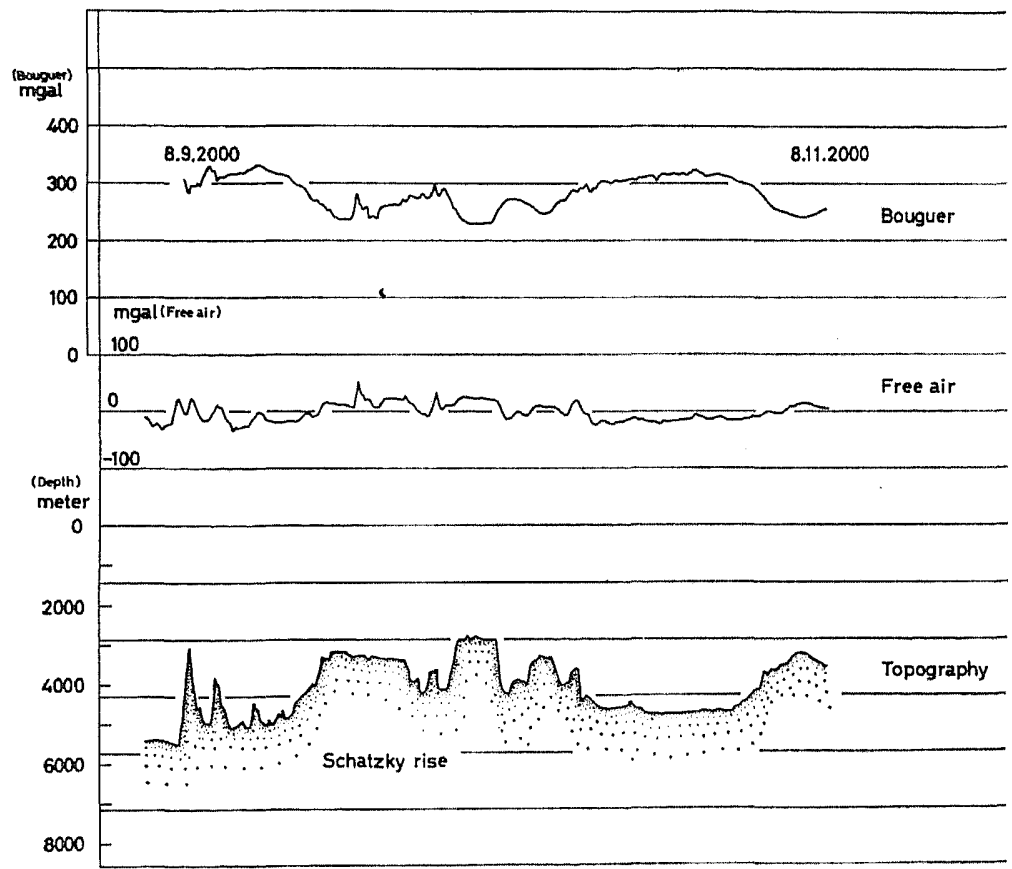

Fig. 53. Profiles of topography, free air anomalies and calculated Bouguer anomalies across the: Shatsky rise (a), (b). 


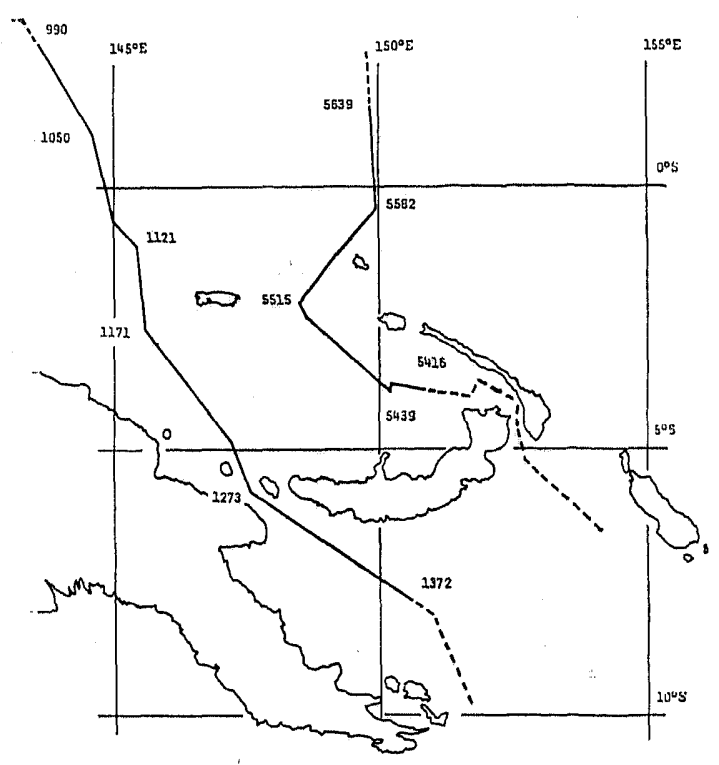

Fig. 54. Measuring tracks across the Bismark archipelago sea in 1967 and 1968.

tracks are shown. In Fig. 55 profiles of free air anomalies and calculated Bouguer anomalies with profiles of topography are shown (see Appendix 3). Numbers indicated in Fig. 54 along the ship's tracks and in Fig. 55 along the profiles are those attached to gravity values found in the table, and can be used as indices. In this figure gravity anomalies measured by submarine observations by use of a Vening Meinesz gravity meter, which are quoted from WORZEL (1965), are plotted also. Though there might be several mile differences in the measured positions agreement of both measurements is supposed to be well.

\section{Interpretation}

In Fig. 55 are shown topography, free air anomalies and calculated Bouguer anomalies along the track from north to south by way of the Vitiaz strait and those values along the track from south to north by way of St. George strait. Averaged free air anomalies in the Bismark plateau, of which the averaged depth is about $2000 \mathrm{~m}$, show positive values of about $40-50 \mathrm{mgal}$. Conspicuous negative free air anomalies are observed at the Vitiaz trench locating at the north end of the plateau as well as at the Solomon trench locating at the south end. Moreover the free air anomalies appear scarcely correlated to the topography above the plateau, implying that there exist complicated subsurface structures. It seems that the Bismark plateau has been subjected by as large tectonic activities as the Japan island and the vicinity.

\section{§3. Summary of Part 1 and 2}

In 1961 a surface ship gravity meter was developed by Tomoda et al at the Geophysical Institute, University of Tokyo. This was named Tokyo Surface Ship Gravity Meter or the T.S.S.G. Gravity measurement at sea was first made in success by Vening Meinesz of Holland in 1923 by use of a Vening Meinesz pendulum on board submarines. Measurement on surface ships had been unsuccessful until 1950's when the La Coste and the Askania surface ship gravity meters appeared. Both of these gravity meters are of the spring type. Gilbert in England, on the other hand, developed a string type gravity meter in 1948, and Lozinskaya in Russia also tried the same type gravity meter in 1949. But it is reported that these gravity meters did not work well as a surface ship instrument to measure gravity under general sea conditions. The T.S.S.G. followed the preceding works and was successfully used, as a first trial, for surface ship measurement under rough sea conditions. These three types of gravity meters consist of a single string tensioned vertically, though the ways of suspension are somewhat different with one another. A string type gravity meter equipped with two strings was tested by $\mathrm{C}$. G. Wing of the Massachusetts Institute of Technology in 1966 (WING 1969), and one equipped with three strings was tested also and now is used by the Geographical Survey Institute of Japan.

A string type gravity meter is characterized by small size, digital output and wide dynamic range. These characteristics have made it easy to make use of electronic computers, which are making progress year by year, to 


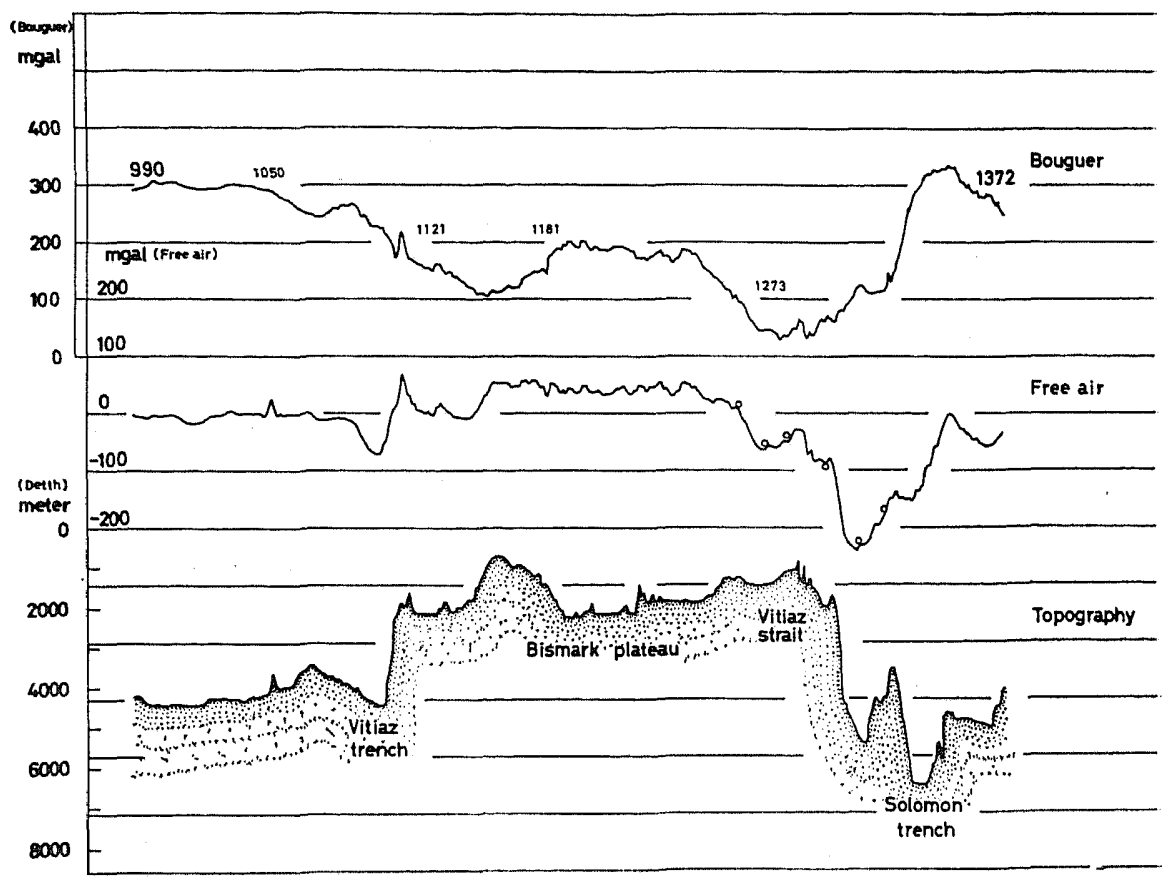

(a)

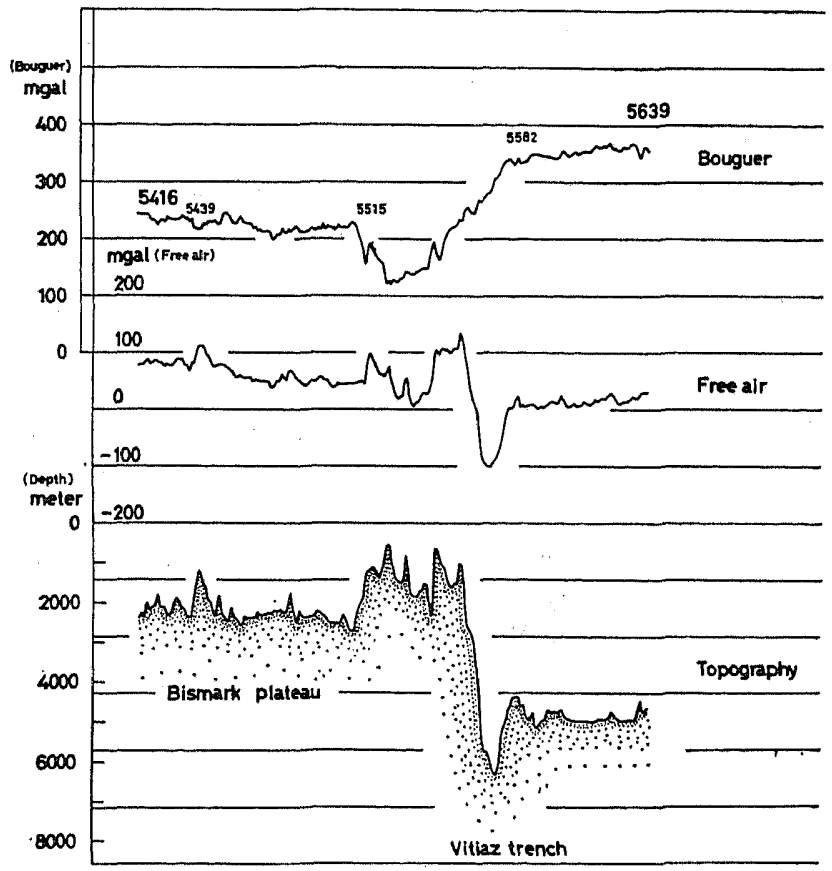

(b)

Fig. 55. Profiles of topography, free air anomalies and calculated Bouguer anomalies across the Bismark archipelago sea (a), (b). O-- gravity measured by Vening Meinesz pendulum. 
obtain $10^{-6}$ relative accuracy. In addition, the T.S.S.G. is composed of exclusively unmovable parts. As is the case of the La Coste's or Askania surface ship gravity meter the meter which has movable beams are likely to be subjected by cross coupling errors caused by the coupling of vertical and horizontal accelerations according to the way of response of the movable beams. The T.S.S.G. is free from such errors.

The verticality of the measuring axis of the T.S.S.G. is maintained by a vertical gyroscope. It is assured that the verticality is $10^{\prime \prime}$ in the short term accuracy and $4^{\prime}$ in the long term accuracy. Fluctuation of the vertical, if it is coupled with horizontal accelerations, produces a large amount of error, but in the actual measurement the error is not affected by the intensity of horizontal accelerations, and shows variation of merely several mgals. This is an evidence that the fluctuation of the vertical in phase with the horizontal accelerations is more or less $10^{\prime \prime}$ in the short term. The accuracy in the long term, on the other hand, can be cheked by a pair of damped bubble tubes, and $4^{\prime}$ accuracy assures $1 \mathrm{mgal}$ accuracy of gravity values.

Though the T.S.S.G. is endowed with various merits mentioned above the nature of the meter has not been completely understood. The first part of this paper is devoted to the description of the nature of the meter and the improved methods of data processing to enhance accuracy of measurement.

Gravity measurements by use of the T.S. S. G. between 1961 and 1969 have been made by the Ocean Research Institute, University of Tokyo and the Hydrographic Office, Maritime Safety Agency. The length of time expended for the measurements aboard totals more than 1000 days and the measured distance amounts to 200,000 miles. The author himself participated in the surveys over 600 days, in which improvement of the data processing methods as well as actual surveys was carried out. A measurement on board the Hakuhomaru carried out in 1969 is worthy of special mention, when it was assured that the instrumental difference of two sets of the T.S.S.G. operated quite independently was less than \pm 3 mgal. Such data were obtained on real time basis by the aid of an electronic computer equipped in the ship for process control.

As to the characteristics of the meter we study deviations of a string in use from an idealized string. The detector of the T.S. S. G. (the dynamic gravity meter) is tensioned by a weight attached to the lower end and supported sideways horizontally by a pair of leaf springs in order to prevent it from swinging. It is difficult to eliminate slight bendings from these springs, which exert initial tension to the vertical string. Furthermore, intrinsic elasticity of the string can not be neglected especially with a detector designed small.

In various papers the following equation is adopted as a fundamental relation which holds for the string gravity meter.

$$
g(t)+\alpha(t)=k[f(t)]^{2}
$$

where $g(t), \alpha(t)$ and $f(t)$ are gravity, ship's vertical acceleration and frequency of the string expressed as functions of time. For the present T.S.S.G. this equation does not sufficiently represent the state of the detector. New relation required in the T.S.S. G. should be

$$
g(t)+\alpha(t)=k[f(t)-\sigma]^{2}-a_{c}
$$

where $\sigma$ is frequency due to elasticity of the string, with which the string vibrate with no tension acting on it, and $a_{0}$ is initial tension expessed in terms of acceleration. $f$ and $\sigma$ are, for example, $2000 \mathrm{~Hz}$ and $40 \mathrm{~Hz}$, respectively. $a_{0}$ shows values ranging from $\pm 20 \sim \pm 100$ gal. Unless the effect of elasticity is taken into account the measured gravity will suffer from errors of $10 \sim 100 \mathrm{mgal}$.

The largest unavoidable difficulty with which we meet in operating the string gravity meter is the 2nd order correction originating from intermittent measurements of frequency. This correction is made to compensate for the decrease of averaged acceleration if it is calculated from squares of averaged frequency. It has been known that the correction is approximately proportional to dispersions of the ship's vertical acceleration, but the co-efficient 
of proportion could not exactly be determined. We deal with this problem by examining data obtained in the actual measurement. The results are

[1] It is most reasonable to interpolate data of frequency measured intermittently over the sampling interval by use of, say, the 4th order polynomials in order to obtain the 2nd order correction, provided that the period of ship's vertical acceleration is $3 \sim 8$ sec and that the sampling interval of frequency or period of the string is about $0.5 \mathrm{sec}$. This method meets the conditions required when the variation of ship's motion is of complex spectra and the spectral distribution varies with time.

[2] The actual 2nd order effects are always larger than those expected from an idealized relation (1) of the string. This question has been explained from the standpoint of elasticity; residual frequency caused by the elasticity of string $\sigma$ produces the 1st order term with respect to $f$ which, if neglected, causes an apparent 2 nd order effect independently of but in phase with the 2nd order effect due to the sampling interval.

In the second part of the paper we describe the process of measurements and their results. Of the gravity measurements which were made by the author those measurements made in the period from 1966 to 1969 have been selected and described in detail. As the results of measurement the following regions, in which the author is most interested from tectonical point of view, are particularly picked up and discussed: The Japan trench and its vicinity, the Mariana trench, the Solomon trench, the Bismark archipelago sea, the Shatsky rise, the Suiko seamount and Brisbane hill. Gravity values over these areas are all tabulated.

It is found from the distribution of free air gravity anomaly over the Japan trench that a line connecting points of minimum free air anomaly lies by about 10 miles apart from the trench axis towards Honshu. This rule does not hold, however, in case of all trenches, implying a peculiarity of the Japan trench that it is accompanied with sudden thickening of crust just beneath the slope of continental side. The free air anomalies are lower at the north and south of the trench compared with those of the middle part. The minimum value amounts to -200 mgal. Judging from the fact that the water depth is shallower at the middle part and that no differences are found in the Bouguer anomaly distribution, sediments or sedimentary rock may be particularly thick at the middle part of the trench.

There are regions of large negative Bouguer anomaly west and east of the Erimo peninsula of Hokkaido. The west negative region was first found by MATSUYAMA et al. in 1934, and the east negative region was found by the author. These anomalous regions are extended over from the land of Hokkaido, and appear as if they agree with extensions of the tertiary or quarternary layers existing at both sides of the Hidaka mountains.

A region of high free air anomaly over $+150 \mathrm{mgal}$ is found at the north east of Honshu. This positive area extends eastwards over the continental shelf. The area of maximum Bouguer anomaly lies at the side of continental shelf.

In the Mariana and Solomon trench we have obtained gravities along one track with each. At both of these trenches minimum free air anomaly is found just above the trench axis. The deepest point at the Mariana trench is $9600 \mathrm{~m}$ (Nero deep) where the free air anomaly is $-230 \mathrm{mgal}$, and the deepest point at the Solomon trench is $7900 \mathrm{~m}$ where the free air anomaly is $-280 \mathrm{mgal}$. Both trenches are much larger in scale compared with the Japan trench. The thickening of crust occuring towards the continental sides (the side towards the Mariana islands or the Solomon islands) seems to be made more gradually at these trenches than at the Japan trench.

Distributions of free air anomaly at the Brisbane Hill and the Suiko seamount indicate that they are all more or less isostatic. It is an evidence from which we have got the results that observed free air anomalies are very different from calculated free air anom- 
alies obtained on the assumption of complete non-isostasy. The difference is characterized by a local decrease of gravity around the foot of the mountains. Owing to the lowering of gravity the free air anomaly indicates negative values of $-60 \sim-80 \mathrm{mgal}$ at the Suiko seamount and of $-50 \mathrm{mgal}$ at the Brisbane Hill. At the Shatsky rise which is of larger scale than the former the relative lowering of gravity is also found around it, of the magnitude of $10 \mathrm{mgal}$. If we try to get a mean density of the mountains by forcibly fitting the observed anomaly to the calculated one by use of the least square method we have a mean density of about 2.3 $\mathrm{gr} / \mathrm{cm}^{3}$, which is too small for the density of rock composing the mountains.

There are measurements along two tracks in the Bismark archipelago sea. Distributions of gravity anomaly in this region imply how complex its subsurface structure is. This area surrounded by the New. Ireland island, New Britain island and New Guinea is accompanied by two trenches, the Vitiaz trench to the north and the Solomon trench to the south, and makes a plateau of the depth of $2000 \mathrm{~m}$. The free air anomaly in this plateau is as an average $+50 \mathrm{mgal}$. Its variation is scarcely related to the bottom topography. The negative free air anomaly found near the Vitiaz strait is conspicuous, and the same tendency of the anomaly is found also at the St. George strait between the New Britain and the New Ireland islands. The bottom of the Bismark archipelago sea may have been uplifted by a certain force uniformly over all the region which had originally been of the isostatic composition.

\section{Acknowledement}

The author wishes to express his thanks to Professor Y. Tomoda of the Ocean Research Institute, University of Tokyo, for the encouragement and advices.

\section{Appendix 1}

Calculation of Bouguer corrections in three dimensional case

Calculated Bouguer corrections are obtained

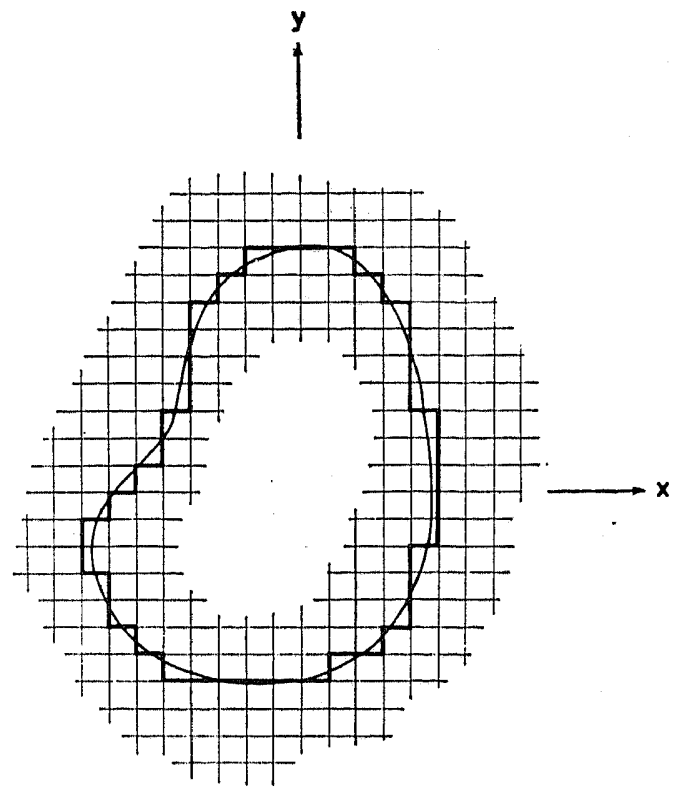

Fig. 56.

from the bottom topography by three dimensional calculations of the effect of water layers. To make three dimensional calculations of the gravitational attraction a modified Talwani's method (TALWANI and EWING, 1960 and SEGAWA, 1969) is used.

With the assumption of uniform density the gravitational attractions of a three dimensional body can be obtained by a surface integral over whole surface of the body, which can be further simplified by dividing the body into a group of thin plates where the integral is converted to summation of line integrals along rims of the plates. If the plate is substituted by a body of simpler form, which is rimmed by portions of straight line perpendicular to each other (Fig. 56), contribution of the plate in gravitational attractions is expressed as

$$
\begin{aligned}
& g_{j}=k^{2} \rho h_{j} \sum_{n=1}^{N_{j}}(-1)^{n-1} \\
& \times \tan ^{-1} \frac{\left(x_{n}-X\right)\left(y_{n}-Y\right)}{\left(z_{j}-Z\right) \sqrt{\left(x_{n}-X\right)^{2}+\left(y_{n}-Y\right)^{2}+\left(z_{j}-Z\right)^{2}}} \\
& \text { A-1-1 }
\end{aligned}
$$

where co-ordinates $x, y, X$ and $Y$ are placed in horizontal planes, $z$ and $Z$ are placed vertical, and 


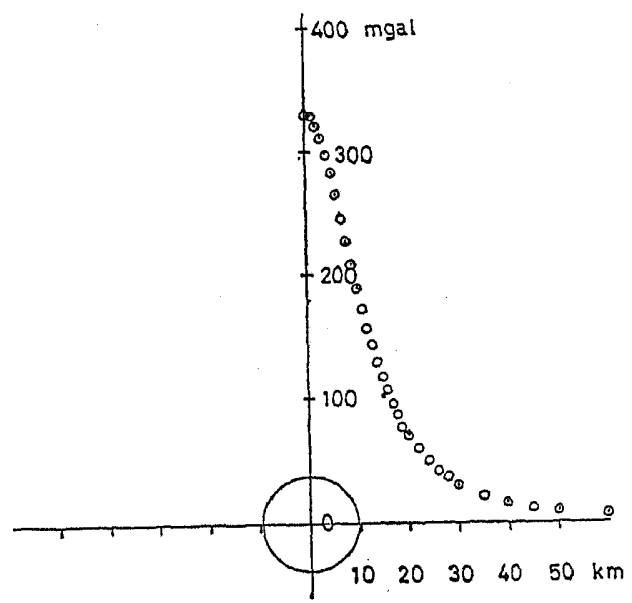

Fig. 57.

analytical values

- numerically calculated values

$g_{j}$; vertical attraction of the $j$-th plate

$k^{2}$; universal constant of gravitation

$\rho$; density of the body

$h_{j}$; thickness of the $j$-th plate

$N_{j}$; number of vertices on the $j$-th plate

$X, Y, Z$; position where the gravitational attraction is observed

$x_{n}, y_{n}, z_{j}$; position of the $n$-th vertex on the $j$-th plate

Hence the vertical attraction of all the plates is given by numerical integration with respect to $j$ as

$$
g=\sum_{j=1}^{m} W_{j} g_{j}
$$

where $m$ is the number of the plates, and $W_{j}$ is a weight function according to the Newton-Cotes' numerical integration. Legitimacy of this method has been checked by applying it to a sphere of $10 \mathrm{~km}$ in radius, when vertical attractions have been calculated on a horizontal line $15 \mathrm{~km}$ distant from the center of the sphere and passing above the center, by dividing the sphere into 20 horizontal plates of $1 \mathrm{~km}$ thick, enclosed by portions of straight line with the shortest length of $1 \mathrm{~km}$. The result is shown in Fig. 57 . Comparison with the result of analytical calculation shows differences less than several milligals.

\section{Appendix 2-1}

Calculation of Bouguer corrections at the Japan trench and its vicinity

Mean contributions of water layer have been calculated with each mesh of $10^{\prime} \times 10^{\prime}$ in extent to be used for Bouguer corrections to the values corresponding to the area. An area is taken which is enclosed by parallels of $35^{\circ} \mathrm{N}$ and $44^{\circ} \mathrm{N}$ and meridians of $140^{\circ} \mathrm{E}$ and $148^{\circ} \mathrm{E}$. Let the water layer involved in it be divided by 17 horizontal surfaces of the depth of $0,200,500,1000,1500,2000, \ldots 7000$ and $7500 \mathrm{~m}$. A chart No. 6301 published by the Hydrographic office is used as a base of the bottom topography and contours corresponding to the respective depth are approximately traced by use of straight lines perpendicular to each other, some of which are parallel to the parallels and others to the meridian. The shortest sides of the polygon drawn in this way are $5^{\prime}$ in both latitudinal and longitudinal direction. The real length of the shortest side is however longer in the longitudinal direction than in the latitudinal direction. Then positions of vertices of the polygons are read. Assuming the density difference between water and crust to be 1.64 $\mathrm{gr} / \mathrm{cm}^{3}$ the calculated Bouguer corrections can be obtained according to equations A-1-1 and A-1-2.

\section{Appendix 2-2}

\section{Calculation of Bouguer corrections at the Bris- bane hill}

Topography at and near the Brisbane hill is contoured at the interval of every $250 \mathrm{~m}$. So the height of the seamount measured from an assumed basic plane at the depth of 4750 $\mathrm{m}$ is first divided by horizontal planes at distance of every 250 meters, and gravitational contributions due to it are calculated according to the method mentioned in the Appendix 1, when the contours are approximated by polygons consisting of mutually perpendicular sides of which the shortest length is $2778 \mathrm{~m}$. Then the gravitational effect of the seamount is subtracted from that of an infinite horizontal layer of $4750 \mathrm{~m}$ in thickness. In these calculations density dif- 
ferences are assumed to be $1.64 \mathrm{gr} / \mathrm{cm}^{3}$. We can thus obtain calculated Bouguer corrections above the Brisbane hill with the assumption that the water depth surrounding it is $4750 \mathrm{~m}$.

\section{Appendix 2-3}

Calculation of Bouguer corrections at the Suiko seamount

Calculation of Bouguer corrections at the Suiko seamount is made just the same as at the Brisbane hill except for the length of the shortest side of polygons, which in the case of the Suiko seamount is selected to be 1 mile $(1852 \mathrm{~m})$ and depth of the sea surrounding it which is assumed to be $6400 \mathrm{~m}$.

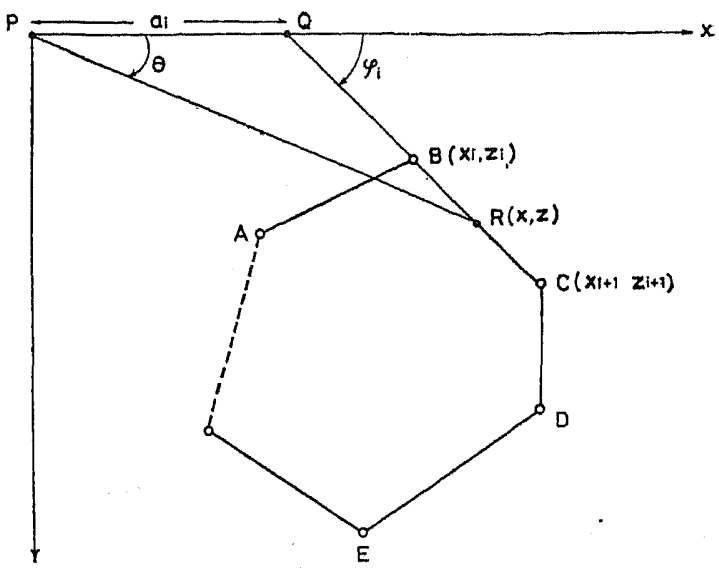

Fig. 58 .

\section{Appendix 3}

Calculation of Bouguer corrections in two dimensional case

Calculation of Bouguer corrections to be applied to two dimensional observations is

made according to Hubbert's method (HUBBERT, 1948) by use of two dimensional observations of water depth.

Supposing a section of a two dimensional body is represented by a polygon ABCD---A

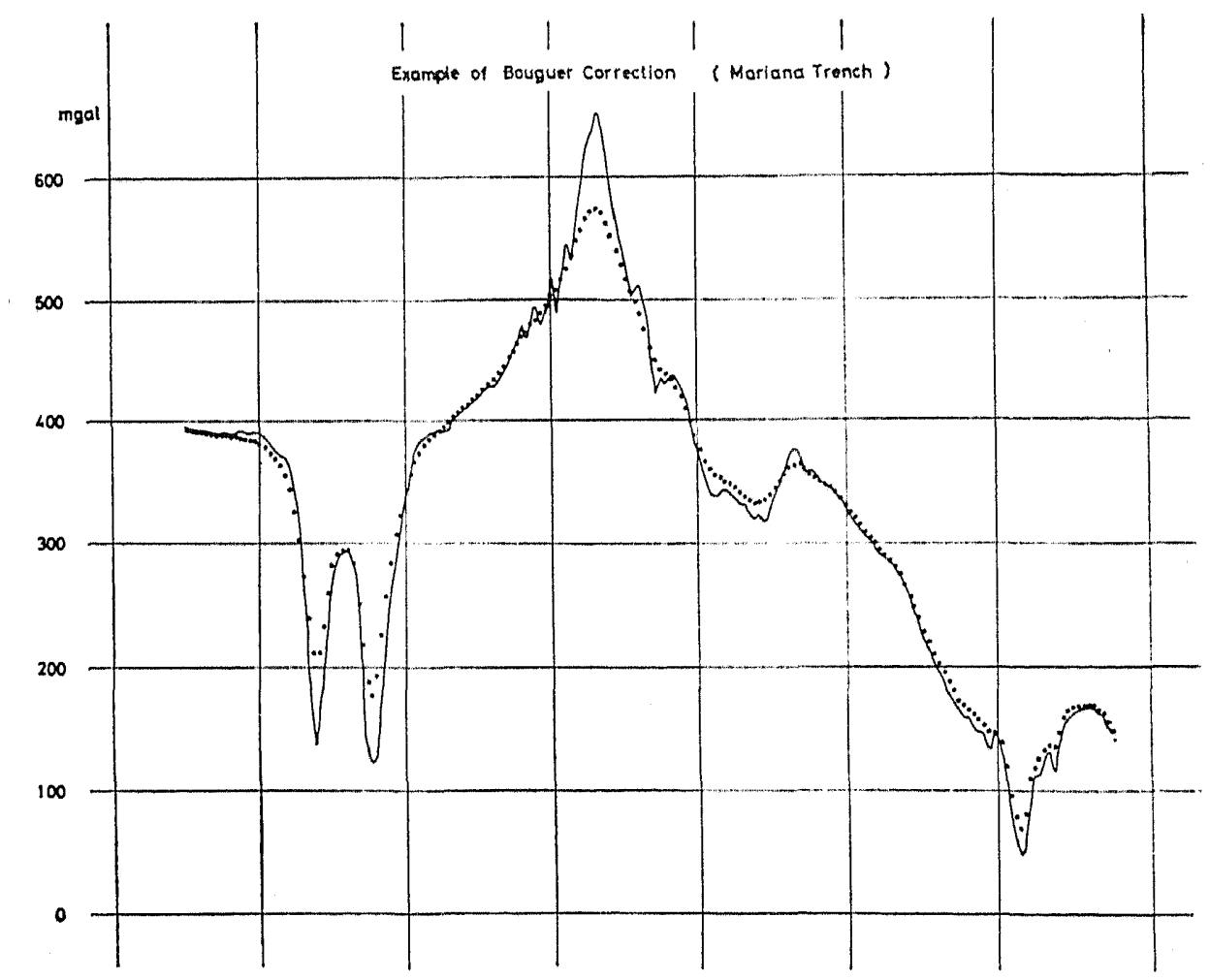

Fig. 59. 
vertical component of the gravitational attraction due to the polygon at point $\mathrm{P}$ is given by the following equation (Fig. 58)

$$
\begin{aligned}
g & =2 k^{2} \rho \oint_{0} r \sin \theta d \theta \\
& =2 k^{2} \rho \oint_{c} z d \theta
\end{aligned}
$$

where $k^{2}$ is a universal constant of gravitation, $\rho$ density of the body and $\oint_{0}$ means a line integral along the rim of the polygon. Though equation A-3-1 holds for a body of general shape it can be more simplified and expressed by only the positions of vertices in the case of polygons.

In the actual calculation of two dimensional Bouguer corrections, sea surface is taken as an upper horizontal side and sea bottom sectioned by points where water depth is measured is taken as groups of the lower sides. Water depth is usually measured at the interval of every 2 to $4 \mathrm{~km}$ distance though it depends on the ship's speed. Left and right sides which are usually taken to be vertical are extended over a little outside the measured area by assuming a certain depth which seems most probable.

Thus Bouguer corrections for the measurements of the Mariana trench, the Solomon trench, the Shatsky rise and the, Bismark plateau have been calculated on the assumption that the observed topography represents cross sections of two dimensional topography. Calculated Bouguer corrections are compared with the simple Bouguer corrections, for example, in the case of the Mariana trench in Fig. 59.

\section{References}

1) Hubbert, M. King, A line integral method of computing the gravimetric effects of two dimensional masses, Geophysics, 13, 215-225, 1948.

2) Kumagai, N., Results of measurements of gravity in Japan and her vicinity, Report of the Japanese Geodetic Commission, New Series No. 4, 1953.

3) Segawa, J., Measurement of Gravity at Sea around Japan (1967) -off South-Western Part of Japan and East China Sea- J. Geodetic Soc. Japan, 13, 53-65, 1968.

4) Segawa, J., Gravity and Sub-bottom Structure of the Ocean, Part 1, Chiky ü Kagaku, 23 (3), 121 131, 1969.

5) Segawa, J., Gravity and Sub-bottom Structure of the Ocean, part 2, Chiky ū Kagaku 23 (4), 153-168, 1969.

6) Segawa, J., Gravity Measurements at Sea by Use of the T.S.S.G. Part 1. Data Processing Method of the T.S.S.G., J. Phys. Earth, 18, 19-49, 1970.

7) Talwani, M. and M. Ewing, Rapid computation of gravitational attraction of three dimensional bodies of arbitrary shape, Geophysics, 25, 203-225, 1960.

8) Tokuhiro, A., On the Digital Data Processing of T.S.S.G., Rep. Hydr. Res. (Japan), 2, 1-12, 1967.

9) Tomoda, Y. and J. Segawa, Measurement of Gravity and Total Magnetic Force in the Sea near and around Japan (1966), J. Geodetic Soc. Japan, 12, 157-164, 1967.

10) Tomoda, Y., Continuous Measurement of Gravity and Magnetic Force in the 4th Southern Sea Expedition of the Umitaka-maru, La Mer (Bull. Soc. francojaponaise d'oceanographie), 5, 175205, 1967.

11) Tomoda, Y., K. Ozawa and J. Segawa, Measurement of Gravity and Magnetic Field on Board a Cruising Vessel, Bull. Ocean Res. Inst., Univ. of Tokyo, 3, 1-170, 1968.

12) Wing, C. G., MIT Vibrating String SurfaceShip Gravimeter, J. Geophys. Res., 74, 58825894, 1969.

13) Worzel, J. L., Pendulum Gravity Measurements at Sea 1936-1959, John Wiley and Sons, New York, London, Sydney, pp 422, 1965.

14) Ocean Res. Inst. Univ. of Tokyo, Preliminary Report of the Hakuho-maru, Cruise KH-68-s edited by Nasu and Tomoda, pp 116, 1968.

15) Ocean Res. Inst. Univ. of Tokyo, Preliminary Report of the Hakuho-maru, Cruise KH-68-4 edited by Horibe, pp 170, 1970.

16) Ocean Res. Inst. Univ. of Tokyo, Preliminary Report of the Hakuho-maru, Cruise $\mathrm{KH}-69-2$ edited by Nasu and Tomoda, 1969 (in press).

17) The Hydrographic Office, Maritime Safety Agency, Japan, Data Report of Hydrographio Observations, Series of Astronomy and Geodesy, No. 4, Sept. 13-45, 1969.

18) The Hydrographic Office, Maritime Safety Agency, Japan, Bathymetric Chart of the Adjacent Seas of Nippon, Sheet 1, No. 6301, 
1966.

19) Geographical Survey Institute, Gravity survey in Japan (1), Gravity survey in Hokkaido district, Bul. Geog. Sur. Inst. Japan, 4, Part 2, 23, 1955.

20) Geographical Survey Institute, Gravity survey in Japan (2), Gravity survey in the Tohoku district, Bul., Geog. Sur. Inst. Japan, 5, Part $3,1,1957$.
21) Geographical Survey Institute, Gravity survey in Japan (3), Gravity survey in the Kanto and Chubu districts, Bul., Geog. Sur. Inst. Japan, 9, Part 3-4, 155, 1964.

22) Geological Survey Institute of Japan, Tectonic Map of Japan 2, Geologic Provinnes, compiled. by H. Isomi, 1965.

(Received April 20, 1970) 


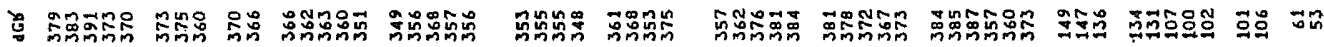

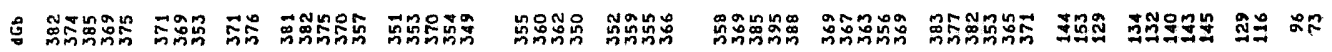

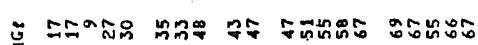
1111111111111111111

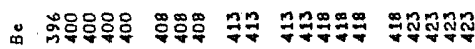

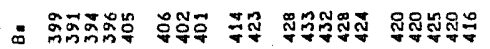

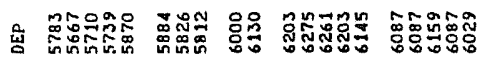

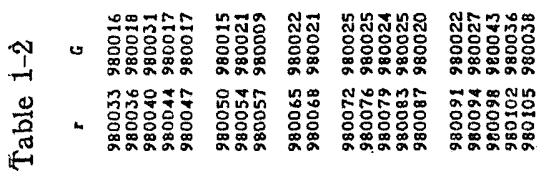

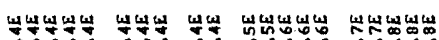

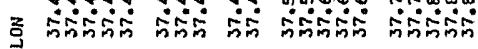
$\ddagger$

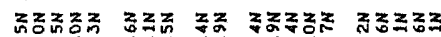

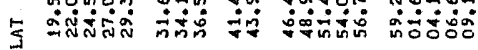
ก

iे

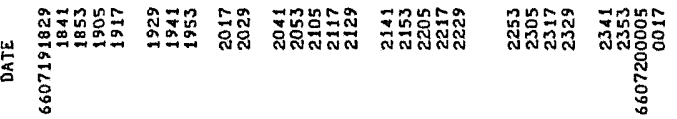

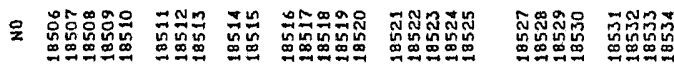

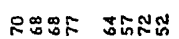

11111111

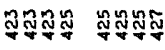

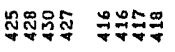

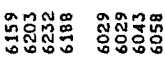

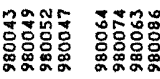

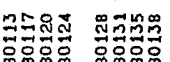

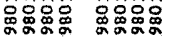

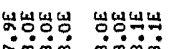

ن்

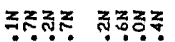

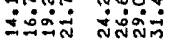

내ํำ

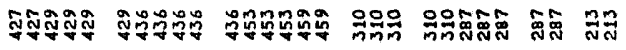

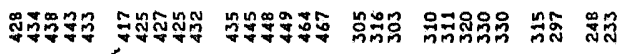

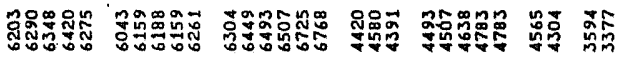

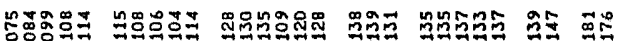

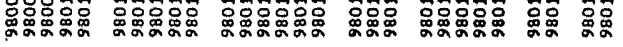

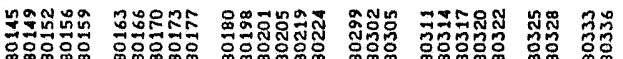

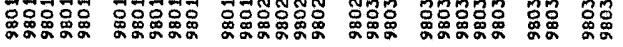

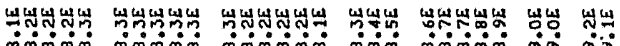

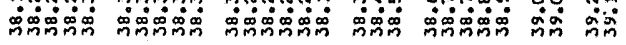

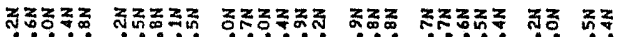

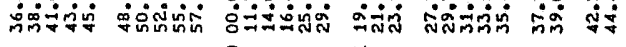

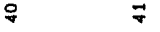

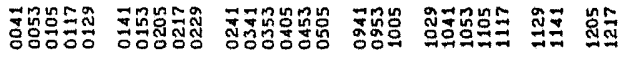

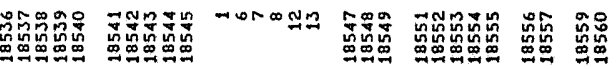

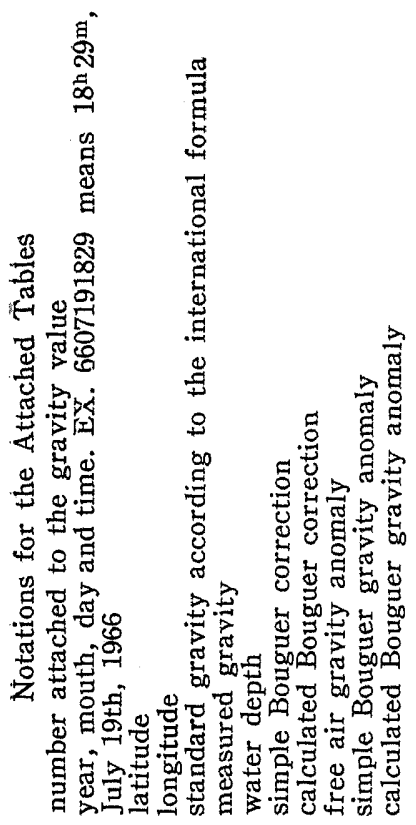

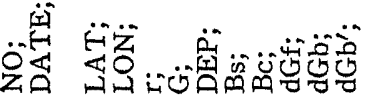

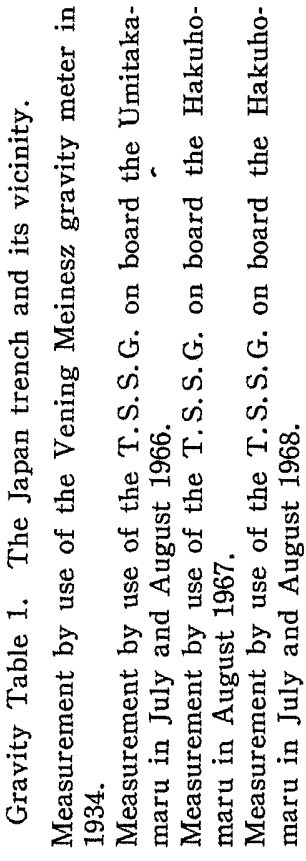

I I $\stackrel{\sim}{\sim} \stackrel{-}{-1}$

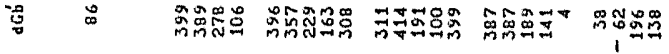

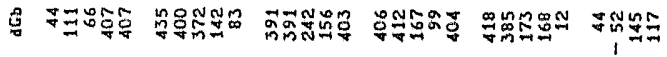

范

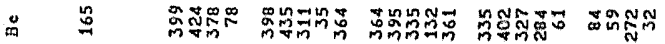

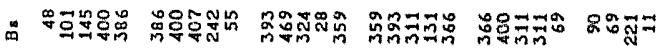

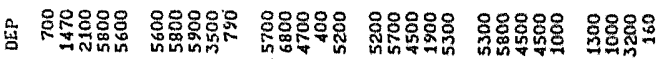

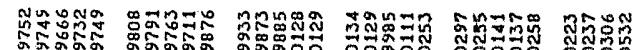

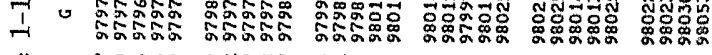

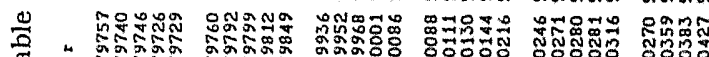

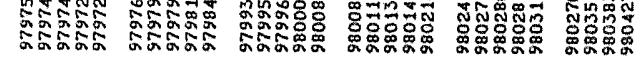

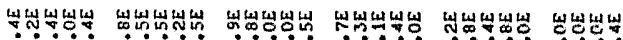

马 คิن

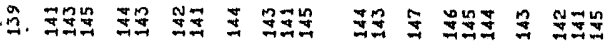

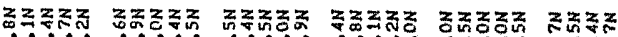

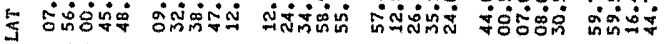

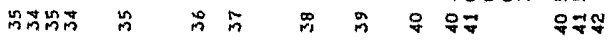

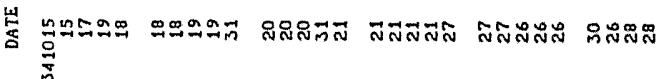

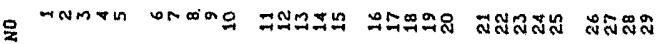


药 号

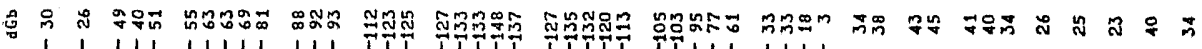

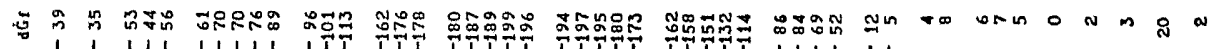

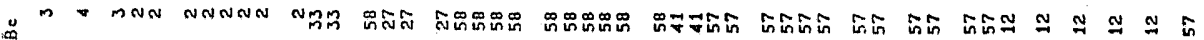

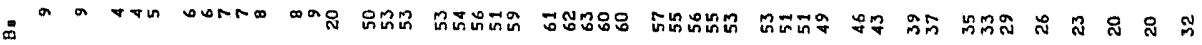

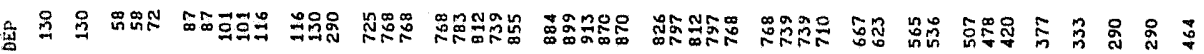

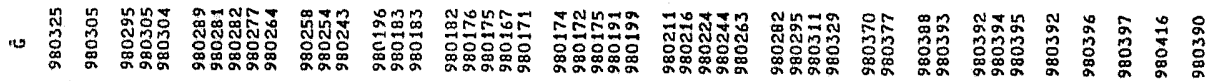

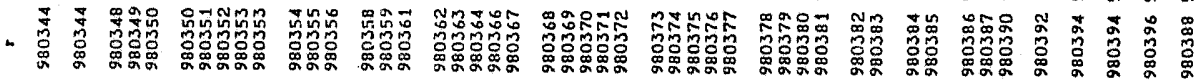

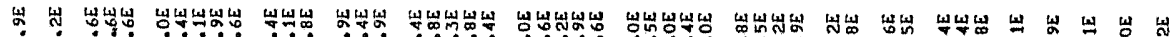
奇 年

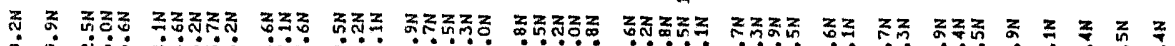

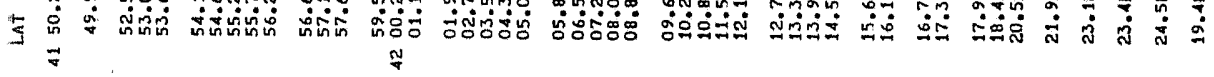

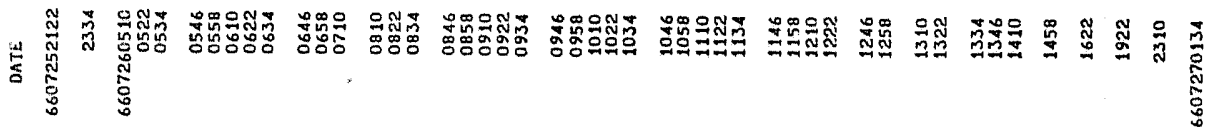

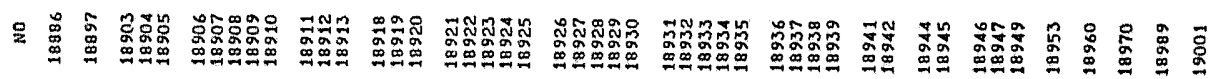

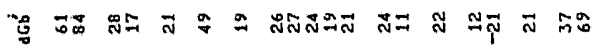
莺

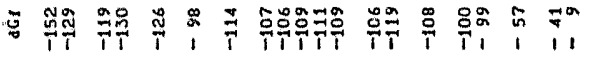

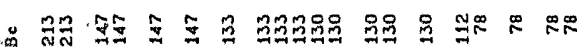
แ

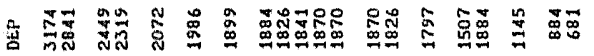

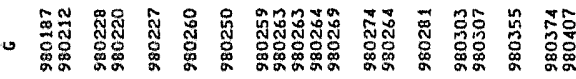

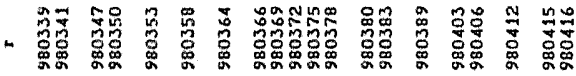

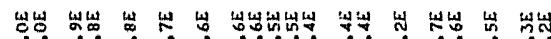

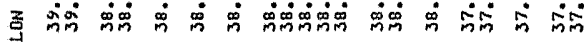

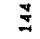

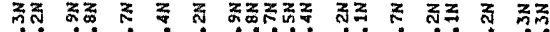

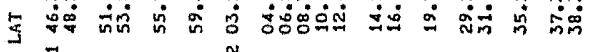

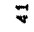
\%

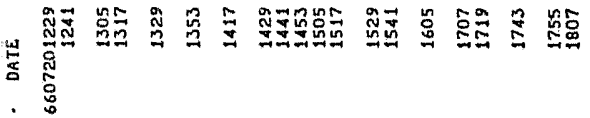

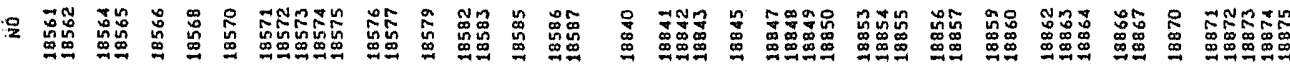

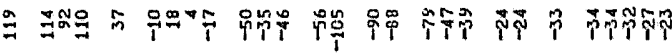

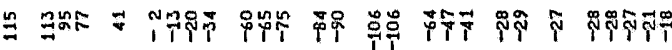

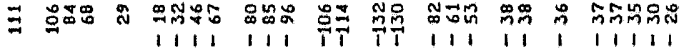

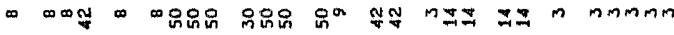

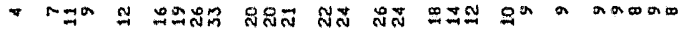

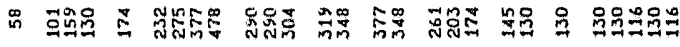

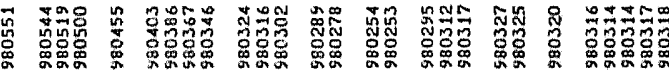

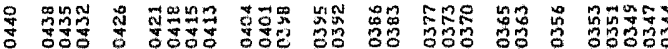

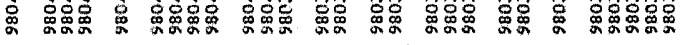

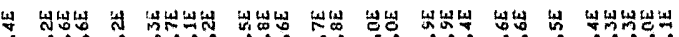

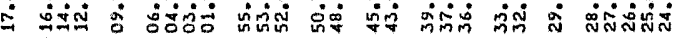
I

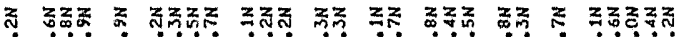

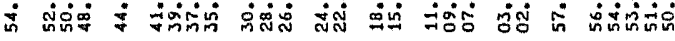
ง

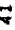

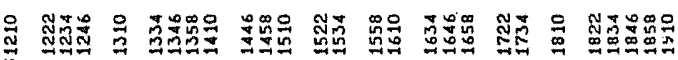
点 


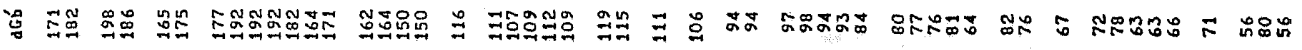

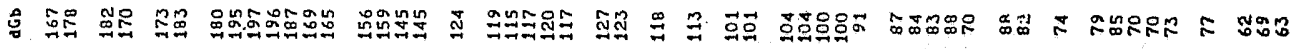

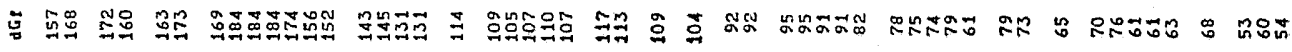
म․

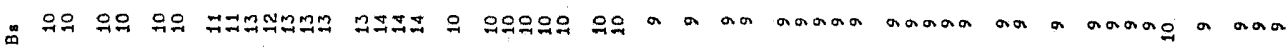

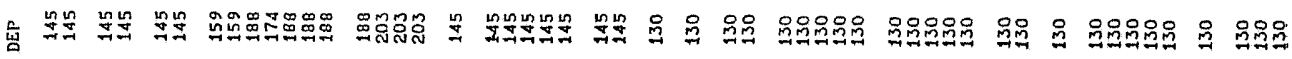

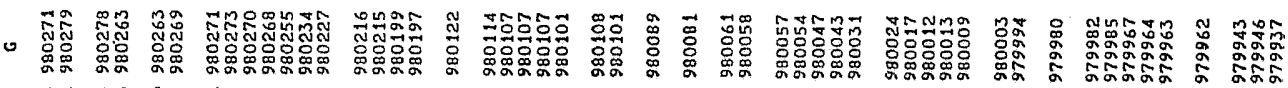

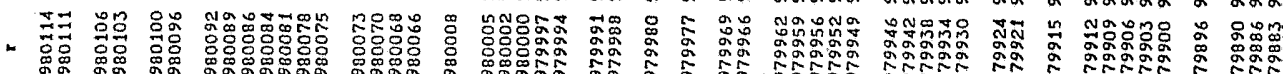

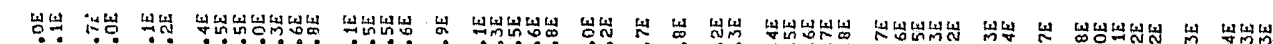

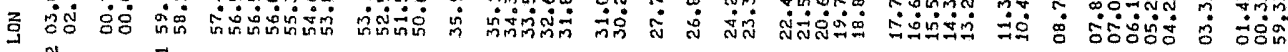
$\stackrel{\ddagger}{\ddagger} \quad \exists$

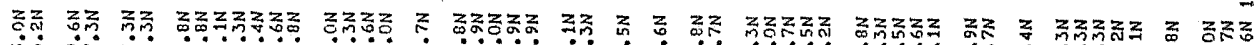

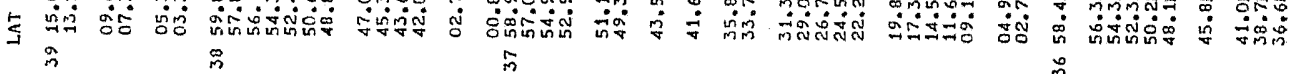
in in in in

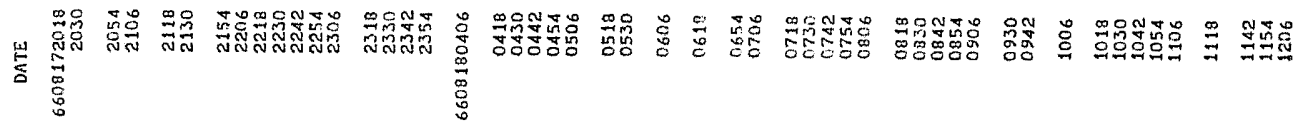

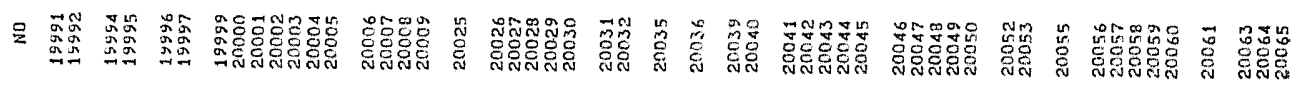

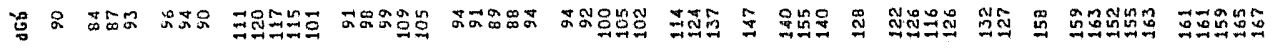

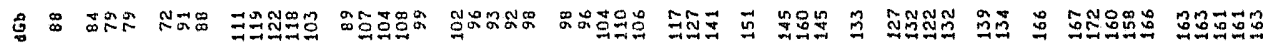

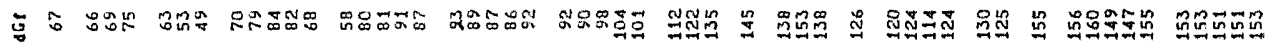

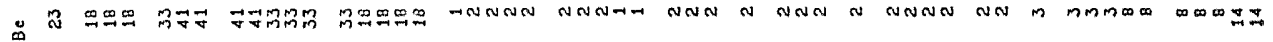

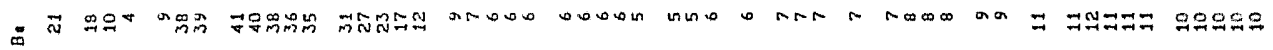

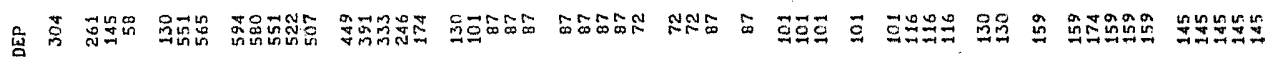

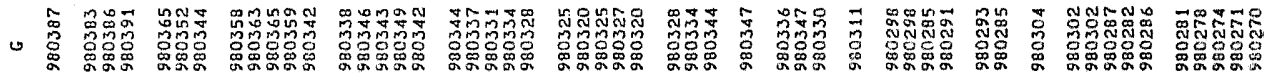

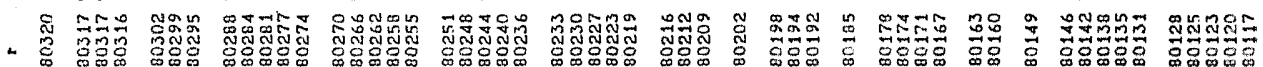

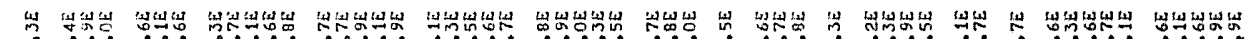
z $\overrightarrow{\mathrm{u}}$

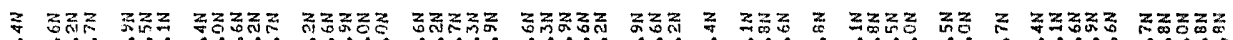

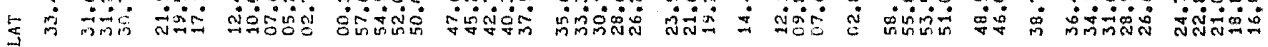
$\bar{\nabla}$ ₹ 出

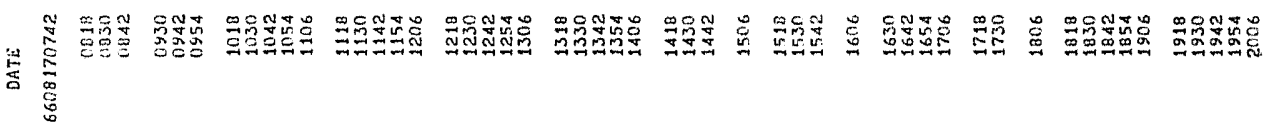

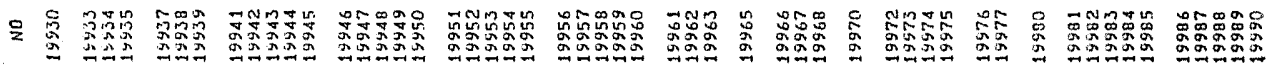




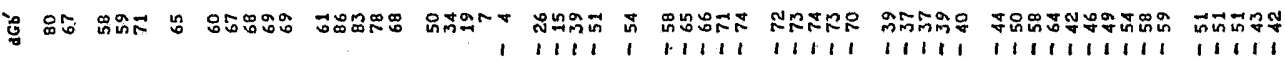

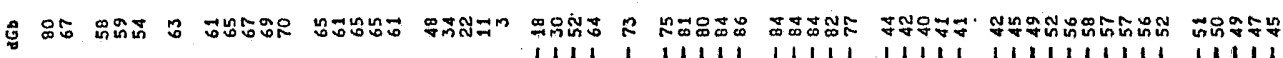

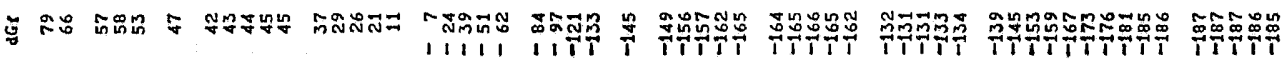

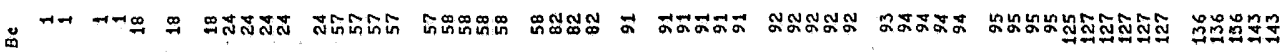

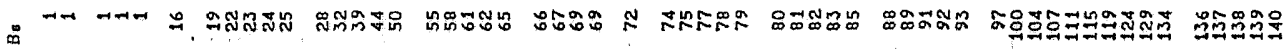

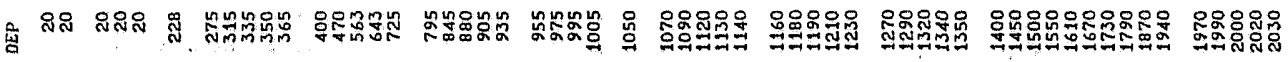

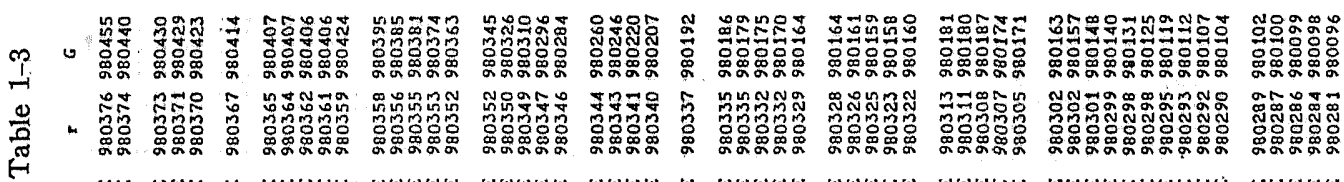

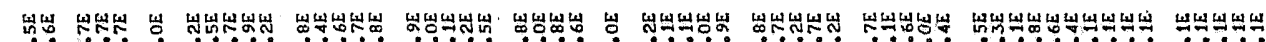

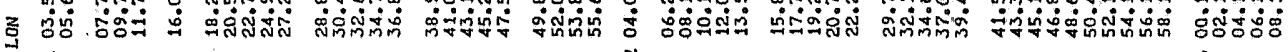
$\vec{\nabla}$

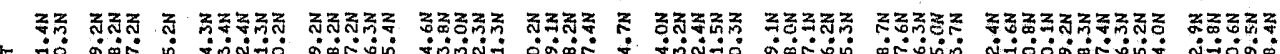

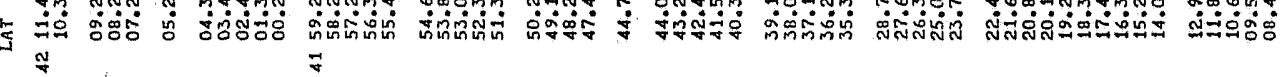

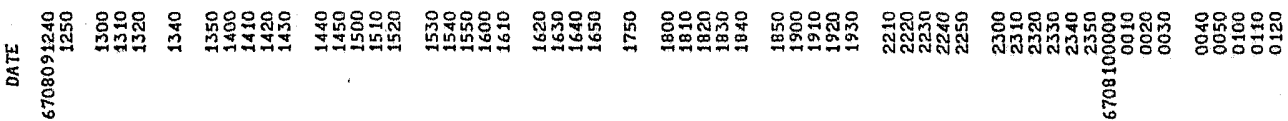

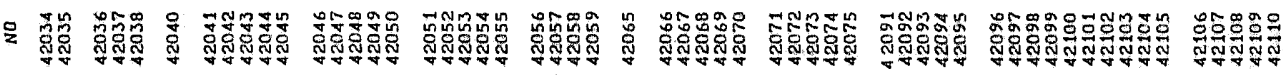

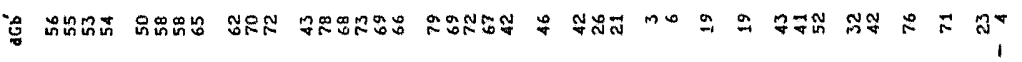

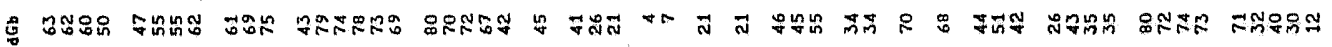

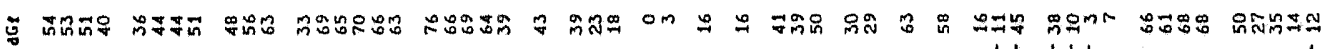

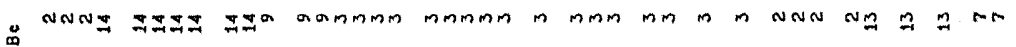

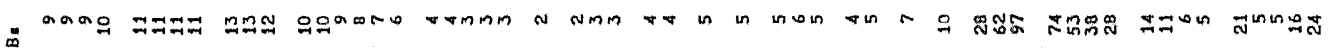

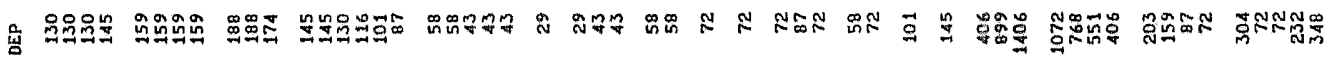

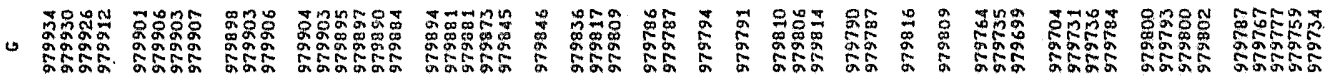

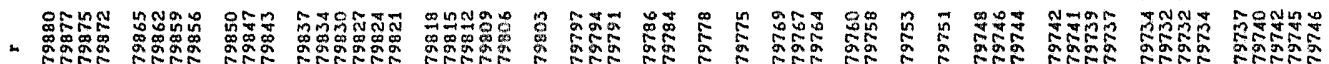

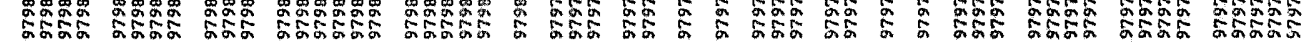

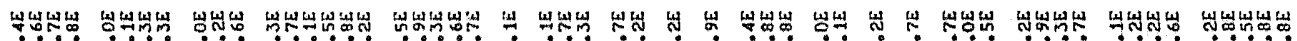

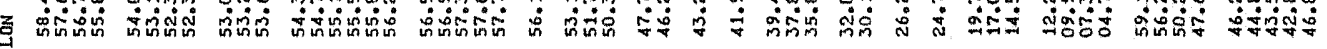
욤

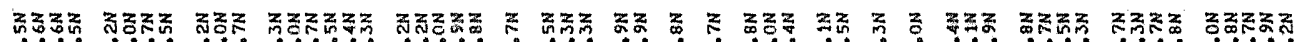

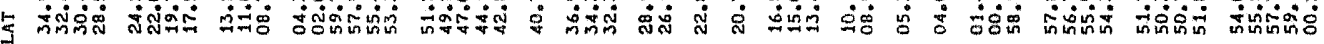
m

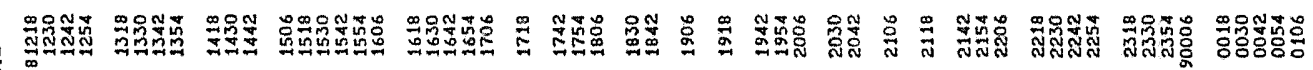
吉 要

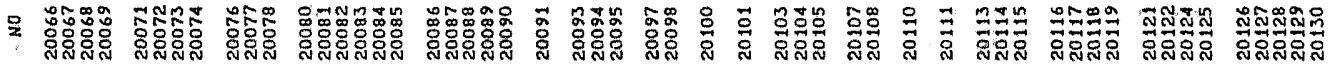




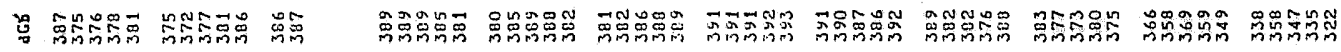

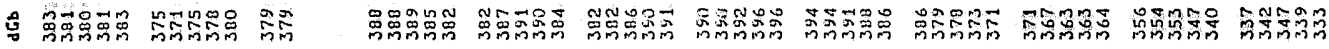

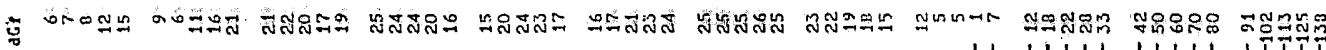

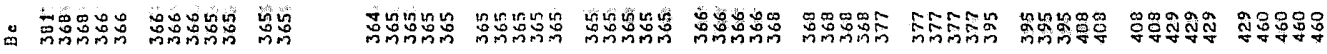

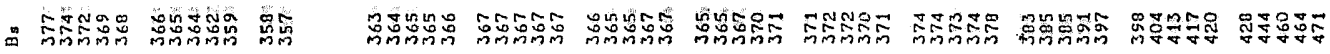

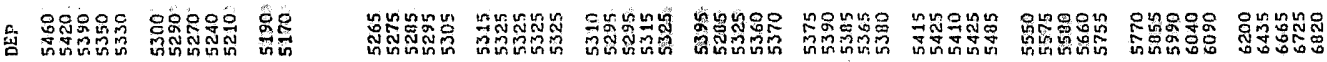

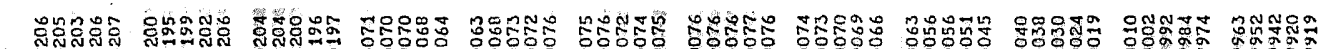

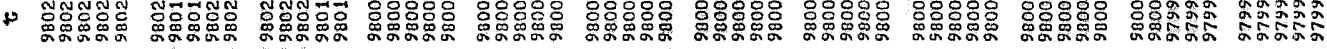
一

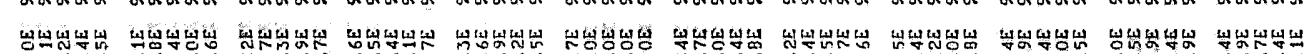

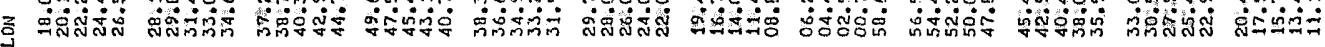
草 $\stackrel{5}{ \pm}$ 专

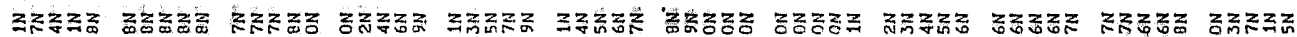

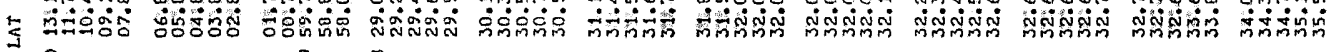
क

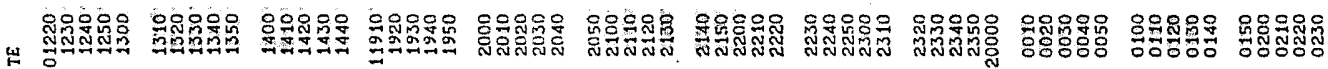
尊

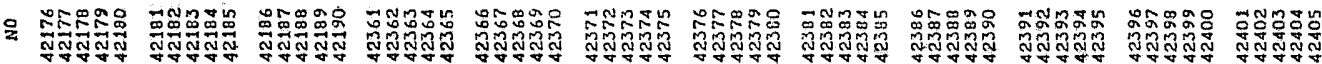

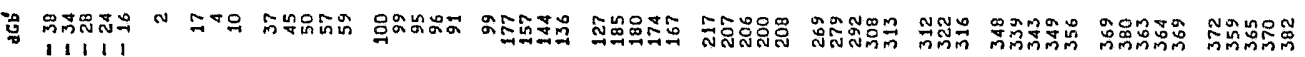

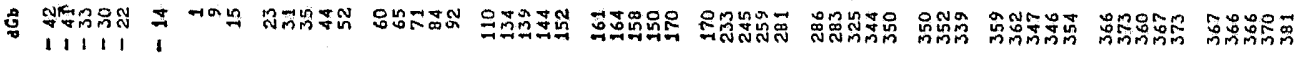

ธิ

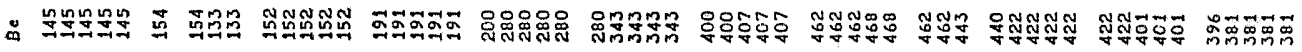

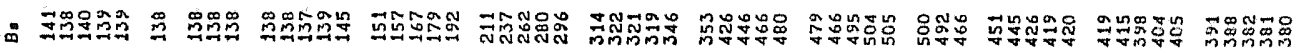

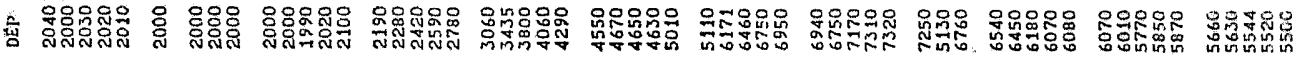

v

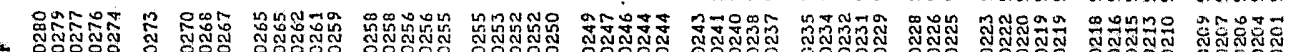

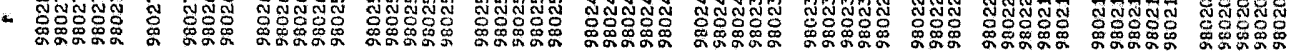

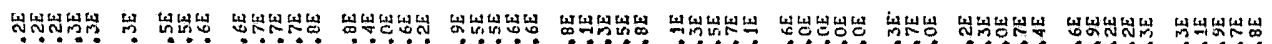

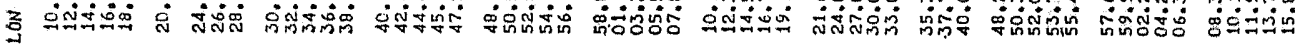
等

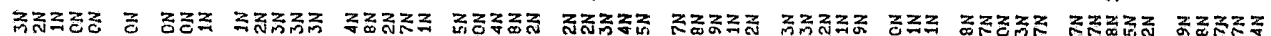

士 $7 \quad$ 안

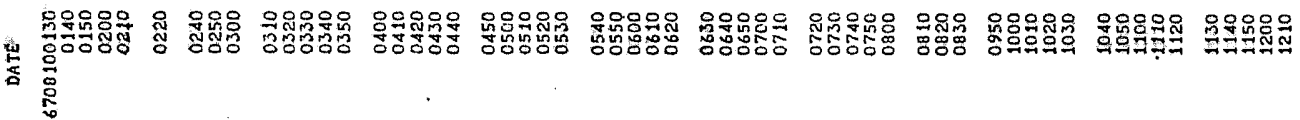

분

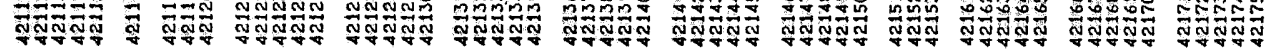


Gravity Measurements at Sea by Use of the T.S.S.G. Part 2.

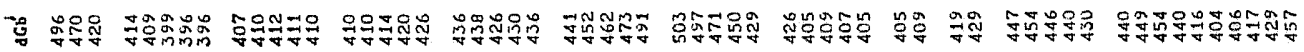

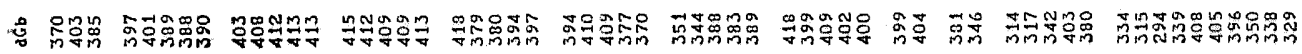

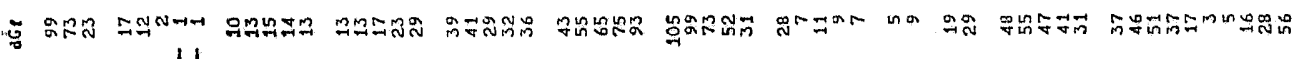

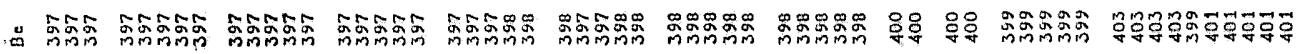

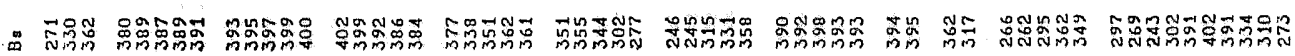

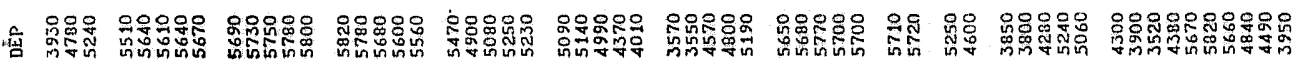

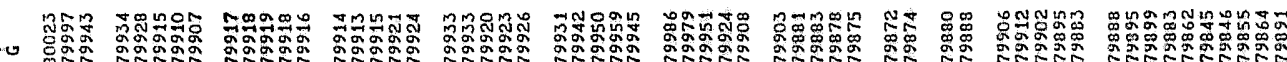

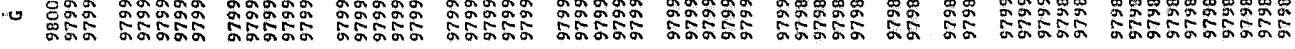

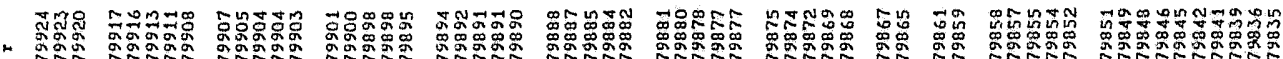
4

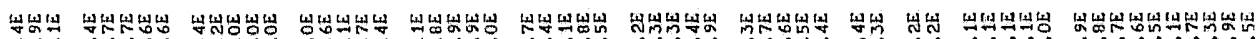

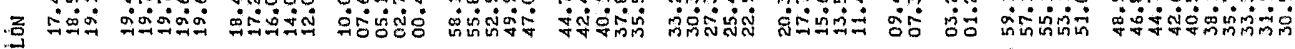

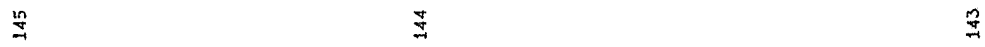

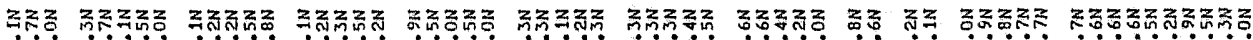

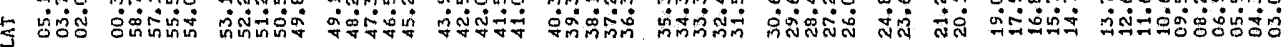
in in

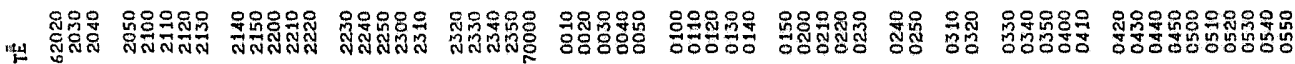
"1.

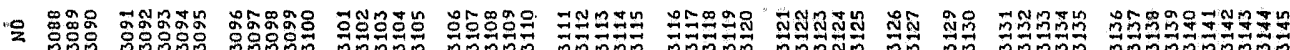

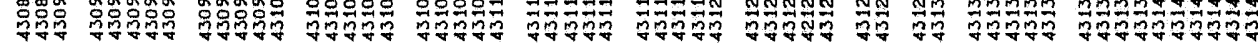

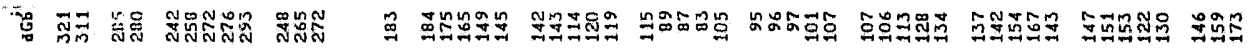

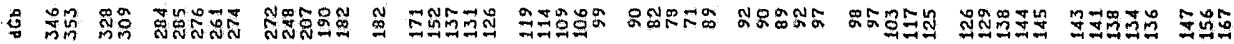
.

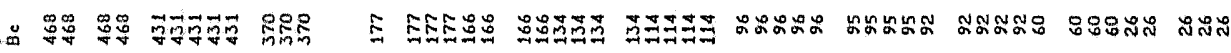

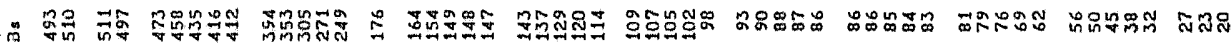

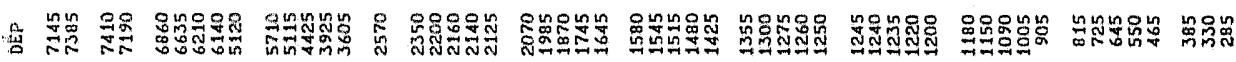

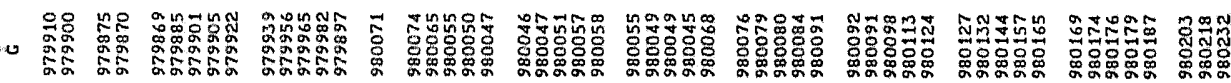

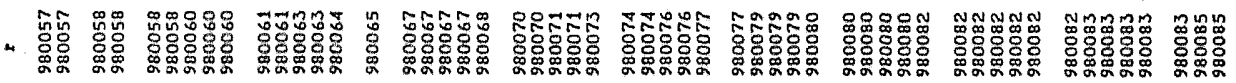

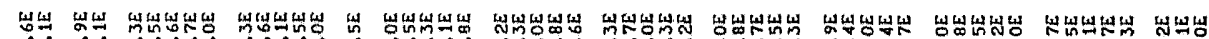

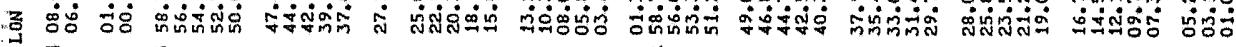
莳等 艺

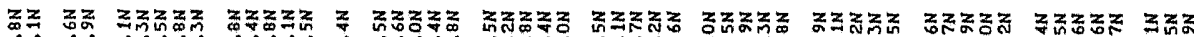

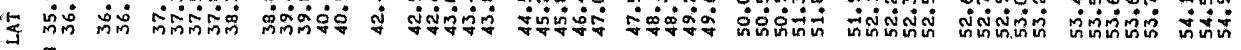
吕

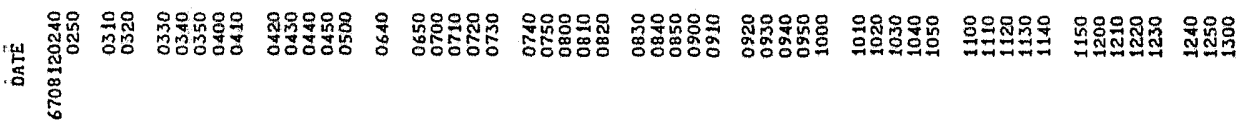

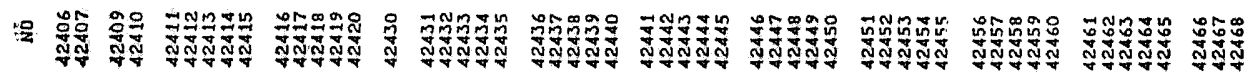




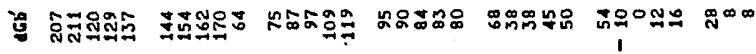

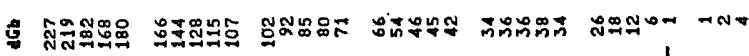

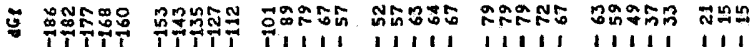

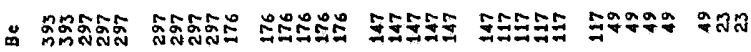

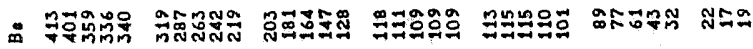

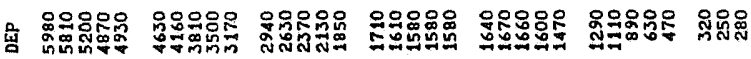

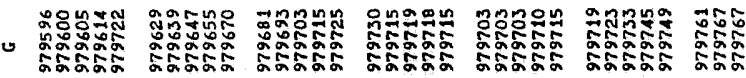

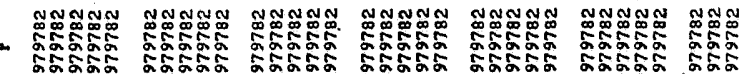

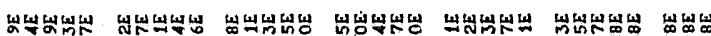

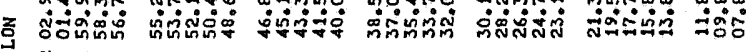
$\cong$

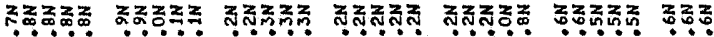

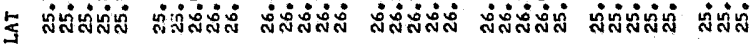
מ

崖

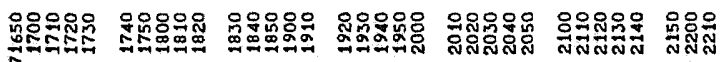

高

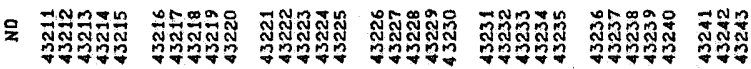

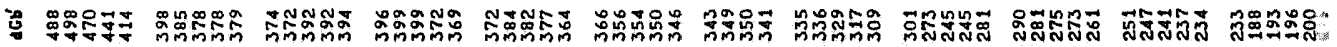

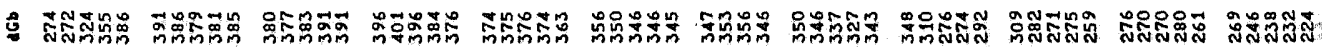

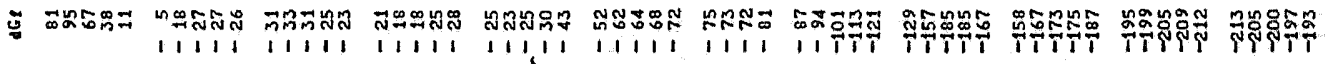

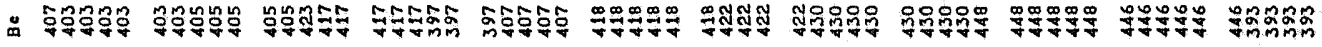

1

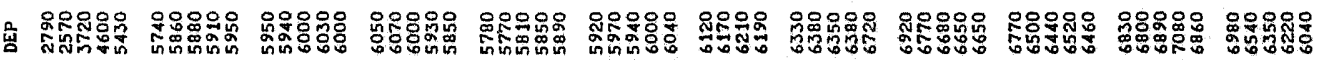

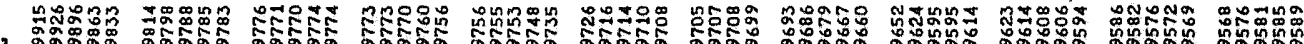

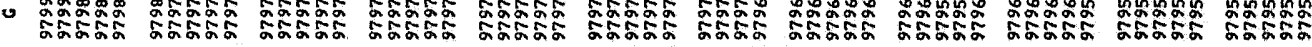

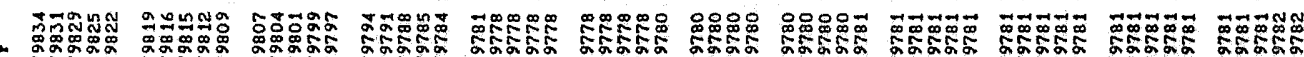

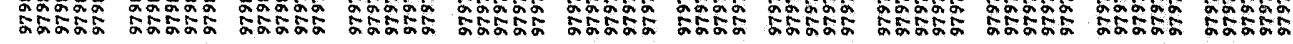

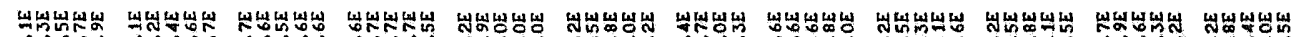

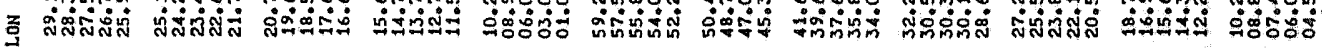

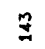
$\cong$

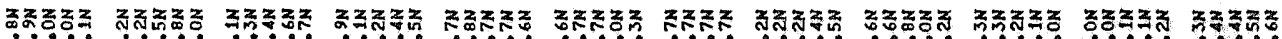

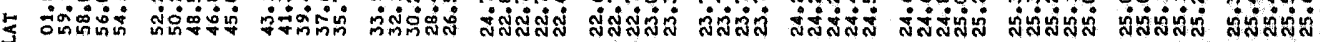
ํำ

崖

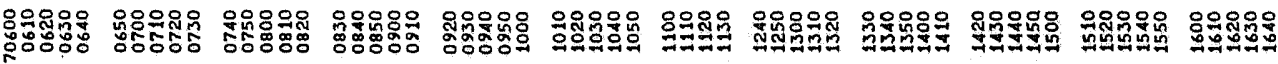

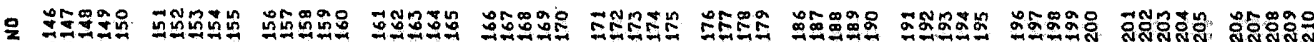

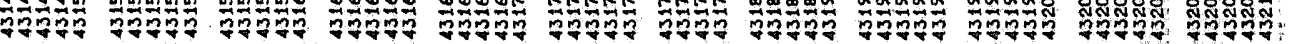




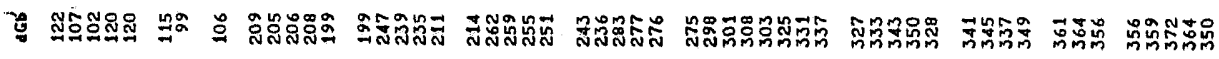

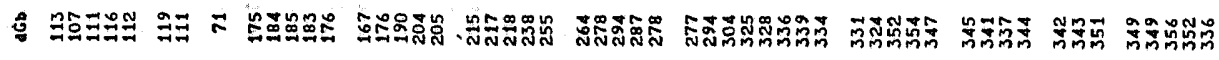

o

.

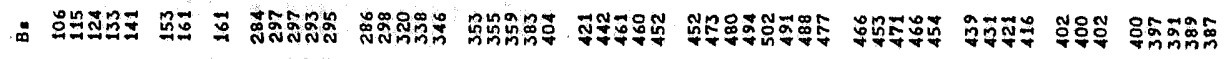

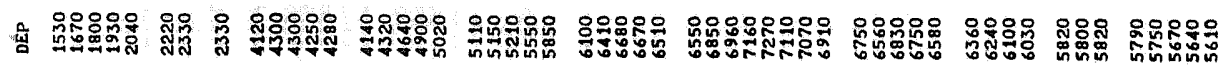

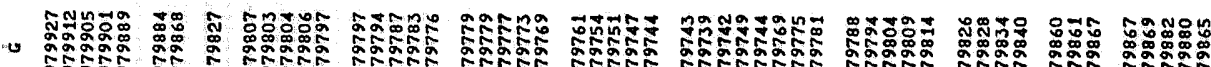

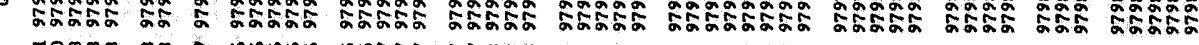

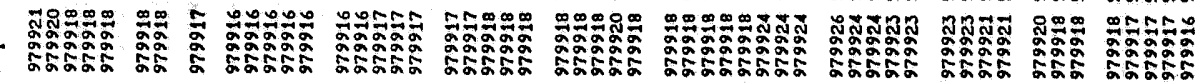

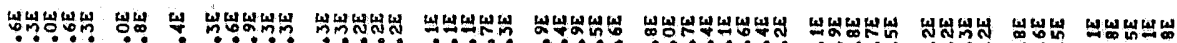

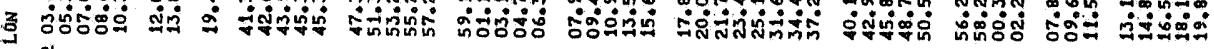
$\cong$

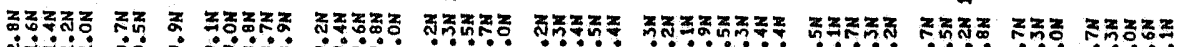

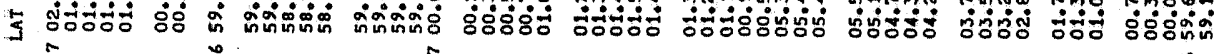
in in in

in

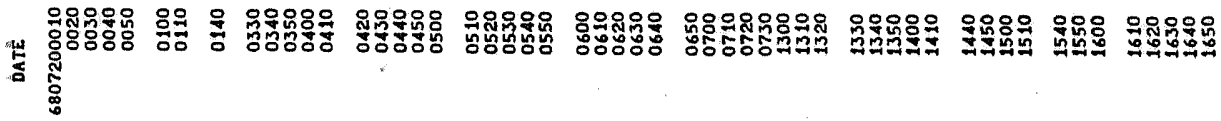

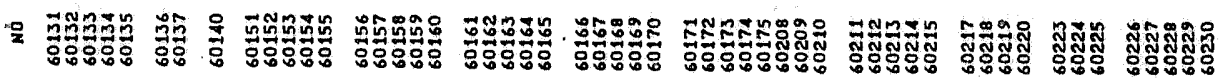

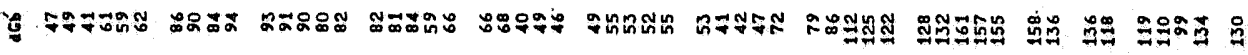

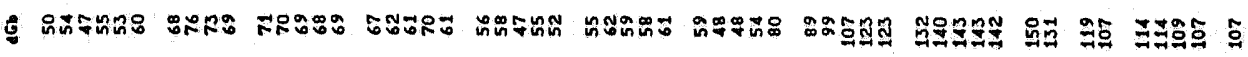

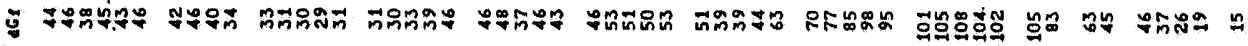

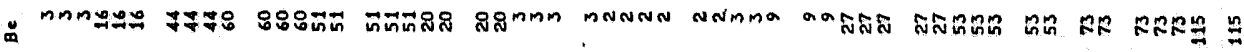

$\ddot{m}$

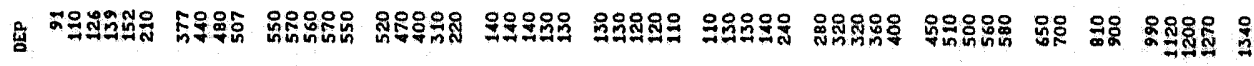

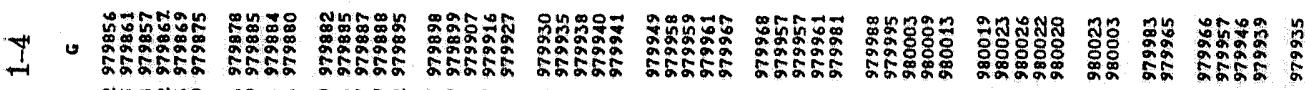

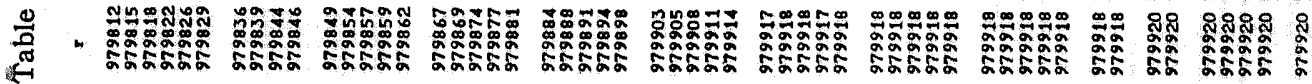

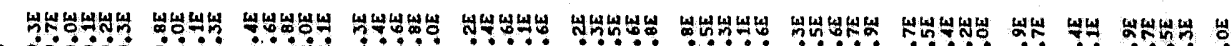

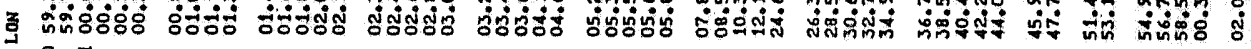
引

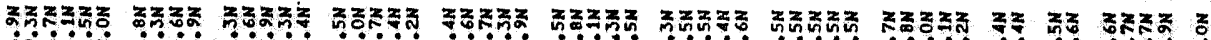

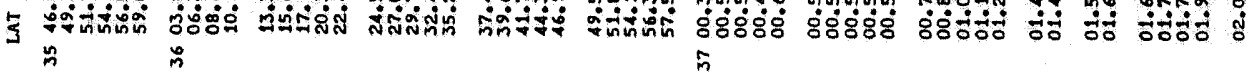

崖

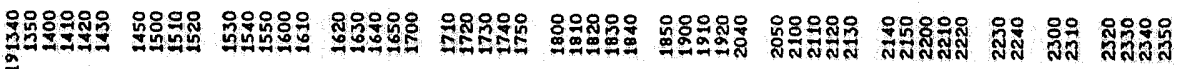
总

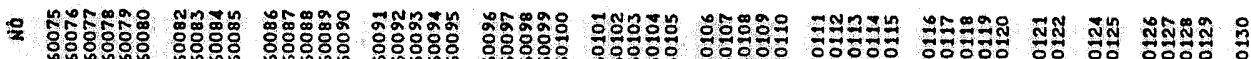




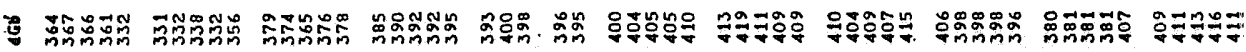

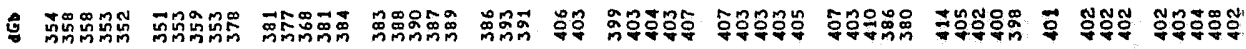

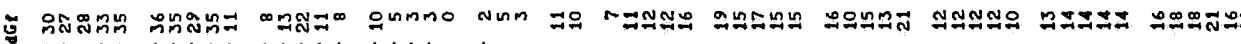
1111111111111111

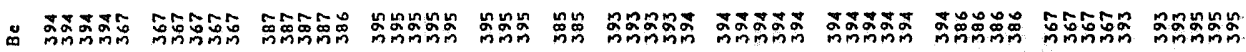

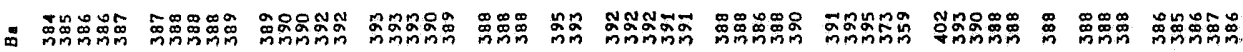

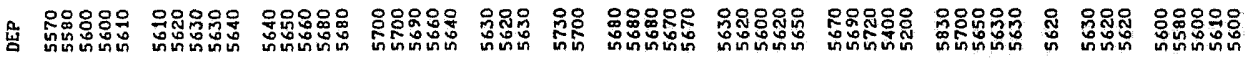

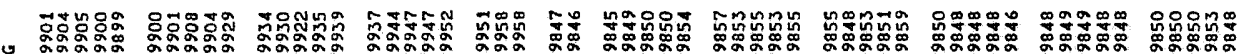

ง

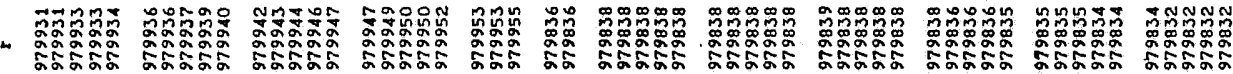

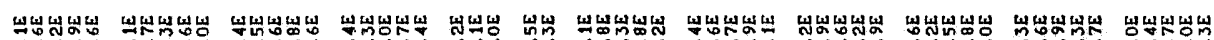

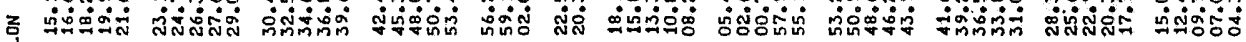
İ

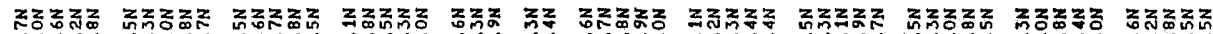

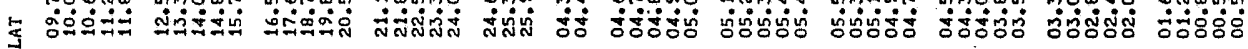
in in

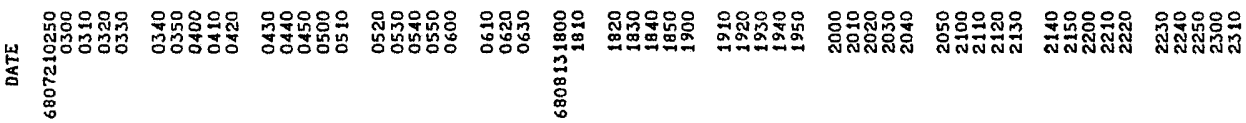

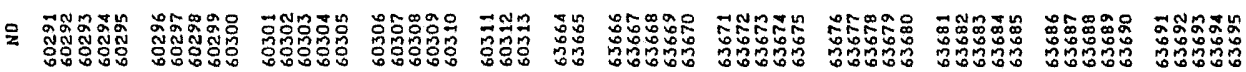

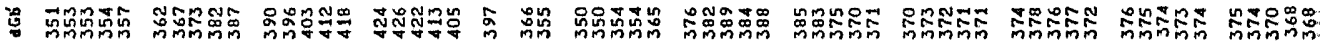

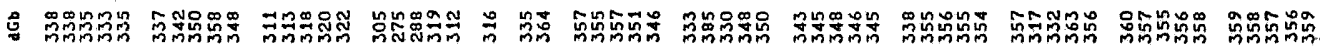

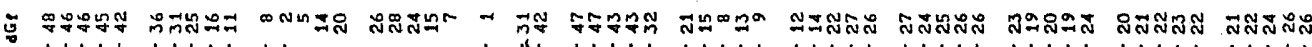

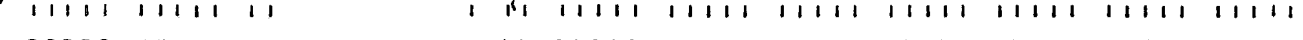

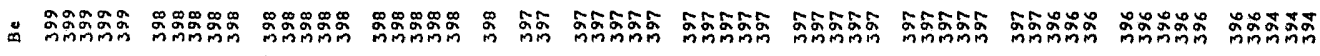

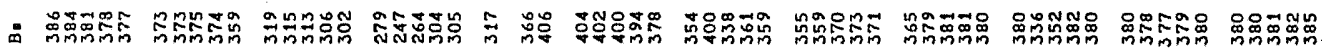

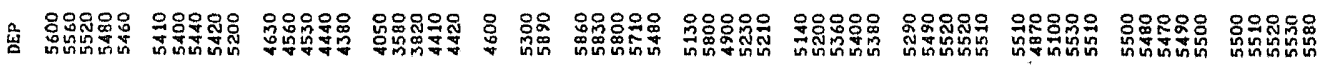

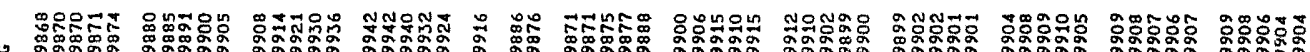

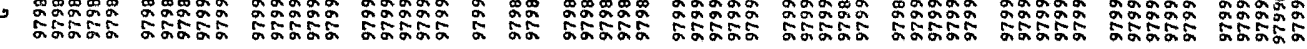

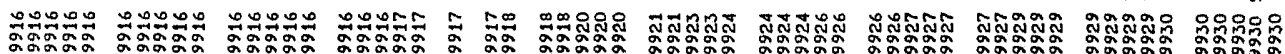

"

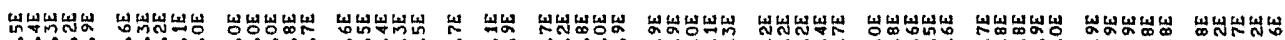

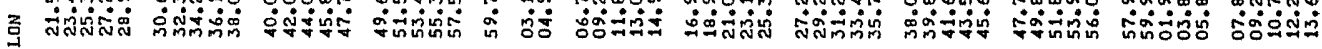
ذ

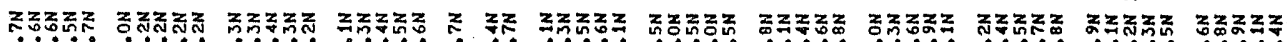

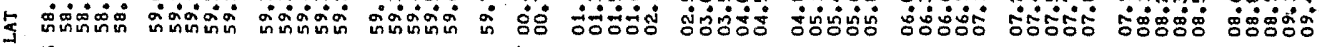
i̊ in

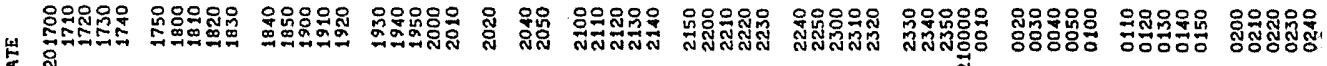
㠃

을 


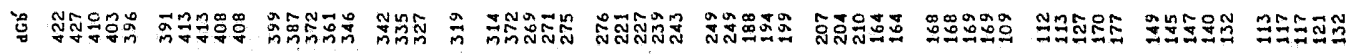

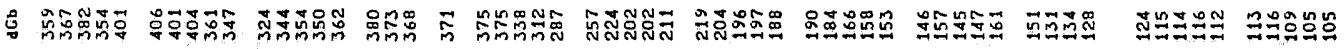

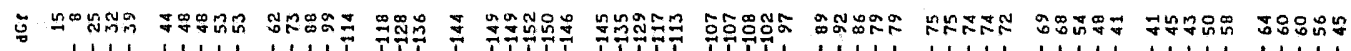

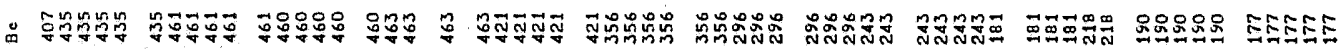

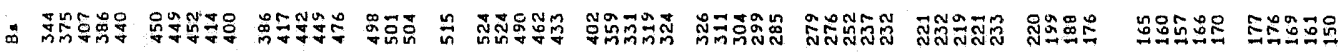

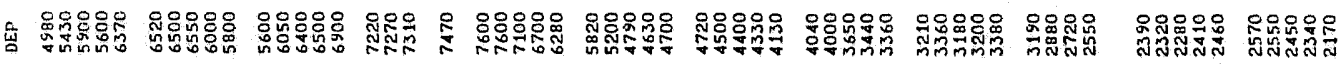

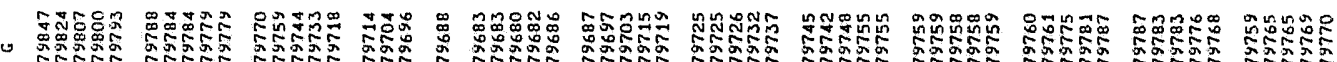

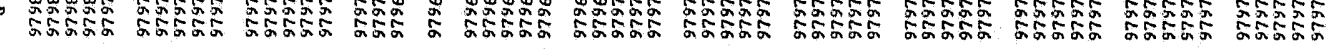

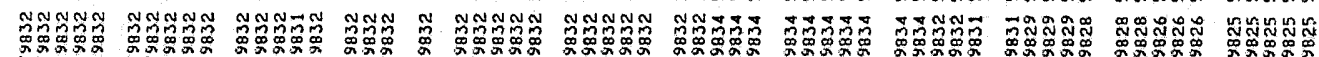

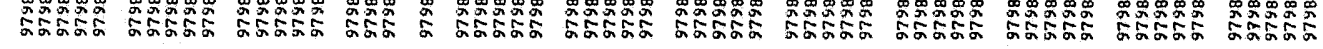

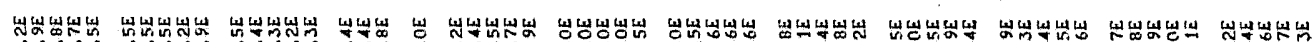

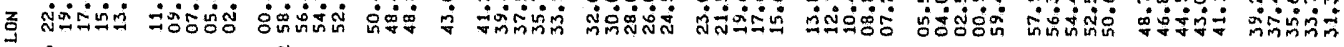
$\cong$

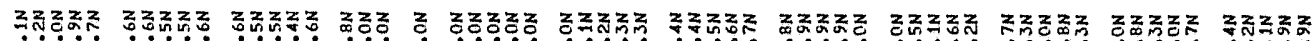

生 i 品

崖

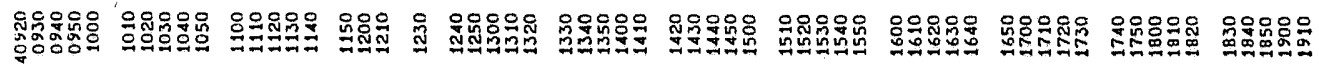
兽

z

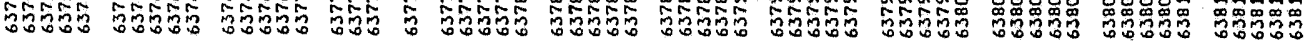

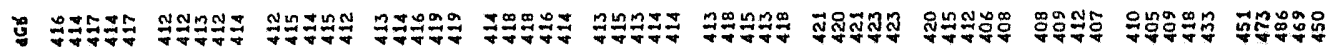

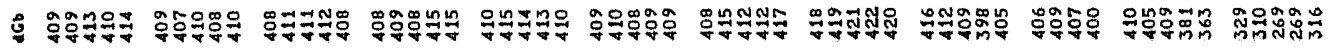

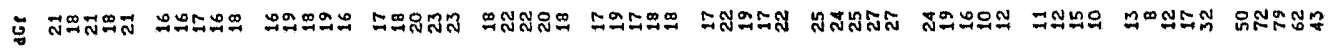

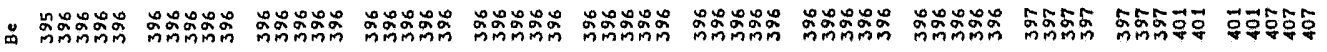

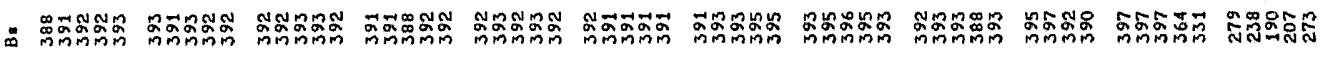

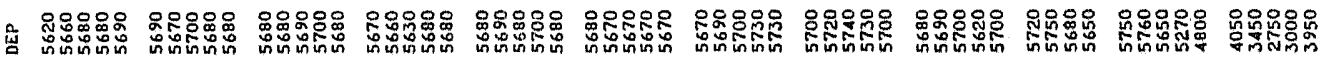

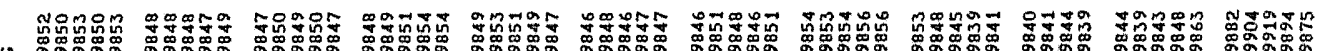

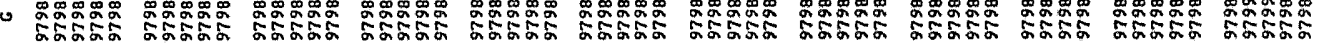

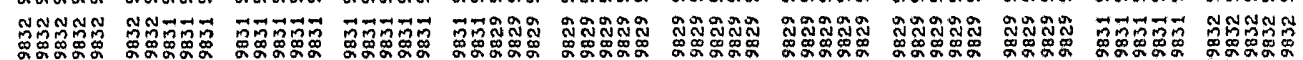

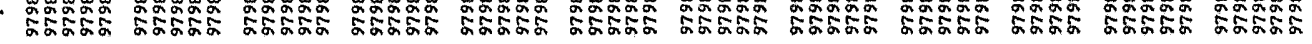

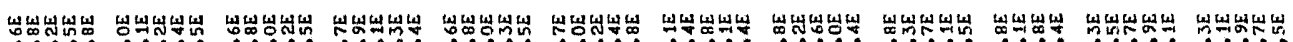

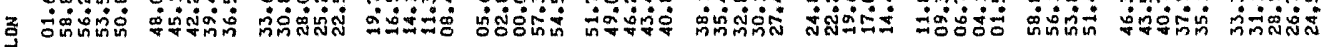

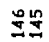
$\Xi$ $\frac{3}{3}$

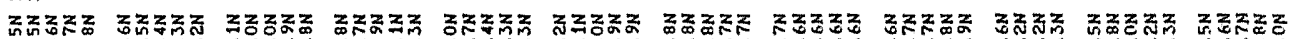

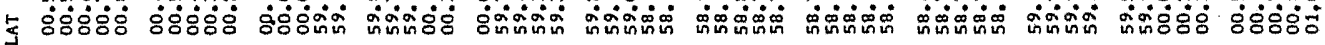
i in in m in

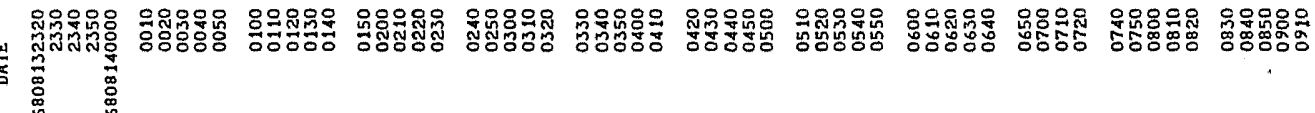

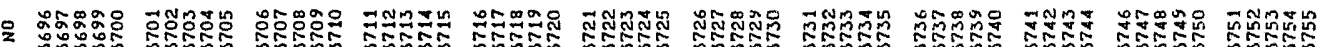

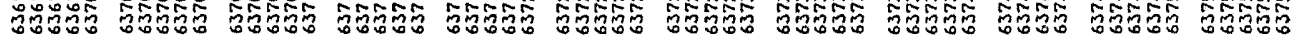




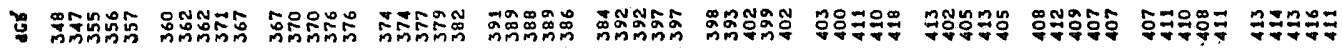

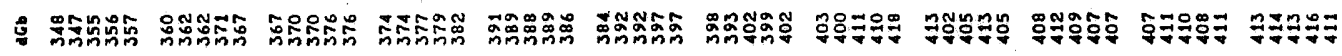

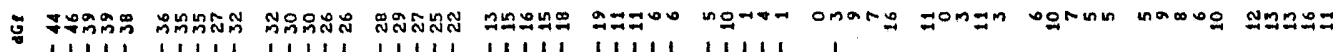
111111111111111111111111111111111

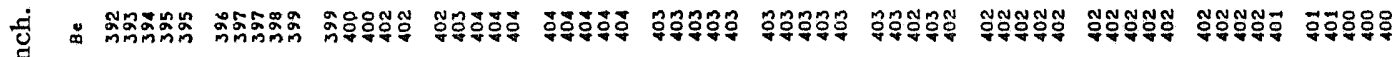

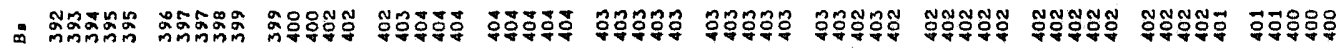

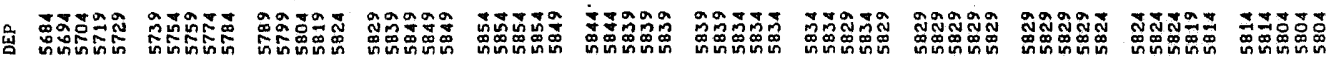

แ

- 5.

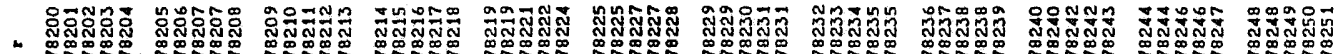

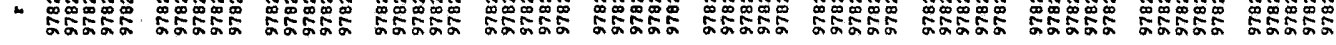

ง่

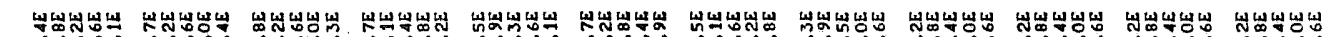

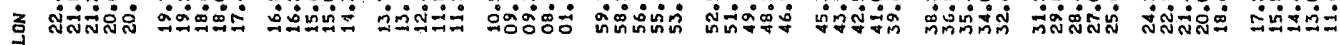
品

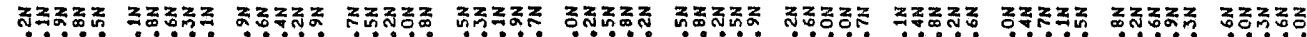

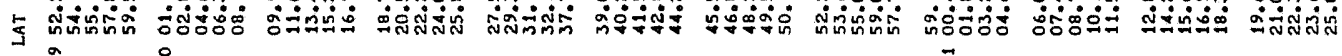
2 $=$

崖

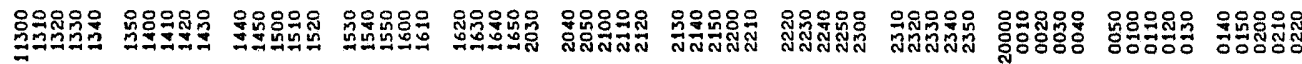
荬

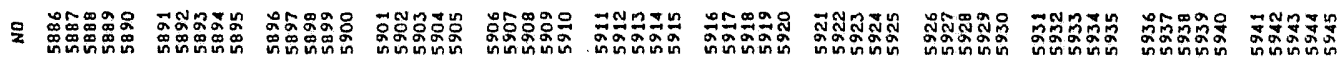

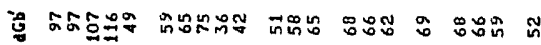

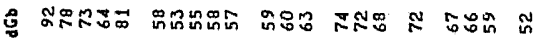

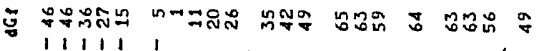

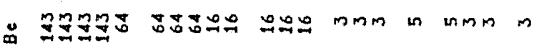

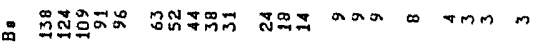

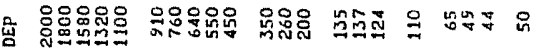

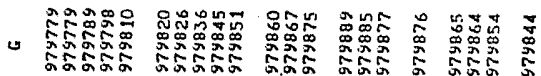

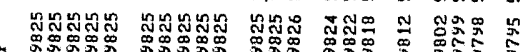

4.

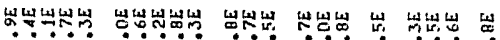

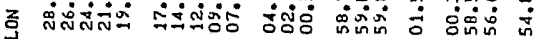
引

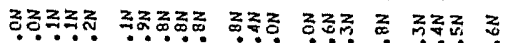

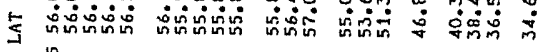
品

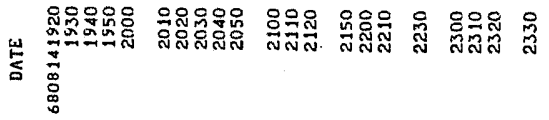

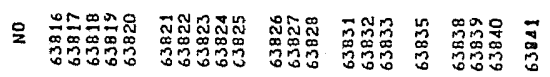




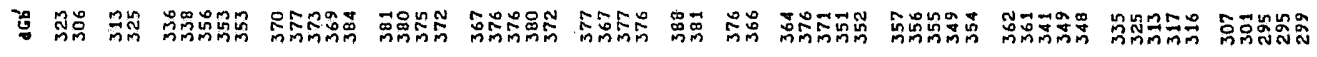

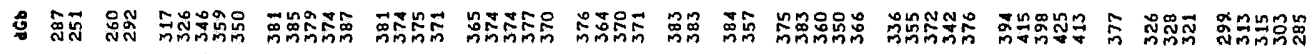

๖

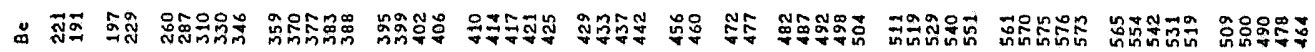

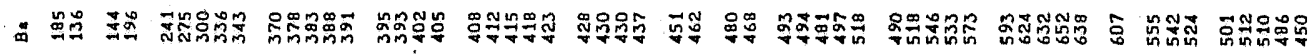

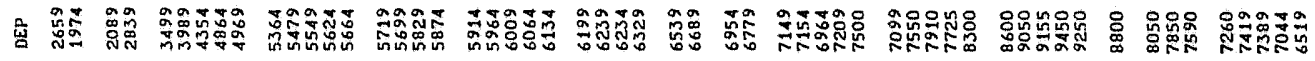

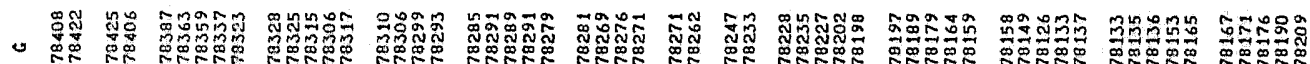

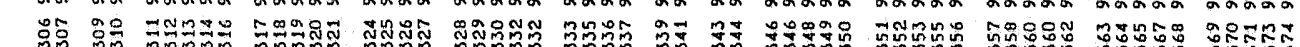

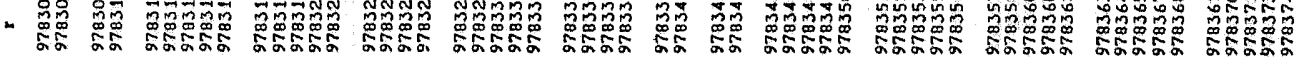

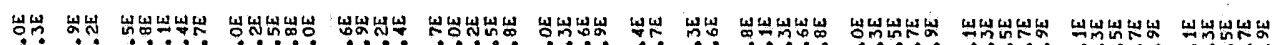

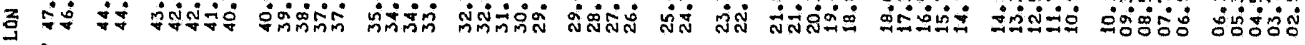
三

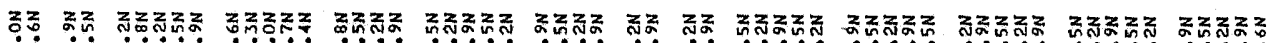

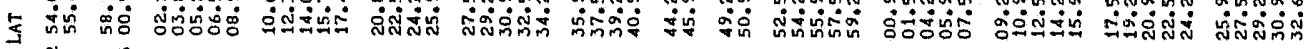
$\cong 2$

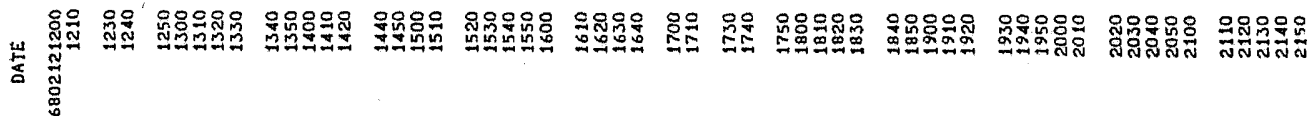

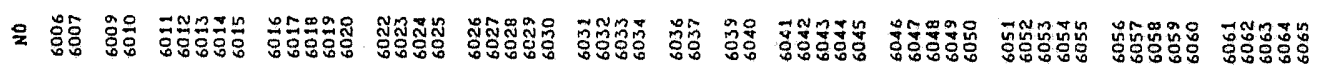

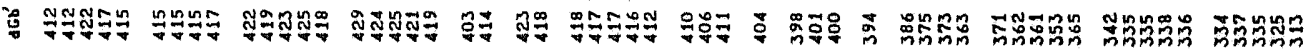

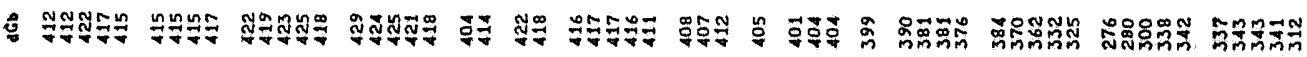

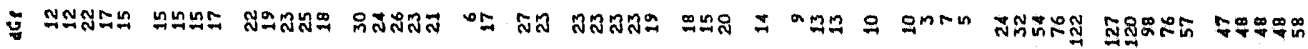

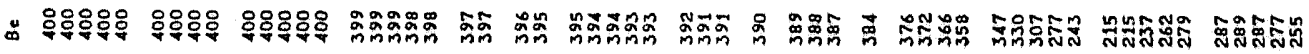

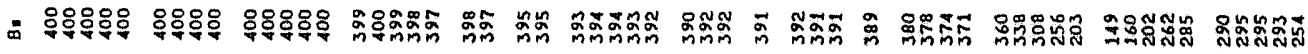

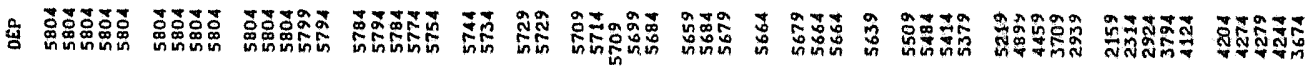

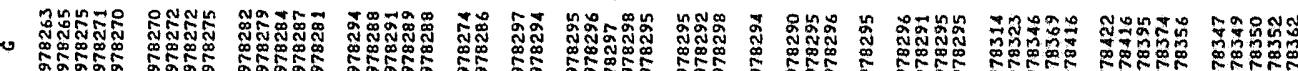

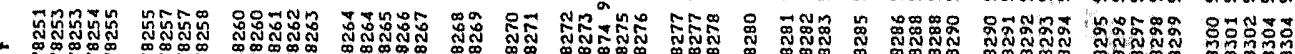

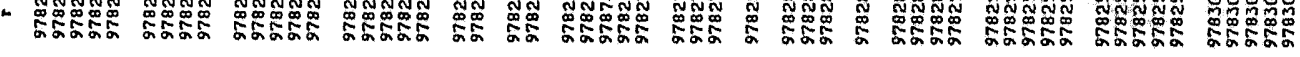

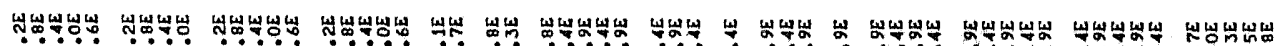

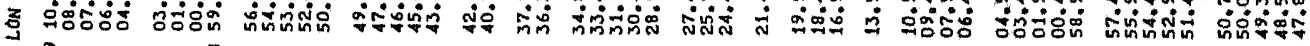
\$

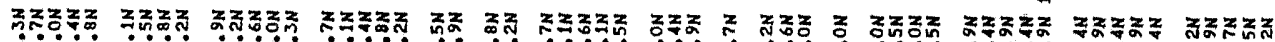

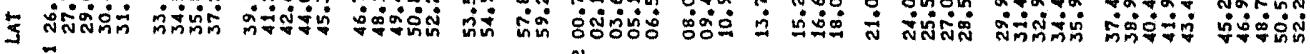
ב ก

容

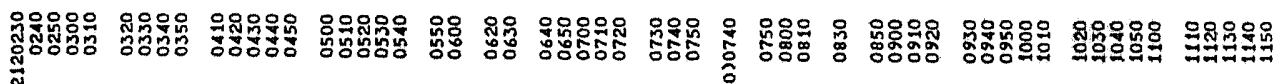
帚

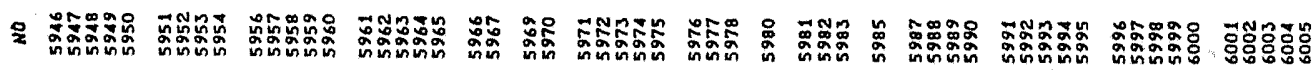




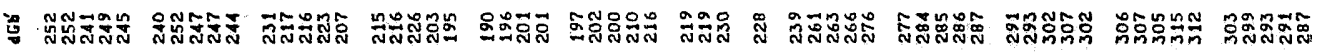

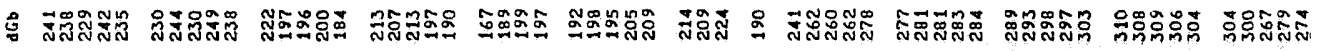

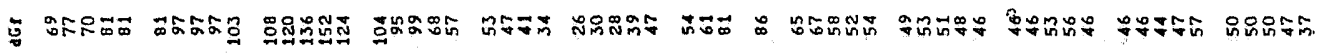

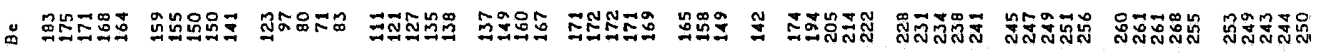

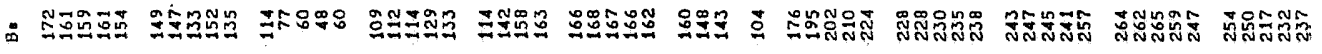

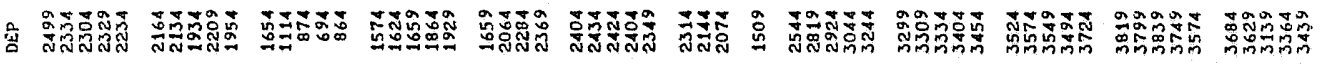

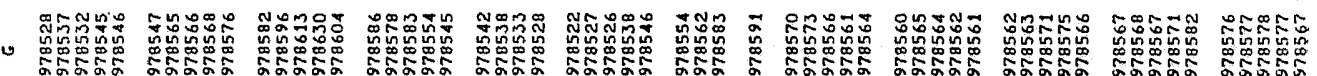

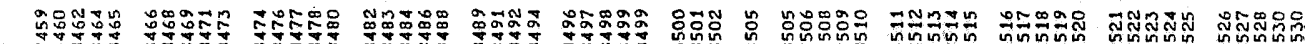

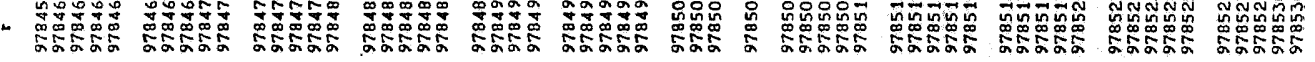

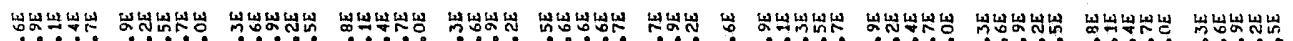

そ

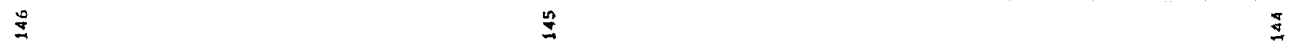

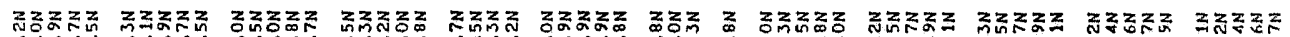

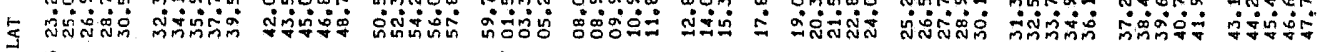

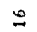

崖

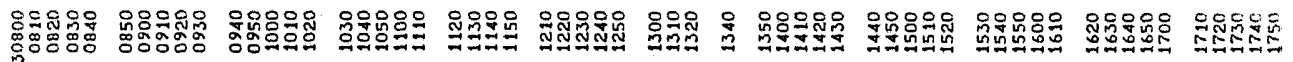
每

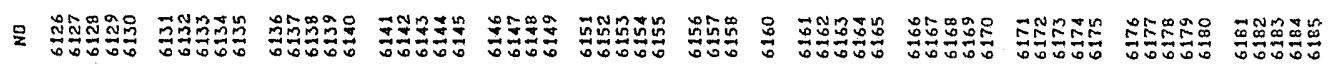

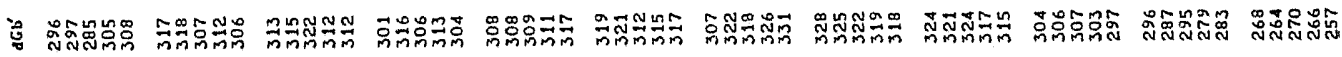

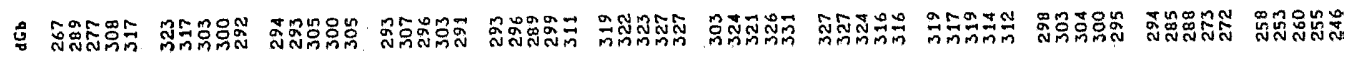

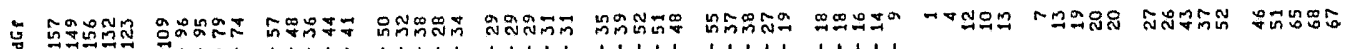

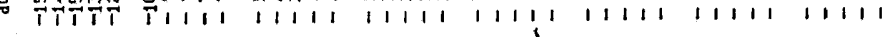

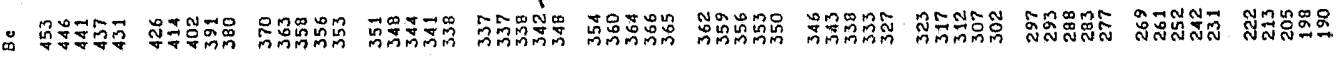

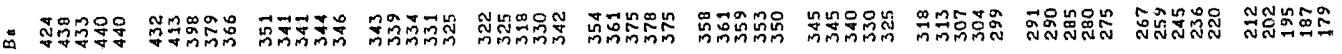

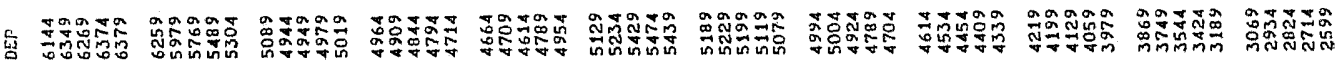

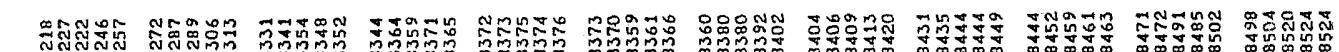

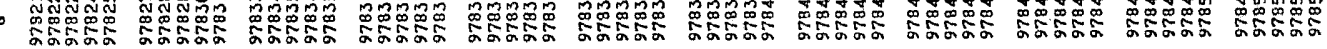

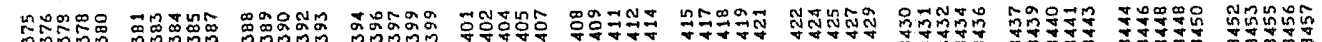

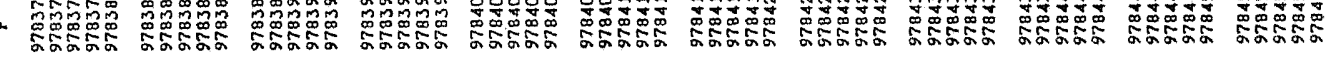

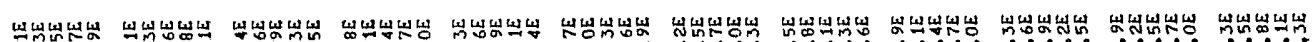

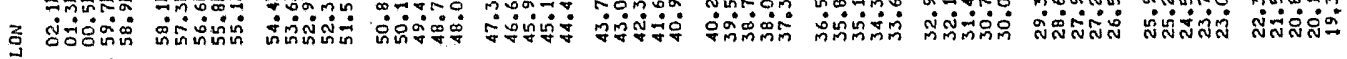
¿

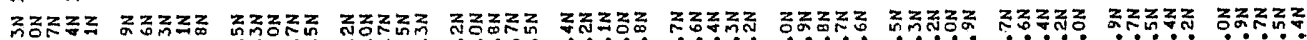

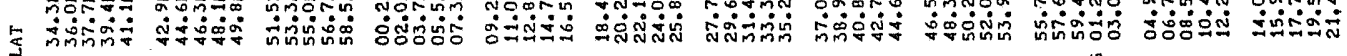
I

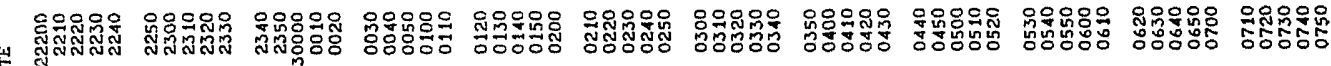

言

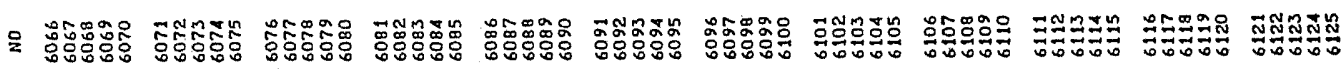




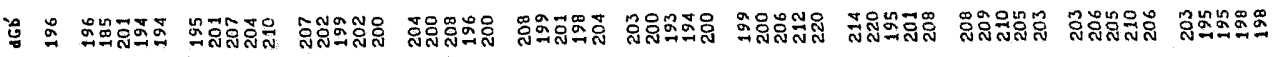

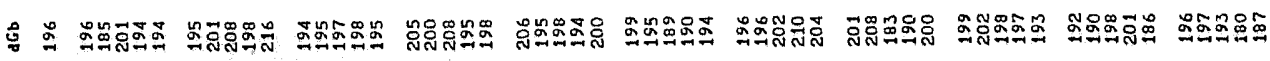

뭄

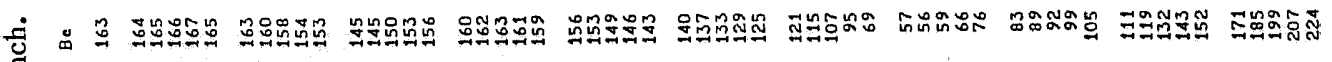

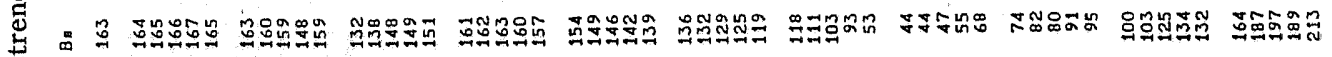

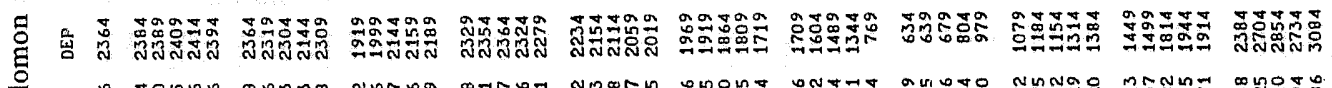

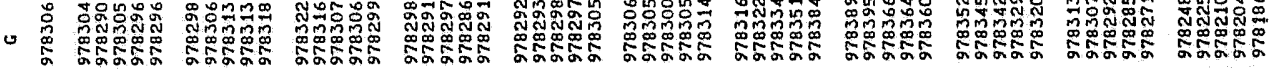

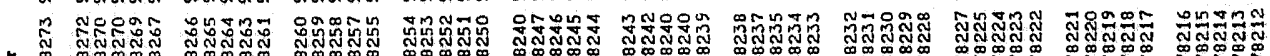

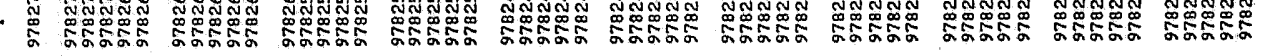

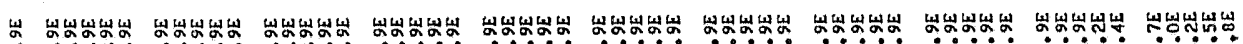
z in

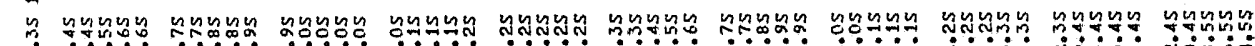

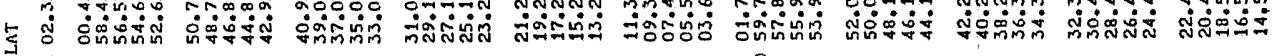

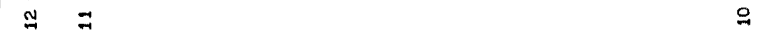

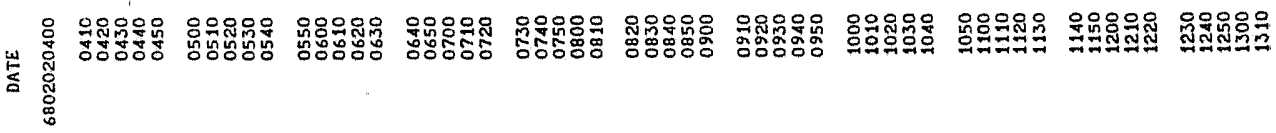

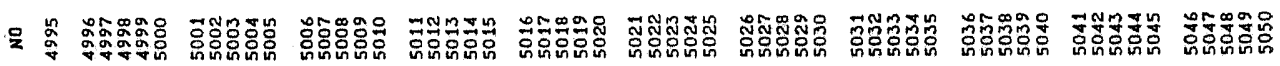

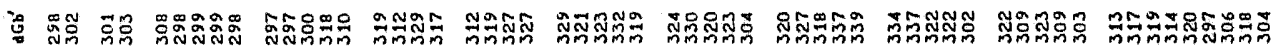

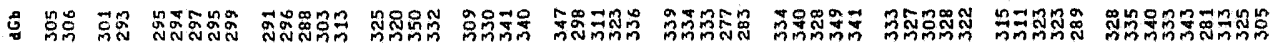

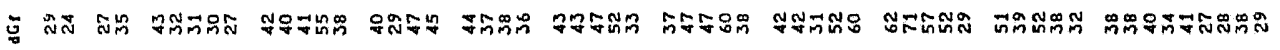

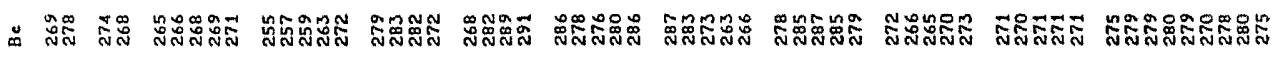

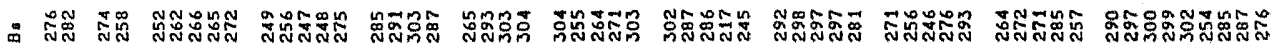

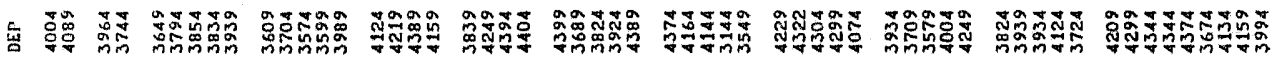

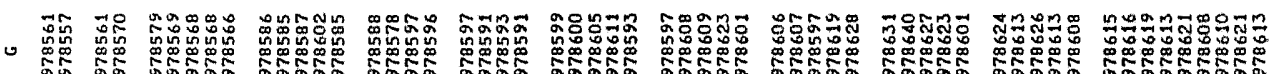

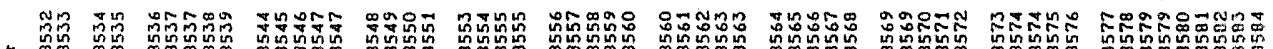

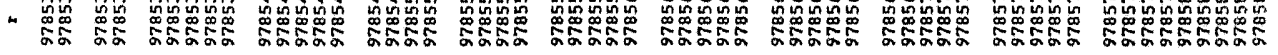

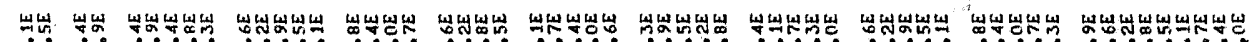

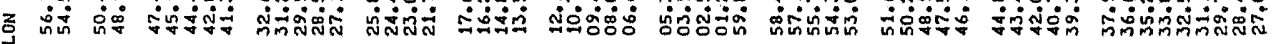
$\Xi$

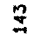

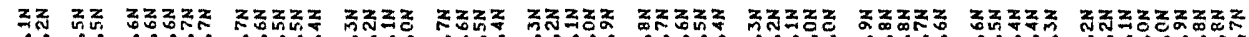
ड $=$ + 崖

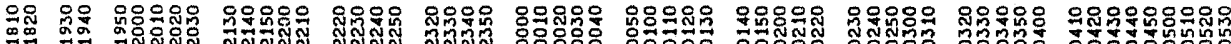

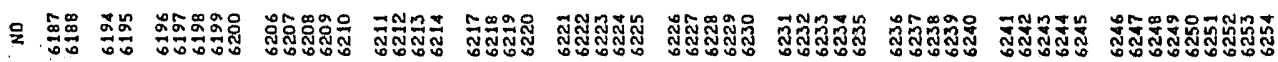


บำ

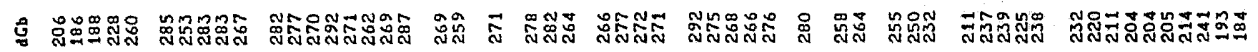

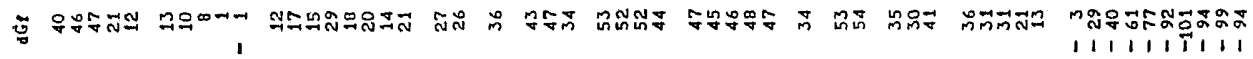

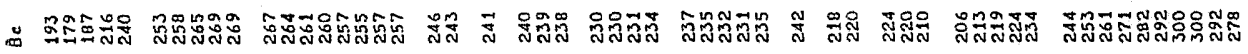

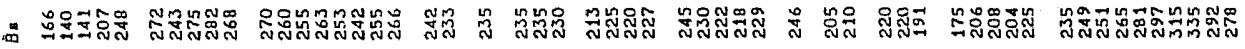

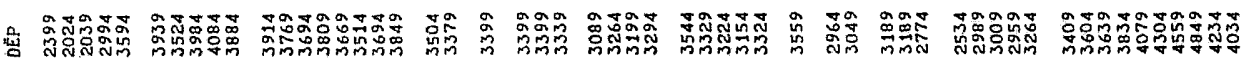

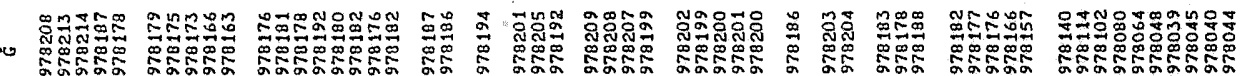

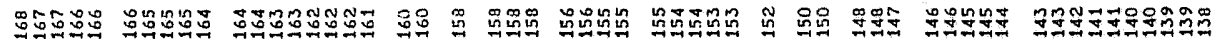

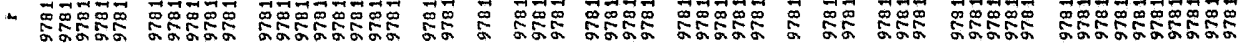

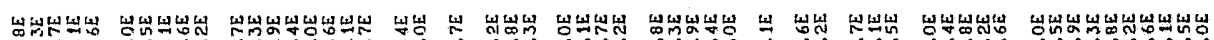

乙. 品

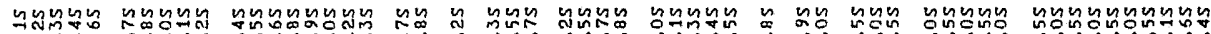

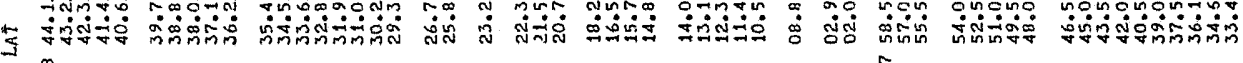
品

岩

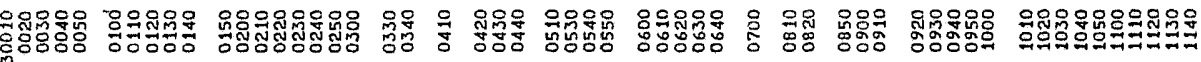

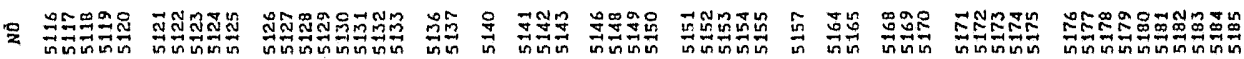

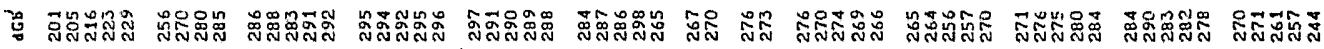

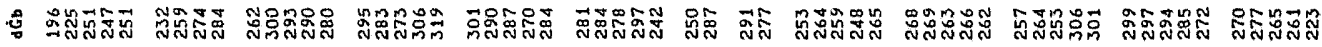

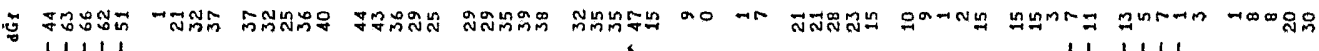
11111 11111

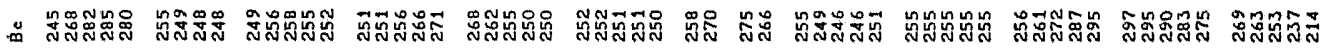

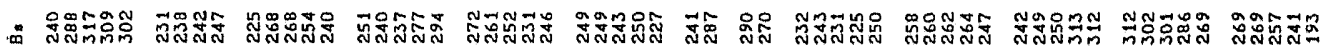

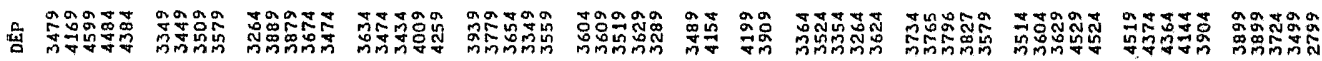

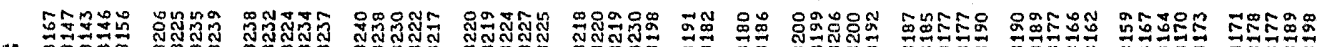

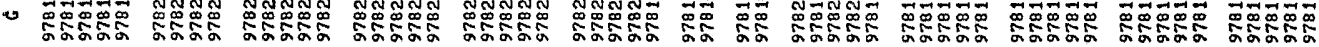

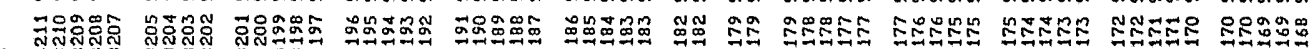

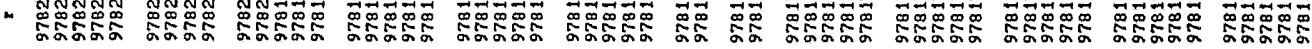

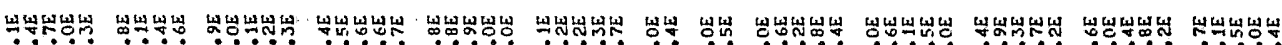
z 栗 ํㅜㄴ

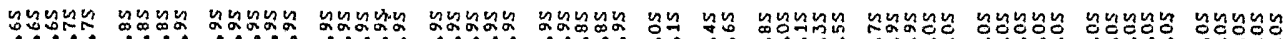

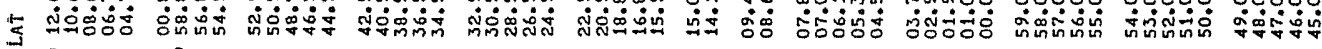
- \&

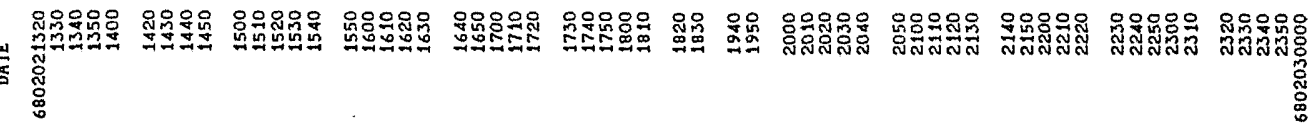

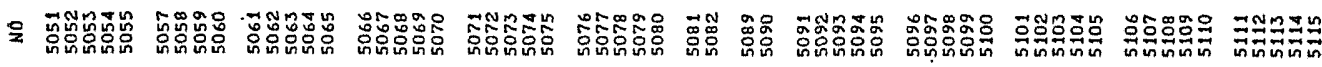




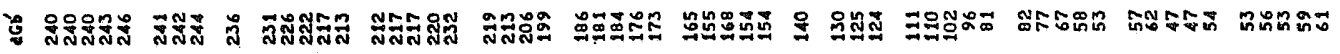

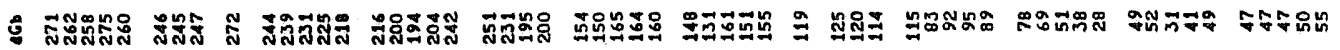

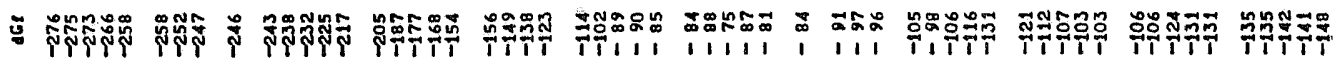

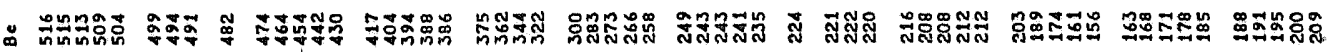

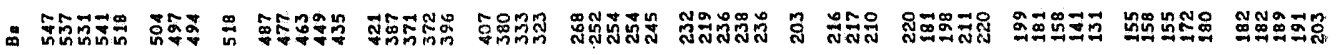

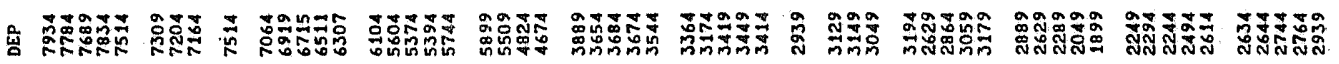

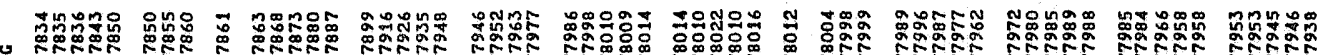

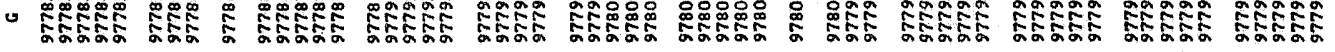

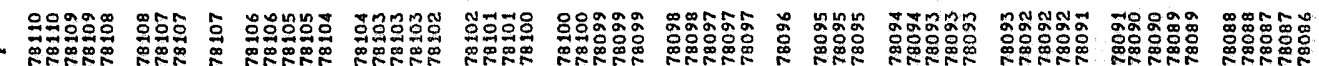

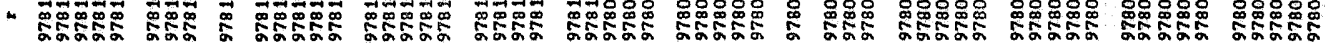

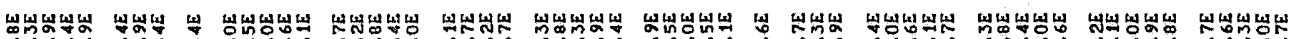

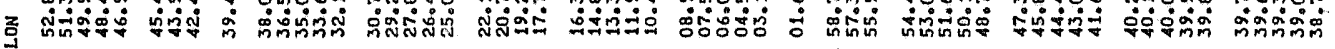
要

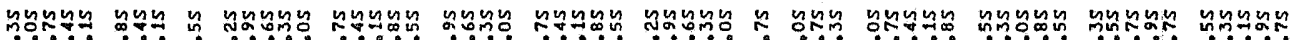

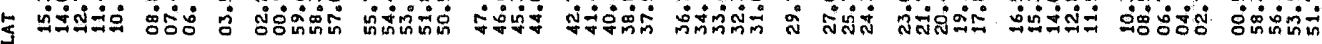
: 웅 ¿

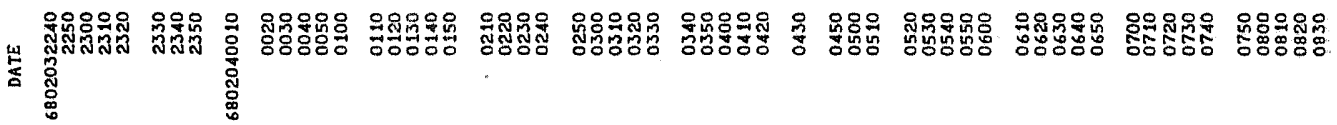

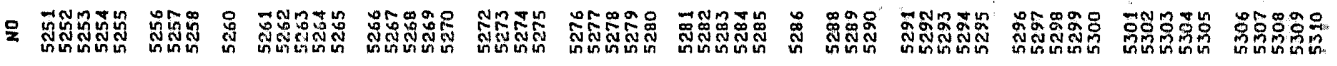

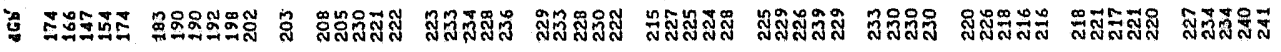

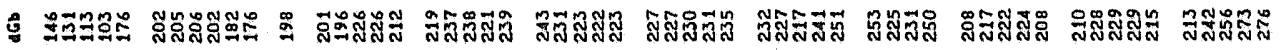

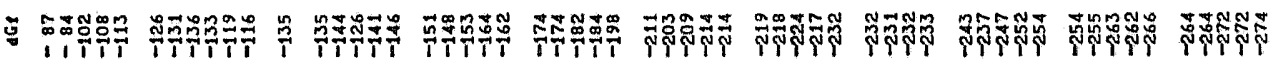

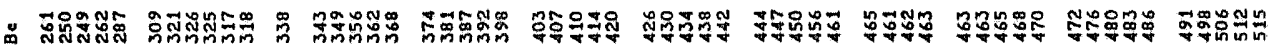

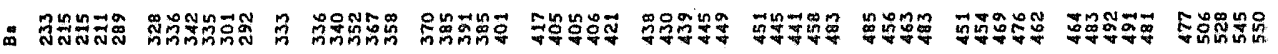

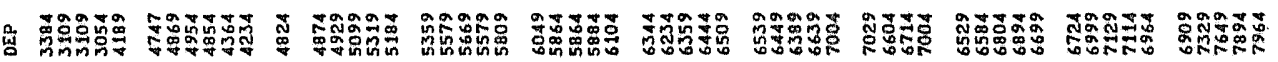

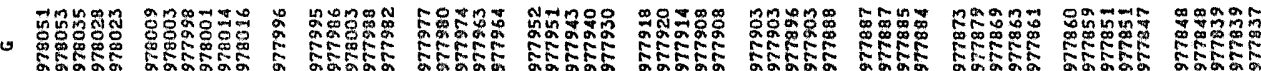
ำ 4

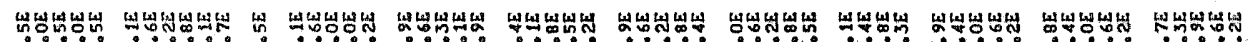
ว 品

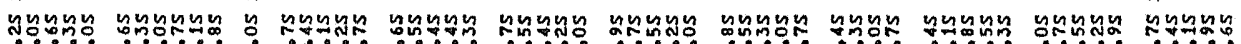

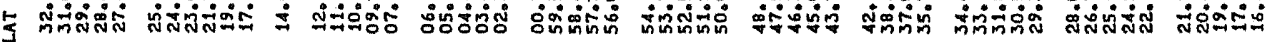
: :

崖

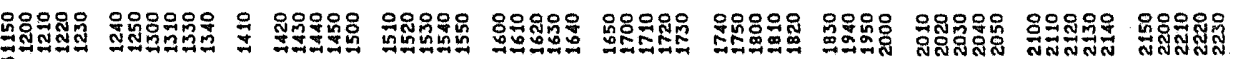
屁

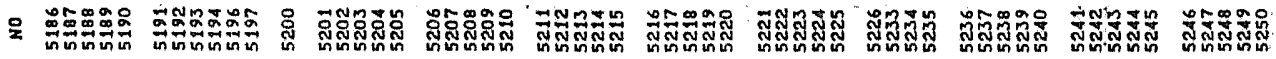




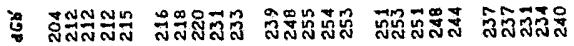

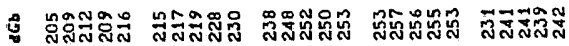

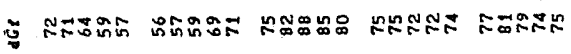

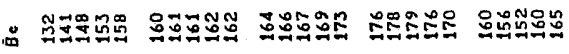

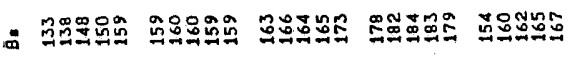

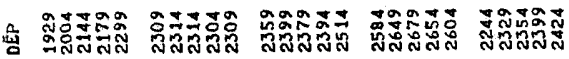

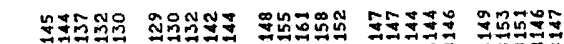

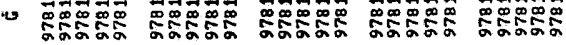

-

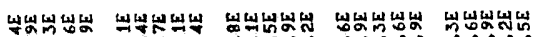

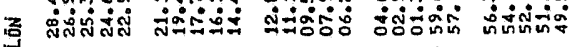
$\vec{n}$

요

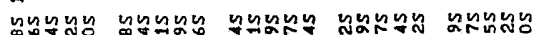

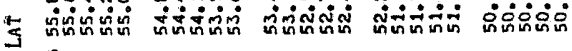
。

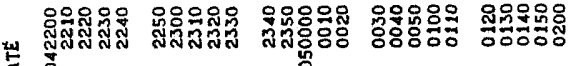

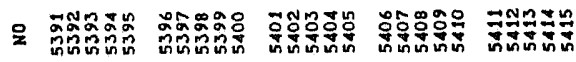

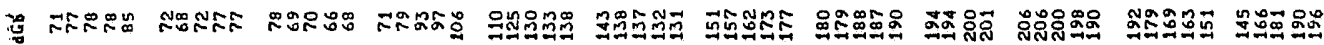

ํำ

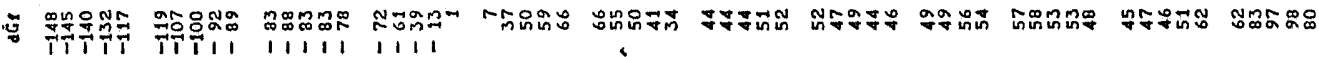

囟

1

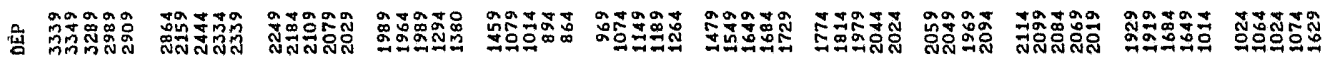

-

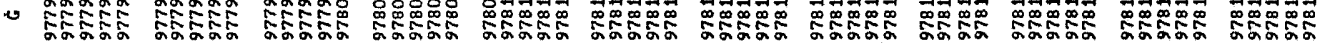

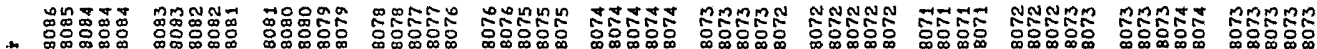

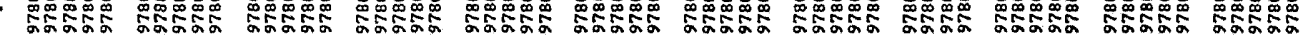

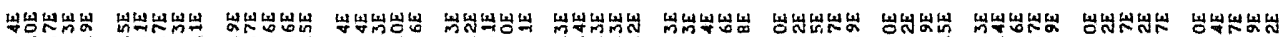

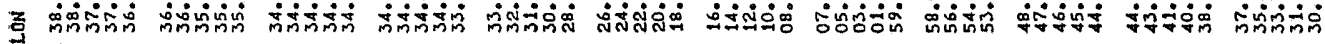
㒖 I

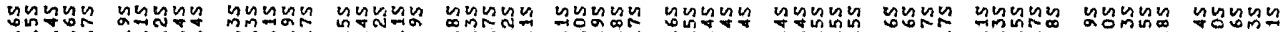

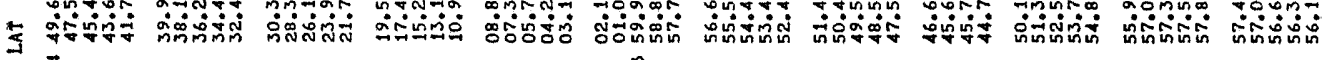
¿

㟧

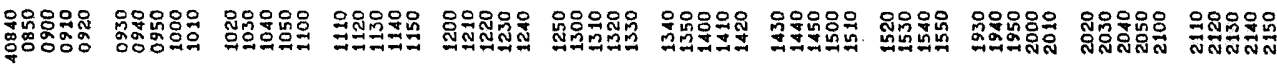
递

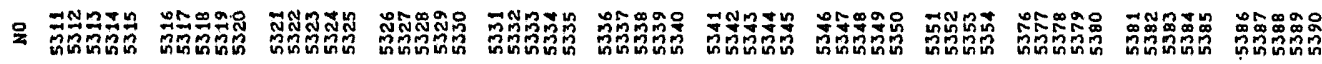




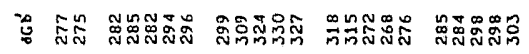

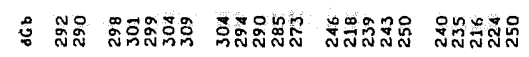

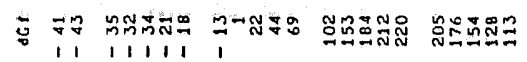

品

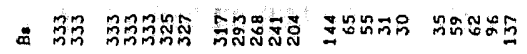

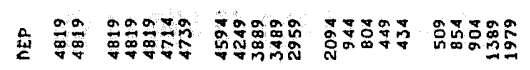

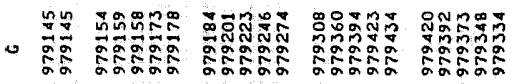

-

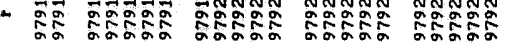

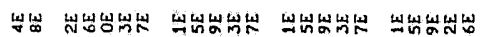

z 品 贴

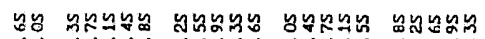

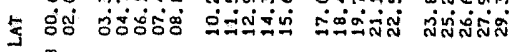
品

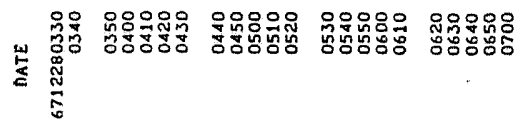

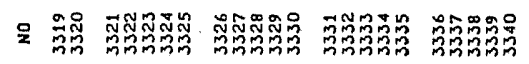

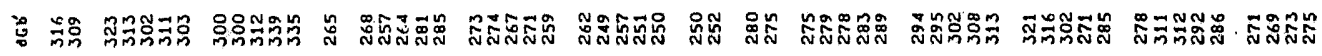
เ

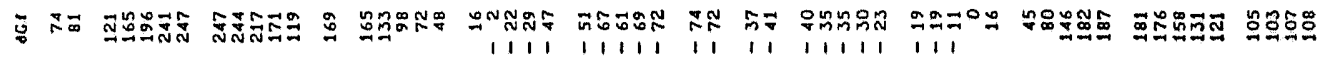

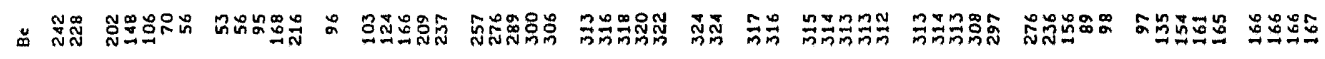

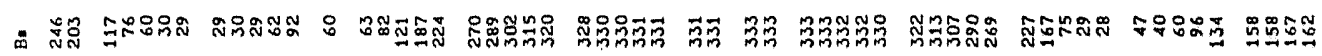

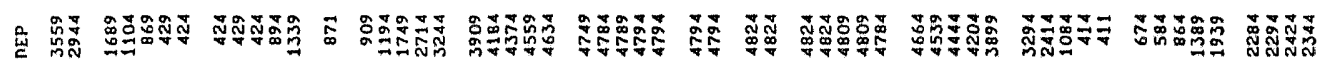

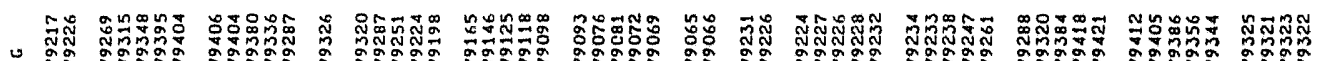

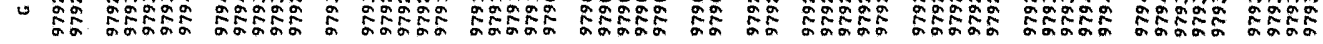

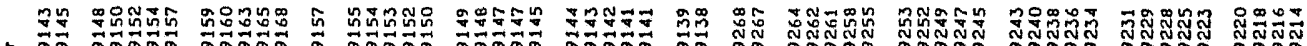

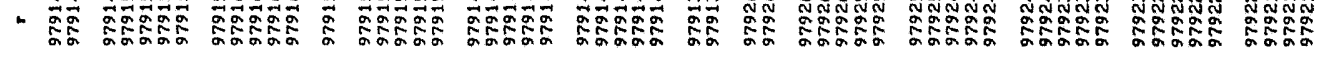

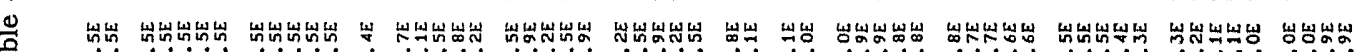

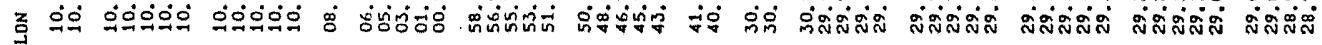
总

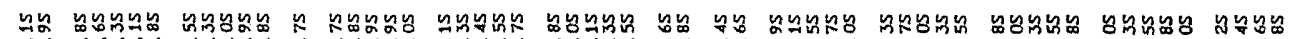
茎 ส

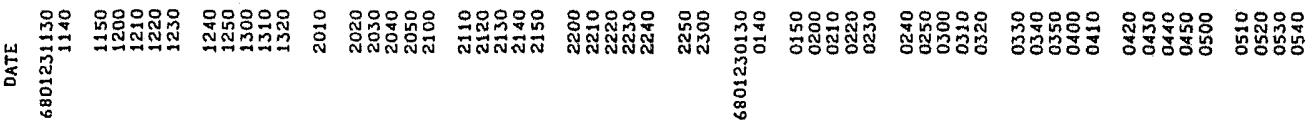

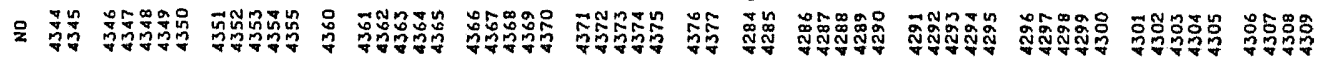




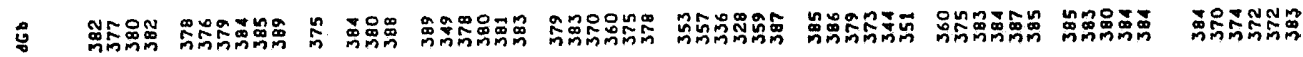

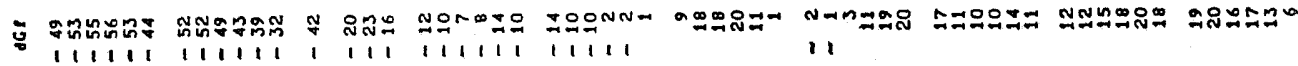

芩

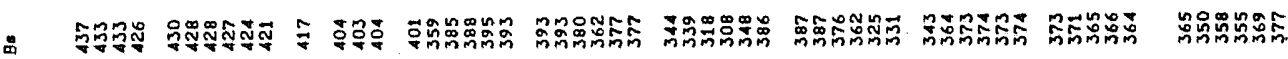

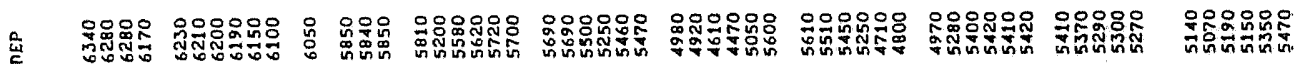

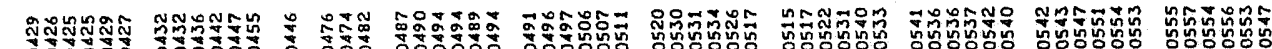

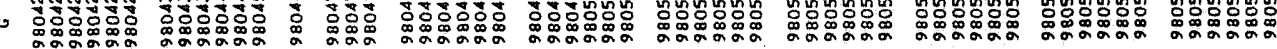

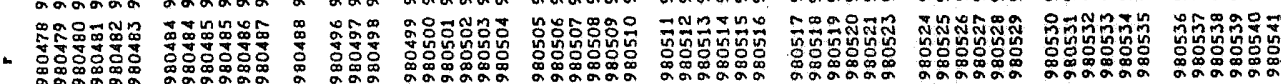

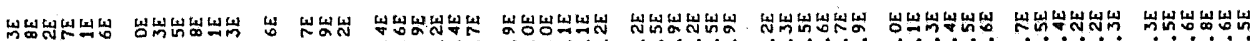

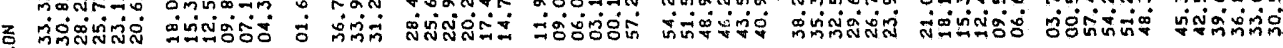

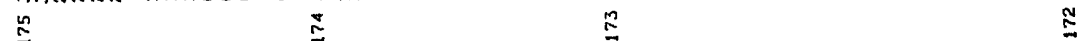

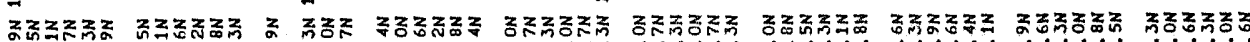

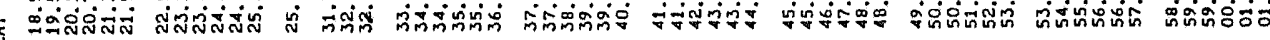
7

욱욱웅 崩 密

₹

iั

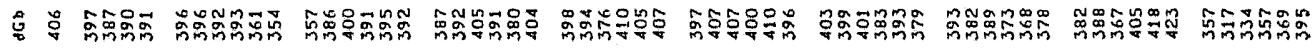

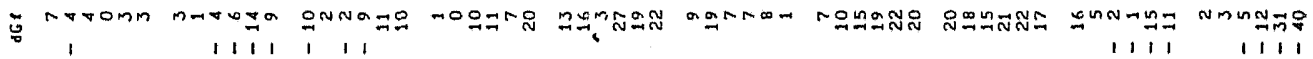

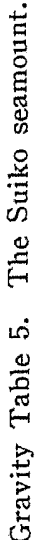
$\stackrel{\text { m }}{\circ}$

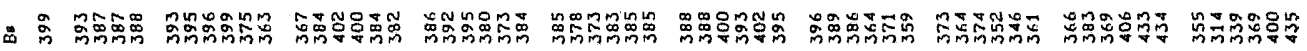

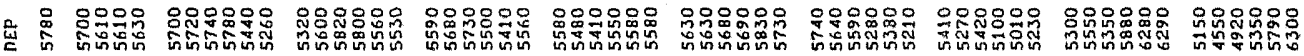

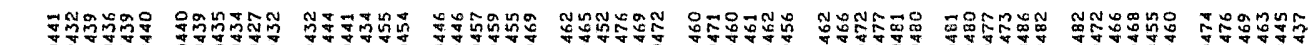

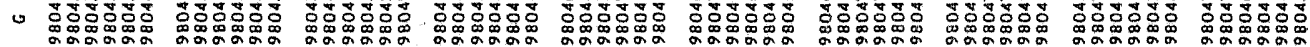

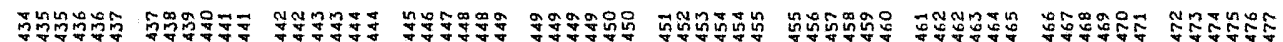

" D. D.

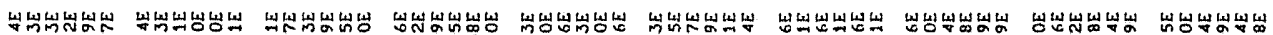

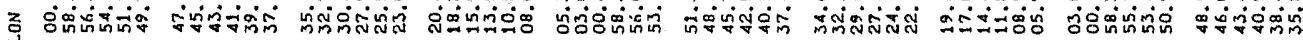

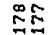
$\stackrel{1}{1}$

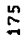

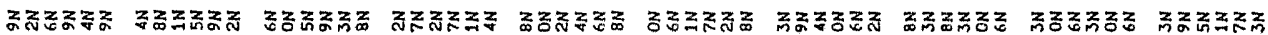

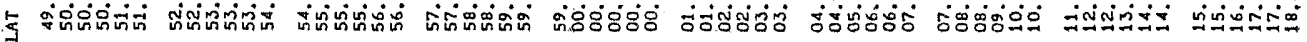
ษ

崖

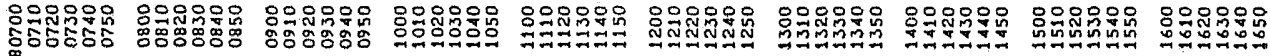


$\ddot{:}$

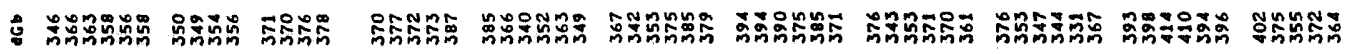

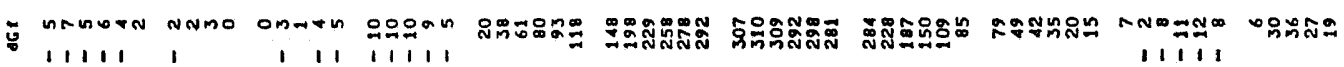
๓

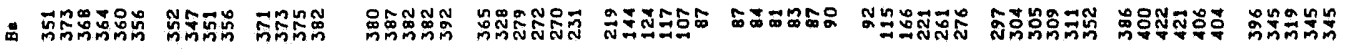

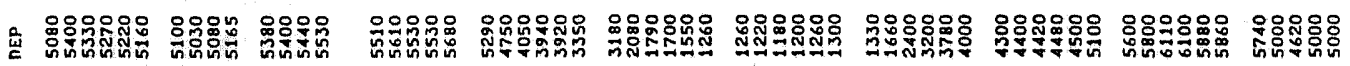

-

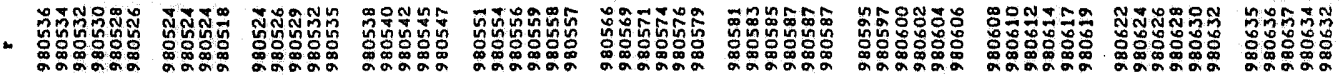

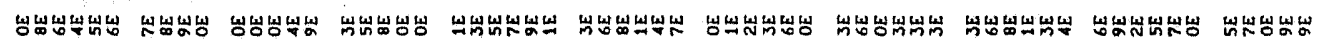

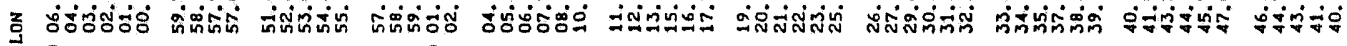
过

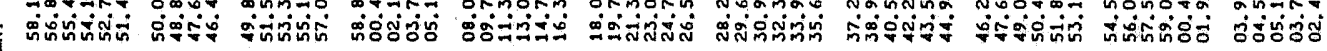
? นิ

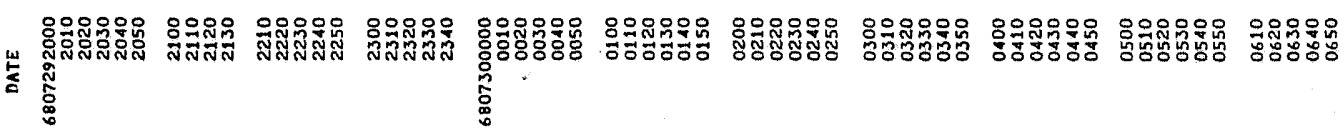
₹

¿

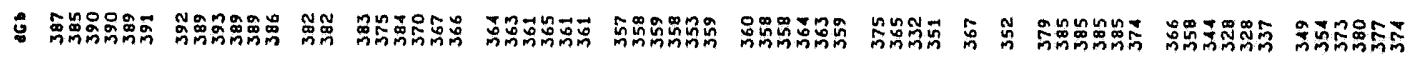

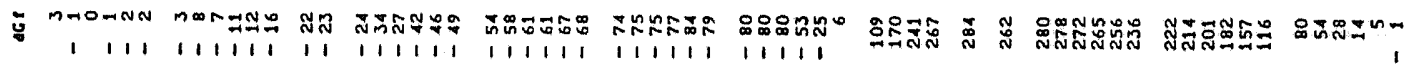
品

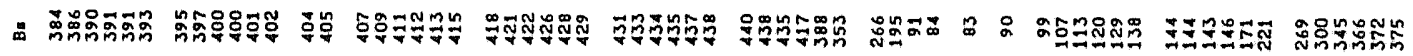

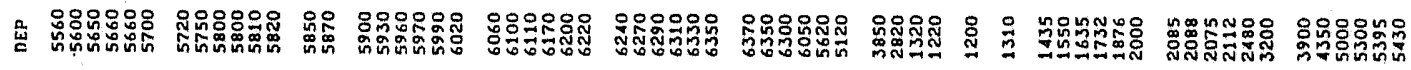

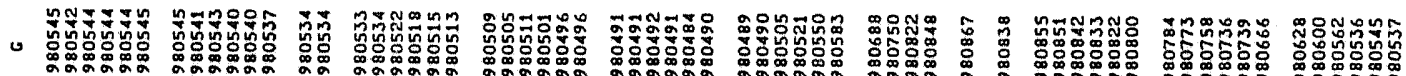
N

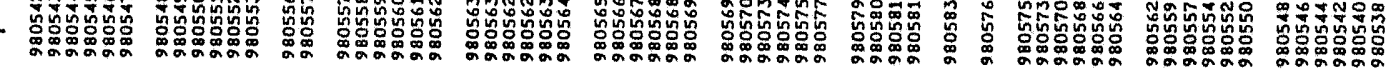

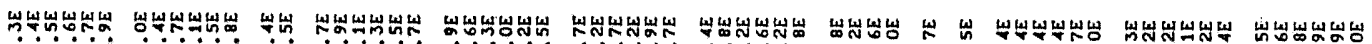

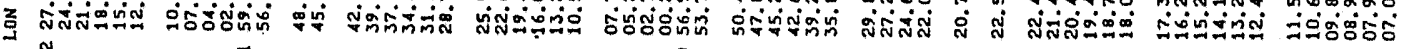
$\cong \quad \Xi \quad \cong$

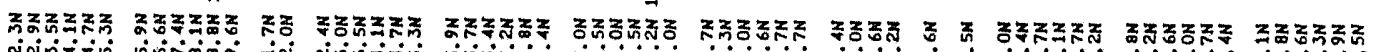

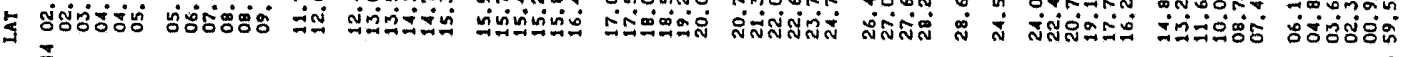
₹

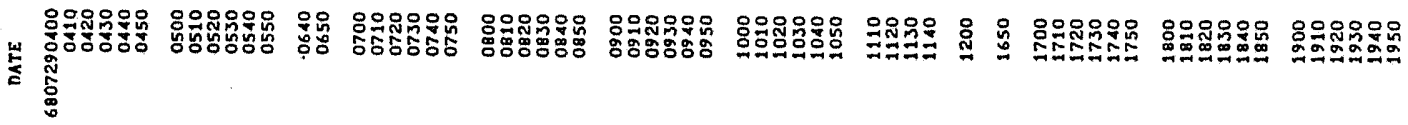


:

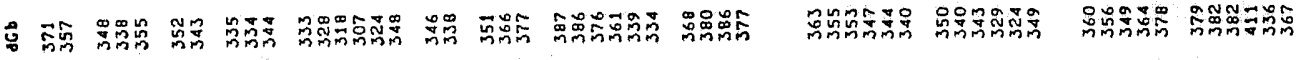

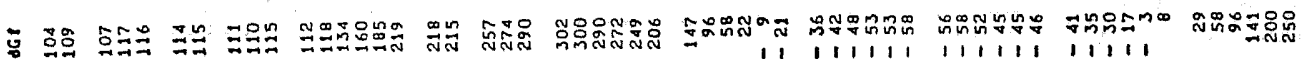

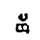

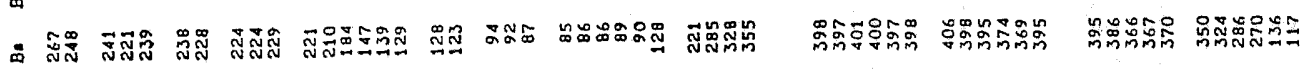

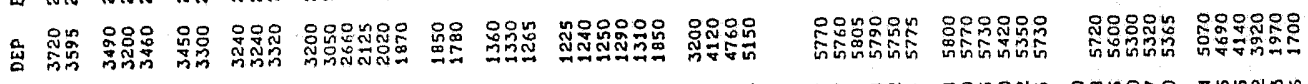

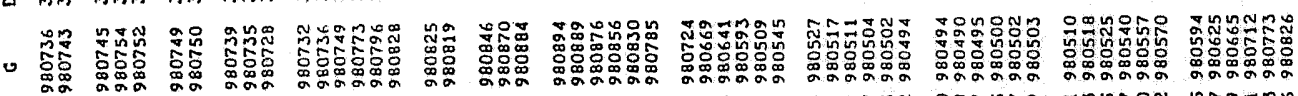

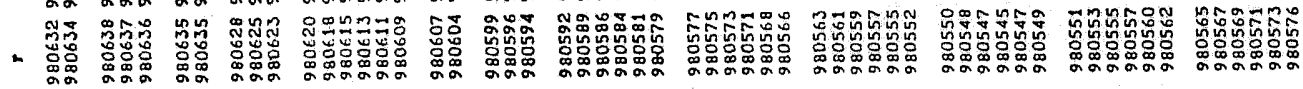

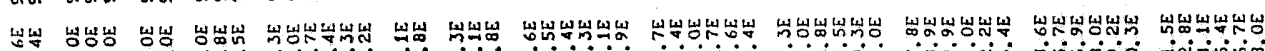

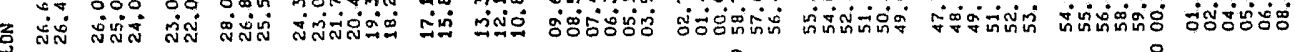
$\stackrel{1}{ }$

$\stackrel{0}{\circ}$

$\stackrel{ }{2}$

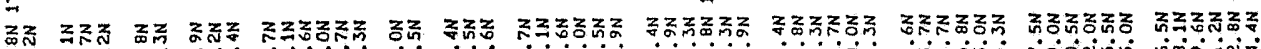

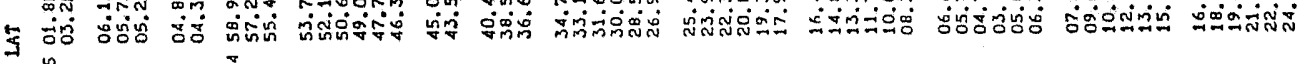
芩

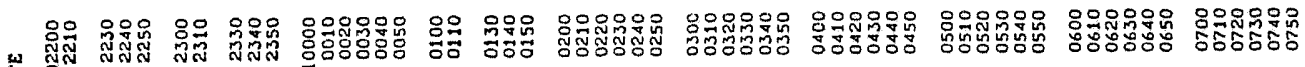

岌 兽

울

:

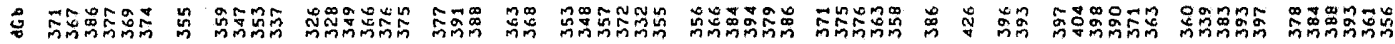

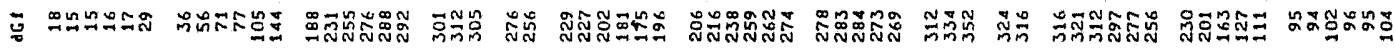

品

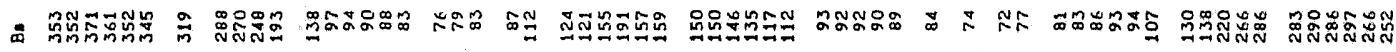

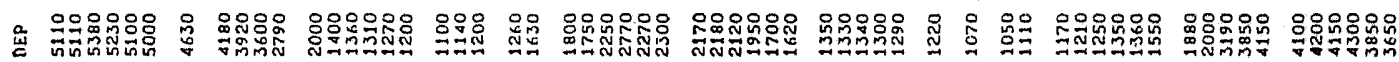

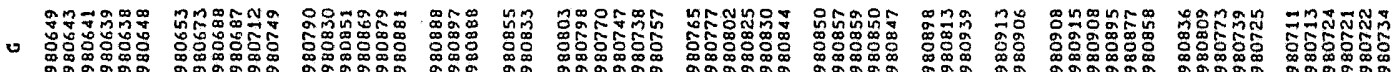

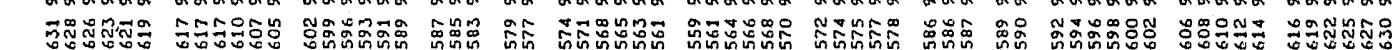

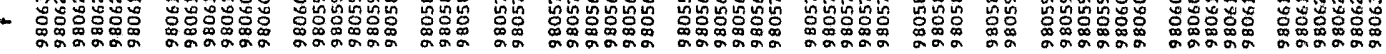

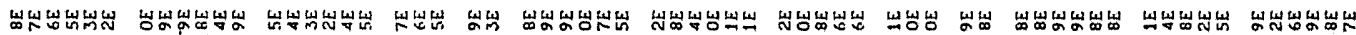

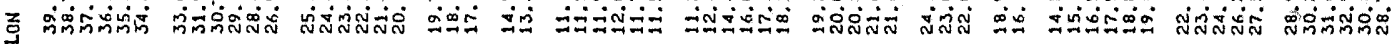
$\stackrel{1}{2}$

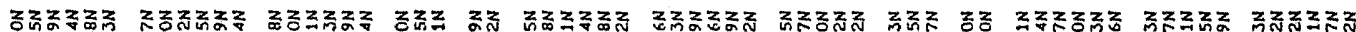

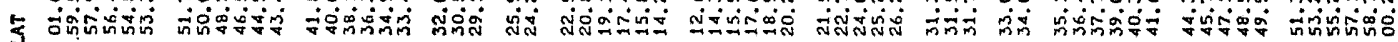
ที 案

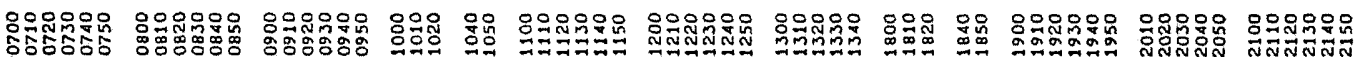




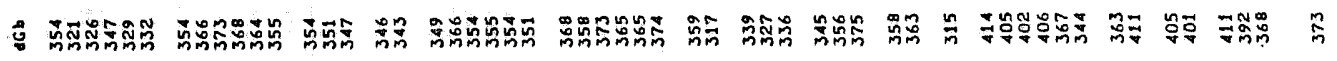

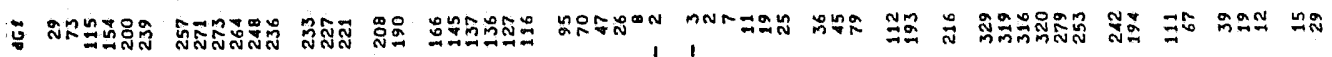
.ั

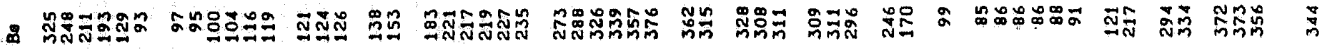

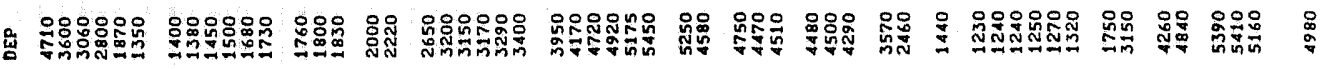

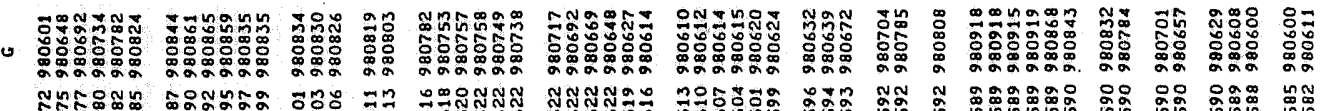

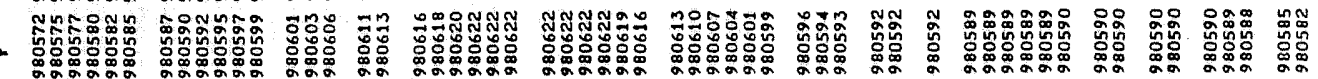

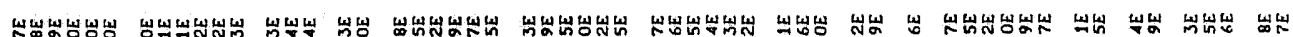

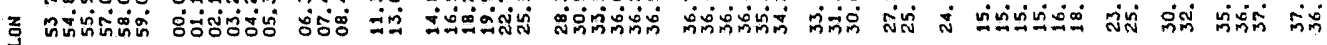
$\stackrel{2}{\square}$

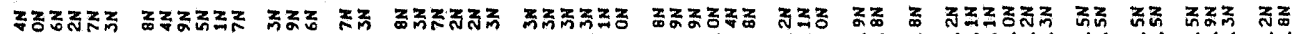

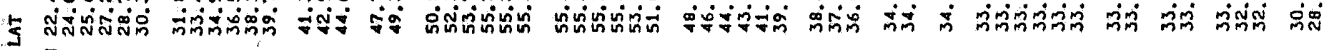
\

崖

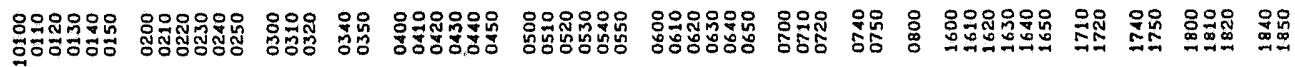
离

g

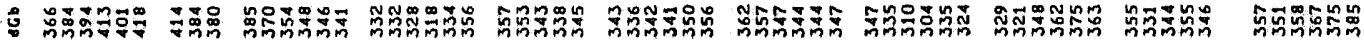

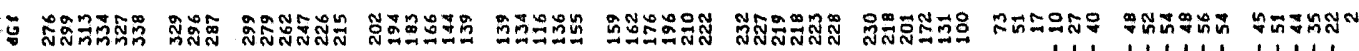

ณ

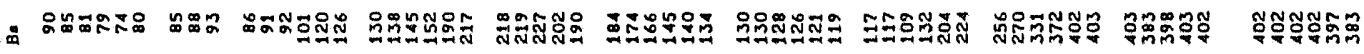

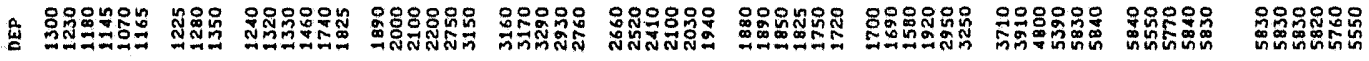

ט

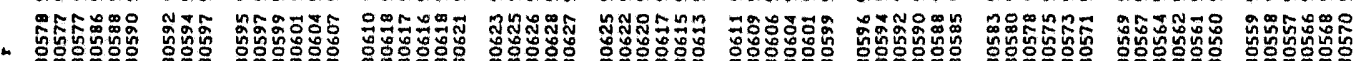

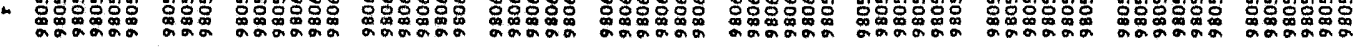

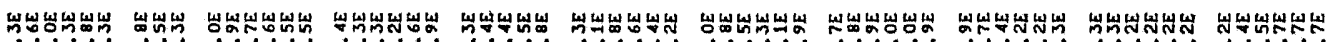

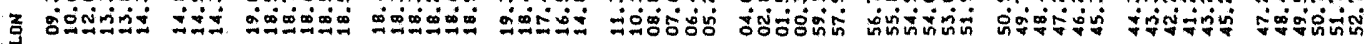
$\stackrel{8}{\stackrel{2}{2}}$

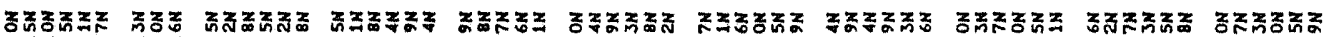

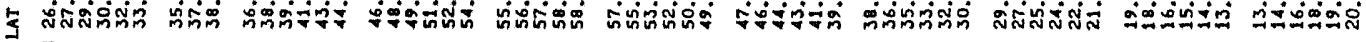
$\checkmark$ 崖

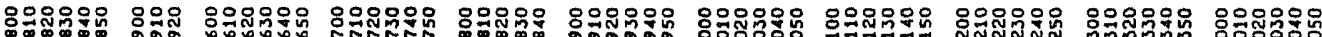
总 
¿

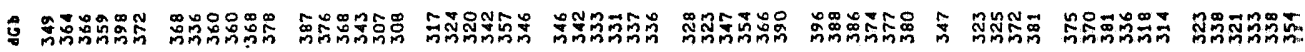

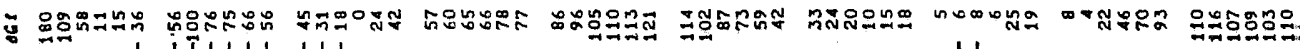

品

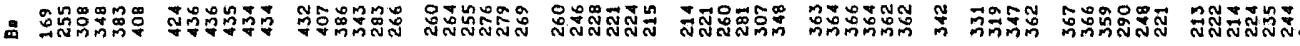

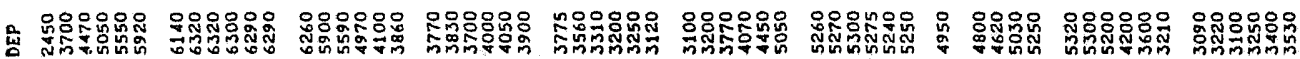

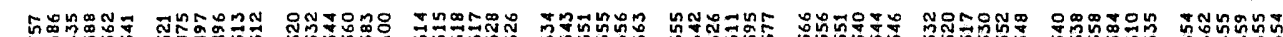
0 - F̂م 岩岩出出出

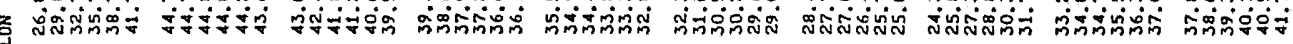
$\stackrel{9}{\stackrel{2}{2}}$

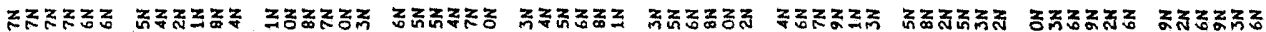

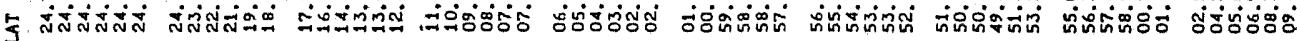
\& m \&

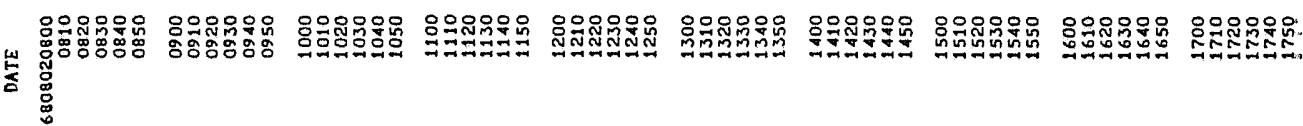
운

范

ఫ ษ คัง

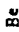

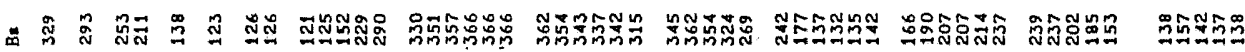

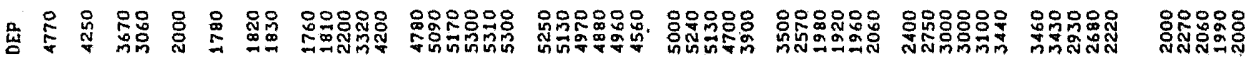

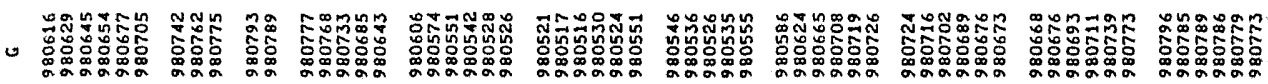
m.

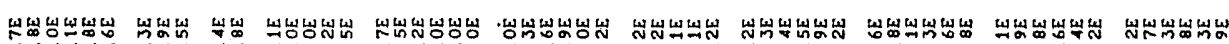

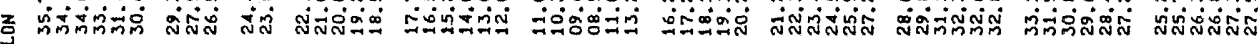
吕

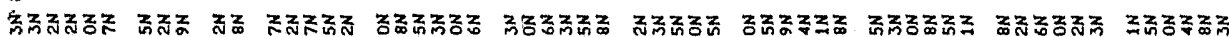

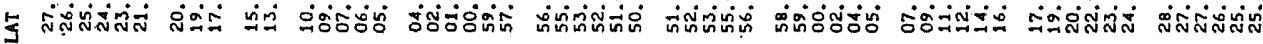
¥ \% 廿

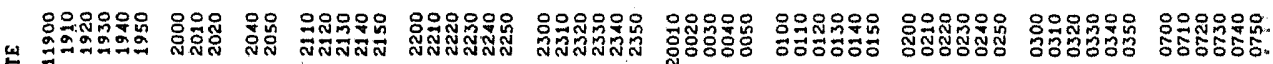
怘 
:

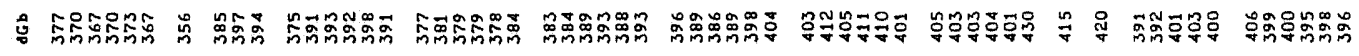

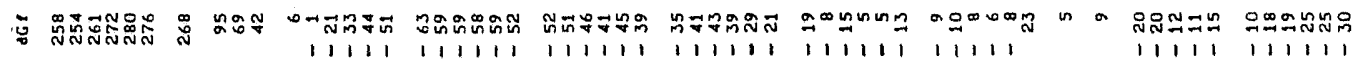

$\stackrel{\circ}{\circ}$

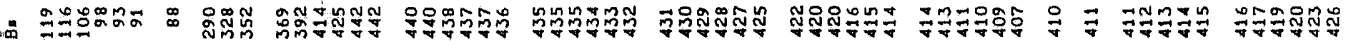

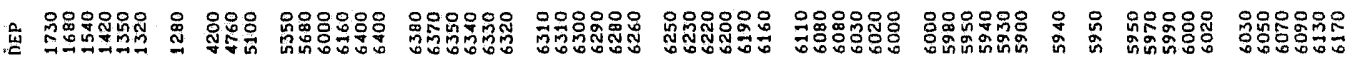

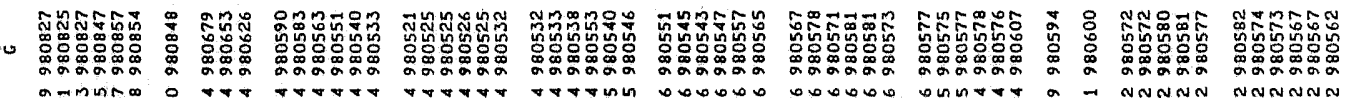

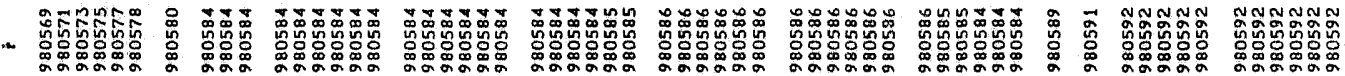

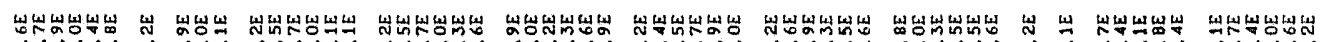

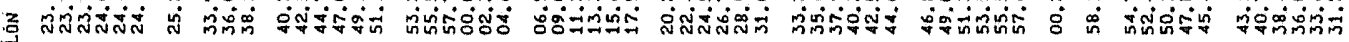
늘

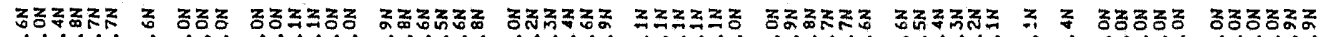

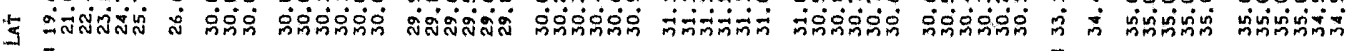
广

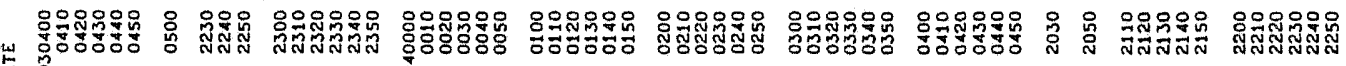
똠 岕 总

号

i⿱

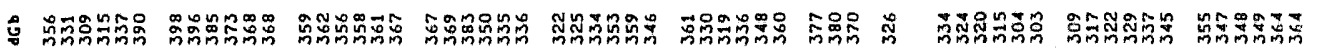

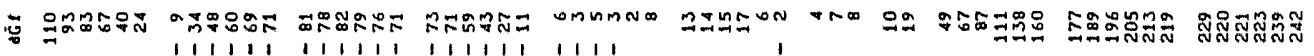
品

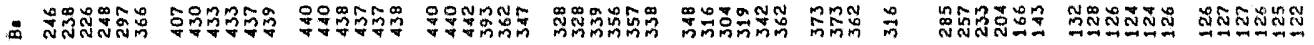

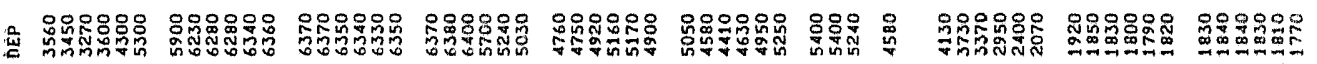

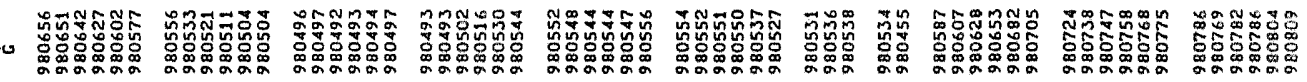

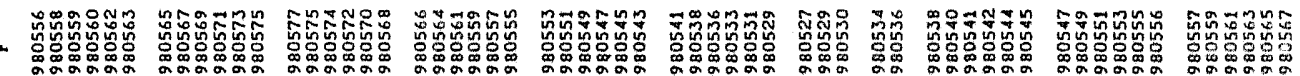

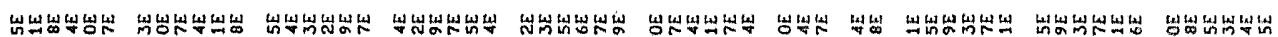

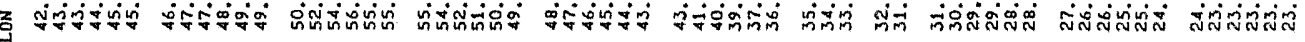
$\therefore$

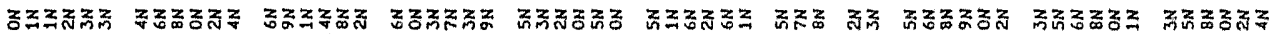

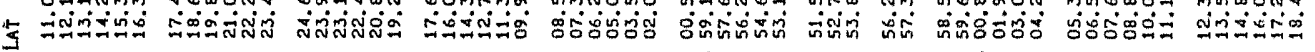
₹ จ \$

崖

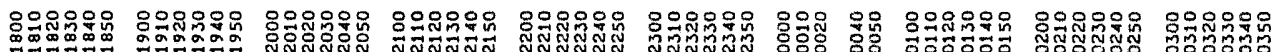
离

문 
荌

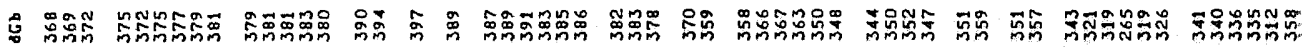

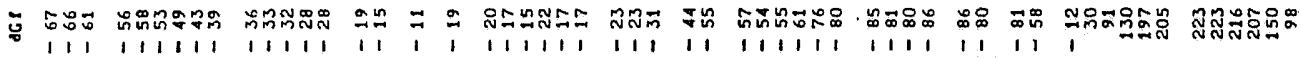
品

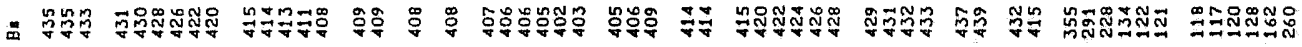

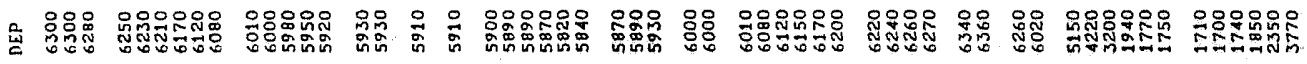

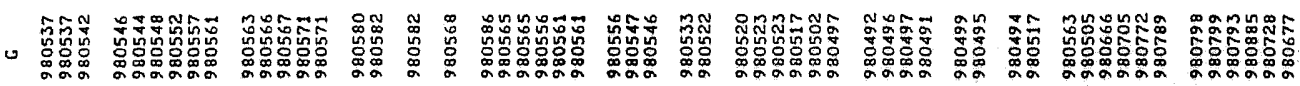

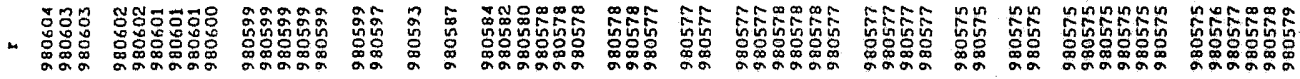

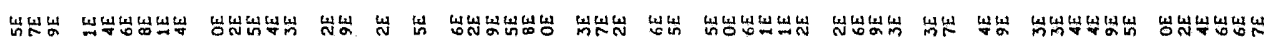

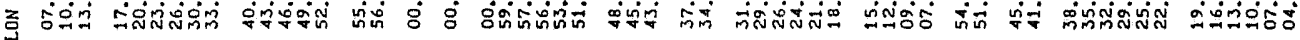
E $\cong \quad \vec{E}$

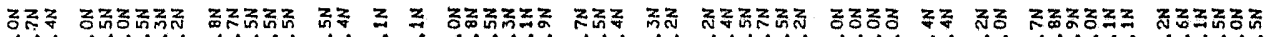

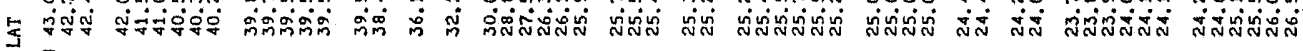
४

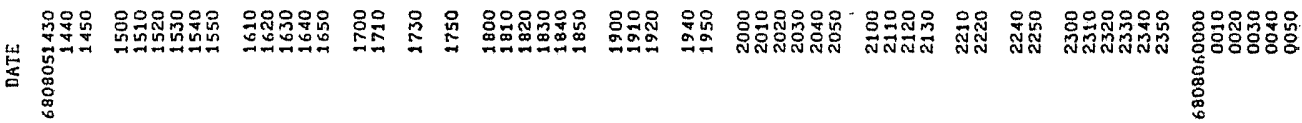
号

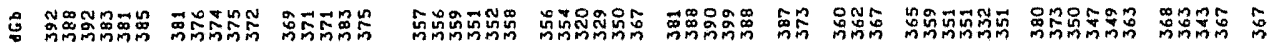

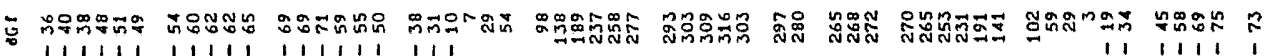
๓

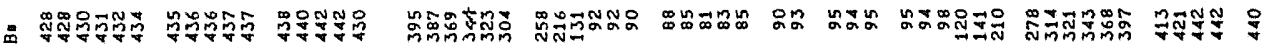

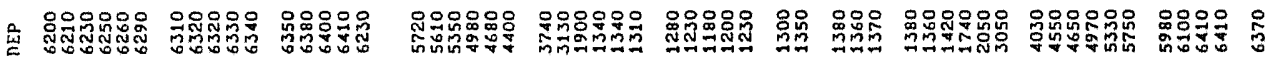

七

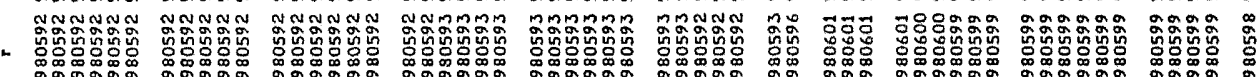

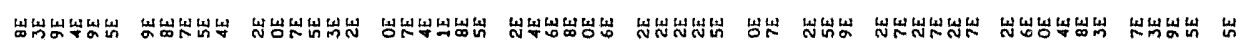

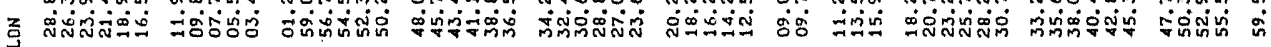

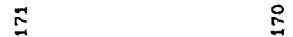

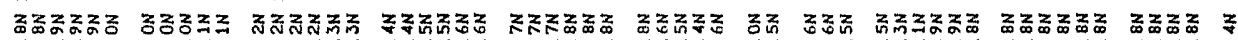

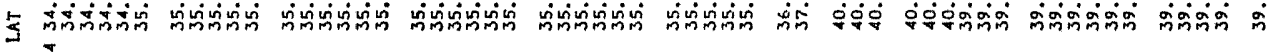
ఫ

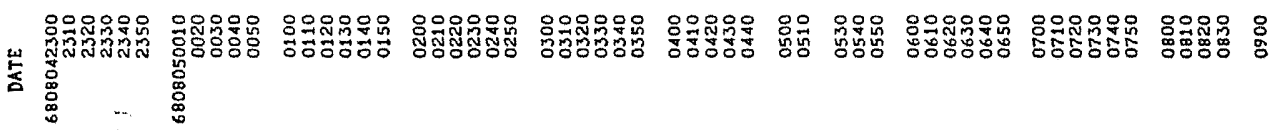

울 
:ै

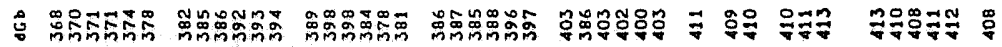

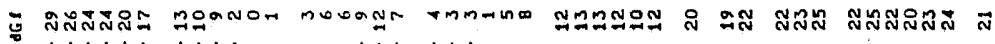

111111111

๕ั

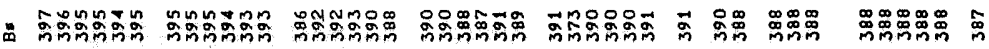

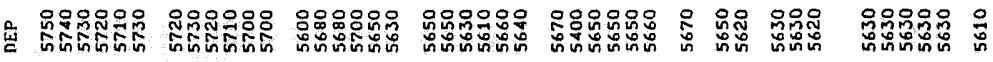

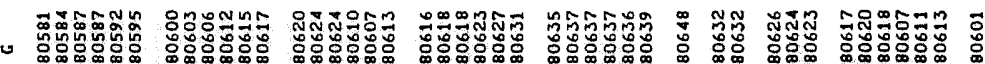

品

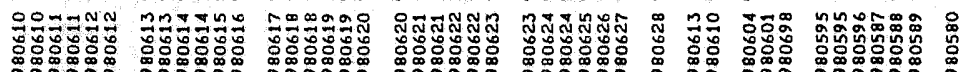

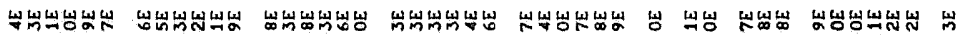

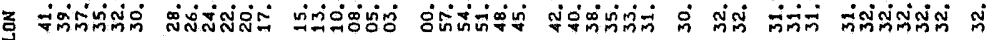
$\stackrel{\infty}{ \pm}$

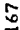

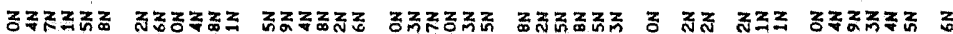

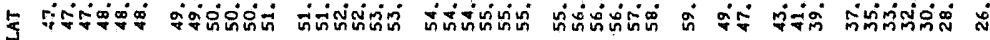
廿

湈

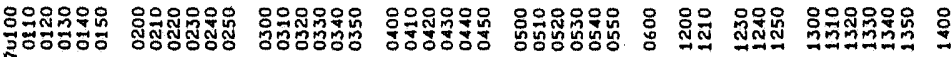

울

$\ddot{\circ}$

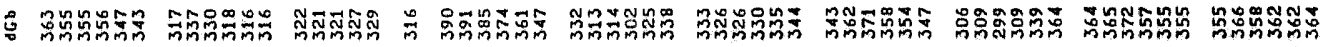

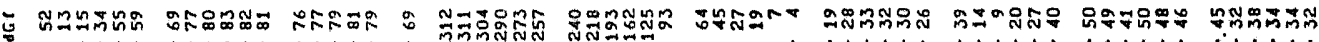
1111111111111111111111111111111111

⿷匚

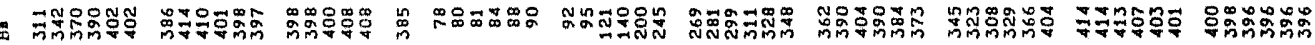

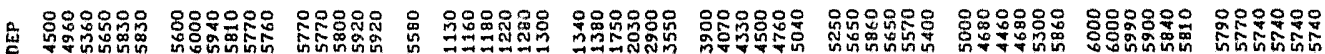

Nㅡㅇำำำ

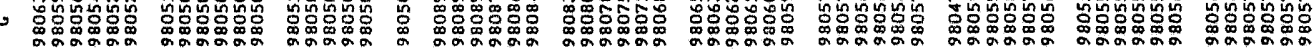

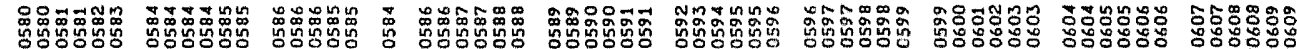

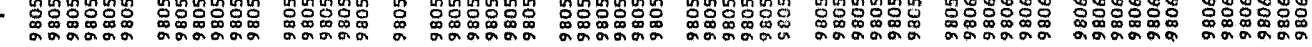

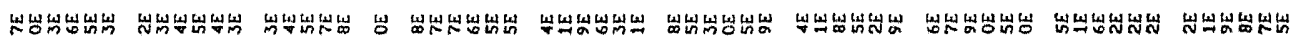

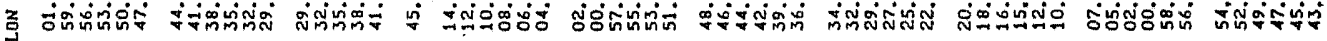

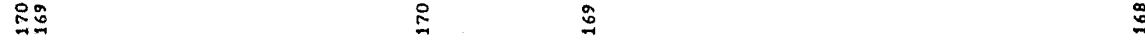

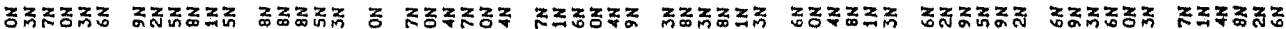

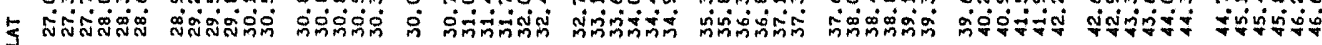
₹

终

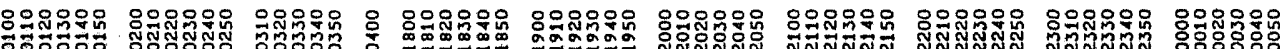
兽 


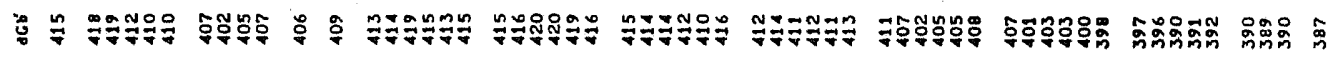

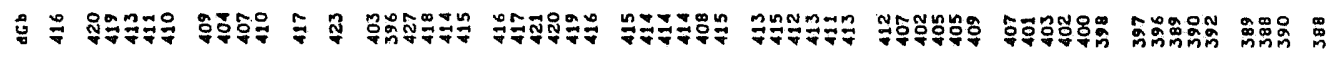

ธุ

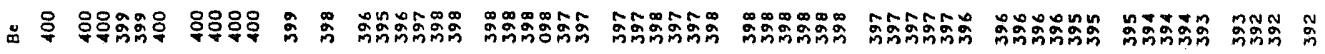

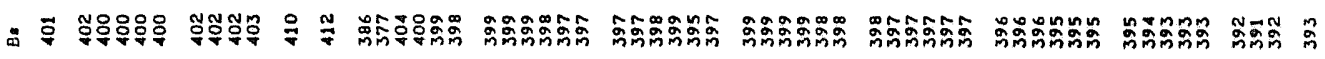

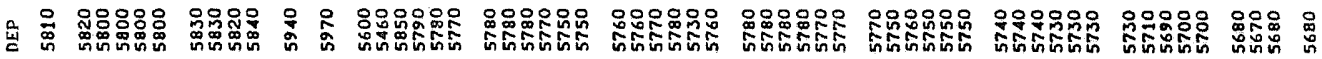

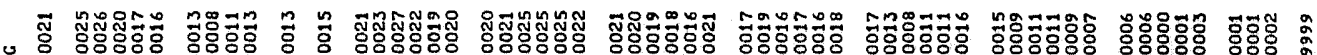

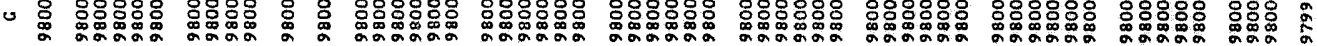

- 宮

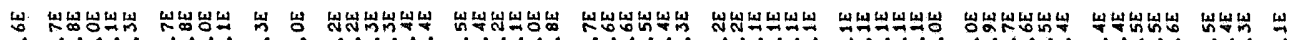

Z ถ ถึ 品

in in

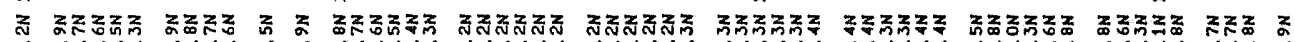

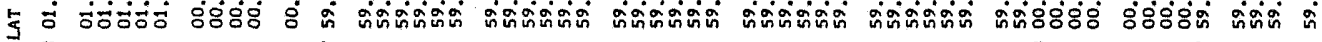

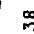
iิ

i is

岁

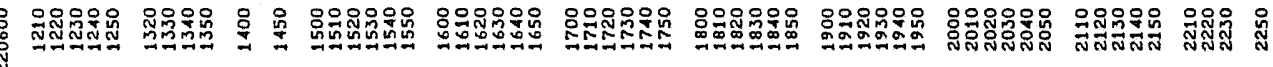

울

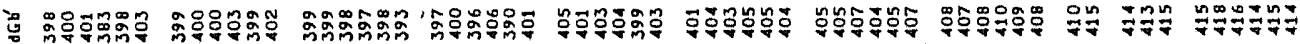

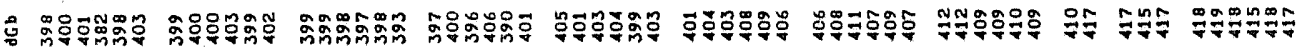

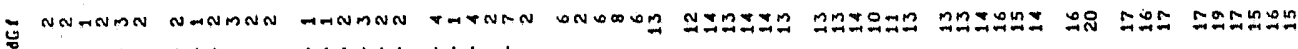
$1111111 \quad 1111111111$

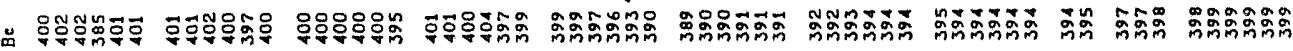

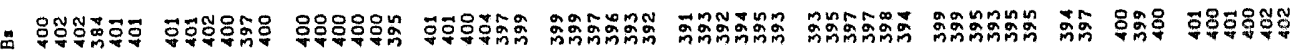

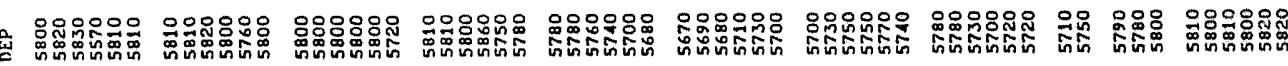

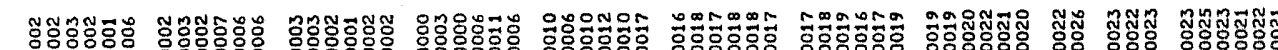

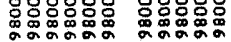

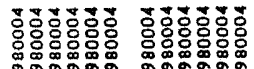

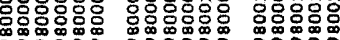

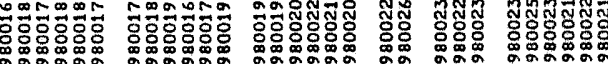

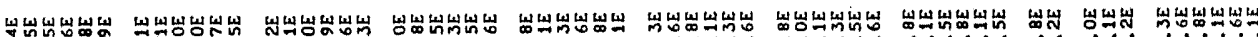

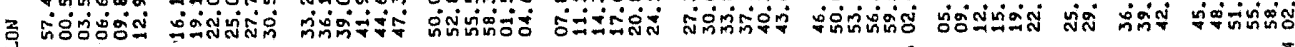

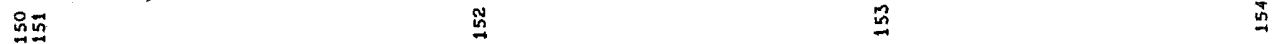

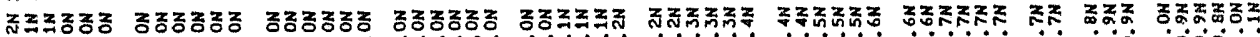

ร m

绦

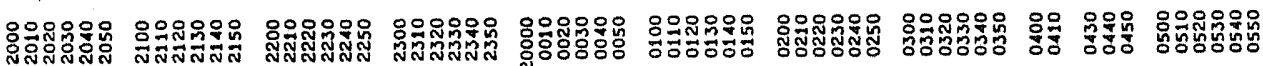
. 芯. 


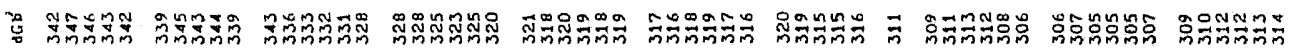

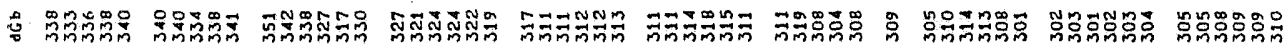

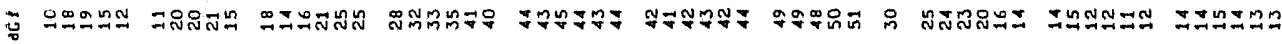

แ :

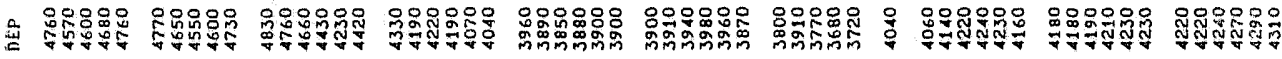

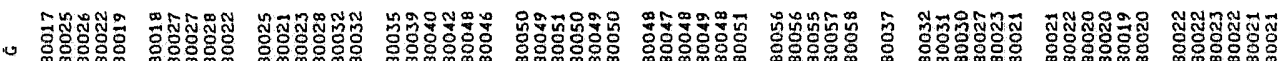

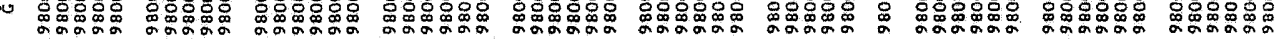

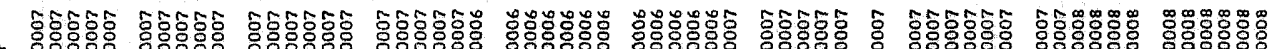

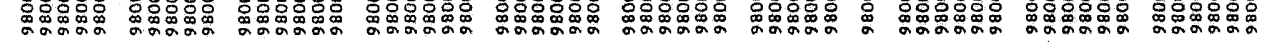

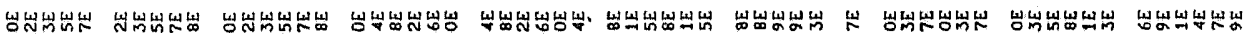

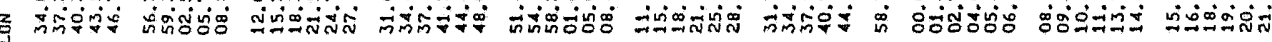

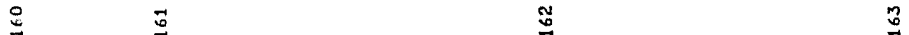

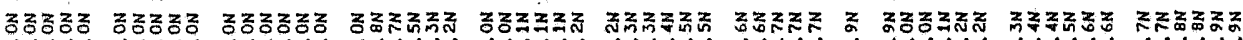

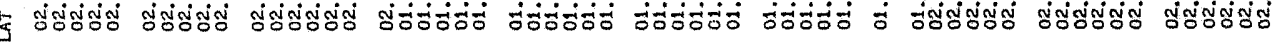
罚

点

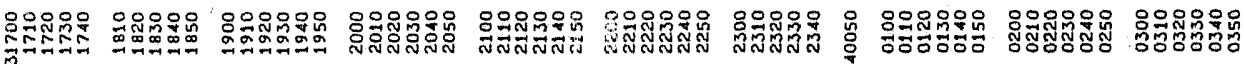
商

운

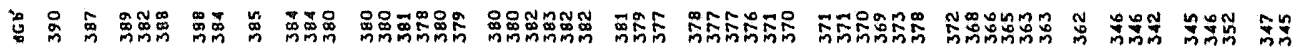

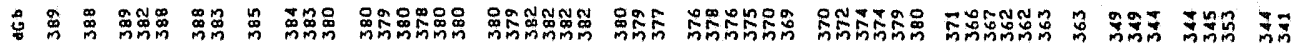

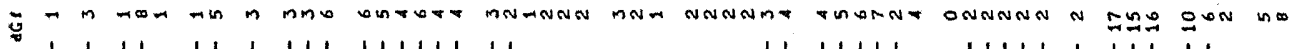

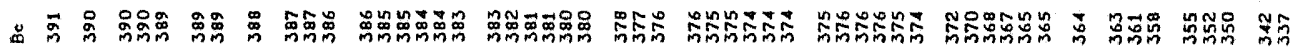

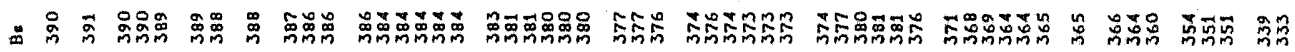

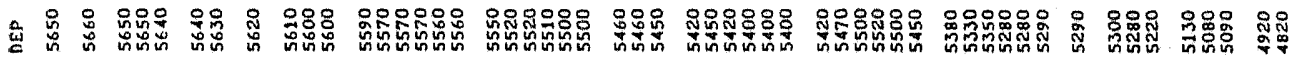

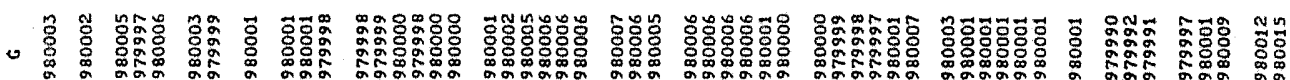

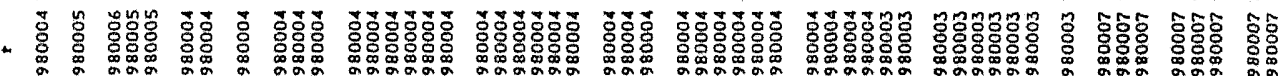

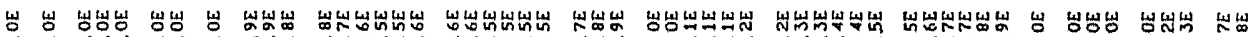

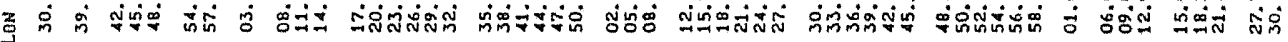

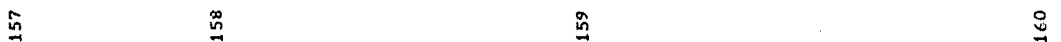

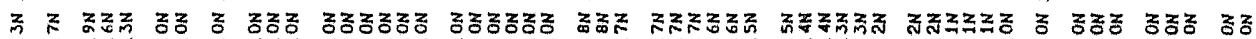

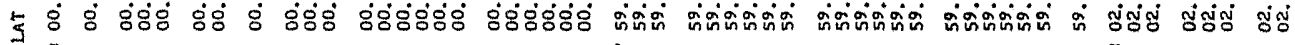
(1) in के

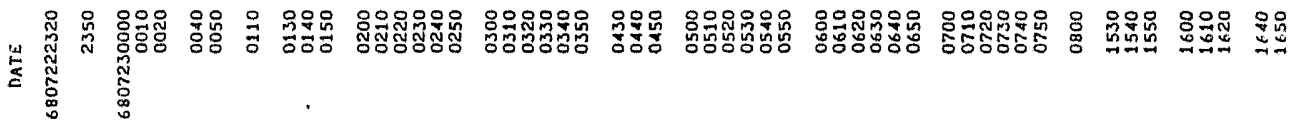




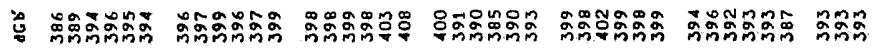

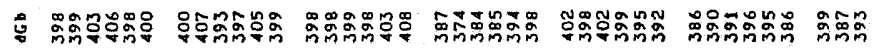

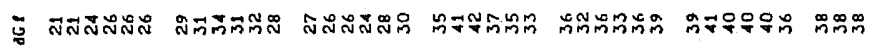

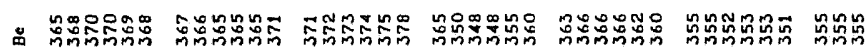

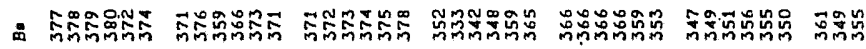

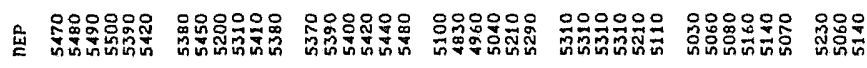

$\rightarrow$

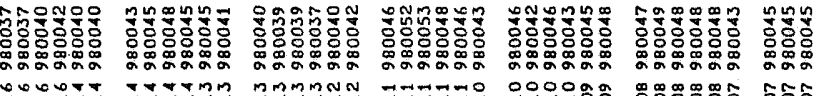

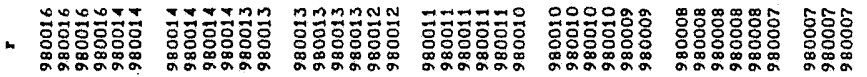

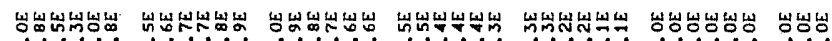

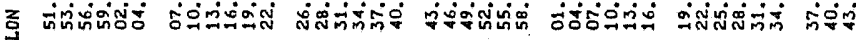
$\stackrel{n}{\longleftarrow}$

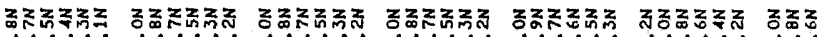

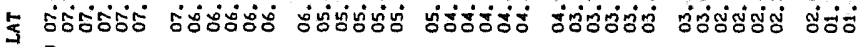
क

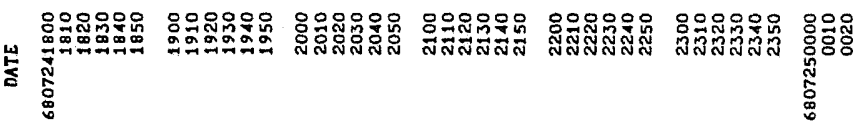

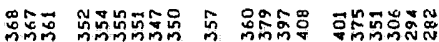

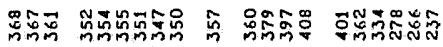

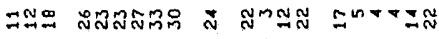
111111111111

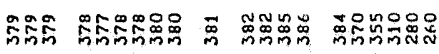

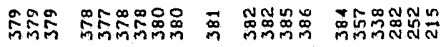

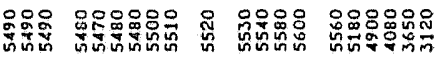

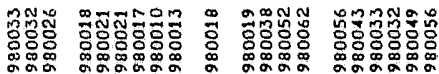

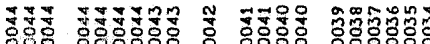

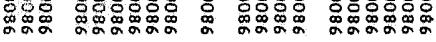

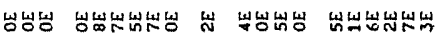

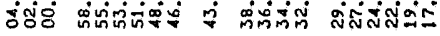
$\stackrel{0}{=}$

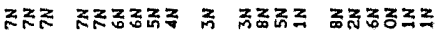

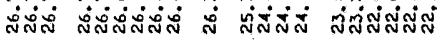
禹

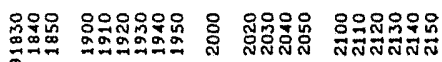

우

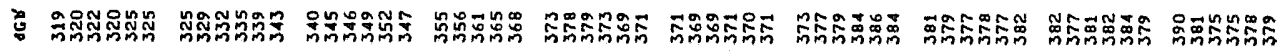

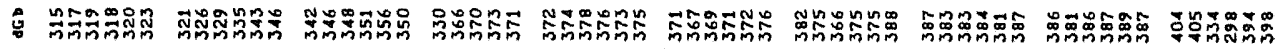

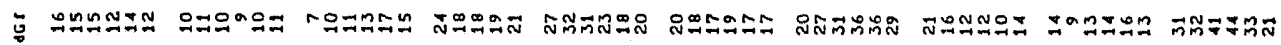

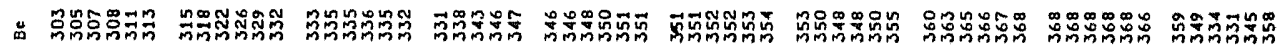

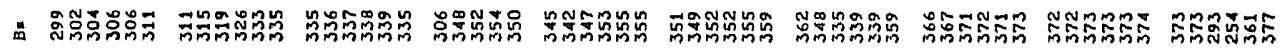

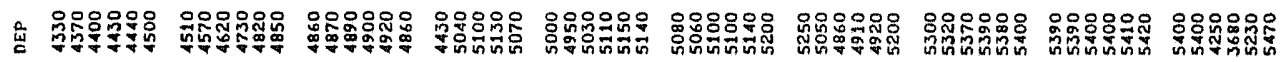

•

-

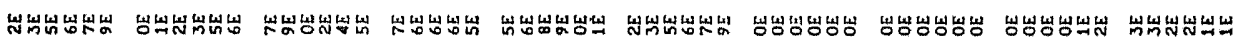

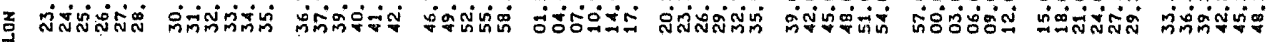
$\$$

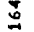

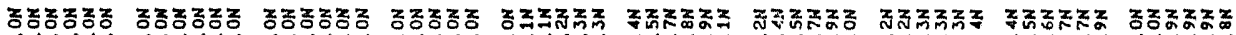

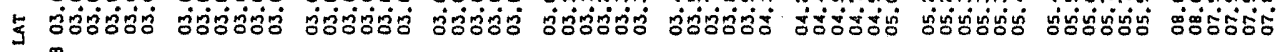
品

岕

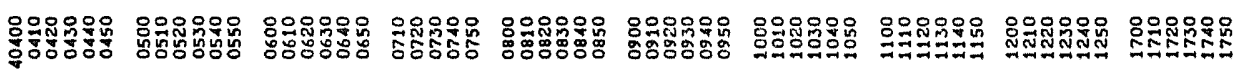
a 


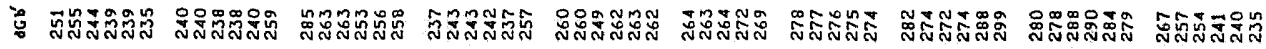

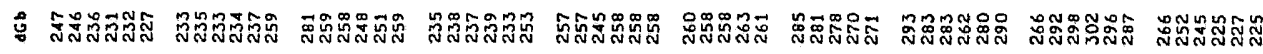

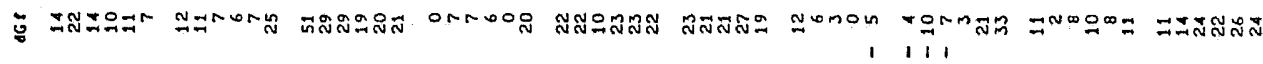

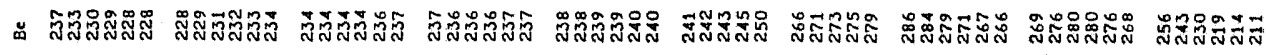

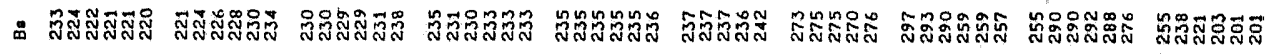

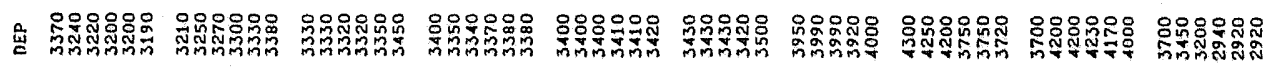

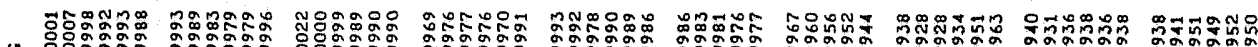

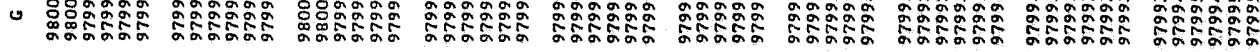

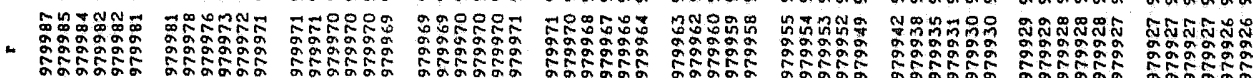

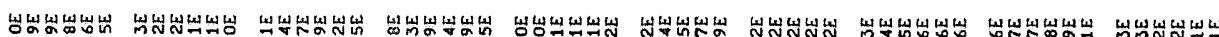

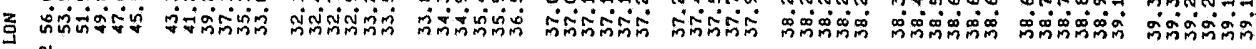
$\stackrel{-10}{2}$

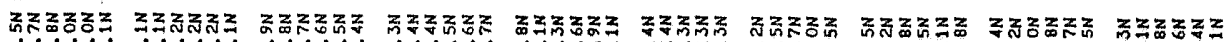

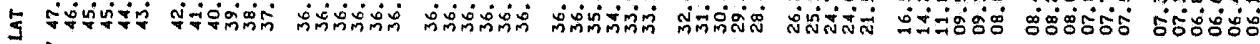
in

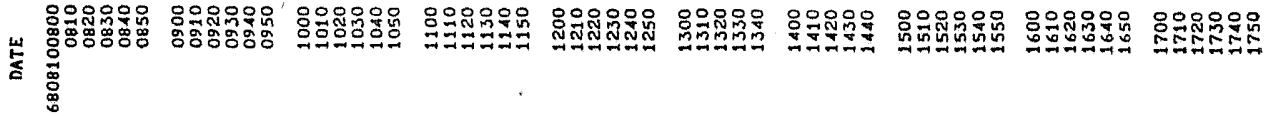

;

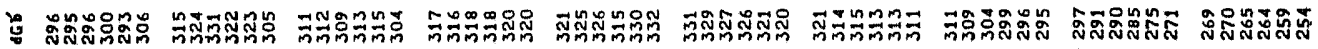

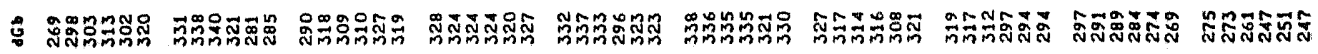

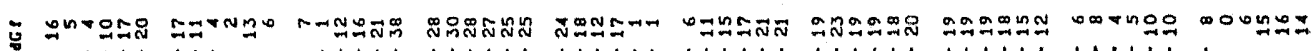

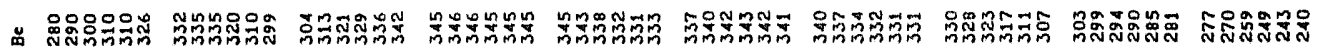

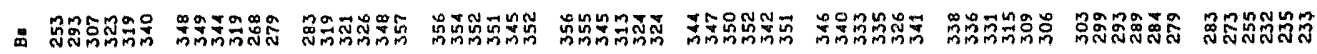

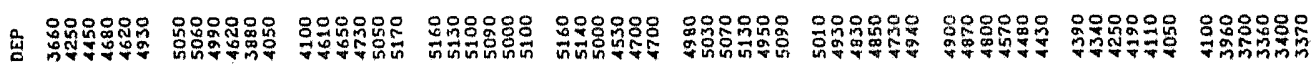

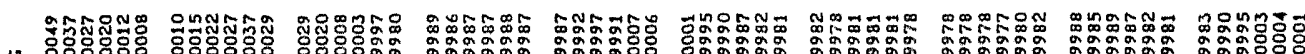

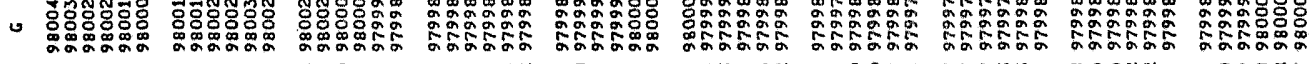

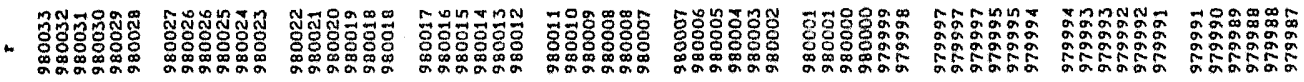

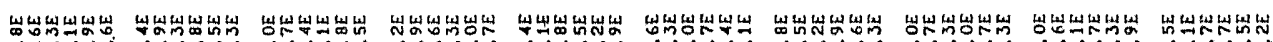

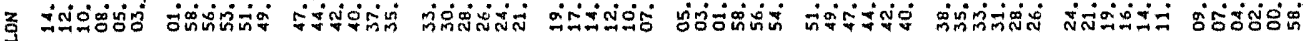
品

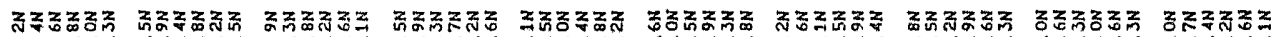

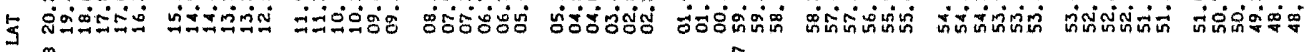
吕

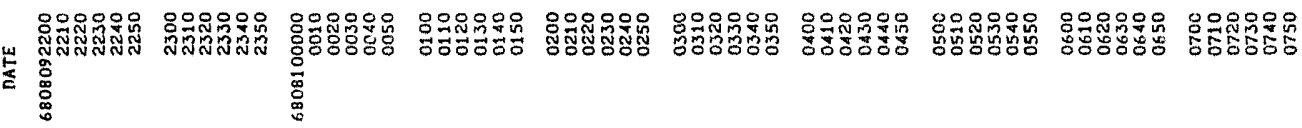


ำ

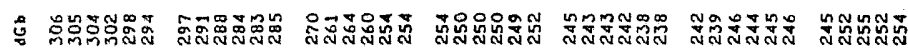

ت

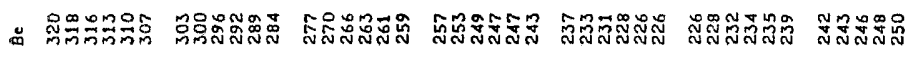

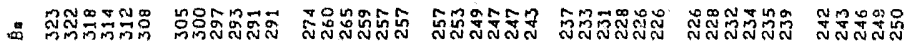

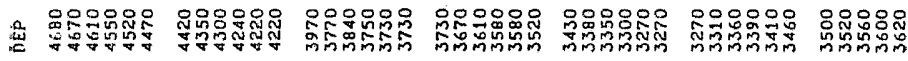

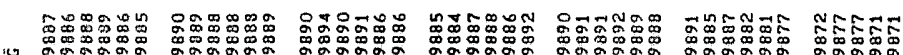

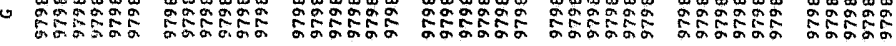

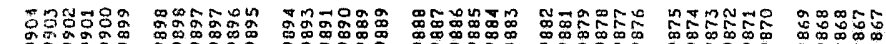

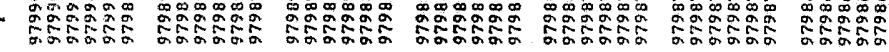

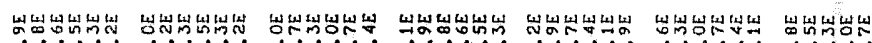

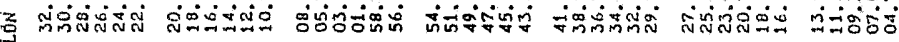
每

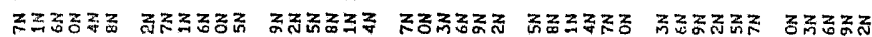

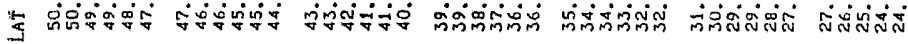
品

管

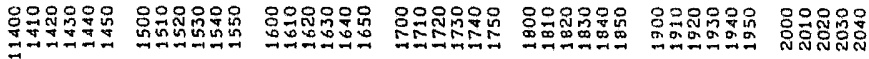
善

是

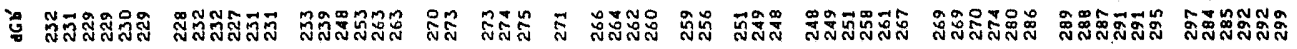

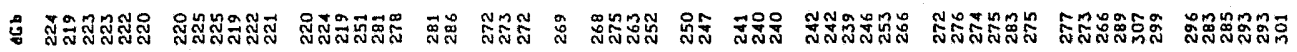

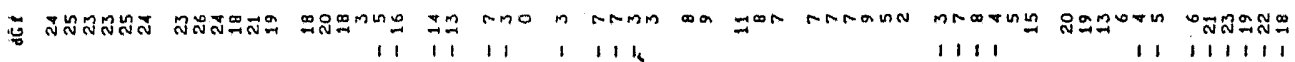

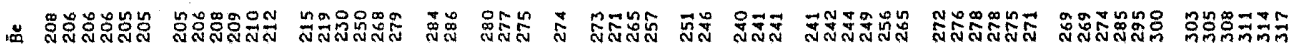

:

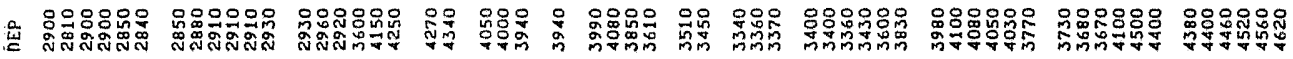

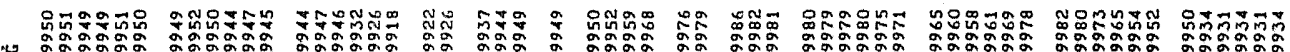

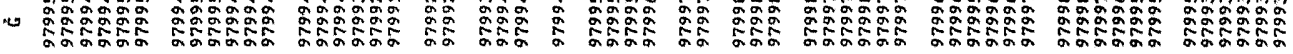

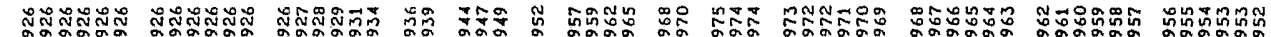

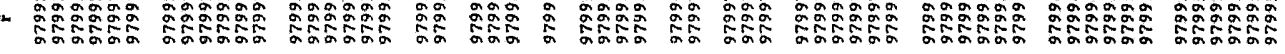

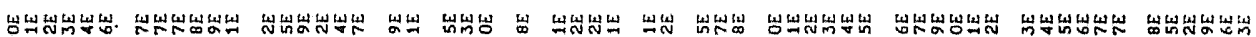

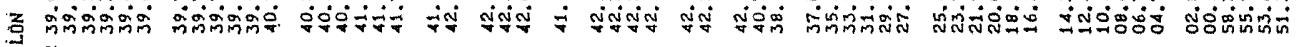
$\cong$

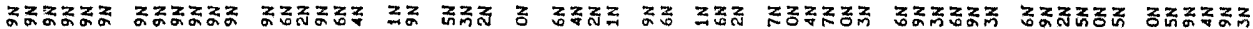

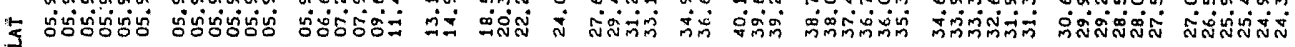
in

宸

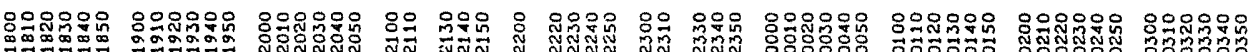




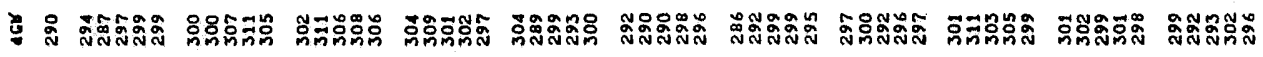

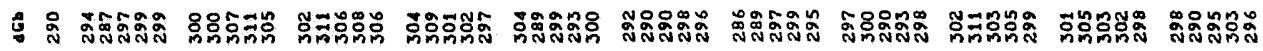

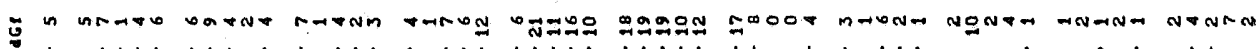
进 \&

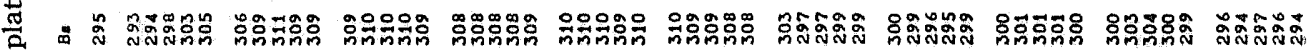

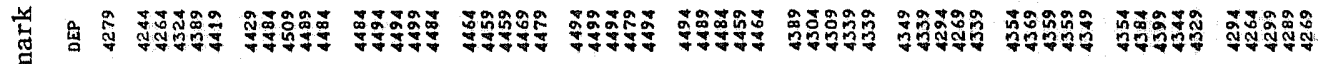

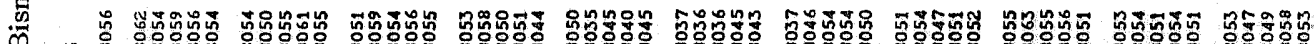

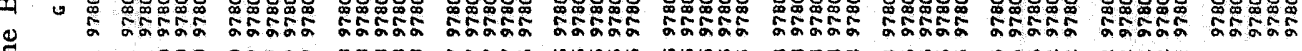
栗

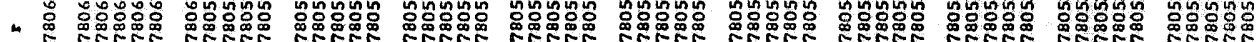

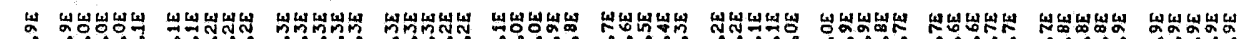

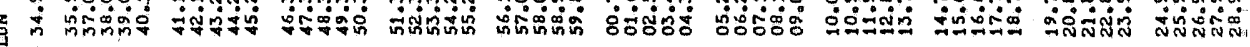
$\underline{\underline{z}}$

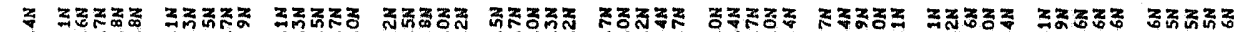

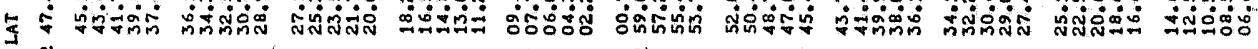
\%

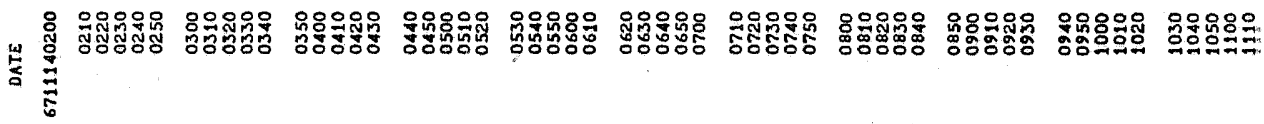

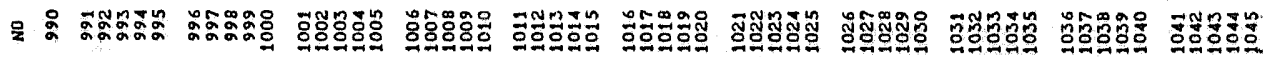

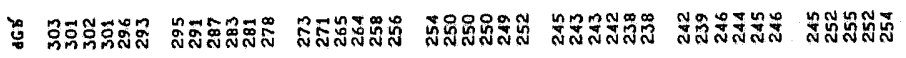

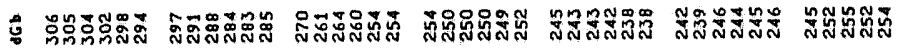

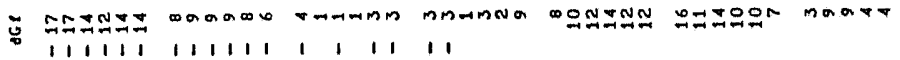

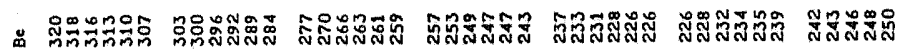

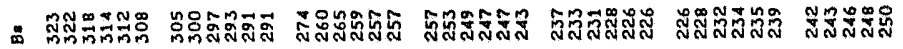

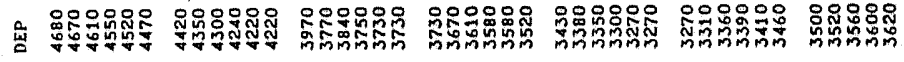

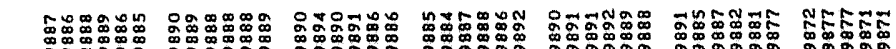

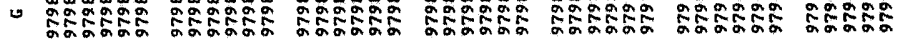

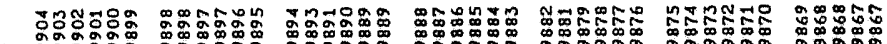

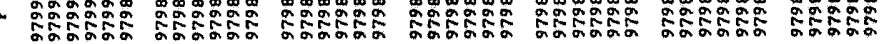

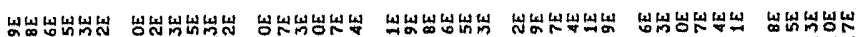

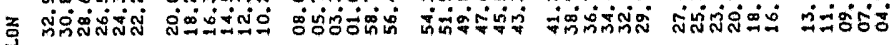
î

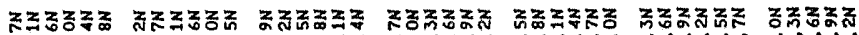

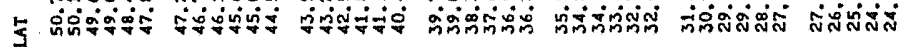
iั

参

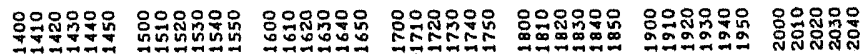
志 


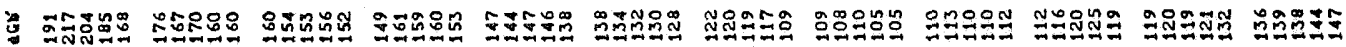

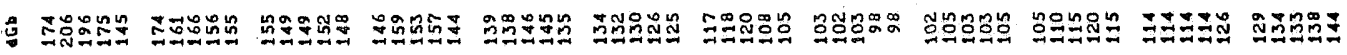

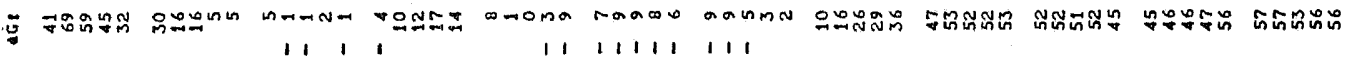

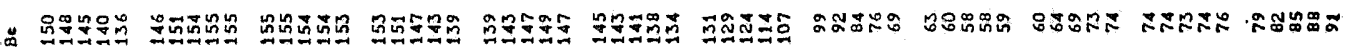

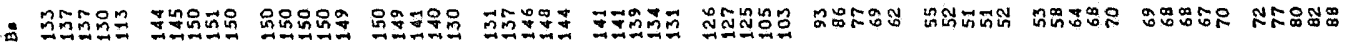

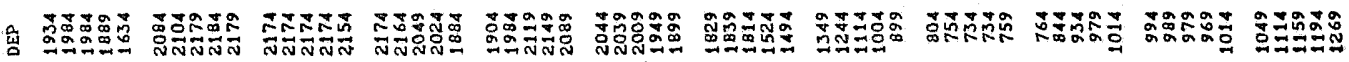

.

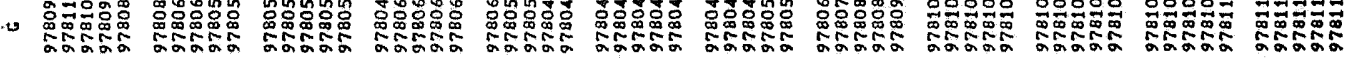

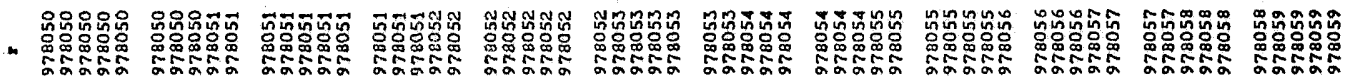

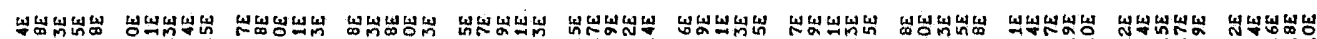

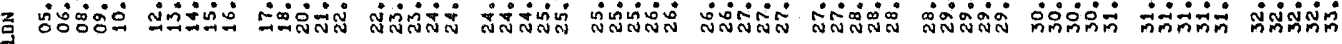
足

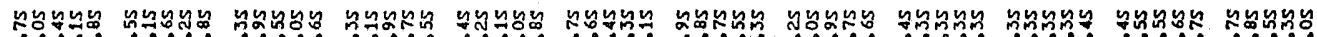

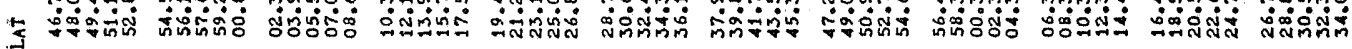

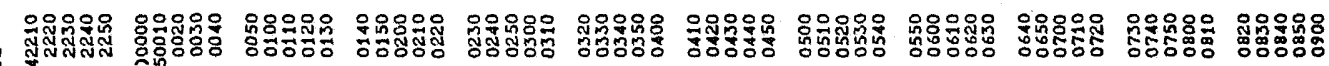

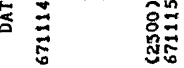

웄

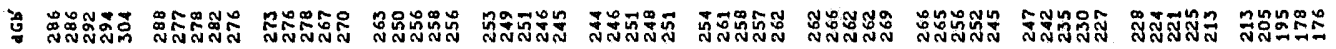

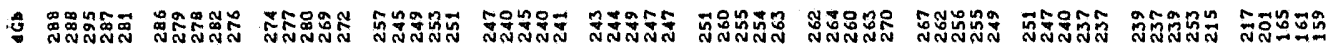

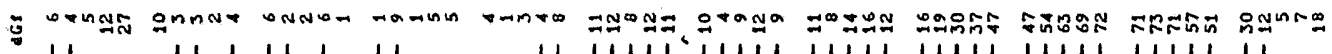

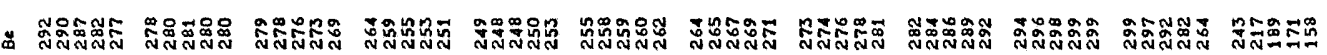

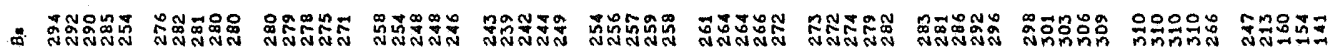

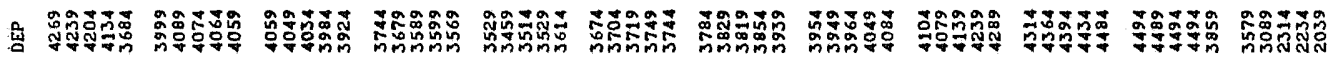

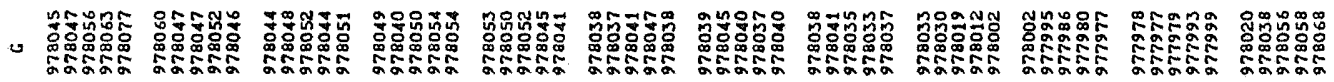

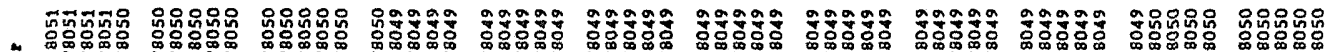

- W0.

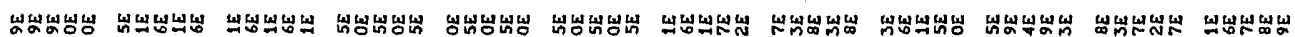

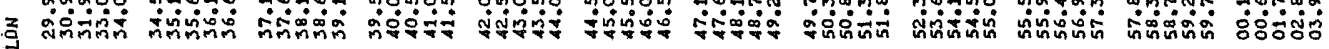
‡

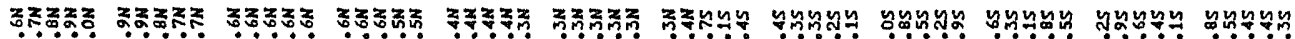

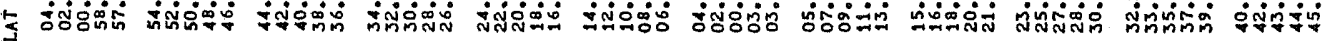
० 8 8

幽

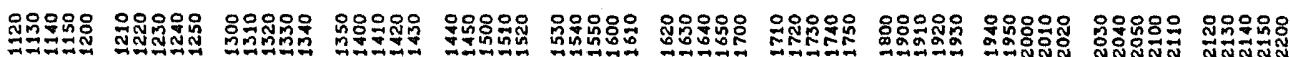
要

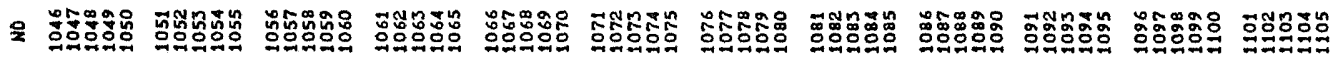




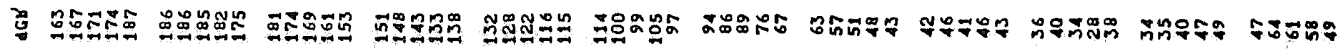

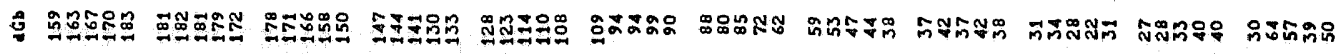

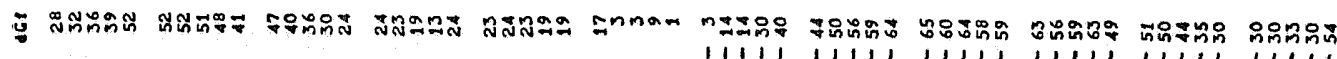

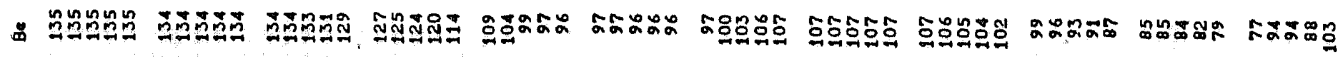

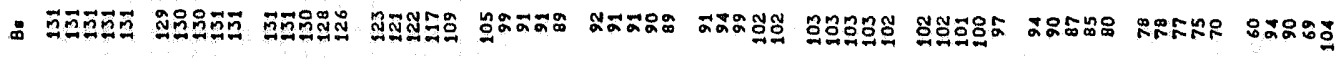

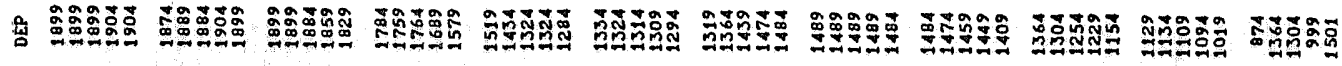

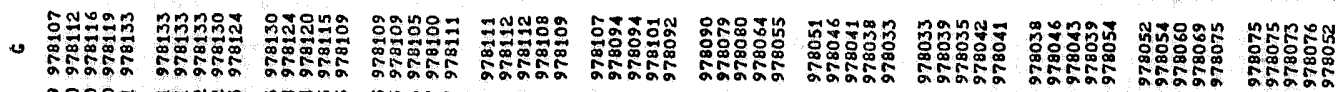

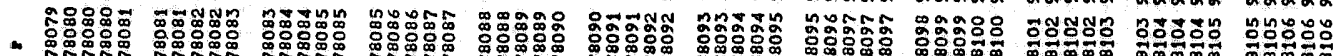

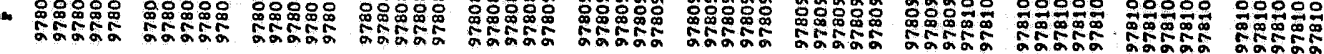

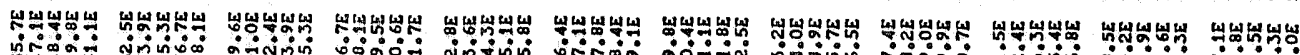

ㄱำ $\vdots \quad$

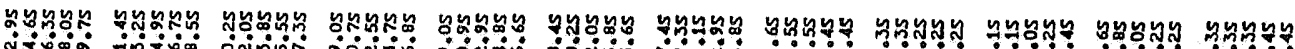

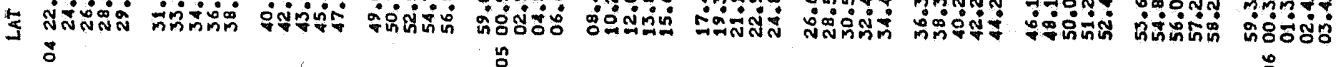

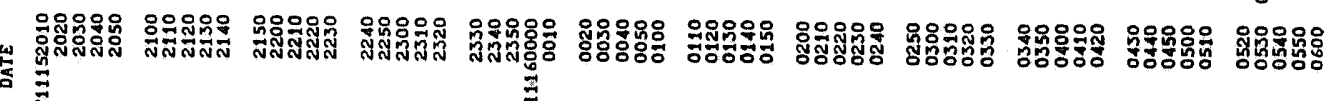
$\underset{3}{3}$

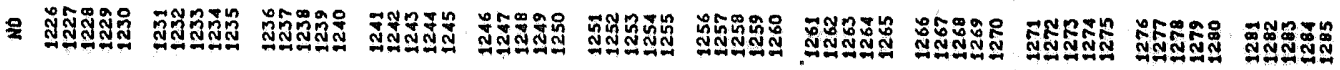

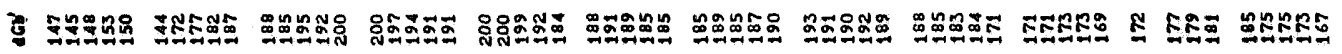

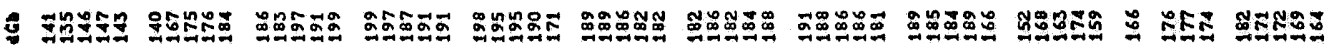

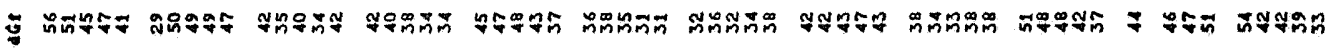

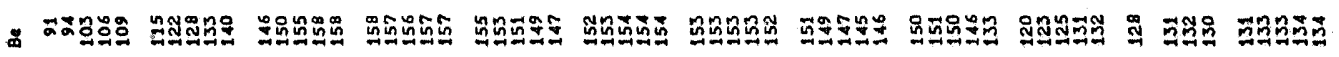

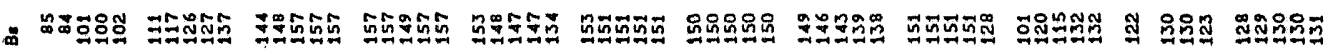

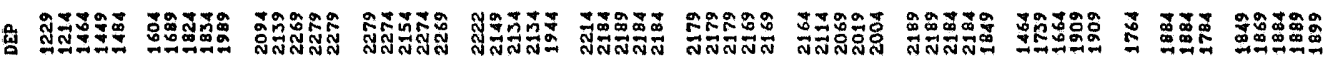

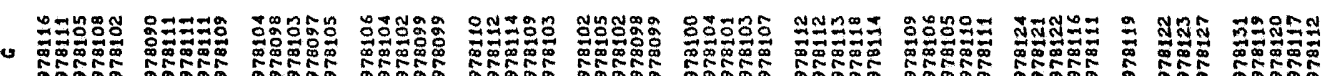

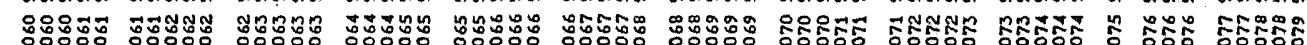

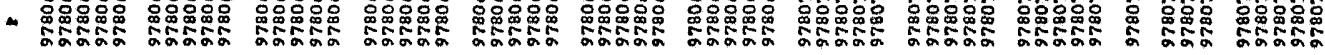

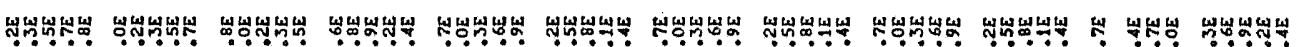

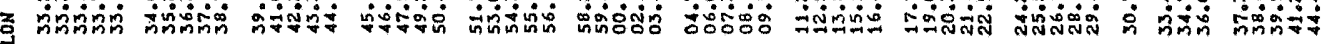
$\stackrel{n}{\geq}$

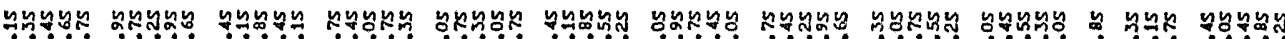

与 ช

3

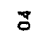

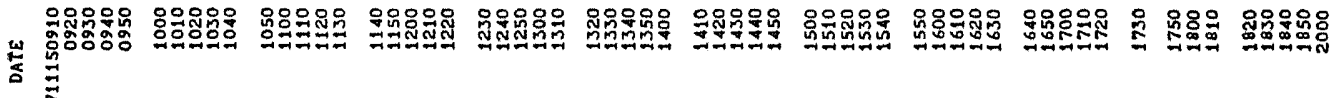

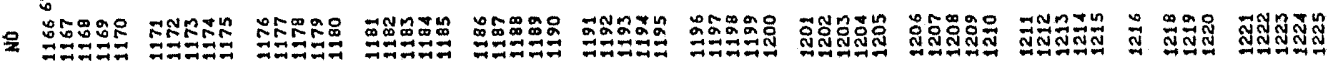




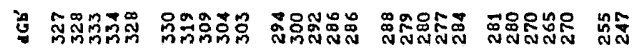

ง วี

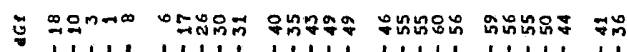

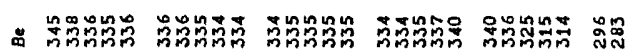

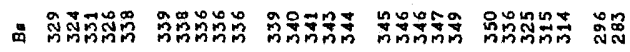

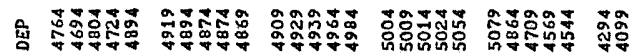

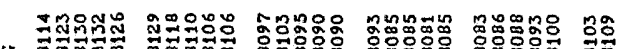

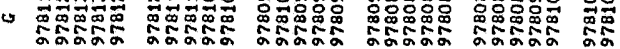

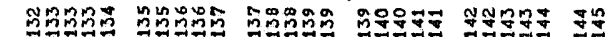

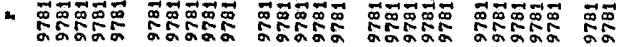

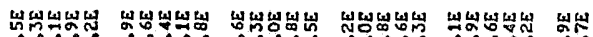

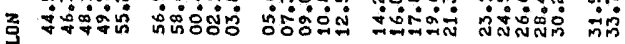
I

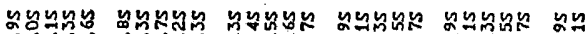

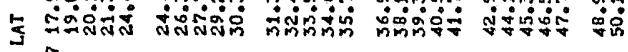
5

แ

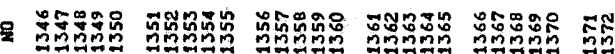

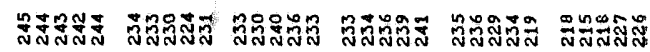

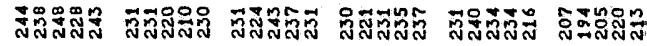

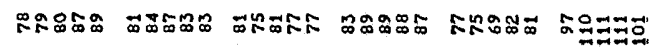

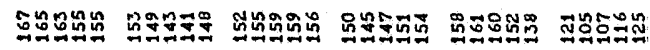

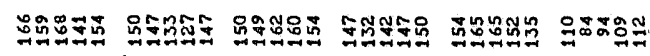

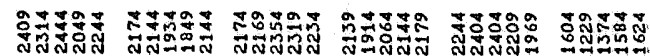
을

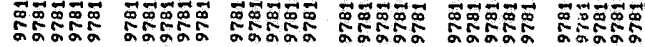

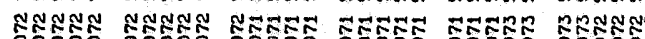

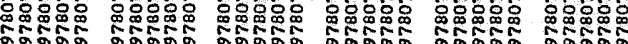

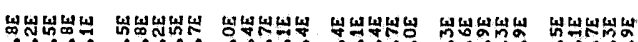

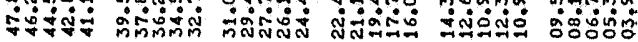
요

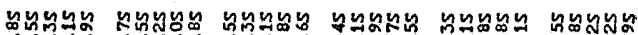

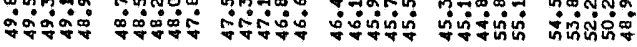
s

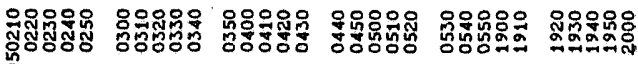
芯

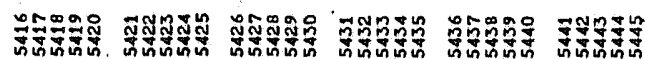

ํํำ

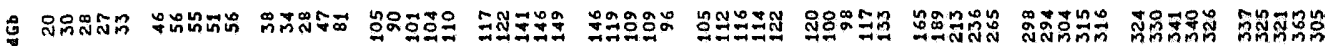

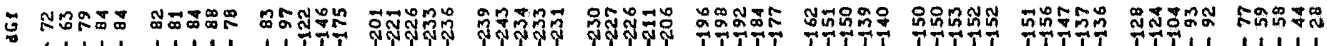
1111111114T \%

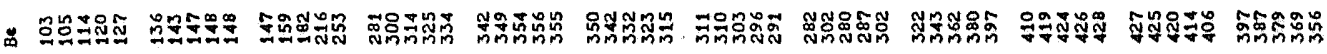

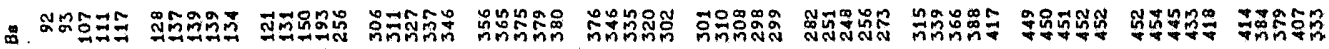

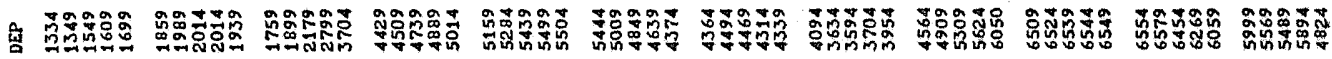

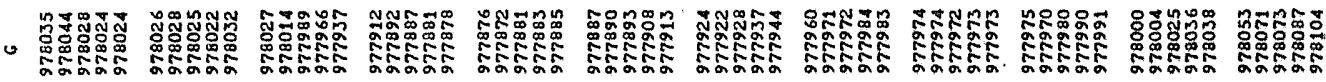

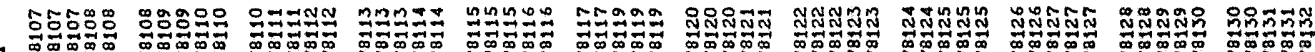

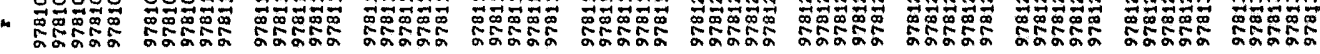

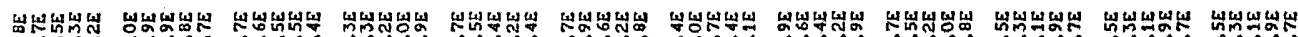

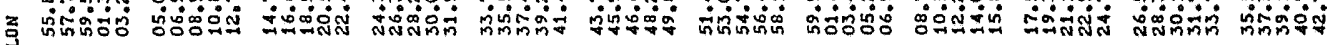

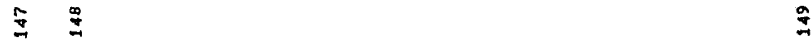

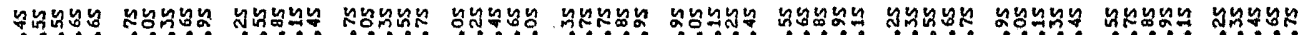

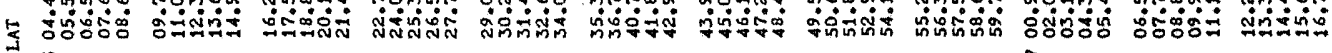
ஃ

崖

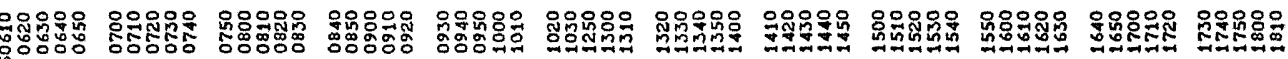
$\underset{\mathrm{B}}{\mathrm{B}}$

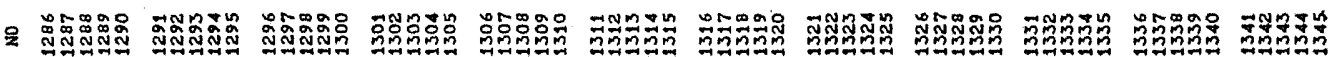


Gravity Measurements at Sea by Use of the T.S.S.G. Part 2.

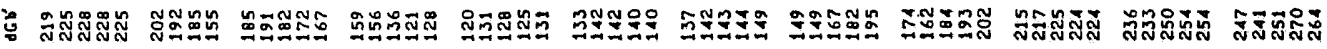

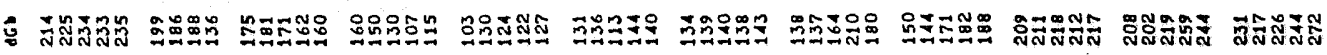

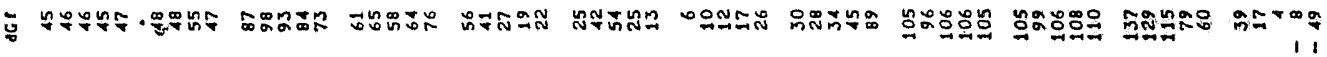

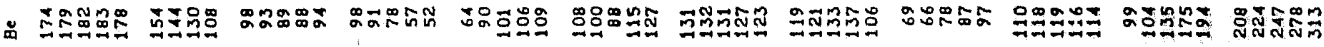

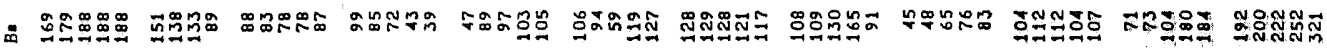

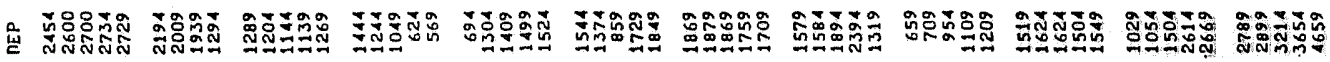

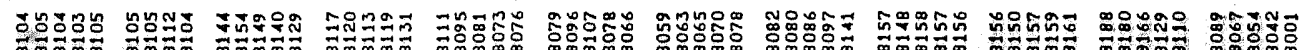

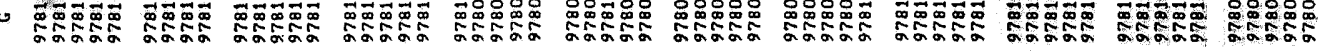

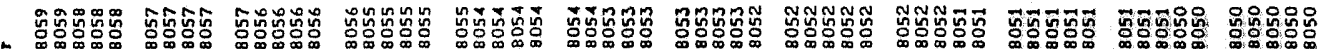

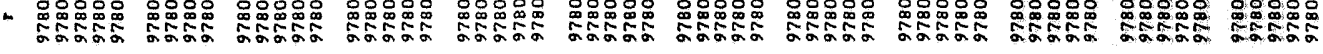

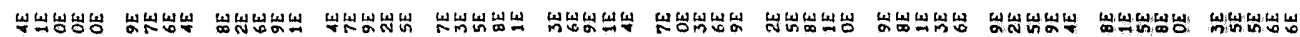

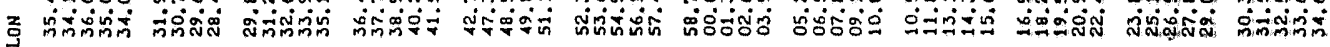

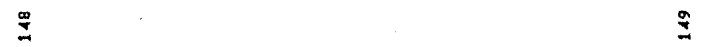

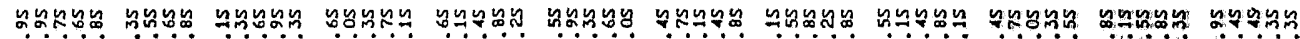

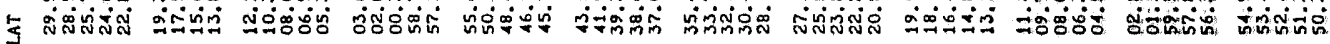
ำ

5

:

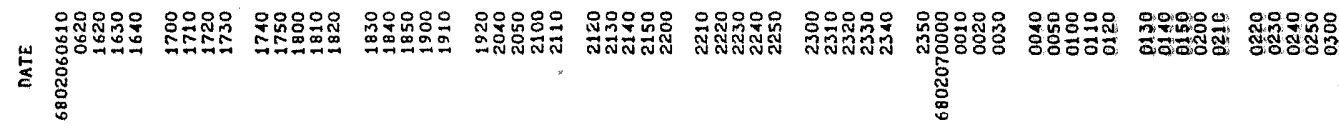

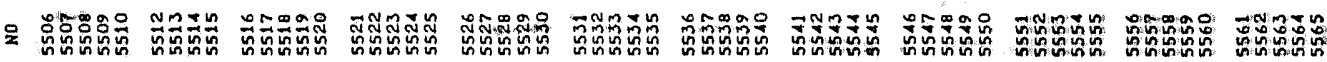

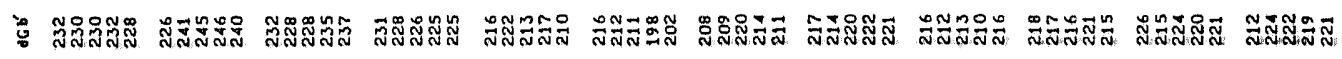

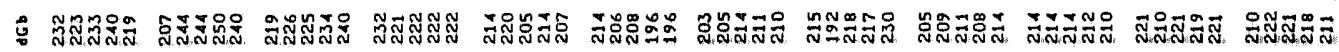

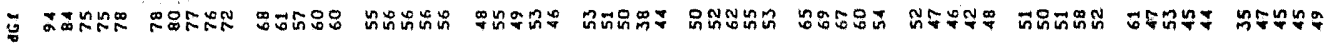

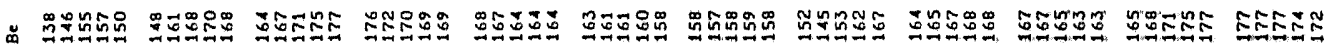

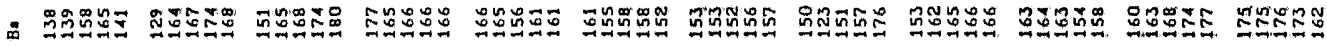

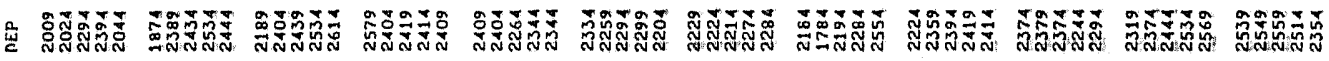

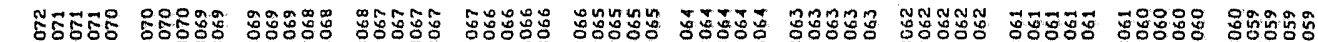

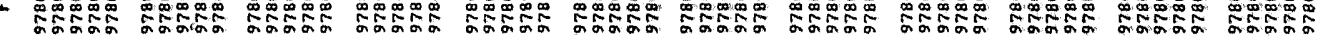

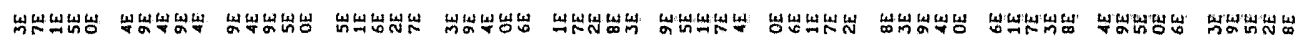

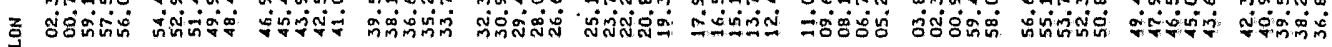
$\stackrel{2}{2}$

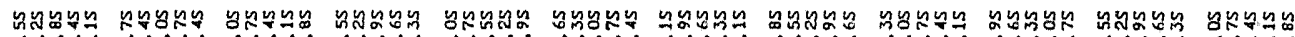

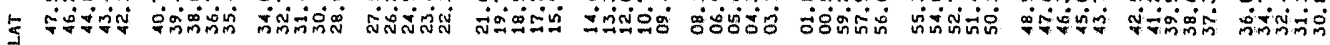
a กั

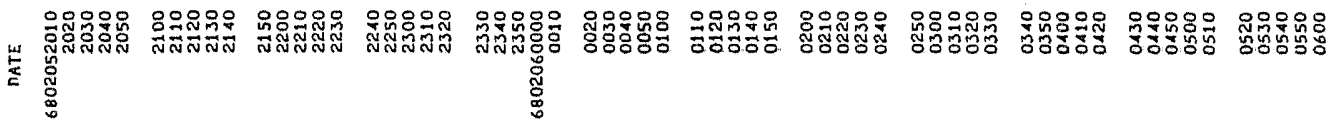

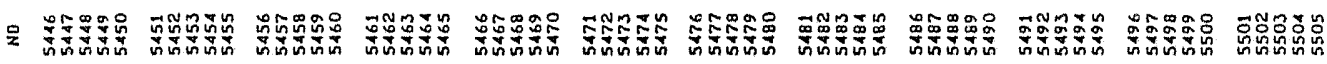




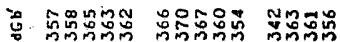

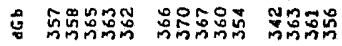

ษ

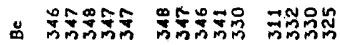

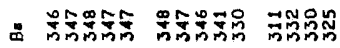

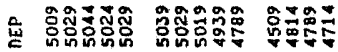

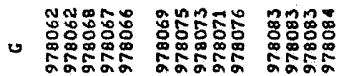

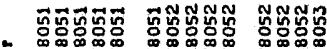

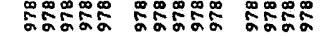

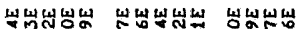

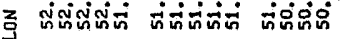
$\stackrel{9}{7}$

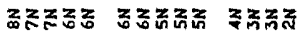

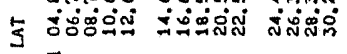
o

压

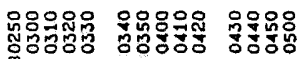
通

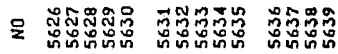

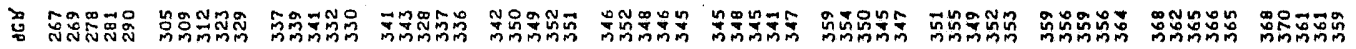

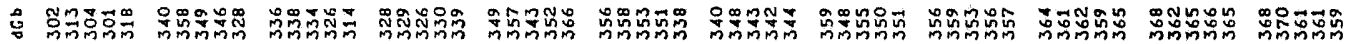

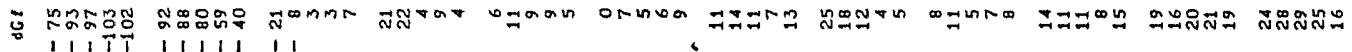

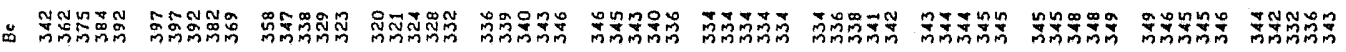

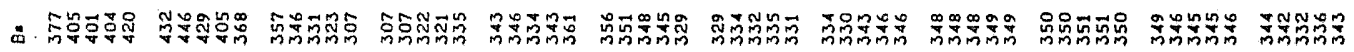

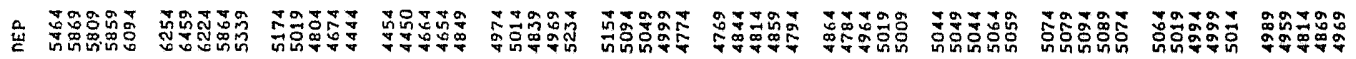
。 法

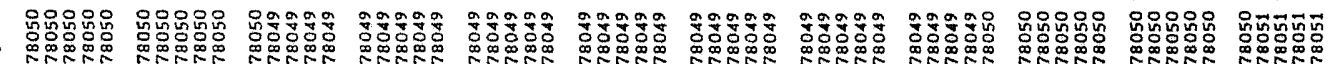

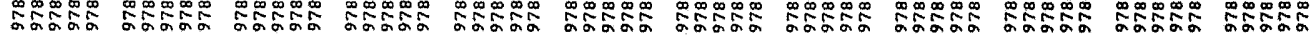

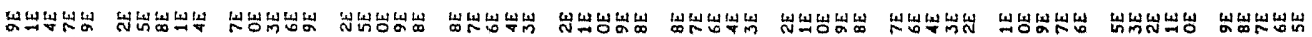

z \%

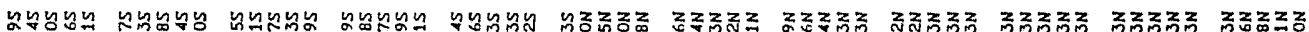

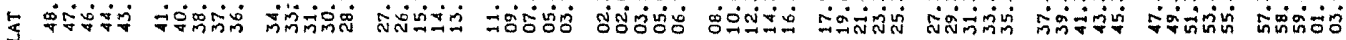
8

tै

压

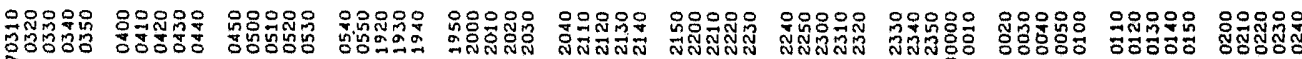

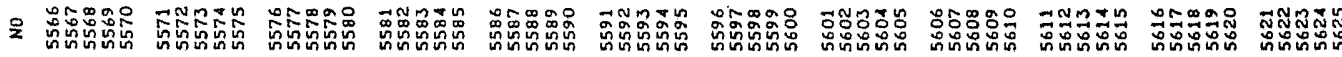

